\title{
Facilitating shared decision making with a patient decision aid for choosing a treatment for multiple sclerosis
}

Citation for published version (APA):

Kremer, I. (2020). Facilitating shared decision making with a patient decision aid for choosing a treatment for multiple sclerosis: guiding stakeholders through a forest of criteria. [Doctoral Thesis, Maastricht University]. Ridderprint. https://doi.org/10.26481/dis.20200827ik

Document status and date:

Published: 01/01/2020

DOI:

10.26481/dis.20200827ik

Document Version:

Publisher's PDF, also known as Version of record

Please check the document version of this publication:

- A submitted manuscript is the version of the article upon submission and before peer-review. There can be important differences between the submitted version and the official published version of record.

People interested in the research are advised to contact the author for the final version of the publication, or visit the DOI to the publisher's website.

- The final author version and the galley proof are versions of the publication after peer review.

- The final published version features the final layout of the paper including the volume, issue and page numbers.

Link to publication

\footnotetext{
General rights rights.

- You may freely distribute the URL identifying the publication in the public portal. please follow below link for the End User Agreement:

www.umlib.nl/taverne-license

Take down policy

If you believe that this document breaches copyright please contact us at:

repository@maastrichtuniversity.nl

providing details and we will investigate your claim.
}

Copyright and moral rights for the publications made accessible in the public portal are retained by the authors and/or other copyright owners and it is a condition of accessing publications that users recognise and abide by the legal requirements associated with these

- Users may download and print one copy of any publication from the public portal for the purpose of private study or research.

- You may not further distribute the material or use it for any profit-making activity or commercial gain

If the publication is distributed under the terms of Article $25 \mathrm{fa}$ of the Dutch Copyright Act, indicated by the "Taverne" license above, 



\section{Facilitating shared decision making with a patient decision aid for choosing a treatment for multiple sclerosis}

Guiding stakeholders through a forest of criteria

Ingrid E.H. Kremer 
The research presented in this thesis was conducted at CAPHRI Care and Public Health Research Institute, department of Health Services Research, of Maastricht University. CAPHRI participates in the Netherlands School of Public Health and Care Research CaRe. Parts of this dissertation were financially supported by an unrestricted donation to the Limburg University Fund by Bayer B.V. A visiting fellowship to the University of British Columbia was made possible by a Student Award by the Association of Canada Studies in the Netherlands.

(C) copyright Ingrid E.H. Kremer, Maastricht 2020

Cover: Bea Palant

Printing: Ridderprint BV (www.ridderprint.nl)

ISBN: 978-94-6380-721-0

All rights are reserved. No parts of this dissertation may be reproduced or transmitted, in any form or by any means, electronic or mechanical, including photocopying, recording or otherwise, without prior written permission of the holder of the copyrights. 


\title{
Facilitating shared decision making with a patient decision aid for choosing a treatment for multiple sclerosis
}

\author{
Guiding stakeholders through a forest of criteria
}

\section{PROEFSCHRIFT}

ter verkrijging van de graad van doctor aan de Universiteit Maastricht, op gezag van de Rector Magnificus, Prof. dr. Rianne M. Letschert volgens het besluit van het college van Decanen, in the openbaar te verdedigen op vrijdag 20 maart 2020 om 14.00 uur

door

Ingrid Elise Hubertine Kremer 


\section{Promotor}

Prof. dr. mr. S.M.A.A. Evers

\section{Co-promotoren}

Dr. M. Hiligsmann

Dr. P.J. Jongen (MS4 Research Institute, Universitair Medisch Centrum Groningen)

\section{Beoordelingscommissie}

Prof. dr. M.A. Joore (voorzitter)

Dr. M.E. van den Akker-van Marle (Leiden Universitair Medisch Centrum)

Prof. dr. R.M.M. Crutzen

Prof. dr. J. Killestein (Amsterdam Universitair Medische Centra, locatie VUmc)

Dr. G.A.P.G. van Mastrigt 
Chapter 2 Identification and Prioritization of Important Attributes of DiseaseModifying Drugs in Decision Making among Patients with Multiple Sclerosis: A Nominal Group Technique and Best-Worst Scaling Published in: PLOS ONE (2016)

Chapter 3 Comparison of preferences of healthcare professionals and MS patients for attributes of disease-modifying drugs: A best-worst scaling Published in: Health Expectations (2018)

Chapter 4 Development of a web-based patient decision aid for diseasemodifying drugs for multiple sclerosis Submitted for publication

Chapter 5 Exploring the cost-effectiveness of shared decision making for choosing between disease-modifying drugs for multiple sclerosis in the Netherlands: a state transition model Submitted for publication

Chapter 6 Adherence to Web-Based Self-Assessments in Long-Term Direct-toPatient Research: Two-Year Study of Multiple Sclerosis Patients Published in: Journal of medical Internet research (2017)

Chapter 7 General discussion

Addenda Summary

Samenvatting 209

Valorisation

Dankwoord

List of publications \& awards 

CHAPTER 1

General introduction 


\section{General introduction}

Advances in treatment options for multiple sclerosis (MS) provide patients with new opportunities to delay disease progression. As the number of treatment options increases, choosing the right disease-modifying drug (DMD) for an individual patient, i.e. a DMD that fits with the patient's preferences and needs, becomes more and more difficult. Therefore, there is a need for patients to be actively involved in their healthcare. This dissertation describes the development of a web-based patient decision aid for choosing the optimal DMD treatment - an aid to facilitate shared decision making between patients with MS and the healthcare professional. This chapter provides a general introduction into the topic. First, the pathology of MS and its different disease courses are described, followed by a description of the consequences of MS on patients' health and quality of life. Second, pharmacological treatment options for MS management are explained, and the importance of appropriate long-term use of the treatments for patients' health outcomes. Third, this chapter highlights the importance of incorporating preference-sensitive decisions into a shared decision making process for MS treatment, and how patient decision aids could support this process. Finally, the role of intervention appraisal for making decisions on policy with regard to the implementation of new interventions, such as patient decision aids, is explained.

\section{Burden of multiple sclerosis}

MS is a progressive disease of the central nervous system. The central nervous system, which includes an extensive and complex network of neurons, processes information obtained from sensory neurons and sends signals via motor neurons to impel action in the body. Signals are transmitted in neurons through axons, which often are covered with a myelin sheet to enable quick transmission of signals. In MS, inflammatory processes trigger demyelination of the neurons' axons. As a consequence, lesions or plaques occur typically in the white and grey matter of the central nervous system. As disease duration increases, the ability of the myelin sheets to recuperate decreases, resulting in permanent damage to the central nervous system. Demyelination obstructs the efficient conduction of pulses across neurons, leading to all sorts of symptoms, such as impaired motor functions and cognitive capabilities, depending on the location of the lesions [1]. The cause of MS is still unknown, but genetic and environmental factors are believed to play a role [2].

Four disease courses can be distinguished in MS [3]. About $89 \%$ of MS patients in the Netherlands have the relapsing-remitting (RRMS) disease course at on set [4]. RRMS is characterized by a recurrent pattern of relapses and remissions. A relapse is an exacerbation of MS symptoms, which can emerge slowly over time or more suddenly. A relapse can last from 24 hours up to a couple of months and is followed by a stable period, called remission. Depending on the disease severity, multiple relapses may occur, and the patient's central nervous system may be less and less able to recover, resulting in an accumulation of 
disabilities $[3,5]$. The majority of patients with RRMS at onset will transition to secondary progressive MS (SPMS) over time. SPMS is characterized by progressive deterioration in abilities. If a progressive disease course has not been preceded by relapses and remissions, patients have primary progressive MS [3]. Clinically isolated syndrome (CIS) is considered the fourth disease course. CIS patients have experienced a single event resembling a relapse in MS, but have yet to meet the criteria of dissemination in time and in place for clinically definite MS $[3,6]$.

Most recent numbers show that 2.3 million people are diagnosed with MS worldwide [4]. Prevalence is higher in North America, Europe and Australia. In the Netherlands, the prevalence is 88 per 100,000 people, representing about 15,000 Dutch people, and each year another 5 per 100,000 people will receive the diagnosis of MS [4]. More women than men are affected by MS, at a ratio of 2:1, and MS manifests itself most often in young adulthood [4]. Physical, cognitive or mental symptoms, such as impairment in mobility, in bladder function, sensory issues, fatigue, reduced information processing, memory impairment, and depression [7, 8], disrupt the person's daily life and the ability to participate in social and occupational activities. This transpires in a time when people generally are establishing a life for themselves: making a career, establishing relationships and having children. MS patients' quality of life is significantly reduced in comparison with that of healthy people, with most pronounced differences found in the physical domains and in patients' social functioning [9]. Moreover, patients with MS have been reported to have an excess risk of mortality [10]. MS thus affects patients' quantity of life and their quality of life at onset and in the following years, making it a considerable burdens for the patient and his/her social environment.

Due to impaired physical, cognitive and social functioning, patients with MS need specialized healthcare and a considerable proportion of patients are less or not able to work [11-13], which contributes to a large economic burden. In the Netherlands, the healthcare cost of MS came to 206.8 million Euros in $2015,45 \%$ of this was for hospital and specialist care and $35 \%$ for medication [14]. Severe MS is related with higher costs, including costs for the healthcare sector and for patients and their family $[11,13]$. The average total costs per patient per year are $€ 27,400$ higher for patients with severe MS in comparison with mild MS, with the latter coming to an average of $€ 23,100$ total costs per year. This difference in costs is mainly driven by more use of community services and informal care [13]. A relapse in RRMS patients costs $€ 2,977$ due to increased use of medical care, informal care, consultations and investments [11]. Accordingly, reducing relapses and disease progression is important for reducing the burden of MS on people's daily functioning, their quality of life and the societal expenditure. 


\section{Treatment options}

No cure is yet available for MS. Nevertheless several pharmacological and nonpharmacological treatments, such as lifestyle interventions, rehabilitation and physical therapy, can manage MS symptoms. As from 1995, disease-modifying drugs (DMDs) have become available for the treatment of RRMS (Figure 1). The first DMDs to receive market authorization by the European Medicines Agency were interferons (interferon beta-1b, interferon beta-1a IM, interferon beta-1a SC) and glatiramer acetate [15]. These immunomodulators are aimed at decreasing the inflammatory processes that destroy the myelin sheets around the axons, and are administered by self-injection once or multiple times a week. These DMDs have shown to be effective in reducing the annualised relapse rate in RRMS patients ranging from a hazard ratio of 0.66 to 0.87 in comparison with placebo [16], and consequently reducing disease progression as fewer disabilities accumulate from the residual symptoms of relapses [16]. Aside from RRMS, these DMDs are also prescribed for the treatment of CIS and secondary progressive MS with ongoing relapse activity [15, 17].

In 2006, natalizumab was granted market authorization, which was the first immunosuppressant drug for RRMS, administered via intravenous infusion once per month. Natalizumab was found to be more effective than interferons and glatiramere acetate [16]. However, with the increase in the probability of reducing relapses came an increase in the risk of severely disabling or life-threatening side effects. Therefore, natalizumab is labelled for use only for those patients with highly active MS not responding to treatment with at least one of the other DMDs or for those patients with rapidly developing MS, and it is also classified as second-line treatment [17]. Interferons and glatiramer acetate were considered first-line treatments [17]. Each of these DMDs has their advantages and disadvantages: they have been shown to be only partially effective, have been associated with burdensome common or severe side effects, and/or have administration regimens generally considered burdensome by patients [18].

Since 2011, the options for first-line and second-line treatment have been increasing rapidly. Orally administered DMDs (fingolimod, teriflunomide and dimethyl fumarate), other infusion-administered DMDs (alemtuzumab, cladribine and ocrelizumab) as well as one other self-injectable DMD with a decreased administration frequency in comparison with other injectable DMDs (peginterferon-1a) have become available, resulting in a total of twelve DMDs currently available in the Netherlands for RRMS (Figure 1). 


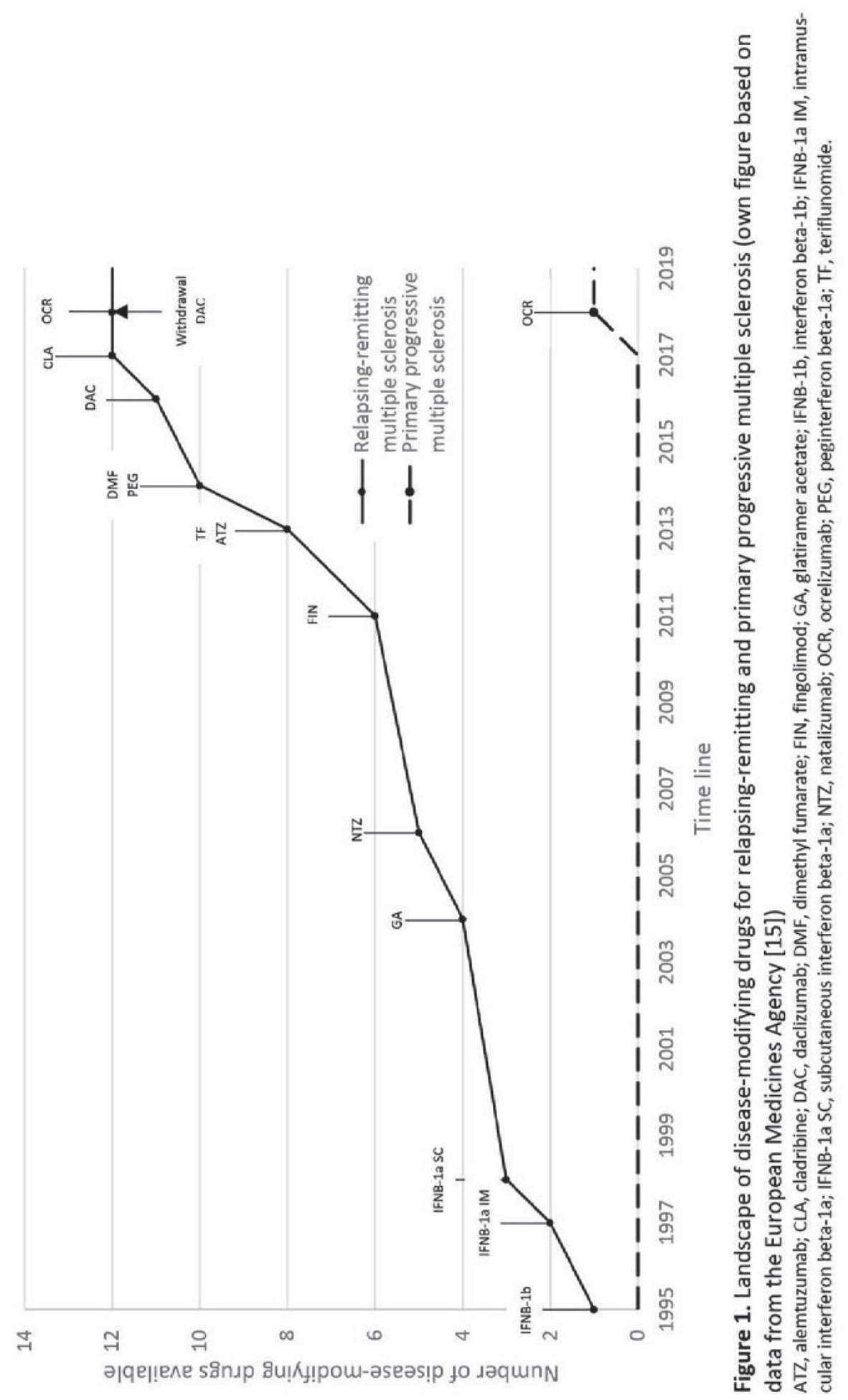


Treatment options for MS are still fast evolving, with a number of new treatments in the pipeline for RRMS, but also specifically for the progressive MS courses [18, 19]. Recently, ocrelizumab has been authorized for the treatment of primary progressive MS (Figure 1). Moreover, new evidence is continuously becoming available about current DMDs, resulting in changes in the treatment mix. For example, daclizumab, authorized in 2016, was withdrawn in 2018 after post-authorisation evidence showed a serious risk of fatal immune reactions. Because of new insights into the risks of severe side effects, alemtuzumab has recently been classified as third-line DMD, only indicated for those patients with highly active MS not responding to at least two other DMDs or when treatment with any of the other DMDs is contra-indicated [17].

\section{Patients' persistence and adherence to MS treatment}

DMD treatment requires long-term persistence and adherence for the DMD to have its optimal effects. Treatment persistence is defined as "the duration of time from initiation to discontinuation of therapy", while adherence is defined as "the extent to which a patient acts in accordance with the prescribed interval, and dose of a dosing regimen" [20]. Treatment persistence and treatment adherence are, however, problematic.

Retrospective and prospective real-world studies in MS show that reported discontinuation rates in the first year after initiating DMD treatment range between $12 \%$ and $32 \%$ for injectable DMDs [21-26] and $10 \%$ to $44 \%$ for orally administered DMDs [21, 24, 25, 27-35], and percentages increase as treatment duration increases $[23,36]$. Of the people who persist with DMD treatment for up to one year, reported rates for optimal adherence range from $82 \%$ to $53 \%$ of patients $[21,22,25,31,37,38]$. Non-adherence was found to be associated with higher relapse rates and more severe relapses [39]. Known reasons for discontinuation are a lack of efficacy [24, 32, 40,41], intolerance of side effects or serious adverse events $[24,32,33,40,41]$ and inconvenience [24, 40]. Forgetfulness [42-47], being tired of taking the drug or anxiety of self-injections [42, 43, 45-47], side effects [42, 43, 45, 47], inconvenient dosing schedule that does not fit with daily life [42, 45, 47], the perception that not every dose is needed [43, 45] and treatment dissatisfaction [47] have been reported reasons for missing doses. Addressing reasons for discontinuation and nonadherence before the patient starts using a DMD could improve persistence and adherence rates. This could be established by ensuring that the patient has realistic expectations regarding the effectiveness of the DMD and the burden of taking the treatment, and by supporting patients in choosing an appropriate DMD.

\section{Preference-sensitive treatment decision making}

Choosing a DMD for the treatment of RRMS is a preference-sensitive decision, meaning that there is no dominant choice in terms of effects and burden, and the choice may depend on what the patient prefers in the treatment. Although a patient's eligibility for DMDs depends 
on the clinical presentation of the disease and their response to earlier treatment, most patients have two or more options, including the option to not start a DMD treatment. DMDs differ from each other to lesser or greater extent according to a number of characteristics. Second-line DMDs are generally more effective than first-line DMDs, but also have less favourable risk profiles for serious adverse events. The administration regimen in terms of methods - i.e. injectable, orally or per intravenous infusion - and frequency, and the burden of common side effects can differ between DMDs as well. Therefore, characteristics of one DMD can be conflicting according to the preferences of a patient: a trade-off between the level of effectiveness, the risk of severe side effects, burden of common side effects, administration regimen and other characteristics needs to be considered. What is most important in the treatment decision may differ from patient to patient. Studies have shown that patients' preferences for DMD characteristics can vary, for example in relation to prior experience with DMDs $[48,49]$, the degree of disability experienced [48], disease duration [49] and age [50].

The importance of involving the patient's preferences into the treatment decision is now widely recognized and has been highlighted in international recommendations for treatment of MS [51, 52]. Shared decision making is an approach to making healthcare decisions by involving the patient in the decision making process [53]. Shared decision making is defined as "an approach where clinicians and patients make decisions together using the best available evidence. Patients are encouraged to think about the available screening, treatment, or management options and the likely benefits and harms of each so that they can communicate their preferences and help select the best course of action for them" [53]. However, involving patients in shared decision making requires effort from both the physician and the patient.

Patient decision aids are increasingly being used to support patients and physicians in achieving a shared decision. Patient decision aids contain information about treatment options and a value elicitation tool, and empower patients to be involved in a shared decision making process with their healthcare provider $[54,55]$. Patient decision aids have been reported to positively influence decisional conflict, patients' knowledge about treatment options, patient's participation in decision making, and the match of patient's preferences to treatment options (24). By developing informed preferences and choosing a treatment option aligned with these preferences, patients may have more realistic expectations of the chosen treatment, resulting in higher satisfaction and improved treatment adherence and persistence. Stalmeier theorizes that patient decision aids havebesides their primary aim of improving patient-physician communication, patient education and patient involvement in the decision for treatment - secondary effects for adherence by helping the patient to develop a more pronounced and persistent attitude towards the chosen treatment [56]. To date, evidence for the effect of a patient decision aid on persistence and adherence is limited [57], with only some studies finding results supporting 
the effect of a patient decision aid on adherence in treatment and screening decisions other than for MS [58-60].

As patient decision aids inform the patient's preferences and thus affect the treatment decision, the tool must be reliable and valid. Accordingly, the adequate development and quality of a patient decision aid is important. Working in a collaboration, expert researchers in the field of shared decision making and patient decision aid development have composed the International Patient Decision Aid Standards (IPDAS). The IPDAS provide a framework consisting of several stages (Figure 2) for user-centred development and testing of a patient decision aid. The initial steps are to define the scope of the patient decision aid and to establish a steering group consisting of experts, such as healthcare professionals, patients and experts in the development of patient decision aids. During the design steps of the patient decision aid, the first step is to elicit which information needs to be included for patients to participate in the decision making process. Both the patients' and the healthcare professionals' perspectives should be queried. Second, the format and the delivery of the patient decision aid should be planned. Third, the clinical evidence for the different treatment options should be reviewed and synthesized. Using the data collected in the previous steps, the fourth step is to develop a prototype of the patient decision aid. In the pilot testing a new patient decision aid, first, an alpha test should be conducted to assess the comprehensibility and usability. Second, in a beta pilot test, feasibility of implementation should be evaluated in a real-world setting by patients and healthcare professionals actually using the patient decision aid in clinical decision making. The aim of the IPDAS' framework is to ensure the quality of patient decision aids and of the implementation of shared decision making supported by patient decision aids in clinical practice [61]. 


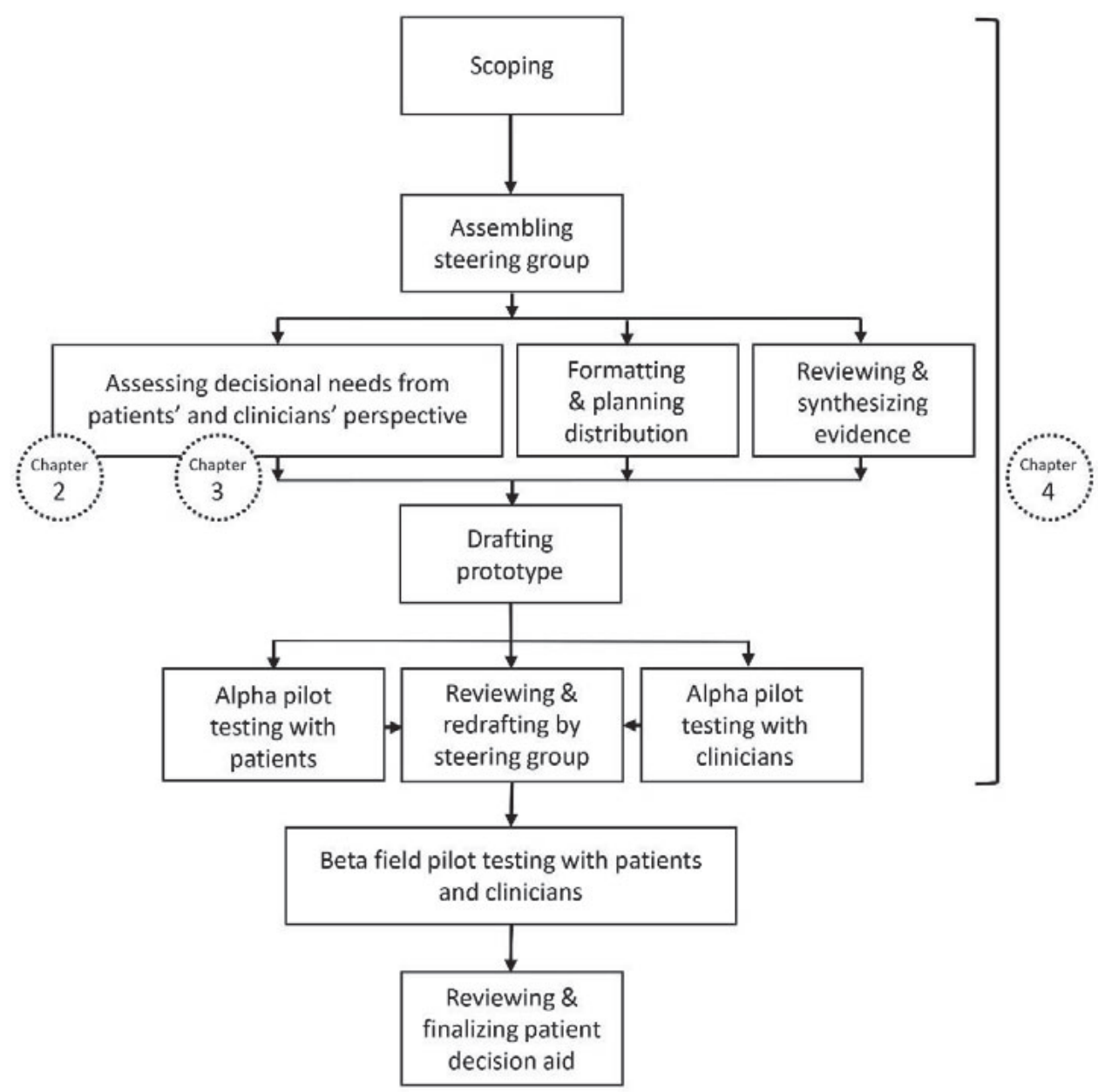

Figure 2. Steps for the systematic development of patient decision aids according to the International Patient Decision Aid Standards (IPDAS) in relation to the chapters of this dissertation. Figure adapted from Coulter et al. [61].

\section{Patient decision aids for MS}

Reviews of patient decision aids for healthcare decisions [62] and information provision specifically for MS patients [63] identified only one study reporting on the evaluation of a German paper-based patient decision aid for DMDs for MS [64]. Three additional patient decision aids for DMDs for MS could be identified. These English patient decision aids focus either on just a part of the decision (whether to start DMD treatment or not) [65], consider only first-line treatment [66], or do not explicitly match the patient's preferences with the available DMDs [67]. The recently published paper about a Canadian patient decision aid matching the patient's preferences with the available first-line DMDs [66] suggests that 
more prescriptive rather than descriptive patient decision aids could be appropriate in complex decisions with many options and many conflicting characteristics [68]. Instead of verbally describing the performance of treatment options and relying on an interpersonal process for weighting the treatment options according to their performance and according to the patient's preferences, these prescriptive (or analytical) patient decision aids use numerical representations of the performance of treatment options for relevant characteristics. Similarly to the descriptive (or verbal) patient decision aids, the analytic patient decision aids elicit the patient's preferences for the treatment characteristics, but also translates these preferences into a numerical weight. Ultimately, the analytic patient decision aid combines the numerical performances and the numerical weights to provide a ranking of treatment options best matching the patient's preferences. In such a way, this type of patient decision aid provides another "opinion" which should be discussed during the patient's consultation with the healthcare professional, and could thus be considered as being a more prescriptive approach in supporting the shared decision making process [68]. At the start of the project described in this thesis, such a prescriptive tool was not yet available, nor is such a tool available now for first-line and second-line DMDs or appropriate for the Dutch patient population.

\section{Economic appraisal of new interventions}

The implementation of shared decision making supported by a patient decision aid in clinical practice means investing healthcare budgets, but it has the possibility to limit future health costs because of improved health outcomes resulting from improved adherence and persistence. Due to limited healthcare budgets, policy makers need to decide whether the financial investment is worthwhile, considering the beneficial effects of implementing shared decision making supported by a patient decision aid. This is most important because funds can be spent only once. Accordingly, investing in shared decision making has opportunity costs, meaning that less or no funds might be available for implementation of other technologies. Through health technology assessment, a technology (an intervention in the broadest sense, for example a drug, medical device, public health program or patient decision aid) is appraised according to a number of aspects, such as safety, efficacy, feasibility, ethical consequences and cost-effectiveness. Assessing the cost-effectiveness of shared decision making means answering the question of whether the additional costs are acceptable in order to achieve the additional benefits of the intervention. Information about the cost-effectiveness of particular interventions plays an increasingly important role in reimbursement and implementation decisions [69].

\section{Objectives of this thesis}

The aim of this thesis is two-fold. The first aim is to develop and user-test a patient decision aid about DMDs for MS to ultimately support shared decision making between the patient and her/his neurologist and MS nurse. The following specific objectives were addressed: 
1. To assess which information about the DMD options is needed to make a treatment decision from the patients' and healthcare professionals' perspectives.

2. To develop a prototype of the patient decision aid that incorporates the informational needs of the patient.

3. To assess the comprehensibility, usability and acceptability of the patient decision aid with patients and healthcare professionals

The second aim was to inform the design of web-based health services and research for MS and, specifically, the potential cost-effectiveness of shared decision making for MS. The following specific objectives were addressed:

1. To evaluate whether shared decision making, whether or not supported by a patient decision aid, for DMDs for MS could potentially be cost-effective, and which parameters would most affect the cost-effectiveness.

2. To evaluate whether a difference in frequency and length of questionnaires affects patients' adherence to online self-assessment in direct-to-patient research.

\section{Outline of the thesis}

As the objective of this thesis was two-fold, the thesis is divided into two parts.

Part I describes the studies conducted to systematically develop an online patient decision aid about DMDs for MS according to the six stages recommended by the IPDAS.

Chapters $\mathbf{2}$ and $\mathbf{3}$ describe the assessment of informational needs in the decision about DMDs according to patients (Chapter 2) and according to healthcare professionals (Chapter 3). In Chapter 2, after an initial exploratory phase of literature review and consultation with healthcare professionals, the characteristics of DMDs that need to be described in the patient decision aid for patients to make an informed decision are identified using focus groups, with a nominal group technique with patients. Chapter 3 describes how the relative importance of the DMD characteristics according to MS patients was quantified using a best-worst scaling survey. This survey was conducted with neurologists and MS nurses to assess the relative importance of DMD characteristics according to their experience. The perspectives of neurologists and nurses were compared with each other, and the overall healthcare professionals' perspective was compared with the MS patients' perspective to evaluate whether there were any discrepancies.

Chapter 4 describes the entire systematic development of the patient decision aid for DMDs for MS. This chapter includes defining the scope of the patient decision aid, assessing the decisional needs, determining the format and delivery system of the patient decision aid, reviewing the literature for the best available evidence, developing the prototype and alpha pilot testing the prototype with patients and healthcare professionals in an iterative process. 
Part II explores how web-based health services and research for MS can be optimized and the potential cost-effectiveness of shared decision making in MS.

Chapter 5 evaluates the potential cost-effectiveness of shared decision making in DMDs for MS using a decision analytical modeling approach. A transition state model was developed to simulate the expected effect of shared decision making on treatment initiation, treatment persistence and treatment adherence, and the further consequences for health outcomes, quality-adjusted life years and costs. The study informs which parameters are of importance in assessing the cost-effectiveness of shared decision making and should be measured in further trial-based research.

Chapter 6 investigates MS patients' adherence to a self-assessment schedule with lowfrequency long questionnaires versus a high-frequency short questionnaire. In direct-topatient research, this study informs how self-assessment schedules could be designed to optimize patients' response and minimize missing data.

Finally, Chapter $\mathbf{7}$ provides a discussion of the main findings in this dissertation, as well as a discussion of the main methodological considerations of this thesis and implications for further research and clinical practice. 


\section{References}

1. Frohman EM, Racke MK, Raine CS. Multiple sclerosis--the plaque and its pathogenesis. N Engl J Med. 2006;354(9):942-55. Epub 2006/03/03. doi: 10.1056/NEJMra052130.

2. Dobson R, Giovannoni G. Multiple sclerosis - a review. Eur J Neurol. 2019;26(1):27-40. Epub 2018/10/10. doi: 10.1111/ene.13819.

3. Lublin FD, Reingold SC, Cohen JA, Cutter GR, Sorensen PS, Thompson AJ, et al. Defining the clinical course of multiple sclerosis: the 2013 revisions. Neurology. 2014;83(3):278-86. Epub 2014/05/30. doi: 10.1212/wnl.0000000000000560.

4. Multiple Sclerosis Internation Federation (MSIF). The atlas of MS 2013: Mapping multiple sclerosis around the world 2013 [cited 2014 April 15]. Available from: http://www.atlasofms.org/./.

5. Lublin FD, Reingold SC. Defining the clinical course of multiple sclerosis: results of an international survey. National Multiple Sclerosis Society (USA) Advisory Committee on Clinical Trials of New Agents in Multiple Sclerosis. Neurology. 1996;46(4):907-11. Epub 1996/04/01.

6. Thompson AJ, Banwell BL, Barkhof F, Carroll WM, Coetzee T, Comi G, et al. Diagnosis of multiple sclerosis: 2017 revisions of the McDonald criteria. Lancet Neurol. 2018;17(2):162-73. Epub 2017/12/26. doi: 10.1016/s1474-4422(17)30470-2.

7. Kobelt G, Thompson A, Berg J, Gannedahl M, Eriksson J. New insights into the burden and costs of multiple sclerosis in Europe. Multiple sclerosis (Houndmills, Basingstoke, England). 2017;23(8):1123-36. Epub 2017/03/10. doi: 10.1177/1352458517694432.

8. Marrie RA, Reingold S, Cohen J, Stuve O, Trojano M, Sorensen PS, et al. The incidence and prevalence of psychiatric disorders in multiple sclerosis: a systematic review. Mult Scler. 2015;21(3):305-17. Epub 2015/01/15. doi: 10.1177/1352458514564487.

9. Riazi A, Hobart JC, Lamping DL, Fitzpatrick R, Freeman JA, Jenkinson C, et al. Using the SF-36 measure to compare the health impact of multiple sclerosis and Parkinson's disease with normal population health profiles. J Neurol Neurosurg Psychiatry. 2003;74(6):710-4. Epub 2003/05/20. doi: 10.1136/jnnp.74.6.710.

10. Manouchehrinia A, Tanasescu R, Tench CR, Constantinescu CS. Mortality in multiple sclerosis: meta-analysis of standardised mortality ratios. J Neurol Neurosurg Psychiatry. 2016;87(3):32431. Epub 2015/05/04. doi: 10.1136/jnnp-2015-310361.

11. Karampampa K, Gustavsson A, van Munster ET, Hupperts RM, Sanders EA, Mostert J, et al. Treatment experience, burden, and unmet needs (TRIBUNE) in Multiple Sclerosis study: the costs and utilities of MS patients in The Netherlands. J Med Econ. 2013;16(7):939-50. Epub 2013/05/23. doi: 10.3111/13696998.2013.807267.

12. Kobelt G, Berg J, Lindgren P, Anten B, Ekman M, Jongen PJ, et al. Costs and quality of life in multiple sclerosis in The Netherlands. Eur J Health Econ. 2006;7 Suppl 2:S55-64. Epub 2007/02/21. doi: 10.1007/s10198-006-0378-6.

13. Uitdehaag B, Kobelt G, Berg J, Capsa D, Dalen J. New insights into the burden and costs of multiple sclerosis in Europe: results for the Netherlands. Mult Scler. 2017;23(2_suppl):117-29. Epub 2017/06/24. doi: 10.1177/1352458517708663.

14. Kosten van ziekten 2015 [Internet]. Rijksinstituut voor Volksgezondheid en Milieu (RIVM). 2017 [cited 5 July 2019]. Available from: Volksgezondheidenzorg.info.

15. European public assessment reports: European Medicines Agency; 2019 [cited 20195 July]. Available from: http://www.ema.europa.eu/.

16. Lucchetta RC, Tonin FS, Borba HHL, Leonart LP, Ferreira VL, Bonetti AF, et al. Disease-Modifying Therapies for Relapsing-Remitting Multiple Sclerosis: A Network Meta-Analysis. CNS drugs. 2018;32(9):813-26. Epub 2018/07/18. doi: 10.1007/s40263-018-0541-5.

17. Zorginstituut Nederland. Farmacotherapeutisch Kompas [cited 2015 January 12th]. Available from: 
https://www.farmacotherapeutischkompas.nl/inleidendeteksten/i/inl\%20middelen\%20bij\%20m ultipele\%20sclerose.asp

18. Gholamzad M, Ebtekar M, Ardestani MS, Azimi M, Mahmodi Z, Mousavi MJ, et al. A comprehensive review on the treatment approaches of multiple sclerosis: currently and in the future. Inflamm Res. 2019;68(1):25-38. Epub 2018/09/05. doi: 10.1007/s00011-018-1185-0.

19. Ontaneda D, Thompson AJ, Fox RJ, Cohen JA. Progressive multiple sclerosis: prospects for disease therapy, repair, and restoration of function. Lancet. 2017;389(10076):1357-66. Epub 2016/11/28. doi: 10.1016/s0140-6736(16)31320-4.

20. Cramer JA, Roy A, Burrell A, Fairchild CJ, Fuldeore MJ, Ollendorf DA, et al. Medication compliance and persistence: terminology and definitions. Value in health : the journal of the International Society for Pharmacoeconomics and Outcomes Research. 2008;11(1):44-7. Epub 2008/02/02. doi: 10.1111/j.1524-4733.2007.00213.x.

21. Burks J, Marshall TS, Ye X. Adherence to disease-modifying therapies and its impact on relapse, health resource utilization, and costs among patients with multiple sclerosis. Clinicoecon Outcomes Res. 2017;9:251-60. Epub 2017/05/13. doi: 10.2147/ceor.S130334.

22. Evans C, Marrie RA, Zhu F, Leung S, Lu X, Melesse DY, et al. Adherence and persistence to drug therapies for multiple sclerosis: A population-based study. Multiple sclerosis and related disorders. 2016;8:78-85. Epub 2016/07/28. doi: 10.1016/j.msard.2016.05.006.

23. Evans C, Tam J, Kingwell E, Oger J, Tremlett H. Long-term persistence with the immunomodulatory drugs for multiple sclerosis: a retrospective database study. Clinical therapeutics. 2012;34(2):341-50. Epub 2012/02/03. doi: 10.1016/j.clinthera.2012.01.006.

24. Lanzillo R, Prosperini L, Gasperini C, Moccia M, Fantozzi R, Tortorella C, et al. A multicentRE observational analysiS of PErsistenCe to Treatment in the new multiple sclerosis era: the RESPECT study. J Neurol. 2018;265(5):1174-83. Epub 2018/03/20. doi: 10.1007/s00415-0188831-x.

25. Munsell M, Frean M, Menzin J, Phillips AL. An evaluation of adherence in patients with multiple sclerosis newly initiating treatment with a self-injectable or an oral disease-modifying drug. Patient Prefer Adherence. 2017;11:55-62. Epub 2017/01/25. doi: 10.2147/ppa.S118107.

26. Zhornitsky S, Greenfield J, Koch MW, Patten SB, Harris C, Wall W, et al. Long-term persistence with injectable therapy in relapsing-remitting multiple sclerosis: an 18-year observational cohort study. PLoS ONE. 2015;10(4):e0123824. Epub 2015/04/14. doi: 10.1371/journal.pone.0123824.

27. Conde S, Moisset X, Pereira B, Zuel M, Colamarino R, Maillet-Vioud M, et al. Dimethyl fumarate and teriflunomide for multiple sclerosis in a real-life setting: a French retrospective cohort study. Eur J Neurol. 2019;26(3):460-7. Epub 2018/10/16. doi: 10.1111/ene.13839.

28. Hersh CM, Love TE, Cohn S, Hara-Cleaver C, Bermel RA, Fox RJ, et al. Comparative efficacy and discontinuation of dimethyl fumarate and fingolimod in clinical practice at 12-month follow-up. Multiple sclerosis and related disorders. 2016;10:44-52. Epub 2016/12/07. doi: 10.1016/j.msard.2016.08.002.

29. Lattanzi S, Danni M, Taffi R, Cerqua R, Carlini G, Pulcini A, et al. Persistence to oral diseasemodifying therapies in multiple sclerosis patients. J Neurol. 2017;264(11):2325-9. Epub 2017/08/24. doi: 10.1007/s00415-017-8595-8.

30. Nazareth T, Friedman HS, Navaratnam P, Herriott DA, Ko JJ, Barr P, et al. Persistency, medication prescribing patterns, and medical resource use associated with multiple sclerosis patients receiving oral disease-modifying therapies: a retrospective medical record review. BMC Neurol. 2016;16(1):187. Epub 2016/09/30. doi: 10.1186/s12883-016-0698-9.

31. Setayeshgar S, Kingwell E, Zhu F, Zhang T, Carruthers R, Marrie RA, et al. Persistence and adherence to the new oral disease-modifying therapies for multiple sclerosis: A populationbased study. Multiple sclerosis and related disorders. 2019;27:364-9. Epub 2018/11/27. doi: 10.1016/j.msard.2018.11.004.

32. Smoot K, Spinelli KJ, Stuchiner T, Lucas L, Chen C, Grote L, et al. Three-year clinical outcomes of relapsing multiple sclerosis patients treated with dimethyl fumarate in a United States 
community health center. Mult Scler. 2018;24(7):942-50. Epub 2017/05/26. doi: $10.1177 / 1352458517709956$.

33. Vollmer B, Ontaneda D, Bandyopadhyay A, Cohn S, Nair K, Sillau S, et al. Discontinuation and comparative effectiveness of dimethyl fumarate and fingolimod in 2 centers. Neurol Clin Pract. 2018;8(4):292-301. Epub 2018/08/25. doi: 10.1212/cpj.0000000000000487.

34. Zimmer A, Coslovsky M, Abraham I, Decard BF. Adherence to fingolimod in multiple sclerosis: an investigator-initiated, prospective, observational, single-center cohort study. Patient Prefer Adherence. 2017;11:1815-30. Epub 2017/11/10. doi: 10.2147/ppa.S140293.

35. Johnson KM, Zhou H, Lin F, Ko JJ, Herrera V. Real-World Adherence and Persistence to Oral Disease-Modifying Therapies in Multiple Sclerosis Patients Over 1 Year. J Manag Care Spec Pharm. 2017;23(8):844-52. Epub 2017/07/25. doi: 10.18553/jmcp.2017.23.8.844.

36. Hersh CM, Love TE, Bandyopadhyay A, Cohn S, Hara-Cleaver C, Bermel RA, et al. Comparative efficacy and discontinuation of dimethyl fumarate and fingolimod in clinical practice at 24month follow-up. Mult Scler J Exp Transl Clin. 2017;3(3):2055217317715485. Epub 2017/09/12. doi: $10.1177 / 2055217317715485$.

37. McKay KA, Tremlett H, Patten SB, Fisk JD, Evans C, Fiest K, et al. Determinants of non-adherence to disease-modifying therapies in multiple sclerosis: A cross-Canada prospective study. Mult Scler. 2017;23(4):588-96. Epub 2016/07/01. doi: 10.1177/1352458516657440.

38. Zhang T, Kingwell E, Zhu F, Petkau J, Kastrukoff LF, Marrie RA, et al. Effect of adherence to the first-generation injectable immunomodulatory drugs on disability accumulation in multiple sclerosis: a longitudinal cohort study. BMJ open. 2017;7(9):e018612. Epub 2017/10/02. doi: 10.1136/bmjopen-2017-018612.

39. Tan H, Cai Q, Afarwal S, Stephenson JJ, Kamat S. Impact of adherence to disease-modifying therapies on clinical and economic outcomes among patients with multiple sclerosis. Adv Ther. 2011;28(1):51-61.

40. Lebrun-Frenay C, Moulignier A, Pierrot-Deseilligny C, Benrabah R, Moreau T, Lubetzki C, et al. Five-year outcome in the copaxone observatory: a nationwide cohort of patients with multiple sclerosis starting treatment with glatiramer acetate in France. J Neurol. 2019;266(4):888-901. Epub 2019/02/08. doi: 10.1007/s00415-019-09211-5.

41. Wicks P, Rasouliyan L, Katic B, Nafees B, Flood E, Sasane R. The real-world patient experience of fingolimod and dimethyl fumarate for multiple sclerosis. BMC research notes. 2016;9(1):434. Epub 2016/09/09. doi: 10.1186/s13104-016-2243-8.

42. de Seze J, Borgel F, Brudon F. Patient perceptions of multiple sclerosis and its treatment. Patient Prefer Adherence. 2012;6:263-73. Epub 2012/04/27. doi: 10.2147/ppa.S27038.

43. Devonshire V, Lapierre $Y$, Macdonell R, Ramo-Tello C, Patti F, Fontoura P, et al. The Global Adherence Project (GAP): a multicenter observational study on adherence to disease-modifying therapies in patients with relapsing-remitting multiple sclerosis. Eur J Neurol. 2011;18(1):69-77. Epub 2010/06/22. doi: 10.1111/j.1468-1331.2010.03110.x.

44. Morillo Verdugo R, Ramirez Herraiz E, Fernandez-Del Olmo R, Roig Bonet M, Valdivia Garcia M. Adherence to disease-modifying treatments in patients with multiple sclerosis in Spain. Patient Prefer Adherence. 2019;13:261-72. Epub 2019/03/14. doi: 10.2147/ppa.S187983.

45. Saiz A, Mora S, Blanco J. Therapeutic compliance of first line disease-modifying therapies in patients with multiple sclerosis. COMPLIANCE Study. Neurologia (Barcelona, Spain). 2015;30(4):214-22. Epub 2014/02/04. doi: 10.1016/j.nrl.2013.12.008.

46. Treadaway K, Cutter G, Salter A, Lynch S, Simsarian J, Corboy J, et al. Factors that influence adherence with disease-modifying therapy in MS. J Neurol. 2009;256(4):568-76. Epub 2009/05/16. doi: 10.1007/s00415-009-0096-y.

47. Koltuniuk A, Rosinczuk J. Adherence to disease-modifying therapies in patients with multiple sclerosis. Patient Prefer Adherence. 2018;12:1557-66. Epub 2018/09/11. doi: 10.2147/ppa.S175095. 
48. Utz KS, Hoog J, Wentrup A, Berg S, Lammer A, Jainsch B, et al. Patient preferences for diseasemodifying drugs in multiple sclerosis therapy: a choice-based conjoint analysis. Ther Adv Neurol Disord. 2014;7(6):263-75. Epub 2014/11/06. doi: 10.1177/1756285614555335.

49. Garcia-Dominguez JM, Munoz D, Comellas M, Gonzalbo I, Lizan L, Polanco Sanchez C. Patient preferences for treatment of multiple sclerosis with disease-modifying therapies: a discrete choice experiment. Patient Prefer Adherence. 2016;10:1945-56. Epub 2016/10/08. doi: 10.2147/ppa.S114619.

50. Wilson LS, Loucks A, Gipson G, Zhong L, Bui C, Miller E, et al. Patient preferences for attributes of multiple sclerosis disease-modifying therapies: development and results of a ratings-based conjoint analysis. Int J MS Care. 2015;17(2):74-82. Epub 2015/04/22. doi: 10.7224/15372073.2013-053.

51. Rae-Grant A, Day GS, Marrie RA, Rabinstein A, Cree BAC, Gronseth GS, et al. Practice guideline recommendations summary: Disease-modifying therapies for adults with multiple sclerosis: Report of the Guideline Development, Dissemination, and Implementation Subcommittee of the American Academy of Neurology. Neurology. 2018;90(17):777-88. Epub 2018/04/25. doi: 10.1212/wnl.0000000000005347.

52. Montalban X, Gold R, Thompson AJ, Otero-Romero S, Amato MP, Chandraratna D, et al. ECTRIMS/EAN Guideline on the pharmacological treatment of people with multiple sclerosis. Mult Scler. 2018;24(2):96-120. Epub 2018/01/23. doi: 10.1177/1352458517751049.

53. Elwyn G, Laitner S, Coulter A, Walker E, Watson P, Thomson R. Implementing shared decision making in the NHS. Brit Med J. 2010;14(341):c5146. doi: 10.1136/bmj.c5146.

54. Entwistle V. Patient involvement in decision making: the importance of a broad conceptualization. In: Edwards A, Elwyn G, editors. Shared decision making in health care: achieving evidence-based patient choice. 2nd ed. Oxford: Oxford University Press; 2009.

55. Stacey D, Legare F, Lewis K, Barry MJ, Bennett CL, Eden KB, et al. Decision aids for people facing health treatment or screening decisions. Cochrane Database Syst Rev. 2017;4:Cd001431. Epub 2017/04/13. doi: 10.1002/14651858.CD001431.pub5.

56. Stalmeier PF. Adherence and decision AIDS: a model and a narrative review. Med Decis Making. 2011;31(1):121-9. doi: 10.1177/0272989X10370487.

57. Trenaman L, Selva A, Desroches S, Singh K, Bissonnette J, Bansback N, et al. A measurement framework for adherence in patient decision aid trials applied in a systematic review subanalysis. J Clin Epidemiol. 2016;77:15-23. Epub 2016/05/18. doi: 10.1016/j.jclinepi.2016.03.032.

58. Ferron $\mathrm{P}$, Asfour SS, Metsch LR, Antoni MH, Rodriguez AE, Duncan R, et al. Impact of a Multifaceted Intervention on Promoting Adherence to Screening Colonoscopy Among Persons in HIV Primary Care: A Pilot Study. Clin TransI Sci. 2015;8(4):290-7. doi: 10.1111/cts.12276.

59. Montori VM, Shah ND, Pencille LJ, Branda ME, Van Houten HK, Swiglo BA, et al. Use of a decision aid to improve treatment decisions in osteoporosis: the osteoporosis choice randomized trial. Am J Med. 2011;124(6):549-56. doi: 10.1016/j.amjmed.2011.01.013.

60. Weymiller AJ, Montori VM, Jones LA. Treatment decisions: statin choice randomized trial. Arch Intern Med. 2007;167(10):1076-82. doi: 10.1001/archinte.167.10.1076.

61. Coulter A, Stilwel D, Kryworuchko J, Dolan Mullen P, Jenn Ng C, van der Weijden T. A systematic development process for patient decision aids. BMC Med Inform Decis Mak. 2013;13(Suppl 2).

62. Stacey D, Légaré F, Lewis K, Barry MJ, Bennett CL, Eden KB, et al. Decision aids for people facing health treatment or screening decisions. Cochrane Database of Systematic Reviews. 2017;(4). doi: 10.1002/14651858.CD001431.pub5.

63. Köpke S, Solari A, Rahn A, Khan F, Heesen C, Giordano A. Information provision for people with multiple sclerosis. Cochrane Database of Systematic Reviews. 2018;(10). doi: 10.1002/14651858.CD008757.pub3. 
64. Kasper J, Kopke S, Muhlhauser I, Nubling M, Heesen C. Informed shared decision making about immunotherapy for patients with multiple sclerosis (ISDIMS): a randomized controlled trial. Eur J Neurol. 2008;15(12):1345-52. Epub 2008/12/04. doi: 10.1111/j.1468-1331.2008.02313.x.

65. Healthwise. Multiple Sclerosis: Should I start taking medicines for MS? 2017 [cited 2019 August 23rd]. Available from: https://www.healthlinkbc.ca/health-topics/tf2571.

66. Bansback N, Chiu JA, Carruthers R, Metcalfe R, Lapointe E, Schabas A, et al. Development and usability testing of a patient decision aid for newly diagnosed relapsing multiple sclerosis patients. BMC Neurol. 2019;19(1):173. Epub 2019/07/22. doi: 10.1186/s12883-019-1382-7.

67. Multiple Sclerosis Trust. MS Decisions Aid [cited 2019 August 23rd]. Available from: https://www.mstrust.org.uk/about-ms/ms-treatments/ms-decisions-aid.

68. Dowie J, Kjer Kaltoft M, Salkeld G, Cunich M. Towards generic online multicriteria decision support in patient-centred health care. Health Expect. 2015;18(5):689-702. Epub 2013/08/06. doi: 10.1111/hex.12111.

69. Drummond MF, Sculpher MJ, Claxton K, Stoddart GL, Torrance GW. Methods for the economic evaluation of health care programmes. 4th ed. New York: Oxford; 2015. 



\section{CHAPTER 2}

Identification and Prioritization of Important Attributes of Disease-Modifying Drugs in Decision Making among Patients with Multiple Sclerosis: A Nominal Group Technique and Best-Worst Scaling

Published as:

Kremer IE, Evers SM, Jongen PJ, van der Weijden T, van de Kolk I, Hiligsmann M. Identification and Prioritization of Important Attributes of Disease-Modifying Drugs in Decision Making among Patients with Multiple Sclerosis: A Nominal Group Technique and Best-Worst Scaling. PLoS One. 2016;11(11):e0164862. 


\begin{abstract}
Objectives. Understanding the preferences of patients with multiple sclerosis (MS) for disease-modifying drugs and involving these patients in clinical decision making can improve the concordance between medical decisions and patient values and may, subsequently, improve adherence to disease-modifying drugs. This study aims first to identify which characteristics - or attributes - of disease-modifying drugs influence patients' decisions about these treatments and second to quantify the attributes' relative importance among patients.
\end{abstract}

Methods. First, three focus groups of relapsing-remitting MS patients were formed to compile a preliminary list of attributes using a nominal group technique. Based on this qualitative research, a survey with several choice tasks (best-worst scaling) was developed to prioritize attributes, asking a larger patient group to choose the most and least important attributes. The attributes' mean relative importance scores (RIS) were calculated.

Results. Nineteen patients reported 34 attributes during the focus groups and 185 patients evaluated the importance of the attributes in the survey. The effect on disease progression received the highest RIS (RIS $=9.64,95 \%$ confidence interval: [9.48-9.81]), followed by quality of life (RIS = 9.21 [9.00-9.42]), relapse rate (RIS = 7.76 [7.39-8.13]), severity of side effects (RIS $=7.63$ [7.33-7.94]) and relapse severity (RIS $=7.39$ [7.06-7.73]). Subgroup analyses showed heterogeneity in preference of patients. For example, side effect related attributes were statistically more important for patients who had no experience in using disease-modifying drugs compared to experienced patients $(p<.001)$.

Conclusions. This study shows that, on average, patients valued effectiveness and unwanted effects as most important. Clinicians should be aware of the average preferences but also that attributes of disease-modifying drugs are valued differently by different patients. Person-centred clinical decision making would be needed and requires eliciting individual preferences. 


\section{Introduction}

Multiple sclerosis (MS) is a demyelinating and degenerative disease of the central nervous system causing physical and cognitive disabilities. MS occurs as different disease courses [1]. Relapsing-remitting MS (RRMS) is characterized by recurring exacerbations of MS symptoms (relapses) that recover partially or completely (remission) [1]. Between relapses, the disease remains stable. Progressive types of MS are characterized by a continuous increase in disability over time, either from the onset of MS (primary progressive MS) or conversion of RRMS to secondary progressive MS [1]. When a central nervous system demyelinating event has occurred that is isolated in time and compatible with the possible future development of MS, clinically isolated syndrome (CIS) is diagnosed [2]. Thirteen different disease-modifying drugs (DMDs) are currently available in the United States and in Europe to reduce the relapse rate and disease progression for patients with RRMS and new DMDs are still being developed. Some of these DMDs are also indicated for the treatment of CIS [3-5]. Adherence to DMD treatment is problematic, however, ranging from $41 \%$ to $88 \%$ of doses taken as prescribed [6], and non-adherence is associated with an increased relapse rate [7].

DMDs differ in their effectiveness, unwanted effects and other characteristics or attributes $[3,5]$. For patients diagnosed with RRMS or CIS, a decision needs to be made between the options the patient has, including the option of no DMD treatment. Decision making can be difficult because it requires comparing different DMD treatment options according to their specific characteristics or attributes.

Patients with MS have been reported to prefer being actively involved in the decision making about DMDs [8]. Therefore, it is important to inform and involve patients in the decision to start or not start taking a DMD, and, in case of starting, it is important to choose the type of DMD that best suits the patient's preferences and situation. In the shared decision making approach, the decision is made through a joint process between the physician and the patient. This entails informing the patient about treatment options and deliberation with the physician about which treatment would best fit the patient's preferences [9]. Understanding which DMD attributes are important according to patients may therefore contribute to the tailoring of information for patients in clinical practice and may support the clinical decision making process. Effective support of the shared decision making process could improve patient satisfaction and treatment adherence [10].

Preference research is often used to elicit patients' preferences for treatment options, i.e. to determine which attributes of the treatment options are important for patients in decision making. Patients are asked to state which treatment or treatment attribute they prefer in hypothetical trade-offs between two or more treatments or attributes [11]. Some preference studies have been conducted on MS patients' preferences for DMD treatments [12-18] but, to the best of our knowledge, no study has attempted to identify among patients the full range of attributes of DMDs in general - regardless of the specific type or administration mode of the DMD - that may be of importance in decision making. 
Therefore, important attributes of DMDs for decision making between all available DMDs may have been omitted in the exercises for prioritization of the attributes.

The current study aimed to use thorough research methodologies for evaluating patients' preferences for the full spectrum of DMD attributes that are of importance in the decision about DMD treatment. More specifically, the study's objective was twofold. The first objective was to identify the range of DMD attributes that influence the decision from the patients' perspective. The second objective was to quantify the relative importance of the identified attributes among a large group of patients.

\section{Methods}

Consecutive studies were conducted (Fig 1). First, an exploratory literature review and telephone interviews with healthcare professionals were performed to identify DMD attributes that may be of importance for decision making in DMD treatment. A full description of the methods used and results of this exploratory phase is provided in S1 and S2 (supplementary information). Next, patient focus groups using a nominal group technique were formed to identify attributes and to verify any additional attributes that were derived from the exploratory phase. A nominal group technique, as developed by Delbecq and Van de Ven $[19,20]$, is a structured method for guiding a group discussion to generate and prioritize ideas for a specific question. The RATS guideline [21] was used for reporting the methods and results of the nominal group technique, when appropriate. Finally, a best-worst scaling was conducted to prioritize the attributes according to a patient sample much larger than the number of patients that participated in the focus groups. A best-worst scaling is a specific method for conducting preference research. Respondents are asked to complete a series of choice tasks in which they have to choose the most and least important attributes from a selection of 4 or 5 attributes from a master list of attributes [22]. The advantage of the best-worst scaling over other stated preference research is the ability to acquire patients' preferences for a large number of attributes, regardless of the levels of the attributes. As the best-worst scaling was administered online, design and results of the best-worst scaling were presented according to the Checklist for Reporting Results of Internet E-Surveys [23]. The protocols of both the focus groups and the best-worst scaling were submitted to the Medical Ethics Committee of the Academic Hospital Maastricht and Maastricht University, the Netherlands (nr. 14-4-172). The committee concluded that the study did not qualify for a review according to the Dutch Medical Research Involving Human Subjects Act of 1998 and provided a positive decision for conducting the study. The study was performed in agreement with the ethical standards laid down in the 1964 Declaration of Helsinki and its later amendments. All participants gave their written informed consent before participating in the studies. 


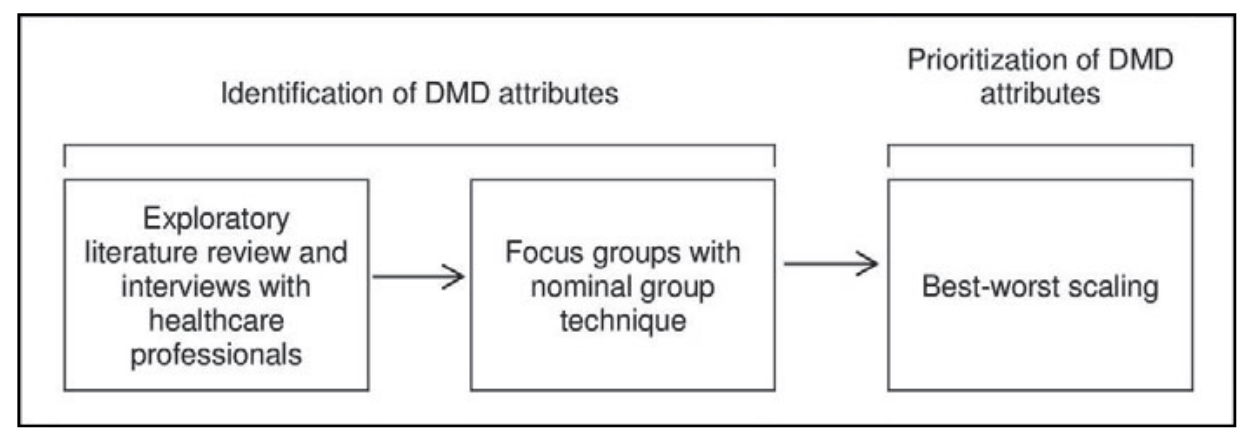

Figure 1. Consecutive process of studies

\section{Patient population}

Both for the focus groups with nominal group technique and the survey with the best-worst scaling, patients were considered eligible for participation if they were diagnosed with RRMS or CIS, were 18 years or older, and were willing and able to participate. For the focus groups an additional criterion was that the participant had experience with making a decision about DMD treatment or had experience with taking DMDs. Potential participants were recruited through advertisements on websites, social media or mailing lists of MS patient organizations.

Patients interested in participating in the focus groups were asked to contact one of the researchers (I.K.) by phone or e-mail. Based on the respondents' place of residence, three locations dispersed over the Netherlands were selected: a hospital in Nijmegen (the eastern part of the Netherlands) and community centres in Nieuwegein (the middle of the Netherlands) and Roermond (the southern part of the Netherlands). Patients who fulfilled the inclusion criteria and were able to travel to one of the selected locations were sent an information leaflet about the study and a consent form by mail. After a week, the patients were contacted by the first author to answer any of their questions and to register their participation. After participation in the focus group, each respondent received a 50 Euro gift card to compensate for any travel expenses and the time invested. Patients willing to participate in the best-worst scaling were redirected to the online questionnaire by means of a link in the advertisement or in the e-mail. After providing information about the purpose and content of the survey, the patients were informed that by filling out the questionnaire, they gave consent to the use of their answers in the study. To prevent the same person filling out multiple questionnaires, cookies were placed on their browser when they submitted their questionnaire. The recruitment method did not allow us to identify which patients did not choose to participate in the best-worst scaling or the focus groups. 


\section{Focus group with nominal group technique}

\section{Design}

Focus groups were performed by applying the nominal group technique. The structured method of a nominal group technique ensures that every participant's perspective is included and allows for differences in perspectives [19, 20]. A nominal group technique is therefore particularly suitable for identifying the full range of important DMD attributes and has already been used in other studies, e.g. to identify attributes of osteoporotic medications [24]. Two researchers were present at each focus group to facilitate the group discussion (IK) and to take notes (IVdK). The nominal group technique consisted of four steps. First, the participants were asked to individually answer the following question: "What characteristics of DMDs do you feel are important to consider when having to make a decision about DMD treatment?" Second, the participants took turns in reporting attributes until all attributes generated were written down on a flip-over by the facilitator. This ensured that every participant's opinion was elicited, and that they participated in the discussion. Third, the discussion was intended to come to an agreement within the group about the meaning and scope of each attribute. The participant that reported the attribute often provided the first description. Other participants were given the opportunity to react to this description. If the descriptions were different or had a broad scope an attribute was split into multiple attributes. If multiple attributes were similar in their meaning, these attributes were combined. This was done upon agreement of the participants. In the second and third focus group, the discussion was followed by asking for the participants' opinions about any additional attributes derived from the exploratory phase and whether these attributes should be included. Participants were entirely free to accept or reject the additional attributes. In the final step of each nominal group technique, participants were asked to select the 10 most important attributes from the list of attributes compiled and rank the top 5. After the third focus group, it was checked whether data saturation had been reached, i.e. whether any new attributes emerged that had not already been derived from the previous focus groups or the exploratory phase. Responses during the nominal group technique were recorded on audio tape so that attribute descriptions could be transcribed correctly and these tapes were erased afterwards. The anonymity of the respondents was ensured in the transcriptions.

\section{Analyses}

An overall list of important DMD attributes for decision making according to patients was created by comparing the attribute definitions from the three groups to each other. If from the transcripts of the discussions it appeared that attributes had similar descriptions across the focus groups, then these attributes were combined. The frequency with which participants included the attributes in their top 10 and top 5 was calculated. The attributes in the top 5 were awarded points, from 5 points for the most important attribute to 1 point for the least important one. Per attribute, the mean importance score was calculated by dividing the total points awarded per attribute by the total number of patients participating 
in all focus groups. Based on the mean importance score and calculated frequencies, an initial ranking of attributes was made from most to least important. Attributes that were not included in any of the participants' top 10 of most important attributes were excluded from the best-worst scaling.

\section{Best-worst scaling}

\section{Design}

Based on the results of the focus groups, a best-worst scaling was developed and converted to an online questionnaire of 3 pages with 6 questions each, and also contained 2 pages with 4 or 5 questions about the respondent's demographic and disease characteristics. All questions had to be filled out before the respondents could proceed to the next page or submit the questionnaire, but respondents were able to go back to change their answers before submission. A "don't know" option was provided for the appropriate demographic questions. Responses were registered automatically. No data were collected that could be referred back to the identity of the respondent (e.g. IP-address). The best-worst scaling consisted of 17 unique choice tasks. Each choice task presented five attributes of the full attribute list as derived from the focus groups. Each respondent was asked to select the most and least important attributes for decision making about DMD treatment. The attributes selected by the respondent represent the attributes that are furthest apart on the importance scale for the individual patient [22]. Additionally, patients were provided the opportunity to list any important DMD attributes that in their opinion were not included in the best-worst scaling. Fig 2 provides an example of a choice task.

\begin{tabular}{|c|c|c|}
\hline \multicolumn{3}{|c|}{$\begin{array}{l}\text { Please choose the most and least important characteristics of disease-modifying drugs } \\
\text { for you when you need to decide on treatment with disease-modifying drugs. }\end{array}$} \\
\hline Most important & & Least important \\
\hline 0 & Method of administration & 0 \\
\hline 0 & Contact person at pharmaceutical company & 0 \\
\hline 0 & Effect on quality of life & 0 \\
\hline 0 & Duration of administration & 0 \\
\hline 0 & Safety & 0 \\
\hline
\end{tabular}

Figure 2. Example of a choice task in the best-worst scaling

A fractional design was created for the best-worst scaling with Sawtooth SSI Web version 8.2.0. This software creates the most efficient design, characterized by orthogonality (the frequency of an attribute paired with other attributes is equal for all attributes), balance (the frequency of attributes occurring in the best-worst scaling is equal), and positional frequency (the frequency of attributes on the $1^{\text {st }}$ to $5^{\text {th }}$ position in the choice task is equal) and determines which attributes are presented to the respondent in each choice task. Four 
best-worst scaling versions were created. Each attribute was presented 12 or 13 times, was combined at least once with every other attribute and appeared 2 to 4 times in each position in the choice tasks. Respondents randomly received 1 of the 4 best-worst scaling versions. The questionnaire was pilot-tested among researchers $(\mathrm{N}=3)$ and $\mathrm{MS}$ patients $(\mathrm{N}=3)$ prior to the start of the study, which resulted in minor revisions of the instructions. The questionnaire was not found to be too cognitively burdensome to patients.

\section{Analyses}

Questionnaires were filled out from 12 May 2015 to 5 June 2015. Only completed bestworst scaling questionnaires were included in the analyses. Descriptive statistics were used to present demographic and disease characteristics of the respondents. Hierarchical Bayes analysis was performed with Sawtooth SSI Web version 8.2.0 to estimate the mean relative importance score per attribute. The raw score, which was obtained with an iterative process of estimating individual utility scores based on the sample means, was rescaled to a probability score on a ratio scale. This score represents the attribute's relative importance for decision making about DMD treatment according to the respondent. The relative importance scores of all attributes combined for an individual respondent sum up to 100 [25]. A mean overall relative importance score was calculated per attribute with its $95 \%$ confidence interval. Based on the mean scores, attributes were ranked from most to least important for decision making in DMD treatment. Attributes with a score of 3.7 were regarded as of average importance (100 points divided by 27 attributes). In lack of consensus on the minimal important difference in relative importance scores, if confidence intervals of two consecutive ranked attributes did not overlap, we considered them to be of different importance in the decision about DMDs.

The quality of the responses was checked based on the individual's fit statistic, i.e. if responses had a fit statistic below 0.247 , these were excluded from analyses because this indicates purely random responses to the choice tasks [26]. Subgroup analyses on gender, age, education, disease duration, relapse rate, experience with $\mathrm{DMD}$, and current and prior DMDs taken were conducted to explore whether patients' preferences for DMD attributes differ according to demographic characteristics, disease characteristics or DMD experience. Subgroups for continuous data (age, disease duration) were made according to the median. For categorical data, subgroups were made based on relevance for comparison (e.g. DMDnaive vs. DMD-experienced). Difference in importance scores between subgroups were statistically tested with an independent t-test for parametric data and the Mann-Whitney test for non-parametric data using SPSS for Windows version 20. An alpha of .05 and a Bonferroni-adjusted alpha of .0019 (for 27 comparisons) were used to assess whether differences in RIS of attributes between subgroups were statistically significant. 


\section{Results}

\section{Patient population}

Table 1 presents the characteristics of the patients that participated in the focus groups and the best-worst scaling. Three focus groups with a total of 19 RRMS patients took place. Each group consisted of male and female participants ranging in age, educational level and experience with DMD use. Age was approximately normally distributed with a mean of 46.8 $( \pm 8.8)$ years old. Thirteen $(68.4 \%)$ patients had prior experience with making a decision about DMDs and six (31.6\%) were considering or reconsidering their DMD options at the time of the focus groups.

Of the 286 people who accessed the survey via the provided link, 193 respondents (67.5\%) started the best-worst scaling exercise and met the inclusion criteria. Of these respondents, 185 people (95.9\%) completed the best-worst scaling exercise. The majority of the respondents who completed the best-worst scaling exercise were female (86.5\%); this is somewhat higher than the Dutch MS population of $72 \%$ [27]. Of the respondents, $54.1 \%$ had completed a higher vocational education or university education. Mean age was 42.1 ( \pm 9.6 ) years, which was approximately normally distributed, and almost all patients reported a diagnosis of RRMS (98.4\%). Twenty-seven (14.6\%) patients reported having no experience with using DMDs and 131 (70.8\%) respondents were currently taking a DMD.

\section{Focus group with nominal group technique}

Data saturation was reached in the third focus group because no new attributes emerged. Combining the attribute lists from the three focus groups resulted in 34 DMD attributes that, according to the patients, were important in decision making about DMD treatment. Based on the mean importance scores, participants in the focus groups regarded the type of side effects as most important, followed by effect on disease progression, method of administration, effect on relapse rate, safety and insurance coverage. Seven attributes were not included in the top 10 by any of the participants (adherence rate, availability of the DMD in the Netherlands, brand recognition, issuance of DMD, wash-out requirements, shelf life and legal liability). For descriptions of all DMD attributes, their ranking and mean importance scores, we refer to the data in S3 (supplementary information). 
Table 1. Patient characteristics: nominal group technique $(\mathrm{N}=19)$ and best-worst scaling $(\mathrm{N}=185)$

\begin{tabular}{|c|c|c|c|}
\hline Characteristics & & $\begin{array}{l}\text { Nominal } \\
\text { group } \\
\text { technique }\end{array}$ & $\begin{array}{l}\text { Best-worst } \\
\text { scaling }\end{array}$ \\
\hline Women n (\%) & & $15(78.9)$ & $160(86.5)$ \\
\hline Age, mean \pm SD (years) & & $46.8 \pm 8.8$ & $42.1 \pm 9.6$ \\
\hline \multicolumn{4}{|l|}{ Educational level $\mathrm{n}(\%)$} \\
\hline & Lower & $7(36.8)$ & 72 (38.9) \\
\hline & Higher & $12(63.2)$ & $113(61.1)$ \\
\hline \multicolumn{4}{|l|}{ Employed } \\
\hline & Yes & $8(42.1 \%)$ & $90(48.6 \%)$ \\
\hline & No & $11(57.9 \%)$ & 95 (51.4\%) \\
\hline \multicolumn{4}{|l|}{ Diagnosis } \\
\hline & RRMS n (\%) & $19(100)$ & $182(98.4)$ \\
\hline & CIS n (\%) & $0(0)$ & $3(1.6)$ \\
\hline Duration of diagnosis, mean \pm SD (years) & & $9.5 \pm 8.4$ & $6.4 \pm 5.9$ \\
\hline \multirow[t]{3}{*}{ Relapse rate previous year, $\mathrm{n}(\%)$} & & $(\mathrm{N}=17)$ & $(\mathrm{N}=172)$ \\
\hline & 0 & $7(41.2)$ & $63(36.6)$ \\
\hline & $\geq 1$ & $10(58.8)$ & $109(63.4)$ \\
\hline Currently taking DMD n (\%) & & 15 (78.9) & $131(70.8)$ \\
\hline Previously taken DMD n (\%) & & $10(52.6)$ & $86(46.5)$ \\
\hline \multirow[t]{5}{*}{ Number of prior taken DMD n (\%) } & & $(\mathrm{N}=19)$ & $(\mathrm{N}=184)$ \\
\hline & 1 & $6(31.6)$ & $43(23.4)$ \\
\hline & 2 & $2(10.5)$ & $35(19.0)$ \\
\hline & 3 & $2(10.5)$ & $5(2.7)$ \\
\hline & 4 & $0(0)$ & $3(1.6)$ \\
\hline
\end{tabular}

$\mathrm{CIS}$, clinically isolated syndrome; DMD, disease-modifying drug; RRMS, relapsing-remitting multiple sclerosis; $S D$, standard deviation.

\section{Best-worst scaling}

The best-worst scaling survey included 27 attributes. From the list of 34 attributes identified in the focus groups, seven attributes were excluded because they were not included in the top 10 by any of the participants in the focus groups. All respondents had a fit statistic higher than 0.247 and were therefore all included in the analysis. Hierarchical Bayes analysis showed that attributes related to effectiveness and unwanted effects were most important for decision making according to patients. Table 2 presents the group average relative importance scores of all 27 attributes with their $95 \%$ confidence intervals ranked from most to least important for decision making in DMD treatment. The effect on disease progression was ranked as the most important attribute with a RIS of $9.6(95 \% \mathrm{Cl} 9.5-9.8)$. The effect on quality of life, defined as the overall increase in the well-being of a patient as a result of the DMD, was ranked second (RIS 9.2; $95 \% \mathrm{Cl} 9.0-9.4$ ), followed by effect on the relapse rate (RIS 7.8; $95 \% \mathrm{Cl} 7.4-8.1$ ), and severity of side effects (RIS 7.6; $95 \% \mathrm{Cl} 7.3-7.9$ ). The severity of side effects scored higher than safety issues, i.e. common side effects were found to be of more influence on the treatment decision than risks of life threatening or severely disabling consequences. The most important attribute not related to beneficial or 
unwanted effects was influence on life style (RIS 5.3; 95\% Cl 4.9-5.7) but this attribute was only half as important as the number one ranked attribute, effect on disease progression. Other convenience issues with taking DMDs were valued far less: the RIS for administration method, administration frequency and required monitoring were 1.6 (95\% $\mathrm{Cl} 1.2-2.0), 0.7$ $(95 \% \mathrm{Cl} 0.5-0.9)$ and $0.6(95 \% \mathrm{Cl} 0.4-0.7)$ respectively. Rankings of attributes as derived from the focus groups deviate from these results. The convenience issues mentioned previously were all ranked in the top 10 , while the effect on quality of life, plaque development and severity of side effects were of less importance.

One MS patient reported "effect of the DMD on pregnancy or child" as an additional attribute that was not already included in the best-worst scaling. Other attributes that were reported, such as effect of the DMD on mental well-being and family members, and feelings of depression or anxiety, were captured in or had considerable overlap with other attributes.

Subgroup analyses showed deviations from the overall importance scores for patients with certain characteristics. As is presented in Fig 3, patients who had never used a DMD ( $n=27)$ valued duration, type and severity of side effects significantly higher than did patients who had DMD experience $(n=157)$ (respectively $U=946, z=-4.59, p<.001 ; t(182)=4.36, p<.001$; $\mathrm{U}=863, \mathrm{z}=-4.92, \mathrm{p}<.001)$. The patients in this last group had higher relative importance scores for the effectiveness of the DMD on the relapse rate, relapse severity, plaque development and life expectancy compared with DMD-naive patients (respectively $\mathrm{U}=1196$, $\mathrm{z}=-3.61, \mathrm{p}<.001 ; \mathrm{U}=1312, \mathrm{z}=-3.16, \mathrm{p}=.001 ; \mathrm{U}=1585, \mathrm{z}=-2.09, \mathrm{p}=.038 ; \mathrm{U}=1549, \mathrm{z}=-2.23$, $p=.026)$. For attributes of which the relative importance score did not significantly differ between DMD-naive and DMD-experienced patients, the results of the analyses are provided in S4 (supplementary information).

Similar differences in the importance of attributes were found for patients who were not using a DMD at the time of survey administration $(n=54)$ in comparison with patients using a DMD ( $n=131)$ : attributes concerning effectiveness were more important in the decision for patients currently using a DMD, while patients who were not using a DMD valued attributes related to unwanted effects significantly higher. Although ranked only $16^{\text {th }}$, the administration method was more important for patients taking orally administered DMDs (mean RIS=2.5; 95\% Cl 1.6, 3.4) in comparison with patients taking parenteral (intramuscular, subcutaneous or intravenous) DMDs (mean RIS=1.0; 95\% Cl 0.6, 1.5), which was a significant difference $(U=1416, z=-3.28, p=.001)$. The safety of the DMD was significantly more important for patients with a diagnosis of MS longer than 4.6 years compared to patients with shorter disease durations $(U=3174, z=-3.03, p=.001)$. Male patients were significantly more concerned about the influence of DMD use on lifestyle and with the effect on life expectancy in comparison with female patients $(U=1366, z=-2.55$, $p=.011 ; U=1468, z=-2.14, p=.032$ ). No significant differences were found in the importance scores of attributes of higher and lower educated patients. Results of all subgroup analyses are provided in S5 Figures. 


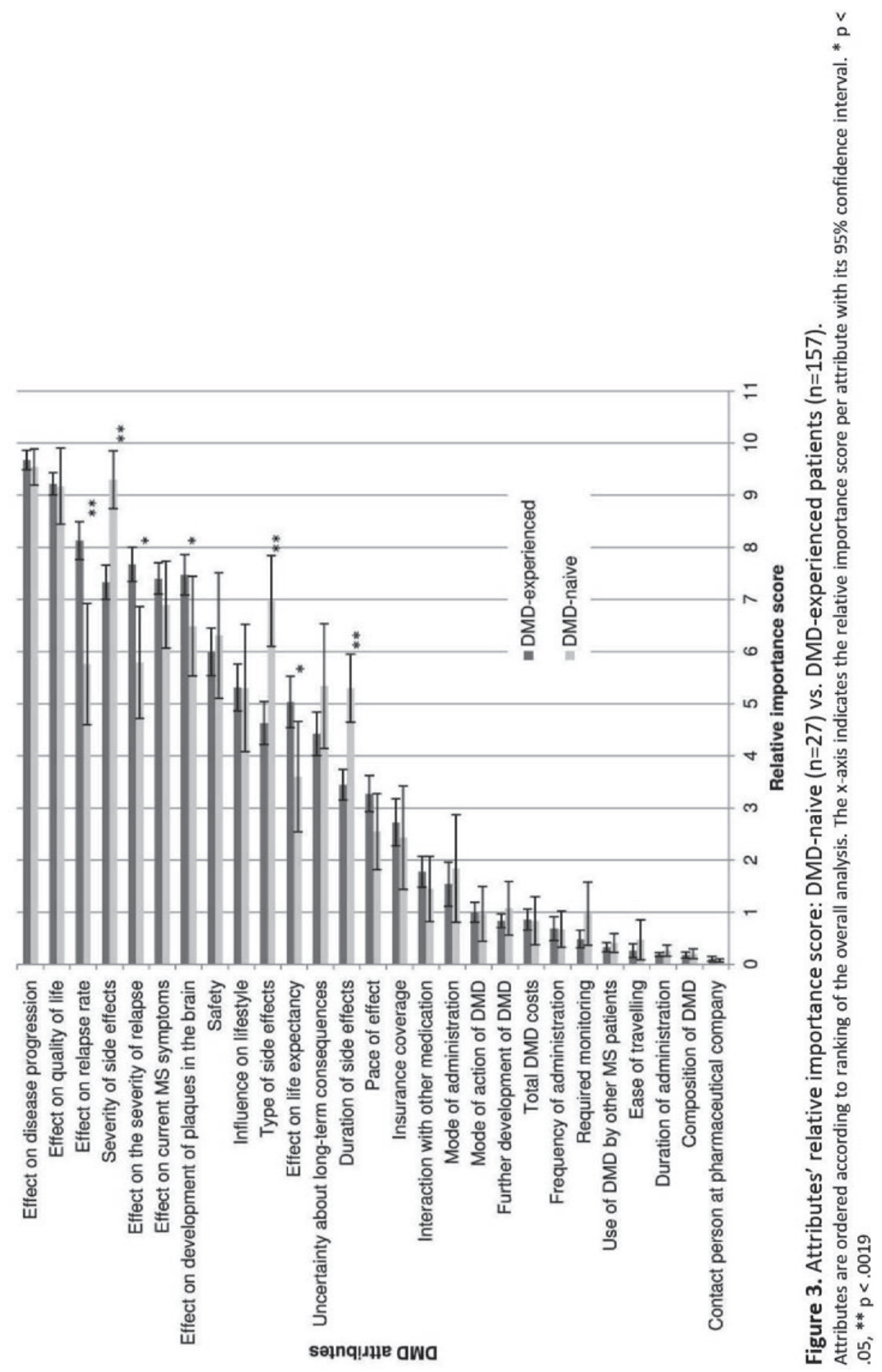


Table 2. Group average relative importance scores of attributes in decision making as derived from the best-worst scaling among 185 patients

\begin{tabular}{|c|c|c|c|}
\hline Attribute & RIS & $\begin{array}{l}95 \% \mathrm{Cl} \\
\text { lower } \\
\text { bound }\end{array}$ & $\begin{array}{l}95 \% \mathrm{Cl} \\
\text { upper } \\
\text { bound }\end{array}$ \\
\hline Effect on disease progression & 9.64 & 9.48 & 9.81 \\
\hline Effect on quality of life & 9.21 & 9.00 & 9.42 \\
\hline Effect on relapse rate & 7.76 & 7.39 & 8.13 \\
\hline Severity of side effects & 7.63 & 7.33 & 7.94 \\
\hline Effect on the severity of relapses & 7.39 & 7.06 & 7.73 \\
\hline Effect on current MS symptoms & 7.32 & 7.03 & 7.60 \\
\hline Effect on plaque development in the brain & 7.31 & 6.94 & 7.67 \\
\hline Safety & 6.04 & 5.62 & 6.47 \\
\hline Influence on lifestyle & 5.31 & 4.88 & 5.73 \\
\hline Type of side effects & 5.00 & 4.60 & 5.39 \\
\hline Effect on life expectancy & 4.81 & 4.36 & 5.27 \\
\hline Uncertainty about long-term consequences & 4.58 & 4.18 & 4.98 \\
\hline Duration of side effects & 3.74 & 3.45 & 4.02 \\
\hline Pace of effect & 3.18 & 2.87 & 3.50 \\
\hline Insurance coverage & 2.71 & 2.29 & 3.12 \\
\hline Interaction with other medication & 1.72 & 1.46 & 1.99 \\
\hline Method of administration & 1.58 & 1.19 & 1.97 \\
\hline Mode of action of DMD & 0.99 & 0.81 & 1.17 \\
\hline Further development of DMD & 0.87 & 0.73 & 1.00 \\
\hline Total DMD costs & 0.86 & 0.68 & 1.04 \\
\hline Frequency of administration & 0.68 & 0.48 & 0.88 \\
\hline Required monitoring & 0.55 & 0.38 & 0.72 \\
\hline Use of DMD among other MS patients & 0.34 & 0.26 & 0.42 \\
\hline Ease of travelling & 0.29 & 0.17 & 0.42 \\
\hline Duration of administration & 0.20 & 0.17 & 0.24 \\
\hline Composition of DMD & 0.18 & 0.13 & 0.23 \\
\hline Contact person at pharmaceutical company & 0.10 & 0.06 & 0.14 \\
\hline
\end{tabular}

$\mathrm{Cl}$, confidence interval; $\mathrm{DMD}$, disease-modifying drug; RIS, relative importance score. 


\section{Discussion}

The current study aimed to identify the full spectrum of DMD attributes and to quantify their relative importance in decision making about DMD treatment according to RRMS and CIS patients. Patients reported a total of 34 different attributes that might influence their decision. Quantification of the relative importance showed that, as a group, patients place the most emphasis on benefits - especially disease progression and quality of life - and on unwanted effects when having to make a decision in DMD treatment, rather than usability issues. The ranking of the attributes showed that the most important attributes are comparable to the attributes used in other stated preference research [12-18]. Preventing disease progression was found in previous preference research to be an important attribute of DMDs [12-18] but quality of life has not yet been reported in these studies. The effect on quality of life - the increase or decrease in the overall well-being of a patient as a result of the DMD - could be interpreted as a summarizing attribute, incorporating the DMD's beneficial effects and burdens into one attribute. This could explain its importance for patients. However, data from high quality randomized controlled trials on the effects of DMDs on quality of life are lacking for DMDs that have been available for the treatment of MS for some time now. It is encouraging that new RCTs and many observational studies are including quality of life as an outcome measure, since the effect of the DMD on quality of life is regarded as important information by the patients.

Regarding unwanted effects, the severity of non-life threatening physical and psychological side effects - essentially, the extent to which these side effects outweigh the desire to treat MS - was found to be the most influential attribute in decision making. This is in contrast to the results from the most comprehensive study about preferences for DMD attributes conducted among a large number of RRMS patients, which found life-threatening or severely disabling side effects to be the most important attribute and minor side effects to be the least important [17]. However, this study included four levels for life-threatening side effects denoted as risk of death or becoming severely disabled ( 0 out of 1,000; 0.5 out of 1,000 ; 1 out of 1,000; or 10 out of 1,000), while common side effects were split into three levels of types of common side effects (headaches and muscle or joint aches; increased risks of infection; and mood changes). Our study did not include levels, and therefore these could not influence how patients valued the attributes, perhaps explaining the differences between the two studies' findings.

Noteworthy are the relatively low ranking and importance scores of administration method and administration frequency, ranked $17^{\text {th }}$ and $21^{\text {st }}$ respectively, as derived from the bestworst scaling, while in the literature these attributes were found to be of substantial importance in decision making among MS patients [17, 28, 29]. Attributes that were valued more highly than mode and frequency of administration by patients in our study, such as insurance coverage, total costs, continuous development of the DMD and interaction with other medication, were not included in other studies. Moreover, influence on lifestyle was valued relatively highly in our study. Although it was described to patients as "the extent to which a patient's habits or lifestyle have to be adjusted for proper use of the medication, 
such as the flexibility in time of administration, restrictions on consuming alcohol, driving, sports, work, etc.", patients may have also included administration method and frequency in this attribute, resulting in a higher ranking in comparison with administration method and frequency.

Subgroup analyses showed heterogeneity in preferences of patients according to different characteristics. For example, attributes related to unwanted effects were stated to be more influential in decision making by patients with no prior DMD experience in comparison with patients who had experience with DMD use. These findings reinforce the individuality of preferences and the need to incorporate the individual's perspective into the clinical decision making process. It underlines the need for shared decision making, as this approach is focused on supporting patients in developing informed preferences based on objective information [30].

By investigating patients' preferences about DMD attributes, our study may help to identify which information patients need about DMDs in order to make an informed decision, therefore enabling clinicians to adjust their information provision accordingly to facilitate the process of shared decision making and to support the development of informed preferences in patients. However, clinicians should also take into account that the study results provide guidance for the average patient. As heterogeneity in the results show, different patients could find different attributes of DMDs important for decision making. Therefore, clinicians should inform each patient who wants to be involved in the decision making about the pros and cons per option based on the patient's personal preferences. As a result, clinicians should support the patient to elicit what is important to him or her and adjust the consultation accordingly, i.e. incorporate the patient's preference in the decision or delay decision making and empower the patient with a patient decision aid. A patient decision aid contains concise summaries of the evidence on important attributes of the treatment options and includes a preference clarification method to assess what attributes of the treatment options are of importance for the individual patient. A decision aid could therefore support the shared decision making process in clinical practice [31]. The results of the current study will inform the development of such a decision aid for MS patients who need to make a decision about DMD treatment.

A strength of our study is the thorough methodology of a nominal group technique followed by a best-worst scaling used for identification and prioritization of attributes. Using focus groups with a nominal group technique ensured the direct elicitation of patients' perspectives on all important DMD attributes for decision making, whereas prior preference studies focused only on a selection of attributes and/or relied on literature review and consultations with clinical experts for identification of attributes. Comparing attribute rankings from the nominal group technique and the best-worst scaling, there were considerable differences. Although data saturation was achieved in the identification of DMD attributes in the nominal group technique, we did not aim for data saturation in the ranking of the attributes. Due to variation in the attributes reported per nominal group technique, not all 34 attributes were included in the rankings of each focus group, resulting in lower validity of the overall ranking in the nominal group technique. In addition, the 
ranking in the nominal group technique was established after an interactive process of participants discussing the attributes and possibly influencing each other's opinion in comparison to the best-worst scaling in which respondents filled out the survey by themselves. The differences in rankings emphasize the importance of using a quantitative method such as a best-worst scaling for prioritization of the attributes, in addition to qualitative work on identifying attributes.

Some limitations should be taken into account with the interpretation of the results. We used patient-centred methodologies for identifying the attributes. However, we cannot exclude that attributes important for some patients were not included in the study. In the best-worst scaling, one patient reported an additional attribute to be important: the effect of the DMD during pregnancy on the unborn child. Although it is generally recommended to discontinue DMD treatment before trying to conceive, treatment with certain DMDs can be continued in case of highly active MS [32-36]. Moreover, during DMD treatment patients may become pregnant inadvertently. A possible reason for omission of this attribute in the best-worst scaling may be that the 19 patients questioned in the focus groups and the six healthcare professionals questioned by interview regarded these risks inherent to safety or side effects. Another reason for omission by the patients in the focus groups may be that they already had children or stopped thinking about having children as the average age of patients in the focus groups was 46.8 years (SD 8.8), meaning that $68 \%$ of patients were between 38.0 and 55.6 years old and ranging from 30 to 68 years old. Actually, only 2 out of 15 women in the focus groups were between 30 and 35 years of age, the other being older. Thus, the number of women in child-bearing age was relatively low, which could explain the omission of the attribute regarding pregnancy risks. Furthermore, to be able to include a large number of attributes, the best-worst scaling did not include attribute levels. The importance scores therefore present the patients' preferences for attributes of DMDs in general; preferences for a specific DMD with a certain attribute level may deviate from the scores obtained in this study. Additionally, although the recruitment method enabled the inclusion of RRMS and CIS patients from all regions of the Netherlands, the samples for the focus groups and the best-worst scaling contained a relatively high proportion of women, older participants and more highly educated participants in comparison with the average MS patient population in the Netherlands [37] and may contain patients who are more involved in their disease management due to our recruitment method via websites and mailing lists of patient organizations. Patients may therefore have a better understanding of what the benefits and risks entail and this could influence the generalizability of the results. Differences were found between men and women in importance of attributes, but subgroup analyses revealed no major difference according to age and level of education of the patient. Moreover, our recruitment method did not enable us to collect data from medical records, and therefore diagnosis, disease duration, relapses experienced and DMD history were self-reported by patients. This may have resulted in incorrect reporting of medical and sociodemographic characteristics. In addition, the transferability of our findings to other settings could be uncertain since the health care system and practice could potentially impact the importance of some attributes, For 
example, we could expect that the total DMD costs would be more important in countries where patients have out-of-pocket contributions. Lastly, the subgroup analyses had an exploratory purpose. We did not aim to recruit a minimum number of patients for each subgroup. Therefore, the difference in importance of attributes according to the subgroups should be interpreted with caution.

In conclusion, this study shows that patients with RRMS and CIS find beneficial and unwanted effects to be the most important DMD attributes in making decisions about DMD treatment, more important than usability issues with taking the DMD. The effect on disease progression and quality of life were the most important attributes. However, this study also recognizes the heterogeneity in preferences of patients. When having to make a decision about DMD treatment, clinicians should be aware of what the average patient finds important and incorporate information on these attributes in the education for the shared decision making process. However, person-centred clinical decision making requires eliciting the individual patient's preferences for DMD treatment at the point of the decision.

\section{Acknowledgments}

We thank the neurologists and nurses for providing their opinions during the exploratory phase of the study. We thank the patients with MS for participating in our study and the National MS Foundation the Netherlands, MS Vereniging Nederland and MS-Anders for their cooperation in informing patients about the study. The Master's thesis based on this study has been awarded the Catharina Pijls Encouragement Award 2015 for an excellent Master's thesis in the health sciences, an initiative of Maastricht University in the Netherlands. 


\section{References}

1. Lublin FD, Reingold SC, Cohen JA, Cutter GR, Soelberg Sorensen P, Thompson AJ, et al. Defining the clinical course of multiple sclerosis: the 2013 revisions. Neurology. 2014;83:278-86. doi: 10.1212/01.wnl.0000462309.76486.c5.

2. Polman $\mathrm{CH}$, Reingold SC, Banwell B, Clanet M, Cohen JA, et al. Diagnostic criteria for multiple sclerosis: 2010 revisions to the McDonald criteria. Ann Neurol. 2011;69:292-302. doi: 10.1002/ana.22366.

3. English C, Aloi JJ. New FDA-Approved Disease-Modifying Therapies for Multiple Sclerosis. Clin Ther. 2015;37(4):691-715. doi: 10.1016/j.clinthera.2015.03.001.

4. European Medicines Agency. European public assessment reports [cited 20169 August]. Available from: http://www.ema.europa.eu/.

5. Michel L, Larochelle C, Prat A. Update on treatments in multiple sclerosis. Presse Med. $2015 ; 44(4$ Pt 2):e137-51. doi: 10.1016/j.lpm.2015.02.008.

6. Menzin J, Caon C, Nichols C, White LA, Friedman M, Pill MW. Narrative review of the literature on adherence to disease modifying therapies among patients with multiple sclerosis. J Manag Care Pharm. 2013;19(1-a):s24-s40.

7. Tan H, Cai Q, Agarwal S, Stephenson JJ, Kamat S. Impact of adherence to disease-modifying therapies on clinical and economic outcomes among patients with multiple sclerosis. Adv Ther. 2011;28(1):51-61. doi: 10.1007/s12325-010-0093-7.

8. Heesen C, Kasper J, Segal J, Kopke S, Muhlhauser I. Decisional role preferences, risk knowledge and information interests in patients with multiple sclerosis. Mult Scler. 2004;10(6):643-50. doi: 10.1191/1352458504ms1112oa.

9. Elwyn G, Laitner S, Coulter A, Walker E, Watson P, Thomson R. Implementing shared decision making in the NHS. Brit Med J. 2010;14(341):c5146. doi: 10.1136/bmj.c5146.

10. Joosten EA, DeFuentest-Merillas L, de Weert GH, Sensky T, van der Staak CP, de Jong CA. Systematic review of the effects of shared decision making on patient satisfaction, treatment adherence and health status. Psychother Psychosom. 2008;77(4):219-26. doi: 10.1159/000126073.

11. Bridges JFP, Hauber AB, Marshall D, Lloyd A, Prosser LA, Regier DA, et al. Conjoint Analysis Applications in Health- a checklist: a report of the ISPOR Good Research Practices for Conjoint Analysis Task Force. Value health. 2011;14:403-13. doi: 10.1016/j.jval.2010.11.013.

12. Johnson FR, Van Houtven G, Özdemir S, Hass S, White J, Francis G, et al. Multiple Sclerosis patients' benefit-risk preferences: serious adverse event risks versus treatment efficacy. J Neurol. 2009;256(4):554-62. doi: 10.1007/s00415-009-0084-2.

13. Poulos C, Kinter E, Yang JC, Bridges JF, Posner J, Reder AT. Patient Preferences for Injectable Treatments for Multiple Sclerosis in the United States: A Discrete-Choice Experiment. Patient. 2015. doi: 10.1007/s40271-015-0136-x.

14. Poulos C, Kinter E, Yang J-C, Bridges JFP, Posner J, Gleißner E, et al. A discrete-choice experiment to determine patient preferences for injectable multiple sclerosis treatment in Germany. Ther Adv Neurol Disord. 2016;9(2):95-104.

15. Utz KS, Hoog J, Wentrup A, Berg S, Lammer A, Jainsch B, et al. Patient preferences for diseasemodifying drugs in multiple sclerosis therapy: a choice-based conjoint analysis. Ther Adv Neurol Disord. 2014;7(6):263-75. doi: 10.1177/1756285614555335. PubMed Central PMCID: PMCPmc4218877. 
16. Wicks P, Brandes DW, Park J, Liakhovitski D, Koudinova T, Sasane R. Preferred features of oral treatments and predictors of non-adherence: two web-based choice experiments in multiple sclerosis patients. Interact J Med Res. 2015;4(1):e6.

17. Wilson L, Loucks A, Bui C, Gipson G, Zhong L, Schwartzburg A, et al. Patient centered decision making: use of conjoint analysis to determine risk-benefit trade-offs for preference sensitive treatment choices. J Neurol Sci. 2014;344(1-2):80-7. doi: 10.1016/j.jns.2014.06.030.

18. Wilson LS, Loucks A, Gipson G, Zhong L, Bui C, Miller E, et al. Patient preferences for attributes of disease-modifying multiple sclerosis therapies: development and results of a ratings-based conjoint analysis. Int J MS Care. 2015. doi: 10.7224/1537-2073.2013-053.

19. Delbecq A, Van de Ven A. A group prcoess model for program identification and program planning. J Appl Behav Sci. 1971;7(4):466-92.

20. Delbecq A, Van de Ven A, Gustafson D. Group techniques for program planning: a guide to nominal group and delphi processes. Glenview, IL: Scott, Foresman and Company; 1975.

21. Clark JP. How to peer review a qualitative manuscript. In: Godlee F, Jefferson T, editors. Peer review in health sciences. Second edition ed. London: BMJ Books; 2003. p. 219-35.

22. Flynn TN, Louviere JJ, Peters TJ, Coast J. Best--worst scaling: What it can do for health care research and how to do it. J Health Econ. 2007;26(1):171-89. doi: 10.1016/j.jhealeco.2006.04.002.

23. Eysenbach $\mathrm{G}$. Improving the quality of web surveys: the checklist for reporting results of internet E-surveys (CHERRIES). J Med Internet Res. 2004;6(3):e34. doi: 10.2196/jmir.6.3e34.

24. Hiligsmann M, van Durme C, Geusens P, Dellaert BG, Dirksen CD, van der Weijden T, et al. Nominal group technique to select attributes for discrete choice experiments: an example for drug treatment choice in osteoporosis. Patient Prefer Adherence. 2013;7:133-9. doi: 10.2147/ppa.s38408.

25. Orme B. Hierarchical Bayes: why all the attention? Sequim, WA: Sawtooth Software, Inc., 2000.

26. Sawtooth Software Inc. SSI Web v8.3: software for web interviewing and conjoint analysis Orem, Utah: Sawtooth Software Inc.; 2014. Available from: http://www.sawtoothsoftware.com/support/manuals/ssi-web-help.

27. Gommer AM, Poos MJJC. Achtergrondcijfers bij rangordetabellen VTV-2010. Bilthoven: RIVM; 2010. Available from: http://www.nationaalkompas.nl/gezondheid-en-ziekte/ziekten-enaandoeningen/achtergrondcijfers-bij-rangordetabellen/.

28. Hanson KA, Agashivala N, Stringer SM, Balantac Z, Brandes DW. A cross-sectional survey of patient satisfaction and subjective experiences of treatment with fingolimod. Patient Prefer Adherence. 2013;7:309-18. doi: 10.2147/ppa.s41992.

29. Visser $\mathrm{LH}$, van der Zande $A$. Reasons patients give to use or not to use immunomodulating agents for multiple sclerosis. Eur J Neurol. 2011;18(11):1343-9. doi: 10.1111/j.1468-1331.2011.03411.x.

30. Elwyn G, Frosch D, Thomson R, Joseph-Williams N, Lloyd A, Kinnersley P, et al. Shared decision making: a model for clinical practice. J Gen Intern Med. 2012;27(10):1361-7. doi: 10.1007/s11606012-2077-6.

31. O'Connor AM, Llewellyn-Thomas HA, Flood AB. Modifying unwarranted variations in health care: shared decision making using patient decision aids. Health Affair. 2004;Suppl Variation:VAR63-72. doi: $10.1377 /$ hlthaff.var.63.

32. Bove R, Alwan S, Friedman JM, Hellwig K, Houtchens M, Koren G, et al. Management of multiple sclerosis during pregnancy and the reproductive years: a systematic review. Obstet Gynecol. 2014;124(6):1157-68. doi: 10.1097/aog.0000000000000541.

33. Lu E, Wang BW, Guimond C, Synnes A, Sadovnick AD, Dahlgren L, et al. Safety of disease-modifying drugs for multiple sclerosis in pregnancy: current challenges and future considerations for 
effective pharmacovigilance. Expert Rev Neurother. 2013;13(3):251-60; quiz 61. doi: 10.1586/ern.13.12.

34. Coyle PK. Management of women with multiple sclerosis through pregnancy and after childbirth. Ther Adv Neurol Disord. 2016;9(3):198-210. doi: 10.1177/1756285616631897.

35. Thiel S, Langer-Gould A, Rockhoff M, Haghikia A, Queisser-Wahrendorf A, Gold R, et al. Interferonbeta exposure during first trimester is safe in women with multiple sclerosis-A prospective cohort study from the German Multiple Sclerosis and Pregnancy Registry. Mult Scler. 2016;22(6):801-9. doi: $10.1177 / 1352458516634872$.

36. Herbstritt S, Langer-Gould A, Rockhoff M, Haghikia A, Queisser-Wahrendorf A, Gold R, et al. Glatiramer acetate during early pregnancy: A prospective cohort study. Mult Scler. 2016;22(6):810-6. doi: 10.1177/1352458515623366.

37. Centraal Bureau voor de Statistiek. Beroepsbevolking; behaalde onderwijs naar persoonskenmerken 2001-2012 2013.2 Available from:

http://statline.cbs.nl/StatWeb/publication/?VW=T\&DM=SLNL\&PA=71822NED\&D1=0-

$1 \& D 2=0 \& D 3=0 \& D 4=0-4 \& D 5=a \& D 6=0 \& D 7=0,4-\mid \& H D=110405-$

$1452 \& H D R=T, G 2, G 1, G 5, G 6 \& S T B=G 4, G 3$. 


\section{Supplementary information}

\section{S1. Exploratory phase: literature review}

\section{Methods}

A literature search was conducted to identify any articles reporting on attributes of DMDs that are of importance for decision making in DMD treatment from a patient's or healthcare provider's perspective. Any articles (quantitative and qualitative research, expert opinions) or abstracts were included in this review that reported on DMD attributes for decision making from a RRMS or CIS patient's or healthcare provider's perspective. Three search strings were entered in PubMed, EMBASE and PsycINFO, and were searched from November 2004 until November 2014. The search was restricted to articles reported in English, Dutch, German and French. Figure 1 provides the search strings for PubMed. Additionally, abstracts from conferences on MS (CMSC ACTRIMS Annual Meetings, Joint ACTRIMS-ECTRIMS meeting) and shared decision making (Society for Medical Decision Making, International Shared Decision Making Conference) were searched up to 1 year (November 2013 until November 2014). Selection of articles was conducted by consecutively assessing the relevance according to title, abstract and full text. Reference lists of identified articles were searched for any additional articles that match the inclusion criteria. DMD attributes that were reported as being of importance for patients, neurologists and/or MS nurses in the decision making process about DMD treatment for MS were combined into a list with a description of the attribute, if provided. The list was completed with attributes included in DMD decision aids for MS known to the authors and studies on reasons for DMD non-adherence in MS patients.

\section{Results}

The electronic search and reference check resulted in 1,213 unique articles. Selection of relevant articles on preferences for DMD attributes based on title and/or abstract resulted in the exclusion of 1,143 articles. Of the 70 remaining articles, 55 articles were excluded because they did not focus on patients' or healthcare providers' preferences for DMD attributes for treatment of RRMS or CIS or because of the study design. Fifteen references were considered relevant for this review. Full articles $(n=10)$ as well as abstracts $(n=5)$ reporting important DMD attributes for decision making were included. The results of the selection procedure are presented in figure 2 . Of the 15 studies, 2 were qualitative $[1,2]$ and were 2 expert opinions $[3,4]$. Out of the quantitative studies, 6 were conjoint analysis [5-10] and 5 were surveys [11-15]. Most articles reported attributes from the patients' perspective. Only 3 articles were found about the healthcare providers' perspective $[3,4$, 13].

In total, 19 attributes were found. Three main categories of attributes could be identified, each consisting of multiple attributes: attributes related to benefits of DMDs, attributes related to unwanted effects of DMDs, and attributes related to ease of use of DMDs. A 
fourth category "others" consisted of treatment adherence, composition of DMDs and cost. The attributes derived from the 15 articles were compared with attributes from existing MS decision aids [16-18] and a selection of studies focusing on patients' reasons for nonadherence [19-21] to evaluate whether major attributes were missing. One attribute, "impact on daily life", was added. Table 1 presents all 20 attributes and a summary of any provided descriptions in the literature.

\section{Search string 1.}

multiple sclerosis [MeSH] OR multiple sclerosis, relapsing-remitting [MeSH] OR multiple sclerosis[tiab] OR ms[tiab] OR clinically isolated syndrome[tiab] OR cis[tiab]

AND

patient preference[MeSH] OR preference[tiab] OR preferences[tiab] OR perspective[tiab]OR perspectives[tiab] OR desire[tiab]OR desires[tiab]OR view[tiab]OR views[tiab]viewpoint[tiab]OR attitude[tiab] OR attitudes[tiab] OR decision[tiab]OR decisions[tiab]patient value[tiab] OR patient value[tiab] OR patients values[tiab] OR patients values[tiab]OR physician value[tiab] OR physician values[tiab]OR physicians value[tiab] OR physicians values[tiab]OR nurse value[tiab] OR nurse values[tiab]OR nurses value[tiab] OR nurses values[tiab]

AND

Immunosuppressive agents[MeSH] OR immunotherapy[MeSH] OR disease modif*[tw] OR immunosuppress*[tw] OR immunomodulat*[tw] OR immunotherap*[tw]

Search string 2.

multiple sclerosis [Mesh] OR multiple sclerosis, relapsing-remitting [Mesh] OR multiple sclerosis[tiab] OR ms[tiab] OR relapsing remitting multiple sclerosis[tiab] OR remittingrelapsing multiple sclerosis[tiab] OR Clinically isolated syndrome[tiab] OR cis[tiab] AND

Immunosuppressive agents[MeSH] OR immunotherapy[MeSH] OR disease modif*[tw] OR immunosuppress*[tw] OR immunomodulat*[tw] OR immunotherap*[tw] AND

decision support techniques [MeSH] OR decision making, computer-assisted [MeSH] OR decision support*[tiab] OR decision aid*[tiab] OR decision tool*[tiab] OR decision instrument*[tiab] OR decision technolog*[tiab] OR decision technique*[tiab] OR decision system*[tiab] OR decision program*[tiab] OR decision algorithm*[tiab] OR decision method*[tiab] OR decision intervention*[tiab] OR decision material [tiab]

\section{Search string 3.}

multiple sclerosis [Mesh] OR multiple sclerosis, relapsing-remitting [Mesh] OR multiple sclerosis[tiab] OR ms[tiab] OR relapsing remitting multiple sclerosis[tiab] OR remittingrelapsing multiple sclerosis[tiab] OR Clinically isolated syndrome[tiab] OR cis[tiab] AND Immunosuppressive agents[MeSH] OR immunotherapy[MeSH] OR disease modif*[tw]OR immunosuppress*[tw] OR immunomodulat*[tw] OR immunotherap*[tw] AND interview*[tiab] OR interviews[MeSH:noexp] OR experience*[Tw] OR qualitative[tiab]

Figure 1. Search strategy in PubMed 
Electronic database search

- 754 through PubMed

- 765 through EMBASE

- 128 through PsycINFO

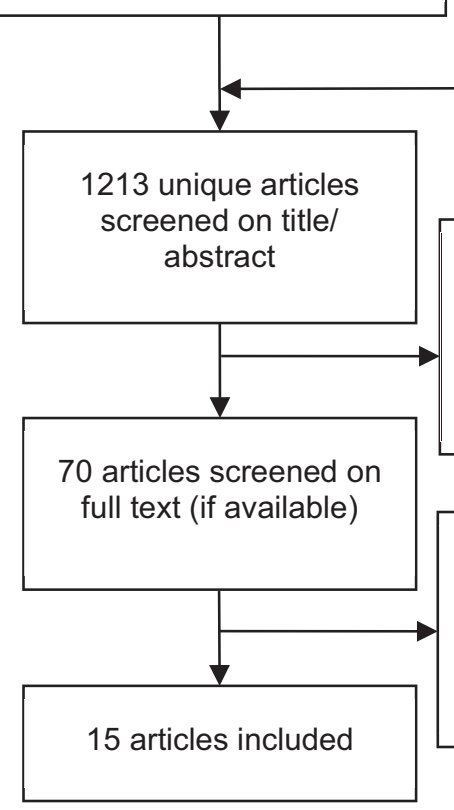

Other sources

- 2 through reference check

Excluded through title/ abstract screening 220 not fulfilling population 922 not fulfilling DMD attribute preferences 1 not fulfilling study design (protocol)

Excluded through full text screening 1 not fulfilling population 47 not fulfilling DMD attribute preferences 7 not fulfilling study design (protocol)

Figure 2. Flow chart literature review DMD, disease-modifying drugs. 
Table 1. Attributes and their descriptions derived from literature review

\begin{tabular}{|c|c|c|}
\hline Attribute & Description & Articles \\
\hline \multicolumn{3}{|c|}{ Attributes related to benefits } \\
\hline $\begin{array}{l}\text { Effect } \\
\text { (in general) }\end{array}$ & $\begin{array}{l}\text { Efficacy, clinical benefits, success rate, } \\
\text { burden of disease or treatment failure }\end{array}$ & $\begin{array}{l}\text { Bhanegaonkar 2011; } \\
\text { Gasperini 2011; Goodin 2007; } \\
\text { Hanson 2013; Hanson 2014; } \\
\text { Sommers 2009; Visser } 2011\end{array}$ \\
\hline $\begin{array}{l}\text { Effect on relapse } \\
\text { frequency }\end{array}$ & & $\begin{array}{l}\text { Goodin 2007; Hanson 2014; } \\
\text { Johnson 2009; Sommers 2009; } \\
\text { Wilson 2014a; Wilson 2014b }\end{array}$ \\
\hline $\begin{array}{l}\text { Effect on worsening of } \\
\text { lesions in the brain }\end{array}$ & $\begin{array}{l}\text { Prevention of formations of new or } \\
\text { enhancing } T 2 \text { lesions in the brain }\end{array}$ & $\begin{array}{l}\text { Goodin 2007; Hanson 2014; } \\
\text { Wilson 2014a; Wilson 2014b }\end{array}$ \\
\hline $\begin{array}{l}\text { Effect on disability } \\
\text { progression }\end{array}$ & $\begin{array}{l}\text { Worsening of disability or MS } \\
\text { symptoms (EDSS score) without } \\
\text { relapses }\end{array}$ & $\begin{array}{l}\text { Goodin 2007; Hanson 2014; } \\
\text { Johnson 2009; Wilson 2014b }\end{array}$ \\
\hline Effect on MS symptoms & $\begin{array}{l}\text { Feeling better due to improvements in } \\
\text { existing MS symptoms }\end{array}$ & Wilson 2014a; Wilson 2014b \\
\hline Pace of effect & & Visser 2011 \\
\hline Action of DMD & $\begin{array}{l}\text { Uncertainty as to the action of the } \\
\text { DMD }\end{array}$ & Visser 2011 \\
\hline
\end{tabular}

Attributes related to unwanted effects

Side effects

(long-term) Safety
Articles reporting on side effects or adverse events differed greatly in how side effects were classified, according to the type and/or severity of side effects. These side effects are considered to be minor but uncomfortable or common side effects.

E.g. local or systemic, tolerability, mild-significant-severe risk and vigilance, injection site reactions, flulike symptoms, gastro-intestinal symptoms, lipoatrophy, depression, vision changes, headaches, muscle joint ache, infections

Risk on life-threatening or severely disabling side effects, such as liver failure, PML, or leukaemia, also after
Bergmann 2014; Bhanegaonkar 2011; Coan 2011; Gasperini 2011; Goodin 2007; Gustavsson 2011; Hanson 2013; Hanson 2014; Miller 2006; Utz 2014; Visser 2011; Wilson 2014a; Wilson 2104b

Gasperini 2011; Goodin 2007; Hanson 2013; 
the patient has stopped using the DMD

Time duration a DMD has been used

Time on market

Attributes related to ease of use of DMD

Convenience

Convenience in administration of the

(in general)

DMD

Mode of administration

Pill, intramuscular injection, subcutaneous injection or intravenous infusion.

Frequency of administration per day, week or month

administrat

Duration of

administration

Required monitoring

Impact of DMD on daily life

Hanson 2014; Johnson 2009;

Miller 2006; Visser 2011

Wilson 2014b

Bhaengoankar 2011; Gasperini

2011; Hanson 2013; Hanson

2014

Bergmann 2014; Gustavsson

2011; Hanson 2013; Miller 2006;

Sommers 2009; Utz 2014; Visser

2011; Wilson 2014a; Wilson

2014b

Bergmann 2014; Gustavsson

2011; Utz 2014; Visser 2011;

Wilson 2014a; Wilson 2014b

Gustavsson 2011

Bergmann 2014; Gasperini 2011;

Gustavsson 2011

University College London NHS

Trust 2004

Consisting of the frequency of administrating the DMD; the method of storing the DMD and its consequences for traveling; required preparation before administration; and whether the DMD contains animal or human products.

$\begin{array}{lll}\begin{array}{l}\text { Others } \\ \text { Composition of DMD }\end{array} & \begin{array}{l}\text { Natural or chemical ingredients in the } \\ \text { DMD }\end{array} & \text { Miller } 2006 \\ \text { Treatment adherence } & & \begin{array}{l}\text { Bhanegaonkar 2011; Gasperini } \\ \text { 2011; Goodin 2007 }\end{array} \\ \text { Cost/ cost-effectiveness } & \begin{array}{l}\text { Healthcare coverage or out-of-pocket } \\ \text { expenses }\end{array} & \begin{array}{l}\text { Bhanegaonkar 2011; Gasperini } \\ 2011 ; \text { Hanson 2013; Miller 2006; } \\ \end{array} \\ & \begin{array}{l}\text { Sommers 2009 } \\ \end{array}\end{array}$

DMD, disease-modifying drug. 


\section{S2. Exploratory phase: interviews with healthcare professionals}

\section{Methods}

Interviews with MS-related healthcare professionals were conducted to obtain their perspectives on important $\mathrm{DMD}$ attributes in the decision making about DMD treatment. $A$ convenience sample of 7 neurologists and $7 \mathrm{MS}$-specialized nurses employed in hospital in the Netherlands were contacted by e-mail (P.J.) to invite them to participate in a 20-minute telephone interview. All contacted healthcare professionals consulted RRMS or CIS patients about DMD treatment on a regular basis. Healthcare professionals that were willing to participate were asked to contact I.K. to schedule the interview. Telephone interviews were fitting for the structured form and not sensitive content of the interview. At the beginning of the interview, demographic characteristics and work experience with MS patients were recorded. Each healthcare provider was asked which DMD attributes they considered to be of importance in the decision making about DMD treatments for patients. After the healthcare provider's attributes were elicited, his/her perspective on any additional attributes derived from literature was asked. Audio recordings of interviews were used to enable transcription of the attribute descriptions and were deleted afterwards. Each interview resulted in a list of attributes that are of importance according to the healthcare provider. One overall attribute list was created by comparing all attributes from the interviews with the attributes derived from literature.

\section{Results}

Six healthcare professionals ( 3 neurologists, 3 MS-specialized nurses) were willing and able to participate in the interview. The neurologists all treated 200 or more MS patients yearly and had work experience ranging between 8 and 24 years. Participating nurses had 10 to 14 years of work experiences as an MS-specialized nurse. Further details on characteristics of the health professionals are presented in table 1 . Four attributes were reported by the healthcare professionals that were not found in the literature: 1) effect on quality of life for the patient; 2) effect on brain atrophy, 3) ease of use for the neurologist, meaning the degree of complexity for the neurologist regarding authorization from health insurance or procedures regarding delivery of DMD; 4 ) total costs of DMDs, meaning that the total costs need to be considered as part of the Dutch Healthcare budget if a patient doubts whether to use a DMD. Therefore, costs had a broader definition than costs as elicited from the literature, which represented insurance coverage or out-of-pocket expenses.

Table 1. Characteristics of healthcare professionals

\begin{tabular}{lll}
\hline & Neurologists $(\mathrm{N}=3)$ & MS nurses $(\mathrm{N}=3)$ \\
\hline Male $\mathrm{n}(\%)$ & $3(100)$ & $0(0)$ \\
Female $\mathrm{n}(\%)$ & $0(0)$ & $3(100)$ \\
Age (years) Mean \pm SD & $50.7 \pm 8.1$ & $52.3 \pm 3.1$ \\
Work experience (years) Mean \pm SD & $18 \pm 8.7$ & $12.0 \pm 2.0$ \\
\hline
\end{tabular}

MS, multiple sclerosis; SD, standard deviation. 


\section{S3. Focus groups with nominal group technique}

\section{Results}

Table 1 presents all DMD attributes that influence the decision making about DMD treatment as identified by patients in the focus groups. In table 2 , the ranking of all reported DMD attributes is presented with the frequency with which they were included in the top 10 and top 5 and their mean importance scores. Compared to the results of the literature review and interviews with healthcare providers, 12 additional attributes were reported. Furthermore, participants described 4 attributes differently from literature and healthcare providers. Side effects were split up into type, duration and severity of non-life threatening side effects. Influence on life style was described by patients as the required changes in habits and activities one has to make in contrast to the literature which incorporates administration frequency, ease of traveling and having a premixed syringe available. Traveling was reported as a separate attribute by the patients and having a premixed syringe was considered to be a part of the method of administration or making traveling easier. Time on the market had a comparable description as uncertainty about long-term consequences and was therefore deleted. Composition of the DMD was of importance for possible allergic reactions instead of the natural or chemical components. Two attributes were found not to be of importance for patients: effect on brain atrophy and ease of use for neurologists. 
Table 1. Attributes and their descriptions as derived from the focus groups

\begin{tabular}{|c|c|}
\hline DMD attribute & Description \\
\hline $\begin{array}{l}\text { Effect on disease } \\
\text { progression/ becoming } \\
\text { disabled }\end{array}$ & $\begin{array}{l}\text { Proven inhibitory effect of the DMD on developing physical and } \\
\text { cognitive disabilities on the long-term. }\end{array}$ \\
\hline $\begin{array}{l}\text { Effect on current MS } \\
\text { symptoms }\end{array}$ & $\begin{array}{l}\text { Proven effect of the DMD on reducing MS symptoms, especially } \\
\text { fatigue, that someone is experiencing at the moment. }\end{array}$ \\
\hline $\begin{array}{l}\text { Effect on the number of } \\
\text { relapses }\end{array}$ & $\begin{array}{l}\text { Proven inhibitory effect of the DMD on the number of relapses } \\
\text { experienced by a person. }\end{array}$ \\
\hline $\begin{array}{l}\text { Effect on the severity of } \\
\text { relapses }\end{array}$ & Proven effect of the DMD on reducing the severity of relapses. \\
\hline $\begin{array}{l}\text { Effect on development of } \\
\text { plaques in the brain }\end{array}$ & $\begin{array}{l}\text { Proven inhibitory effects of the DMD on the development and } \\
\text { presence of plaques (scarring) in the brain which can be } \\
\text { identified on an MRI. }\end{array}$ \\
\hline Effect on quality of life & $\begin{array}{l}\text { Proven effect on improving the overall (physical, mental and } \\
\text { social) well-being of a patient as a result of the DMD [22]. }\end{array}$ \\
\hline Effect on life expectancy & Proven effect of the DMD on prolonging life duration. \\
\hline Pace of effect & $\begin{array}{l}\text { Speed at which the beneficial effects occur after administrating } \\
\text { the DMD }\end{array}$ \\
\hline Action of DMD & $\begin{array}{l}\text { The way the DMD works in the body and therefore has beneficial } \\
\text { effects, e.g. reducing inflammations that cause nerve damage. }\end{array}$ \\
\hline Safety & $\begin{array}{l}\text { Risks of serious side effects that can be life-threatening or result } \\
\text { in severe disabilities. }\end{array}$ \\
\hline Type of side effects & $\begin{array}{l}\text { Risk of physical or psychological side effects that are not life- } \\
\text { threatening or leading to severe disabilities. Examples of these } \\
\text { side effects are injection site reactions, panic attacks, } \\
\text { gastrointestinal symptoms, flu-like symptoms, hair loss, and } \\
\text { flushing. }\end{array}$ \\
\hline $\begin{array}{l}\text { Duration to which side } \\
\text { effects persist }\end{array}$ & $\begin{array}{l}\text { The extent to which effects are temporary (e.g. muscle pain) or } \\
\text { permanent (e.g. subcutaneous lumps) }\end{array}$ \\
\hline Severity of side effects & $\begin{array}{l}\text { The extent to which the severity of the side effects outweigh the } \\
\text { desire to treat MS. }\end{array}$ \\
\hline $\begin{array}{l}\text { Uncertainty about long-term } \\
\text { consequences }\end{array}$ & $\begin{array}{l}\text { The lack of knowledge and experience regarding serious side } \\
\text { effects on the long-term, especially for medication that have } \\
\text { been only shortly available on the market. }\end{array}$ \\
\hline Method of administration & $\begin{array}{l}\text { The form in which the DMD is to be taken (tablet, injection or } \\
\text { infusion), and whether this can be self-administered or whether } \\
\text { help is needed. }\end{array}$ \\
\hline Frequency of administration & How often the DMD should be taken per day, week or month. \\
\hline Duration of administration & Length of time that the administration of one dose takes up. \\
\hline Traveling & $\begin{array}{l}\text { The ease with which the DMD can be brought on holidays or } \\
\text { outings. The extent to which cooling of the DMD is needed and } \\
\text { regulations regarding possession of the medication when } \\
\text { traveling abroad is considered. }\end{array}$ \\
\hline
\end{tabular}


Required monitoring

Use of DMD among other MS patients

Insurance coverage

Total costs

Interaction with other medication

Composition of DMD

Contact person at pharmaceutical company

Development of DMD

Influence on lifestyle

Adherence rates

Availability of DMD in the Netherlands

Brand recognition

Legal liability

Issuance of DMD

Wash out requirement

Shelf life
Medical checks that are required during the use of the DMD, such as blood tests and MRIs.

The proportion of MS patients in the country that is currently using the specific DMD.

The extent to which the medication is reimbursed by the health insurance.

Total costs of the DMD for the health insurance, independent of the out-of-pocket expenses for the patient Interaction of the DMD in combination with other medication, including contraception, which may change the effectiveness of either one of the medications or which may result in additional side effects.

The substances processed in the DMD that may cause allergic reactions.

The extent to which help from the pharmaceutical company is available, such as a nurse, which the patient can contact about questions regarding side effects and administration.

The extent to which the DMD will remain in constant development after has become available on the market, in order to fine-tune the DMD in effectiveness and side-effects The extent to which a patient's habits or lifestyle have to be adjusted for proper use of the medication, such as the extent of flexibility in time of administration, being able and allowed to drive, work, do sports, drink alcohol, etc.

The known rates for a specific DMD of patients persisting to use the DMD over a long period of time, following the prescribed dose.

Whether the DMD is available in the Netherlands or whether it must be obtained abroad.

The extent to which the DMD is known to patients because it is appointed by neurologists, nurses, websites and other information sources

Whether a statement of legal liability needs to be signed before being able to start the DMD

The method of acquiring the DMD, e.g. method of delivery, place it can be picked up.

Minimum required wash out period and method in case of stopping or switching treatments.

Duration the DMD can be kept before using it.

DMD, disease-modifying drug; MS, multiple sclerosis. 
Table 2. Ranking and attribute scores derived from focus groups

\begin{tabular}{|c|c|c|c|c|}
\hline Ranking & Attribute & Top 10 & Top 5 & $\begin{array}{l}\text { Mean } \\
\text { score }\end{array}$ \\
\hline 1 & Type of side effects & 12 & 11 & 2.11 \\
\hline 2 & Effect on disease progression/ becoming disabled & 11 & 9 & 1.82 \\
\hline 3 & Method of administration & 16 & 9 & 1.58 \\
\hline 4 & Effectiveness in reducing relapse rate & 13 & 8 & 1.45 \\
\hline 5 & Safety & 15 & 9 & 1.16 \\
\hline 6 & Insurance coverage & 13 & 8 & 0.95 \\
\hline 7 & Duration to which side effects persist & 5 & 4 & 0.74 \\
\hline 8 & Influence on lifestyle & 12 & 7 & 0.63 \\
\hline 9 & Required monitoring & 8 & 5 & 0.58 \\
\hline 10 & Frequency of administration & 8 & 3 & 0.58 \\
\hline 11 & Effect on current MS symptoms & 7 & 3 & 0.55 \\
\hline 12 & Severity of side effects & 6 & 3 & 0.47 \\
\hline 13 & Traveling & 7 & 4 & 0.32 \\
\hline 14 & Effect on quality of life & 4 & 3 & 0.32 \\
\hline 15 & Uncertainty about long-term consequences & 8 & 2 & 0.32 \\
\hline 16 & Effect on life expectancy & 3 & 2 & 0.32 \\
\hline 17 & Interaction with other medication & 7 & 2 & 0.26 \\
\hline 18 & Action of DMD & 3 & 1 & 0.26 \\
\hline 19 & Pace of effect & 4 & 1 & 0.21 \\
\hline 20 & Effect on development of plaques in the brain & 4 & 2 & 0.13 \\
\hline 21 & Contact person at pharmaceutical company & 2 & 1 & 0.11 \\
\hline 22 & Development of DMD & 6 & 1 & 0.05 \\
\hline 23 & Use of DMD among other MS patients & 3 & 1 & 0.05 \\
\hline 24 & Total costs & 1 & 1 & 0.05 \\
\hline \multirow[t]{3}{*}{25} & Duration of administration & 2 & 0 & 0 \\
\hline & Composition of DMD & 2 & 0 & 0 \\
\hline & Effect on the severity of relapses & 2 & 0 & 0 \\
\hline \multirow[t]{7}{*}{28} & Adherence rates & 0 & 0 & 0 \\
\hline & Availability of DMD in the Netherlands & 0 & 0 & 0 \\
\hline & Brand recognition & 0 & 0 & 0 \\
\hline & Issuance of DMD & 0 & 0 & 0 \\
\hline & Wash out requirement & 0 & 0 & 0 \\
\hline & Shelf life & 0 & 0 & 0 \\
\hline & Legal liability & 0 & 0 & 0 \\
\hline
\end{tabular}

DMD, disease-modifying drug; MS, multiple sclerosis. 


\section{S4. Subgroup analyses in best-worst scaling}

Table 1. Results of subgroup analyses DMD naive vs. DMD experienced patients

\begin{tabular}{|c|c|c|c|c|c|c|}
\hline \multirow[b]{2}{*}{ Attribute } & \multicolumn{2}{|c|}{$\begin{array}{l}\text { DMD naïve } \\
\quad \mathrm{N}=27\end{array}$} & \multicolumn{2}{|c|}{$\begin{array}{l}\text { DMD experienced } \\
\qquad \mathrm{N}=157\end{array}$} & \multirow{2}{*}{$\begin{array}{c}\text { Test } \\
\text { statistic: } \\
\text { difference } \\
\end{array}$} & \multirow[b]{2}{*}{$\mathrm{p}$} \\
\hline & $\begin{array}{c}\text { Mean RIS } \\
(95 \% \mathrm{CI})\end{array}$ & $\begin{array}{c}\text { Mean } \\
\text { rank }\end{array}$ & $\begin{array}{c}\text { Mean RIS } \\
(95 \% \mathrm{Cl})\end{array}$ & $\begin{array}{l}\text { Mean } \\
\text { rank }\end{array}$ & & \\
\hline $\begin{array}{l}\text { Effect on disease } \\
\text { progression }\end{array}$ & $\begin{array}{r}9.54 \\
(9.18-9.91)\end{array}$ & 81.44 & $\begin{array}{r}9.68 \\
(9.49-9.86)\end{array}$ & 94.40 & $\begin{array}{r}1821 \\
(-1,17)^{2}\end{array}$ & .244 \\
\hline $\begin{array}{l}\text { Effect on quality of } \\
\text { life }\end{array}$ & $\begin{array}{r}9.17 \\
(8.41-9.94)\end{array}$ & 97.56 & $\begin{array}{r}9.22 \\
(9.01-9.43)\end{array}$ & 91.63 & $\begin{array}{r}1983 \\
(-0,53)^{2}\end{array}$ & .596 \\
\hline Effect on relapse rate & $\begin{array}{r}5.76 \\
(4.54-6.98)\end{array}$ & 58.30 & $\begin{array}{r}8.13 \\
(7.76-8.49)\end{array}$ & 98.38 & $\begin{array}{r}1196 \\
(-3,61)^{2}\end{array}$ & $<.001$ \\
\hline $\begin{array}{l}\text { Severity of side } \\
\text { effects }\end{array}$ & $\begin{array}{r}9.30 \\
(8.72-9.88)\end{array}$ & 139.04 & $\begin{array}{r}7.33 \\
(7.01-7.66)\end{array}$ & 84.50 & $\begin{array}{r}863 \\
(-4,92)^{2}\end{array}$ & $<.001$ \\
\hline $\begin{array}{l}\text { Effect on the severity } \\
\text { of relapses }\end{array}$ & $\begin{array}{r}5.79 \\
(4.67-6.92)\end{array}$ & 62.59 & $\begin{array}{r}7.67 \\
(7.34-8.01)\end{array}$ & 97.64 & $\begin{array}{r}1312 \\
(-3,16)^{2}\end{array}$ & .001 \\
\hline $\begin{array}{l}\text { Effect on current MS } \\
\text { symptoms }\end{array}$ & $\begin{array}{r}6.90 \\
(6.03-7.77)\end{array}$ & 81.11 & $\begin{array}{r}7.40 \\
(7.10-7.71)\end{array}$ & 94.46 & $\begin{array}{r}1812 \\
(-1,20)^{2}\end{array}$ & .230 \\
\hline $\begin{array}{l}\text { Effect on plaque } \\
\text { development in the } \\
\text { brain }\end{array}$ & $\begin{array}{r}6.49 \\
(5.49-7.49)\end{array}$ & 72.70 & $\begin{array}{r}7.47 \\
(7.08-7.87)\end{array}$ & 95.90 & $\begin{array}{r}1585 \\
(-2,09)^{2}\end{array}$ & .038 \\
\hline Safety & $\begin{array}{r}6.31 \\
(5.05-7.57)\end{array}$ & NA & $\begin{array}{r}6.00 \\
(5.54-6.46)\end{array}$ & NA & $.51^{1}$ & .611 \\
\hline Influence on life style & $\begin{array}{r}5.30 \\
(4.02-6.58)\end{array}$ & 92.41 & $\begin{array}{r}5.31 \\
(4.86-5.77)\end{array}$ & 92.52 & $\begin{array}{r}2117 \\
(-0,01)^{2}\end{array}$ & .992 \\
\hline Type of side effects & $\begin{array}{r}6.97 \\
(6.06-7.89)\end{array}$ & NA & $\begin{array}{r}4.63 \\
(4.63-4.22)\end{array}$ & NA & $4.36^{1}$ & $<.001$ \\
\hline $\begin{array}{l}\text { Effect on life } \\
\text { expectancy }\end{array}$ & $\begin{array}{r}3.60 \\
(2.49-4.71)\end{array}$ & 71.37 & $\begin{array}{r}5.04 \\
(4.54-5.53)\end{array}$ & 96.13 & $\begin{array}{r}1549 \\
(-2,23)^{2}\end{array}$ & .026 \\
\hline $\begin{array}{l}\text { Uncertainty about } \\
\text { long-term } \\
\text { consequences }\end{array}$ & $\begin{array}{r}5.34 \\
(4.09-6.60)\end{array}$ & 105.67 & $\begin{array}{r}4.42 \\
(4.00-4.84)\end{array}$ & 90.24 & $\begin{array}{r}1764 \\
(-1,39)^{2}\end{array}$ & .168 \\
\hline $\begin{array}{l}\text { Duration of side } \\
\text { effects }\end{array}$ & $\begin{array}{r}5.30 \\
(4.62-5.98)\end{array}$ & 135.96 & $\begin{array}{r}3.45 \\
(3.15-3.74)\end{array}$ & 85.03 & $\begin{array}{r}946 \\
(-4,59)^{2}\end{array}$ & $<.001$ \\
\hline Pace of effect & $\begin{array}{r}2.55 \\
(1.78-3.31)\end{array}$ & 76.89 & $\begin{array}{r}3.27 \\
(2.92-3.62)\end{array}$ & 95.18 & $\begin{array}{r}1698 \\
(-1,65)^{2}\end{array}$ & .101 \\
\hline Insurance coverage & $\begin{array}{r}2.43 \\
(1.39-3.47)\end{array}$ & 89.89 & $\begin{array}{r}2.72 \\
(2.27-3.18)\end{array}$ & 92.95 & $\begin{array}{r}2049 \\
(-0,28)^{2}\end{array}$ & .781 \\
\hline $\begin{array}{l}\text { Interaction with } \\
\text { other medication }\end{array}$ & $\begin{array}{r}1.45 \\
(0.79-2.10)\end{array}$ & 84.33 & $\begin{array}{r}1.78 \\
(1.48-2.08)\end{array}$ & 93.90 & $\begin{array}{r}1899 \\
(-0,86)^{2}\end{array}$ & .388 \\
\hline $\begin{array}{l}\text { Method of } \\
\text { administration }\end{array}$ & $\begin{array}{r}1.84 \\
(0.76-2.92)\end{array}$ & 106.89 & $\begin{array}{r}1.54 \\
(1.11-1.96)\end{array}$ & 90.03 & $\begin{array}{r}1731 \\
(-1,52)^{2}\end{array}$ & .131 \\
\hline $\begin{array}{l}\text { Mode of action of } \\
\text { DMD }\end{array}$ & $\begin{array}{r}0.97 \\
(0.42-1.52)\end{array}$ & 87.33 & $\begin{array}{r}1.00 \\
(0.81-1.19)\end{array}$ & 93.39 & $\begin{array}{r}1980 \\
(-0,55)^{2}\end{array}$ & .587 \\
\hline $\begin{array}{l}\text { Further development } \\
\text { of DMD }\end{array}$ & $\begin{array}{r}1.08 \\
(0.54-1.62)\end{array}$ & 99.04 & $\begin{array}{r}0.84 \\
(0.70-0.97)\end{array}$ & 91.38 & $\begin{array}{r}1943 \\
(-0,69)^{2}\end{array}$ & .492 \\
\hline Total DMD costs & $\begin{array}{r}0.84 \\
(0.35-1.32)\end{array}$ & 87.41 & $\begin{array}{r}0.86 \\
(0.66-1.06)\end{array}$ & 93.38 & $\begin{array}{r}1982 \\
(-0,54)^{2}\end{array}$ & .593 \\
\hline $\begin{array}{l}\text { Frequency of } \\
\text { administration }\end{array}$ & $\begin{array}{r}0.67 \\
(0.31-1.04)\end{array}$ & 111.70 & $\begin{array}{r}0.68 \\
(0.45-0.91)\end{array}$ & 89.20 & $\begin{array}{r}1601 \\
(-2,03)^{2}\end{array}$ & .045 \\
\hline
\end{tabular}




\begin{tabular}{|c|c|c|c|c|c|c|}
\hline Required monitoring & $\begin{array}{r}0.97 \\
(0.34-1.61)\end{array}$ & 99.81 & $\begin{array}{r}0.49 \\
(0.31-0.66)\end{array}$ & 91.2 & $\begin{array}{r}1922 \\
(-0,77)^{2}\end{array}$ & .441 \\
\hline $\begin{array}{l}\text { Use of DMD among } \\
\text { other MS patients }\end{array}$ & $\begin{array}{r}0.41 \\
(0.22-0.60)\end{array}$ & 107.74 & $\begin{array}{r}0.33 \\
(0.24-0.42)\end{array}$ & 89.88 & $\begin{array}{r}1708 \\
(-1,61)^{2}\end{array}$ & .109 \\
\hline Ease of travelling & $\begin{array}{r}0.47 \\
(0.07-0.87)\end{array}$ & 104.67 & $\begin{array}{r}0.26 \\
(0.13-0.40)\end{array}$ & 90.41 & $\begin{array}{r}1791 \\
(-1,29)^{2}\end{array}$ & .200 \\
\hline $\begin{array}{l}\text { Duration of } \\
\text { administration }\end{array}$ & $\begin{array}{r}0.26 \\
(0.15-0.38)\end{array}$ & 110.04 & $\begin{array}{r}0.19 \\
(0.15-0.23)\end{array}$ & 89.48 & $\begin{array}{r}1646 \\
(-1,85)^{2}\end{array}$ & .066 \\
\hline Composition of DMD & $\begin{array}{r}0.20 \\
(0.11-0.30)\end{array}$ & 99.63 & $\begin{array}{r}0.18 \\
(0.12-0.24)\end{array}$ & 91.27 & $\begin{array}{r}1927 \\
(-0,75)^{2}\end{array}$ & .460 \\
\hline $\begin{array}{l}\text { Contact person at } \\
\text { pharmaceutical } \\
\text { company }\end{array}$ & $\begin{array}{r}0.08 \\
(0.04-0.11)\end{array}$ & 98.02 & $\begin{array}{r}0.11 \\
(0.06-0.15)\end{array}$ & 91.55 & $\begin{array}{r}1970,5 \\
(-0,58)^{2}\end{array}$ & .566 \\
\hline
\end{tabular}




\section{References}

1. Bhanegaonkar A, Madhavan S, Pawar GV, Rajagopalan K, Langlois J. Understanding health related quality of life changes and issues related to disease modifying drugs among multiple sclerosis patients: a qualitative study. Value Health. 2011;14 (3):A211..

2. Miller CE, Jezewski MA. Relapsing MS patients' experiences with glatiramer acetate treatment: a phenomenological study. J Neurosci Nurs. 2006;38(1):37-41..

3. Gasperini C, Ruggieri S. Emerging oral drugs for relapsing-remitting multiple sclerosis. Expert Opin Emerg Drugs. 2011;16(4):697-712. doi: 10.1517/14728214.2011.642861.

4. Goodin DS, Biermann LD, Bohlega S, Boiko A, Chofflon M, Gebeily S, et al. Integrating an evidencebased assessment of benefit and risk in disease-modifying treatment of multiple sclerosis. Curr Med Res Opin. 2007;23(11):2823-32. doi: 10.1185/03007×233007.

5. Bergmann A, Lang $M$, Bischoff $C L$, Schicklmaier $P$, Nolting HD, Schiffhorst $G$, et al. Patient preferences in the choice of disease modifying drugs for multiple sclerosis. Neurology. 2014;1.

6. Gustavsson A, Karampampa K, Miltenburger C, Eckert B. Treatment experience, burden, and unmet needs (TRIBUNE) in multiple sclerosis study: patient preferences for MS treatments. Multi Scler. 2011;1:S239. doi: http://dx.doi.org/10.1177/1352458511422300.

7. Johnson FR, Van Houtven G, Özdemir S, Hass S, White J, Francis G, et al. Multiple Sclerosis patients' benefit-risk preferences: serious adverse event risks versus treatment efficacy. J Neurol. 2009;256(4):554-62. doi: 10.1007/s00415-009-0084-2.

8. Utz KS, Hoog J, Wentrup A, Berg S, Lammer A, Jainsch B, et al. Patient preferences for diseasemodifying drugs in multiple sclerosis therapy: a choice-based conjoint analysis. Ther Adv Neurol Disord. 2014;7(6):263-75. doi: 10.1177/1756285614555335.

9. Wilson L, Loucks A, Bui C, Gipson G, Zhong L, Schwartzburg A, et al. Patient centered decision making: use of conjoint analysis to determine risk-benefit trade-offs for preference sensitive treatment choices. J Neurol Sci. 2014;344(1-2):80-7. doi: 10.1016/j.jns.2014.06.030.

10. Wilson LS, Loucks A, Gipson G, Zhong L, Bui C, Miller E, et al. Patient preferences for attributes of disease-modifying multiple sclerosis therapies: development and results of a ratings-based conjoint analysis. Int J MS Care. 2015. doi: 10.7224/1537-2073.2013-053.

11. Caon C, Memon A, Perumal J, Khan O. Patient response to new disease-modifying therapies: results of a questionnaire study in RRMS patients receiving selfinjected disease-modifying therapies. Multiple Sclerosis. 2011;1:S472. doi: http://dx.doi.org/10.1177/1352458511422301.

12. Hanson KA, Agashivala N, Stringer SM, Balantac Z, Brandes DW. A cross-sectional survey of patient satisfaction and subjective experiences of treatment with fingolimod. Patient Prefer Adherence. 2013;7:309-18. doi: 10.2147/ppa.s41992.

13. Hanson KA, Agashivala N, Wyrwich KW, Raimundo K, Kim E, Brandes DW. Treatment selection and experience in multiple sclerosis: survey of neurologists. Patient Prefer Adherence. 2014;8:415-22. Epub 2014/04/15. doi: 10.2147/ppa.s53140.

14. Sommers R, Phillips A. Unmet needs in the treatment of multiple sclerosis: patient perspectives. J Manag Care Pharm. 2009;15 (7):602-3.

15. Visser $\mathrm{LH}$, van der Zande $\mathrm{A}$. Reasons patients give to use or not to use immunomodulating agents for multiple sclerosis. Eur J Neurol. 2011;18(11):1343-9. doi: 10.1111/j.1468-1331.2011.03411.x.

16. Kasper J, Kopke S, Muhlhauser I, Nubling M, Heesen C. Informed shared decision making about immunotherapy for patients with multiple sclerosis (ISDIMS): a randomized controlled trial. Eur J Neurol. 2008;15(12):1345-52. doi: 10.1111/j.1468-1331.2008.02313.x.

17. University College London NHS Trust. MS Decisions: an independent aid to your decision 2004 (revised in 2009). Available from: www.msdecisions.org.uk. 
18. Winn K, Oliver BJ. Shared decision making in multiple sclerosis: option grid point of care engagement tools for disease-modifying treatment (work in progress) Int J MS Care. 2014;16(Suppl 3):S20.

19. Bischoff C, Schreiber H, Bergmann A. Background information on multiple sclerosis patients stopping ongoing immunomodulatory therapy: a multicenter study in a community-based environment. J Neurol. 2012;259(11):2347-53. doi: 10.1007/s00415-012-6499-1..

20. Fox RJ, Salter AR, Tyry T, Sun J, You X, Laforet G, et al. Treatment discontinuation and disease progression with injectable disease-modifying therapies: findings from the north american research committee on multiple sclerosis database. Int J MS Care. 2013;15(4):194-201. doi: 10.7224/1537-2073.2012-034.

21. Salter AR, Marrie RA, Agashivala N, Belletti DA, Kim E, Cutter GR, et al. Patient perspectives on switching disease-modifying therapies in the NARCOMS registry. Patient Prefer Adherence. 2014;8:971-9. doi: 10.2147/ppa.s49903.

22. Sprangers M. Wat is kwaliteit van leven en hoe wordt het gemeten? Volksgezondheid Toekomst Verkenning, Nationaal Kompas Volksgezondheid. Bilthoven. http://www.nationaalkompas.nl/gezondheid-en-ziekte/functioneren-en-kwaliteit-vanleven/kwaliteit-van-leven/wat-is-kwaliteit-van-leven-en-hoe-wordt-het-gemeten/ Accessed 6 May 2015: RIVM; 2013. 




\section{CHAPTER 3}

\section{Comparison of preferences of healthcare professionals and patients with multiple sclerosis for attributes of disease-modifying drugs: a best-worst scaling study}

\section{Published as:}

Kremer IEH, Evers S, Jongen PJ, Hiligsmann M. Comparison of preferences of healthcare professionals and MS patients for attributes of disease-modifying drugs: A best-worst scaling. Health Expect. 2018;21(1):171-80. 


\section{Abstract}

Background. The choice between disease-modifying drugs (DMDs) for the treatment of multiple sclerosis (MS) becomes more often a shared decision between the patient and the neurologist and MS nurse. This study aimed to assess which DMD attributes are most important for the healthcare professionals in selecting a DMD for a patient. Subsequently, within this perspective, the neurologists' and nurses' perspectives were compared. Lastly, the healthcare professionals' perspective was compared with the patients' perspective to detect any differences that may need attention in the communication about DMDs.

Design. A best-worst scaling (BWS) was conducted among 27 neurologists and $33 \mathrm{MS}$ nurses treating MS patients to determine the importance of $27 \mathrm{DMD}$ attributes. These attributes were identified through three focus groups with MS patients in a previous study $(\mathrm{N}=19)$. Relative importance scores (RISs) were estimated for each attribute. Multivariable linear regression analyses were used to compare the different perspectives.

Results. According to the neurologists and nurses, safety of the DMD was the most important DMD attribute in the treatment decision, closely followed by effect on disability progression, quality of life and relapse rate. MS patients agreed with the importance of the last three attributes, but valued safety significantly lower $(b=-2.59, p<.001)$.

Conclusions. This study suggests that, overall, neurologists and nurses regard the same DMD attributes as important as MS patients with the notable exception of safety. This study provides valuable information for the development of interventions to support shared decision making, and highlights which attributes of DMDs may need additional attention.

\section{Key points}

- Understanding the healthcare professionals' perspective about the importance of attributes of disease-modifying drugs for multiple sclerosis, and comparing this perspective with the patients' perspective, would be important to develop a patient decision aid that is accepted by, and usable for, both patients and healthcare professionals in the shared decision making process

- The healthcare professionals and patients overall agree about the importance of the effects of DMDs on disability progression, quality of life and relapse rate, but safety was valued significantly lower by patients.

- The study results provide guidance for the selection of information to be included in a patient decision aid for disease-modifying drugs in multiple sclerosis to effectively support the patient and healthcare professional in making a shared decision. 


\section{Introduction}

Multiple sclerosis (MS) is a degenerative disease of the central nervous system causing physical and cognitive disabilities [1]. The relapsing-remitting form of MS (RRMS) can be treated with disease-modifying drugs (DMDs) to reduce progression or even induce improvements. DMD treatment requires long-term administration with a minimum of missed doses. DMDs are classified as first, second or third line treatments. First line DMDs are used in patients with mild disease activity. In case of high disease activity or intolerance to the side effects, second or third line DMDs may be chosen. These DMDs have more favourable effectiveness rates but less favourable safety profiles [2, 3]. Overall, thirteen DMDs are currently approved by the European Medicine Agency and the Food and Drug Administration $[4,5]$. This variety in DMDs often provides MS patients with more than one acceptable option for treatment.

Therefore, a choice between DMDs needs to be made, which is often difficult. Besides differences in effectiveness rates and safety profiles, the DMDs can differ in other characteristics, or attributes, such as mode of administration and side effects. To make an optimal choice, the patient's preferences for such attributes should be incorporated in the decision. In shared decision making, the patient makes the decision about the treatment together with the healthcare professional [6]. The healthcare professional ensures the patient is informed about the best available treatment options, and supports the patient in clarifying the advantages and disadvantages of each of the options. The patient communicates his/her values and preferences for these advantages and disadvantages, and deliberates with the healthcare professional, in this case a neurologist and/or an MS nurse, about the treatment options to reach a decision. Decision aids, which are specifically designed to support shared decision making, have been shown to improve the patient's involvement in the decision and the quality of the decision [7].

Understanding the preferences of patients and healthcare professionals for treatment options could inform the development of a decision aid. Although the treatment decision should be individualized to every patient and should include the patient's preferences and healthcare professional's opinion tailored to the patient's needs, the evaluation of the average perspectives about the importance of the treatment attributes in the decision could be useful for developing a patient decision aid that meets most patients' and healthcare professionals' informational needs. An assessment of the average preferences could be valuable for selecting the information that needs to be included in the decision aid to ensure effectively supporting the shared decision making process without making the use of the decision aid too cognitively burdensome for the patient. Preferences of patients for attributes of DMDs have been evaluated in several stated preference studies [8-16]. Recently, focus groups and a best-worst scaling were conducted to identify and prioritize a range of attributes that could be important in clinical decision making from the patients' perspective [8]. This study found that the average MS patient regarded the effects on disability progression and quality of life as the most important attributes of DMDs in the decision, followed by the effect on the relapse rate, severity of side effects and the effect 
on the severity of relapses [8]. Several studies showed that preferences of healthcare professionals for treatment options can differ from the preferences of patients [17-21]. These differences in preferences could result in different expectations and information needed from the decision aid [19]. In MS, one study has assessed the neurologists' perspective regarding the importance of a limited number of five attributes in the DMD choice [22]. To our knowledge, the patients' perspective on important DMD attributes for choosing between DMDs has not yet been directly compared with the healthcare professionals' perspective.

This study aimed first to use a rigorous method, a best-worst scaling, to identify which DMD attributes the healthcare professionals (neurologists and MS nurses) find important to take into consideration in the decision regarding DMD treatment. As the relationship with the patient may differ between neurologists and MS nurses because of the more frequent and informal contact between MS nurses and patients, the second aim of this study was to evaluate whether the perspectives on the importance of DMD attributes differ between neurologists and MS nurses. Third, the overall MS healthcare professionals' (neurologists and MS nurses) perspective was compared with the MS patients' perspective on the importance of DMD attributes in the treatment decision.

\section{Methods}

A best-worst scaling case 1 as described by Flynn and Marley [23] was conducted to obtain the neurologists' and MS nurses' perspective on the importance of attributes of DMDs. In contrast to discrete choice experiments a best-worst scaling allows for obtaining the relative importance of attributes for a large number of attributes, regardless of the levels of the attributes [24]. The best-worst scaling was embedded in an online questionnaire. Therefore, the Checklist for Reporting Results of Internet E-Surveys was followed for reporting the design and the results [25]. We used the same best-worst scaling that was performed to elicit preferences for patients with MS [8]. The best-worst scaling included 27 attributes, which were identified in a two-stage procedure. First, in an exploratory phase, possible relevant attributes were identified through a literature review and interviews with three neurologists and three nurses. Second, three focus groups $(\mathrm{N}=19)$ were conducted to elicit the attributes that MS patients regarded important in the decision. At the end of each focus group, any additional attributes from the exploratory phase that were not mentioned yet, were discussed to evaluate whether these additional attributes were relevant as well. A total of 27 important attributes for the decision about DMD treatment were identified. Using Sawtooth SSI Web version 8.2.0, four best-worst scaling versions, each consisting of 17 unique choice tasks with 5 attributes per choice task, were created to obtain the most efficient, fractional design. In such a design, it is not needed to include all possible combinations of attributes in the choice tasks, which is far too burdensome to administer. Instead, specific sets of five attributes from the full attribute lists are created to ensure that the relative importance of each attribute can be derived. Each attribute was presented 12 
or 13 times in the four best-worst scaling version, was combined at least once with every other attribute, and appeared two to four times in each position in the choice task. Each respondent randomly received one of the best-worst scaling versions. In every choice task, the respondent was asked to state which attributes were the most and the least important in the decision about DMDs, making a hypothetical trade-off between the attributes [24]. The best-worst scaling was pilot tested among researchers $(n=3)$ and MS patients $(n=3)$ to ensure comprehensibility of the questionnaire. An example of a choice task for neurologists and MS nurses is presented in Figure 1. Further description on the identification, selection and definition of attributes and on the development of the choice tasks and the questionnaire is described in detail elsewhere [8].

\begin{tabular}{|c|c|c|}
\hline \multicolumn{3}{|c|}{$\begin{array}{l}\text { Which attribute do you in general find most important } \\
\text { and which attribute do you in general find least } \\
\text { important of the } 5 \text { attributes presented if you need to } \\
\text { make a treatment choice in disease modifying drugs for } \\
\text { patients with relapsing-remitting multiple sclerosis or } \\
\text { clinically isolated syndrome? } \\
\text { Please choose the most and least important attribute. }\end{array}$} \\
\hline $\begin{array}{c}\text { Most } \\
\text { important }\end{array}$ & & $\begin{array}{l}\text { Least } \\
\text { important }\end{array}$ \\
\hline 0 & $\begin{array}{l}\text { Frequency of } \\
\text { administration }\end{array}$ & 0 \\
\hline 0 & $\begin{array}{l}\text { Effect on the } \\
\text { development of plaques } \\
\text { in the brain }\end{array}$ & 0 \\
\hline 0 & Effect on relapse rate & 0 \\
\hline 0 & Type of side effects & 0 \\
\hline 0 & Effect on quality of life & 0 \\
\hline
\end{tabular}

Figure 1. Example of a choice task in the best-worst scaling

In addition to the best-worst scaling choice tasks, questions about demographical and professional characteristics were included. The respondents had to answer all questions to complete the questionnaire. At the end of the questionnaire, an optional open question provided the respondents the opportunity to report any important attributes in the decision about DMD treatment they missed in the choice tasks of the best-worst scaling.

\section{Subjects}

Healthcare professionals were eligible for participation in the study if they were neurologists (i.e. MS-specialized neurologists or general neurologists) or MS nurses (i.e. MS- 
specialized nurses or nurse practitioners, physician assistants or nurse consultants specialized in MS) and involved in the treatment of MS patients in the Netherlands. These healthcare professionals generally work in hospitals. The Netherlands counts about 80 (academic or general) hospitals. The neurological department of a hospital generally consists of multiple neurologists of which some neurologists may have one or a few specific areas of focus. The exact number of MS neurologists in the Netherlands is unknown, but most departments have one, two or three neurologists who focus on the treatment of MS patients. About $135 \mathrm{MS}$ nurses were working in the Netherlands at the time of the study. Neurologists with a focus on the treatment of MS were identified by searching websites of all hospitals in the Netherlands. We compiled a mailing list for 120 neurologists through the network of one of the authors (PJ) - including the MS working group of the Dutch Neurologists Association and the MSmonitor Working group - or through personal contact with the hospital. The neurologists were asked to participate through an e-mail explaining the purpose of the study and containing a direct link to the online questionnaire. Additionally, an extra reminder e-mail, in which the neurologists were personally addressed, was sent to 52 members of the MS Working Group of the Dutch association for neurology and the MSmonitor Working Group, of which six neurologists responded to have completed the questionnaire earlier and four neurologists responded to have completed the questionnaire after the e-mail was sent.

Nurses were contacted through a call on the communication system of the professional association for MS nurses to which about $150 \mathrm{MS}$ nurses and other nurses with an interest in MS had access, and, additionally, through an e-mail to 88 nurses to increase response. MS nurses for this mailing list were identified via an inventory of MS caregivers and healthcare institutions published on a patient information website about MS endorsed by a Dutch patient association. Additionally, all nurse practitioners and physician assistants in MS ( $N=15)$ were also contacted through a mailing list of their professional association. In case of no response among the neurologists and nurses, a reminder e-mail was sent after one and two weeks after the first e-mail. The neurologists and nurses were informed that by completing the questionnaire they gave consent for their responses to be used in the study. Cookies were used to prevent the same respondent from filling out the questionnaire twice. The study was fully anonymous, and no data, such as IP addresses, were recorded that could lead to the identity of the healthcare professional.

\section{Analyses}

Only completed questionnaires were included in the analyses. Descriptive statistics were used to present characteristics of the neurologists and MS nurses. To evaluate the preferences of the healthcare professionals for the DMD attributes, Sawtooth SSI Web version 8.2.0 was used to perform a hierarchical Bayes model employing a multinomial logit procedure [26]. A raw score for the importance of each attribute was calculated in an iterative process of estimating each respondent's utility score conditionally on estimates of other respondents' utility scores. The raw score was rescaled to a relative importance score 
(RIS) on a ratio scale [27]. The RIS of an attribute represents the importance of the attribute in relation to the importance of the other attributes in the decision about the DMD treatment of MS according to the professionals. The RISs of all 27 attributes for each respondent sum up to 100 . Therefore, if there would be no difference in importance of the attributes, each attribute would obtain a RIS of 3.7. Deviations from this score would suggest that some attributes are more important in the treatment decision than others. To ensure only responses of neurologists and MS nurses who answered the questions carefully were included in the analyses, respondents with a fit statistic (root likelihood) below 247 were omitted from the analyses as a fit statistic below this score would suggest random answers to the choice tasks [28]. In addition to the RISs, most-minus-least counts were calculated to confirm the rankings of the attributes. To adjust for an imbalance in the number of times an attributes was shown to each respondent in the best-worst scaling, the most-minus-least counts were divided by the frequency of each attribute being included in the questionnaire across the four versions [24].

Multivariable linear regression analyses with robust standard errors were conducted with SPSS for Windows version 24 to assess whether the RISs of the 27 attributes differed between neurologists and MS nurses while controlling for sex and three professional characteristics. Two characteristics indicated the amount of experience in treating MS patients: the number of years treating MS patients dichotomized into $\leq 15$ years or $>15$ years and the number of MS patients treated yearly dichotomized into $\leq 150$ patients per year or $>150$ patients treated per year. The third characteristic denoted the extent to which the healthcare professional was specialized in treating MS patients on a continuous scale, and was defined as the number of MS patients treated as proportion of the total number of patients treated.

To assess whether the RISs assigned by the neurologists and nurses to the 27 attributes differed from the RISs assigned by the MS patients, hierarchical Bayes analyses was conducted including responses of the neurologists and nurses, and responses of patients obtained in a previous study [8]. A second linear regression model was built to control for age, sex and level of education in the function between the respondent type (i.e. healthcare professional or patient) and the RISs of the 27 attributes. Level of education was dichotomized into respondents who had completed primary and/or secondary school only and respondents who had completed any additional type of tertiary education. The patients' perspective was obtained from a previous study among 185 patients with relapsing remitting MS or clinically isolated syndrome, and with a range in experience with DMDs (from having never used a DMD to having used more than 3 different DMDs) and duration of diagnosis. Further detailed description of the patient recruitment and the patients characteristics can be found elsewhere [8]. 


\section{Results}

Of the 120 neurologists and an estimated 140 nurses contacted, 79 healthcare professionals accessed the questionnaire between 20 November 2015 and 8 February 2016. In total, 62 healthcare professionals completed the questionnaire (estimated overall completion rate of $24 \%$ ), of which two healthcare professionals did not meet the inclusion criteria because they were working in Belgium $(n=1)$ or did not treat MS patients on a regular basis $(n=1)$. The sample of 60 healthcare professionals that met the inclusion criteria consisted of 27 (45\%) neurologists and 33 (55\%) nurses. Table 1 presents their characteristics. Twenty-four (89\%) neurologists reported to be specialized in MS. Of the MS nurses, $23(70 \%)$ MSspecialized nurses, 1 (3\%) nurse consultant MS, 7 (21\%) nurse practitioners MS and 2 (6\%) physician assistants MS completed the questionnaire. The median proportion of MS patients expressed as a percentage of the total number of patients treated was $20 \%$ among neurologists and $50 \%$ among nurses, of which 8 nurses reported to only treat MS patients.

As all fit statistics of the questionnaires were above .247 (mean .557; range .341, .769), indicating that none of the healthcare professionals answered the choice tasks completely at random, all completed questionnaires were included in the analyses. The ranking of the DMD attributes according to the mean RISs showed that healthcare professionals regarded safety, i.e. risks of life threatening or severely disabling adverse events, as most important (mean RIS (SD): 9.29 (0.92)), but was followed closely by effect on disability progression, effect on quality of life and effect on relapse rate with only small differences between the RISs (mean RIS (SD): 9.27 (1.58), 9.19 (0.83) and 8.89 (0.88), respectively). Other highly ranked attributes were effect on development of plaques in the brain (i.e. MS activity on $\mathrm{MRI}$ ), severity of side effects and the effect on severity of relapses. Ten DMD attributes were of little or no importance in the decision for the healthcare professionals with mean RIS below 1.0, including the required monitoring and administration frequency. The results of the adjusted most-minus-least counts (Supporting information Table Most-minus-least counts) did not substantially affect the rankings obtained based on the hierarchical Bayes analyses, and therefore confirmed the results. Of the 60 neurologists and nurses, 2 (3\%) neurologists reported additional DMD attributes that were not included in the best-worst scaling: teratogenic properties of the DMD and the certainty of achieving the effects of the DMD. 
Table 1. Characteristics of the healthcare professionals

\begin{tabular}{|c|c|c|c|c|}
\hline & & $\begin{array}{l}\text { All healthcare } \\
\text { professionals } \\
(\mathrm{N}=60)\end{array}$ & $\begin{array}{c}\text { Neurologists } \\
(\mathrm{N}=27)\end{array}$ & $\begin{array}{l}\text { Nurses and } \\
\text { physician } \\
\text { assistants } \\
(\mathrm{N}=33)\end{array}$ \\
\hline \multirow[t]{2}{*}{ Sex, N (\%) } & Male & $21(35.0)$ & $20(74.1)$ & $1(3.0)$ \\
\hline & Female & $39(65.0)$ & $7(25.9)$ & 32 (97.0) \\
\hline \multirow[t]{2}{*}{ Age (in years) } & mean (SD) & $47.6(8.7)$ & $49.7(9.2)$ & $45.9(8.1)$ \\
\hline & Range & $30-64$ & $35-64$ & 30-59 \\
\hline \multirow[t]{6}{*}{ Work function, $\mathrm{N}(\%)$} & $\begin{array}{l}\text { MS Specialized } \\
\text { neurologist }\end{array}$ & $24(40)$ & 24 (88.9) & - \\
\hline & $\begin{array}{l}\text { General } \\
\text { neurologist }\end{array}$ & $3(5.0)$ & $3(11.1)$ & - \\
\hline & MS nurse & $23(38.3)$ & - & $23(69.7)$ \\
\hline & $\begin{array}{l}\text { Nurse } \\
\text { practitioner MS }\end{array}$ & 7 (11.7) & - & $7(21.2)$ \\
\hline & $\begin{array}{l}\text { Physician } \\
\text { assistant }\end{array}$ & $2(3.3)$ & - & $2(6.1)$ \\
\hline & Nurse consultant & $1(1.7)$ & - & $1(3.0)$ \\
\hline Work experience (in & $\leq 15$ & $45(75.0)$ & $16(59.3)$ & 29 (87.9) \\
\hline years) mean (SD) & $>15$ & $15(25.0)$ & $11(40.7)$ & $4(12.1)$ \\
\hline Number of MS patients & $\leq 150$ & $24(40.0)$ & $11(40.7)$ & $13(39.4)$ \\
\hline $\begin{array}{l}\text { treated yearly, mean } \\
\text { (SD) }\end{array}$ & $>150$ & $36(60.0)$ & $16(59.3)$ & $20(60.6)$ \\
\hline $\begin{array}{l}\text { Proportion MS patients } \\
\text { from total number of } \\
\text { patients treated (in \%) }\end{array}$ & Median (IQR) & $40(20-67.5)$ & $20(10-40)$ & $50(40-95)$ \\
\hline
\end{tabular}

\section{Comparison of neurologists with MS nurses}

Only few differences were found between neurologists and nurses (Table 2). When comparing neurologists to nurses, relatively large differences in mean RISs (absolute difference in RISs of 1 or more) were found in effect on current MS symptoms, effect on life expectancy, total costs of the DMD, which were higher for the neurologists, and interaction with other medication, which was higher for nurses. However, when controlling for sex, the years of work experience, the number of MS patients treated each year and the degree of focus on MS treatment, only a significant difference was found between neurologists and nurses in the low ranked attributes total cost of the $D M D(b=-1.27, p=.015)$ and interaction with other medication $(b=2.09, p=.007)$. These differences resulted in quite substantial shifts in ranking: total cost of the DMD was ranked $17^{\text {th }}$ by neurologists (RIS=1.22) and $25^{\text {th }}$ by nurses (RIS=0.16), and interaction with other medication was ranked $18^{\text {th }}$ by neurologists $\left(\mathrm{RIS}=1.10\right.$ ) and $13^{\text {th }}$ by nurses (RIS=2.97). Based on their RISs though, these attributes did not influence the treatment decision severely. 


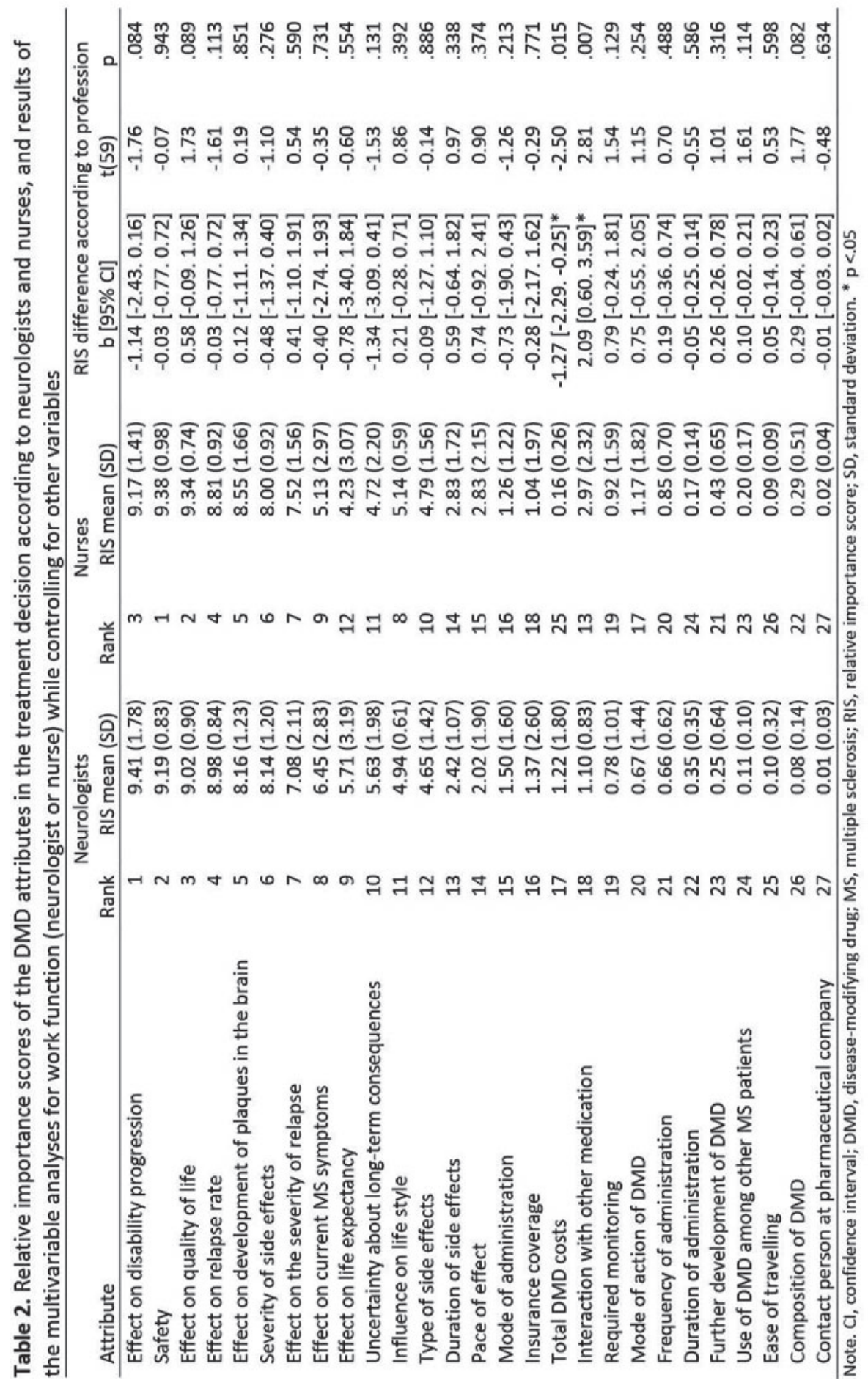




\section{Comparison of healthcare professionals (neurologists and MS nurses) with patients}

When controlling for age, sex and level of education, there were significant differences found between the RISs of the healthcare professionals and the MS patients for six attributes at an alpha of .05: effect on relapse rate and safety were more important for neurologists and nurses, while effect on current MS symptoms, pace of effect, insurance coverage and further development of the DMD were more important for the patients in the decision about DMDs. Furthermore, while the difference in RIS of 1.01 between the healthcare professionals and patients for influence on lifestyle was quite substantial, this difference was not significant when controlling for age, sex and level of education ( $p=.063$ ). For safety, the difference was the most notable: the RIS for patients was substantially lower than for neurologists and nurses $(b=-2.59, p<.001)$, making safety the fourth most important attribute for neurologists and nurses, and only the eighth most important attribute for patients. Table 3 presents the results of the multivariable regression analyses for all 27 attributes. Fig. 2 presents the relative importance score of each attribute according to MS patients and neurologists and MS nurses. 


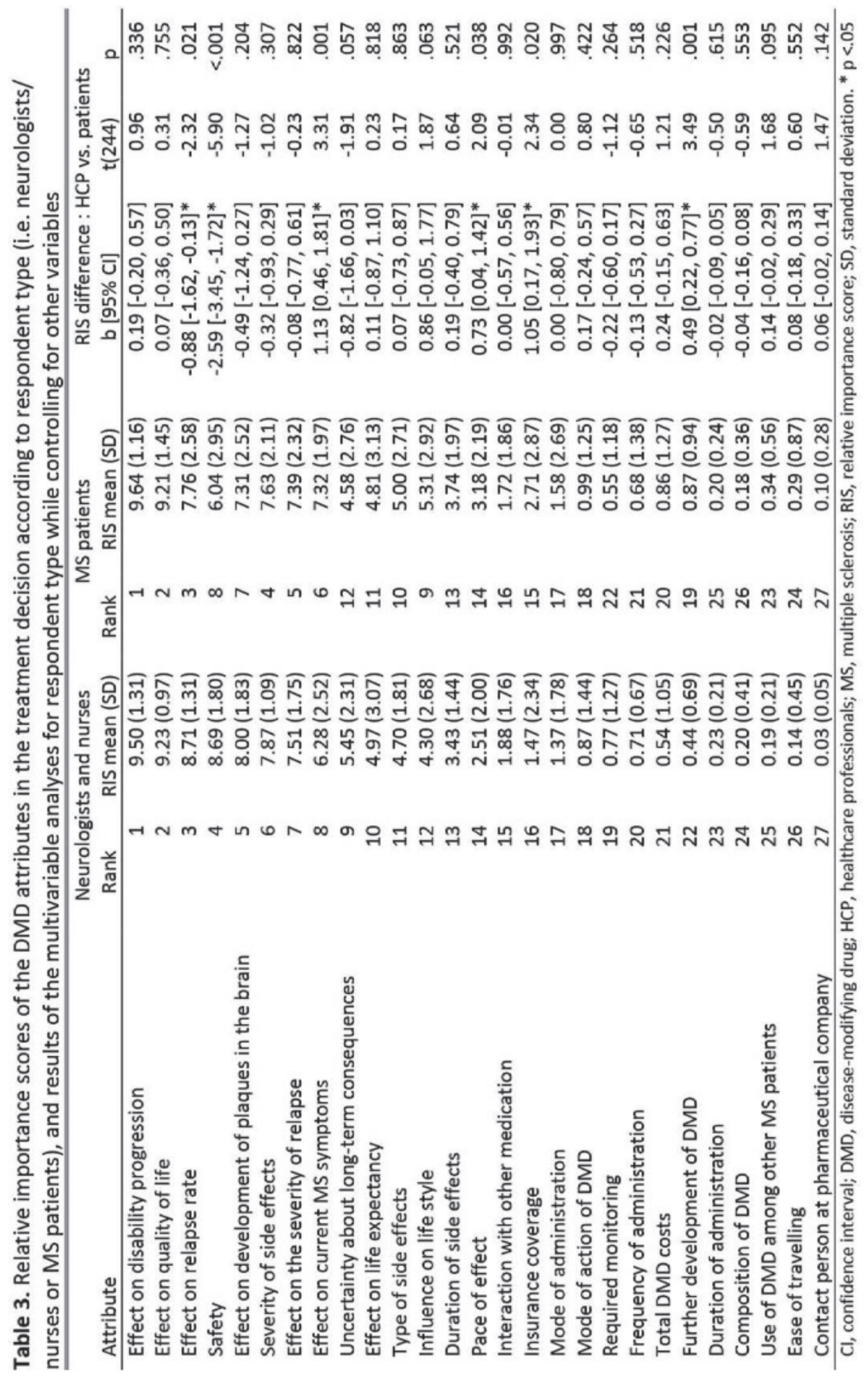




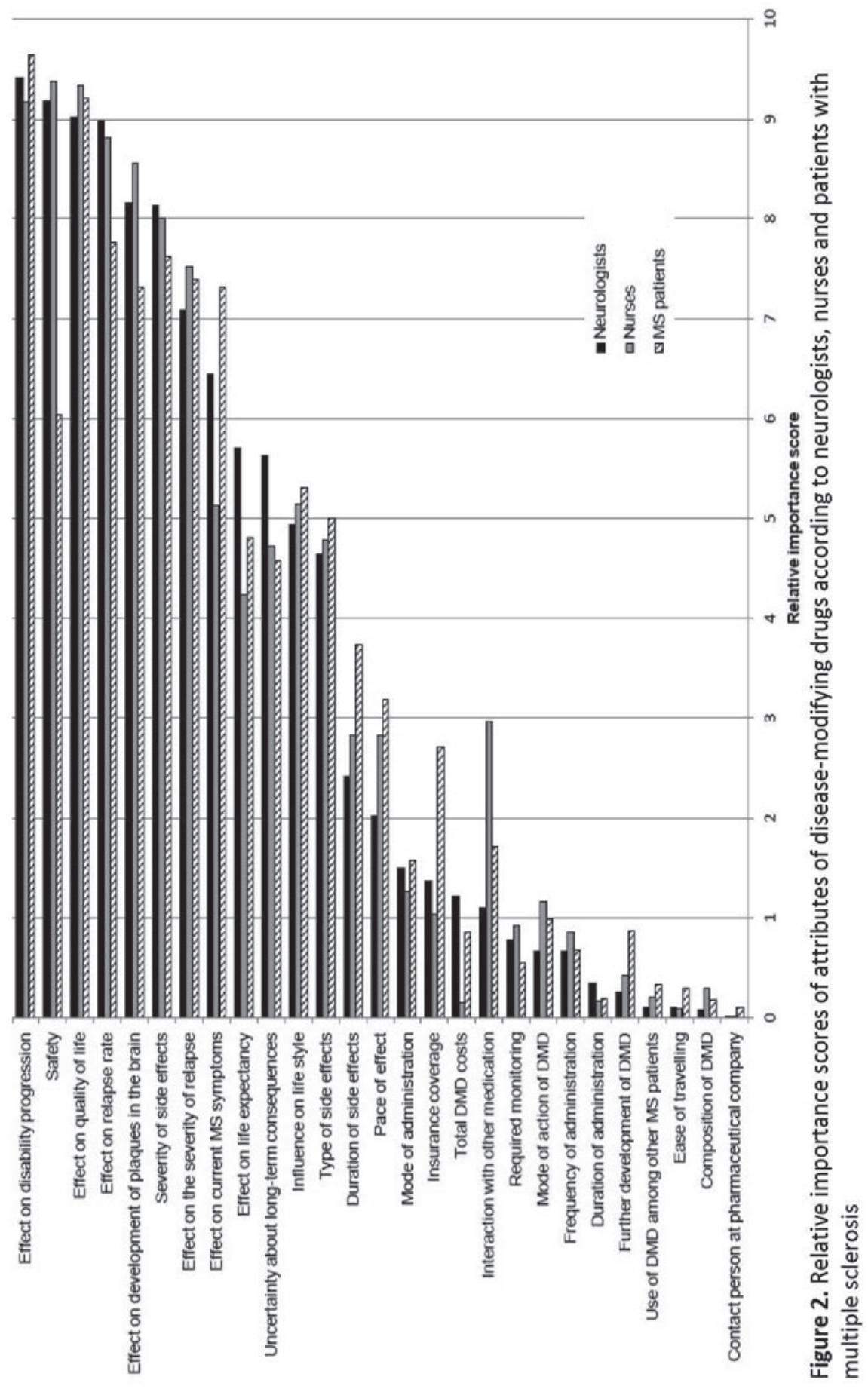




\section{Discussion}

The healthcare professionals and the patients both valued effect on disease progression, quality of life and relapse rate highly, which is not unexpected because these are the primary aims of DMD treatment. The most notable difference between the two perspectives was found in the importance of safety. The healthcare professionals gave significantly more value to this attribute compared with patients. More specifically, safety was ranked as fourth most important by healthcare professionals, while ranked only eighth by patients, who gave more value to other attributes focused on effectiveness and the severity of more common side effects. In the process of shared decision making, this could be an issue. Healthcare professionals may, for example, be less inclined than patients to choose a DMD for which experience and research has shown risks for life-threatening or severely disabling side effects, such as progressive multifocal leukoencephalopathy. Motivations of patients, neurologists and nurses for the importance of the attributes were not elicited in the questionnaire, therefore we can only speculate about the reasons for the difference found in the importance of the attributes, in particularly safety. A first explanation for the difference in the importance of safety might be that healthcare professionals have a different understanding of the seriousness of the risks and consequences than patients. Second, patients might be willing to take more risk, as a previous study showed that patients were willing to accept larger risks than the risks associated with the DMDs available at that time, in exchange for effectiveness in reducing relapse rate and disability progression [9]. Healthcare professionals may be less inclined to take these risks, for example, because of forensic and legal liability in case of incidents of serious adverse events.

This study shows which attributes are most important in the decision, and that the rankings of the attributes are overall quite similar for neurologists, MS nurses and MS patients, with the exception of a few attributes - especially safety. It should be noted that the rankings reflect the average preferences. Therefore, the discrepancies do not necessarily play a role in every consultation. However, incorporating the patient's preferences in the decision is an essential part of reaching a shared decision, which may be complicated if the healthcare professional and patient do not agree on the importance of some attributes in the decision. Patient decision aids can, besides provide information, also support the patient and the healthcare professional in eliciting and discussing the patient's preferences [30]. The results of this study contribute to the development of an MS decision aid by indicating the attributes - those attributes that both patients and healthcare professionals find most important and those attributes that are substantially more important for either patients or healthcare professionals - about which information and preference elicitation questions should be included in the decision aid to enable effective support for reaching a shared decision. Moreover, this study shows that a best-worst scaling could be a useful tool in the future development of other interventions for supporting shared decision making, such as patient decision aids. Especially when there is a risk of developing overly cognitive 
burdensome tools, a best-worst scaling may be useful in selecting the most essential attributes.

Some limitations of this study need to be considered. Only an estimated $24 \%$ of the contacted healthcare professionals completed the questionnaire. Possibly, more healthcare professionals with a more positive attitude towards research responded because of our recruitment methods. Therefore the sample might not perfectly represent all MS neurologists and MS nurses in the Netherlands because they may have been better informed about the latest DMD developments, and they might have had different preferences for DMD attributes accordingly. Another limitation could be the small sample size, but the number of eligible healthcare professionals for this study is also limited. The Netherlands counts about 80 hospitals of which most hospitals have one, two or three neurologist with a focus on MS and one or two MS nurses, and we made efforts to invite all of them to participate. The sample size limited the ability to conduct a latent class analysis. In future research, evaluation of heterogeneity in preferences using latent class analysis could potentially provide more insight into groups of healthcare professionals with similar preferences. Furthermore, in order to compare the perspectives of the neurologists and the MS nurses with those of the patients, the best-worst scaling for both parties included the same attributes. These attributes were, however, identified through focus groups among patients only, and may not be the same attributes that the neurologists and MS nurses would have reported if focus groups among them would have been performed. Nevertheless, only 2 neurologists reported other attributes that were not included in the best-worst scaling - teratogenic properties and uncertainty whether effects would be achieved" - to be of importance as well. Another limitation is that it was necessary to ask different questions in the best-worst scaling for healthcare professionals compared with the patients. Both groups were asked to choose the most and least important attribute for decision making, but patients were expected to answer this question according to their individual situation, while healthcare professionals were asked to answer the question for MS patients in general. This difference in framing of the question may have led to differences in what is regarded as important in the decision. Additionally, because of small deviations from normality of the residuals and homoscedasticity found in the regression analyses, generalization of the found differences in total costs of the DMD and interaction with other medication between neurologists and nurses and the differences in effect on relapse rate, insurance coverage, and further development of the DMD between the healthcare professionals and the patients beyond our sample should be done with caution. Lastly, it is uncertain whether our results may be transferred to other settings as the healthcare systems in other settings may differ. Therefore, some attributes, such as DMD costs, may be more important for the decision in other settings. Other limitations that apply to the best-worst scaling method and the results of the patients' perspective have been reported elsewhere [8]. 


\section{Conclusion}

This study showed that safety, effect on disability progression and effect on quality of life were the most influential attributes of DMDs for healthcare professionals in the treatment decision. The importance of these and other highly ranked attributes did not differ between neurologists and nurses when making a decision for MS patients in general. Additionally, the average healthcare professionals' perspective and the average patients' perspective agree that the ability of DMDs to reduce disability progression and maintain or improve quality of life are the most important attributes of a DMD. The perspectives differ however considerably about the importance of safety. These results provide valuable information for the development of interventions to support shared decision making. This study also demonstrates the feasibility of combining focus groups and a best-worst scaling to identify important attributes that could later be included in a patient decision aid. A best-worst scaling could be an interesting method when having to restrict the number of attributes for inclusion in a patient decision aid.

\section{Acknowledgment}

We would like to thank the discussant Janne Schepers for her helpful comments on an earlier draft of this manuscript presented during the Lowlands Health Economics' Study Group conference, Ghent, Belgium, May 2016. We would like to thank the professional associations for their cooperation in contacting MS nurses, physician assistants and nurse practitioners about the study. We would like to thank the neurologists and nurses who contributed to this study by telephone interviews for the identification of the attributes or by completing the survey.

\section{Source of funding}

Financial support for this study was provided by an unrestricted donation to the Limburg University Fund by Bayer B.V. The funding agreement ensured the authors' independence in designing the study, interpreting the data, writing, and publishing the report. 


\section{References}

1. Lublin FD, Reingold SC, Cohen JA, Cutter GR, Soelberg Sorensen P, Thompson AJ, et al. Defining the clinical course of multiple sclerosis: the 2013 revisions. Neurology. 2014;83:278-86. Epub 2015/03/04. doi: 10.1212/01.wnl.0000462309.76486.c5.

2. Michel L, Larochelle C, Prat A. Update on treatments in multiple sclerosis. Presse Med. $2015 ; 44(4$ Pt 2):e137-51. doi: 10.1016/j.lpm.2015.02.008.

3. Torkildsen O, Myhr KM, Bo L. Disease-modifying treatments for multiple sclerosis - a review of approved medications. Eur J Neurol. 2016;23 Suppl 1:18-27. Epub 2015/11/14. doi: 10.1111/ene.12883.

4. U.S. Food and Drug Administration. Drugs@FDA: FDA approved drug products [cited 20162 September]. Available from: http://www.accessdata.fda.gov/scripts/cder/daf/index.cfm.

5. European Medicines Agency. European public assessment reports [cited 20162 September]. Available from: http://www.ema.europa.eu/ema/.

6. Elwyn G, Lainter S, Coulter A, Watson P, Thomson R. Implementing shared decision making in the NHS. BMJ. 2010;341:c5146.

7. Stacey $D$, Légaré $F$, Col NF, Bennett $C L$, Barry MJ, Eden KB, et al. Decision aids for people facing health treatment or screening decisions. Cochrane Database Syst Rev. 2014;(1). doi: 10.1002/14651858.CD001431.pub4.

8. Kremer IEH, Evers SMAA, Jongen PJ, van der Weijden T, van de Kolk I, Hiligsmann M. Identification and prioritization of important attributes of disease-modifying drugs in decision making among patients with multiple sclerosis: a nominal group technique and best-worst scaling. PLoS ONE. 2016;11(11). Epub 2016/11/05. doi: 10.1371/journal.pone.0164862.

9. Johnson FR, Van Houtven G, Özdemir S, Hass S, White J, Francis G, et al. Multiple Sclerosis patients' benefit-risk preferences: serious adverse event risks versus treatment efficacy. J Neurol. 2009;256(4):554-62. doi: 10.1007/s00415-009-0084-2.

10. Poulos C, Kinter E, Yang JC, Bridges JF, Posner J, Reder AT. Patient Preferences for Injectable Treatments for Multiple Sclerosis in the United States: A Discrete-Choice Experiment. Patient. 2015. doi: 10.1007/s40271-015-0136-x.

11. Poulos C, Kinter E, Yang J-C, Bridges JFP, Posner J, Gleißner E, et al. A discrete-choice experiment to determine patient preferences for injectable multiple sclerosis treatment in Germany. Ther Adv Neurol Disord. 2016;9(2):95-104.

12. Utz KS, Hoog J, Wentrup A, Berg S, Lammer A, Jainsch B, et al. Patient preferences for diseasemodifying drugs in multiple sclerosis therapy: a choice-based conjoint analysis. Ther Adv Neurol Disord. 2014;7(6):263-75. doi: 10.1177/1756285614555335.

13. Wicks P, Brandes DW, Park J, Liakhovitski D, Koudinova T, Sasane R. Preferred features of oral treatments and predictors of non-adherence: two web-based choice experiments in multiple sclerosis patients. Interact J Med Res. 2015;4(1):e6.

14. Wilson L, Loucks A, Bui C, Gipson G, Zhong L, Schwartzburg A, et al. Patient centered decision making: use of conjoint analysis to determine risk-benefit trade-offs for preference sensitive treatment choices. J Neurol Sci. 2014;344(1-2):80-7. doi: 10.1016/j.jns.2014.06.030.

15. Wilson LS, Loucks A, Gipson G, Zhong L, Bui C, Miller E, et al. Patient preferences for attributes of disease-modifying multiple sclerosis therapies: development and results of a ratings-based conjoint analysis. Int J MS Care. 2015. doi: 10.7224/1537-2073.2013-053.

16. Lynd LD, Traboulsee A, Marra CA, Mittmann N, Evans C, Li KH, et al. Quantitative analysis of multiple sclerosis patients' preferences for drug treatment: a best-worst scaling study. Ther Adv Neurol Disord. 2016;9(4):287-96. Epub 2016/07/02. doi: 10.1177/1756285616648060.

17. de Bekker-Grob EW, Essink-Bot ML, Meerding WJ, Koes BW, Steyerberg EW. Preferences of GPs and patients for preventive osteoporosis drug treatment: a discrete-choice experiment. Pharmacoeconomics. 2009;27(3):211-9. Epub 2009/04/10. 
18. Mantovani LG, Monzini MS, Mannucci PM, Scalone L, Villa M, Gringeri A. Differences between patients', physicians' and pharmacists' preferences for treatment products in haemophilia: a discrete choice experiment. Haemophilia. 2005;11(6):589-97. Epub 2005/10/21. doi: 10.1111/j.1365-2516.2005.01159.x.

19. Montgomery AA, Fahey T. How do patients' treatment preferences compare with those of clinicians? Qual Health Care. 2001;10 Suppl 1:i39-43. Epub 2001/09/05.

20. Park MH, Jo C, Bae EY, Lee EK. A comparison of preferences of targeted therapy for metastatic renal cell carcinoma between the patient group and health care professional group in South Korea. Value Health. 2012;15(6):933-9. Epub 2012/09/25. doi: 10.1016/j.jval.2012.05.008.

21. van Hulst LT, Kievit W, van Bommel R, van Riel PL, Fraenkel L. Rheumatoid arthritis patients and rheumatologists approach the decision to escalate care differently: results of a maximum difference scaling experiment. Arthritis Care Res. 2011;63(10):1407-14. Epub 2011/07/13. doi: 10.1002/acr.20551.

22. Hanson KA, Agashivala N, Wyrwich KW, Raimundo K, Kim E, Brandes DW. Treatment selection and experience in multiple sclerosis: survey of neurologists. Patient Prefer Adherence. 2014;8:415-22. Epub 2014/04/15. doi: 10.2147/ppa.s53140.

23. Flynn TN, Marley AAJ. Best-worst scaling: theory and methods. In: Hess S, Daly A, editors. Handbook of choice modeling. Cheltenham: Edward Elgar Publishing Limited; 2014.

24. Flynn TN, Louviere JJ, Peters TJ, Coast J. Best--worst scaling: What it can do for health care research and how to do it. J Health Econ. 2007;26(1):171-89. doi: 10.1016/j.jhealeco.2006.04.002.

25. Eysenbach G. Improving the quality of web surveys: the checklist for reporting results of internet E-surveys (CHERRIES). J Med Internet Res. 2004;6(3):e34. doi: 10.2196/jmir.6.3e34.

26. Muhlbacher AC, Kaczynski A, Zweifel P, Johnson FR. Experimental measurement of preferences in health and healthcare using best-worst scaling: an overview. Health Econ Rev. 2015;6(1):2. Epub 2016/01/09. doi: 10.1186/s13561-015-0079-x.

27. Orme B. Hierarchical Bayes: why all the attention? Sequim, WA: Sawtooth Software, Inc., 2000.

28. Orme B. SSI Web v8.3: software for web interviewing and conjoint analysis. Orem, Utah: Sawtooth Software Inc.; 2014. Available from: http://www.sawtoothsoftware.com/support/manuals/ssi-web-help.

29. Cheung KL, Wijnen BF, Hollin IL, Janssen EM, Bridges JF, Evers SM, et al. Using best-worst scaling to investigate preferences in health care. Pharmacoeconomics. 2016. Epub 2016/07/13. doi: 10.1007/s40273-016-0429-5.

30. O'Connor AM, Llewellyn-Thomas HA, Flood AB. Modifying unwarranted variations in health care: shared decision making using patient decision aids. Health Aff (Millwood). 2004;Suppl Variation:Var63-72. Epub 2004/10/09. doi: 10.1377/hlthaff.var.63. 


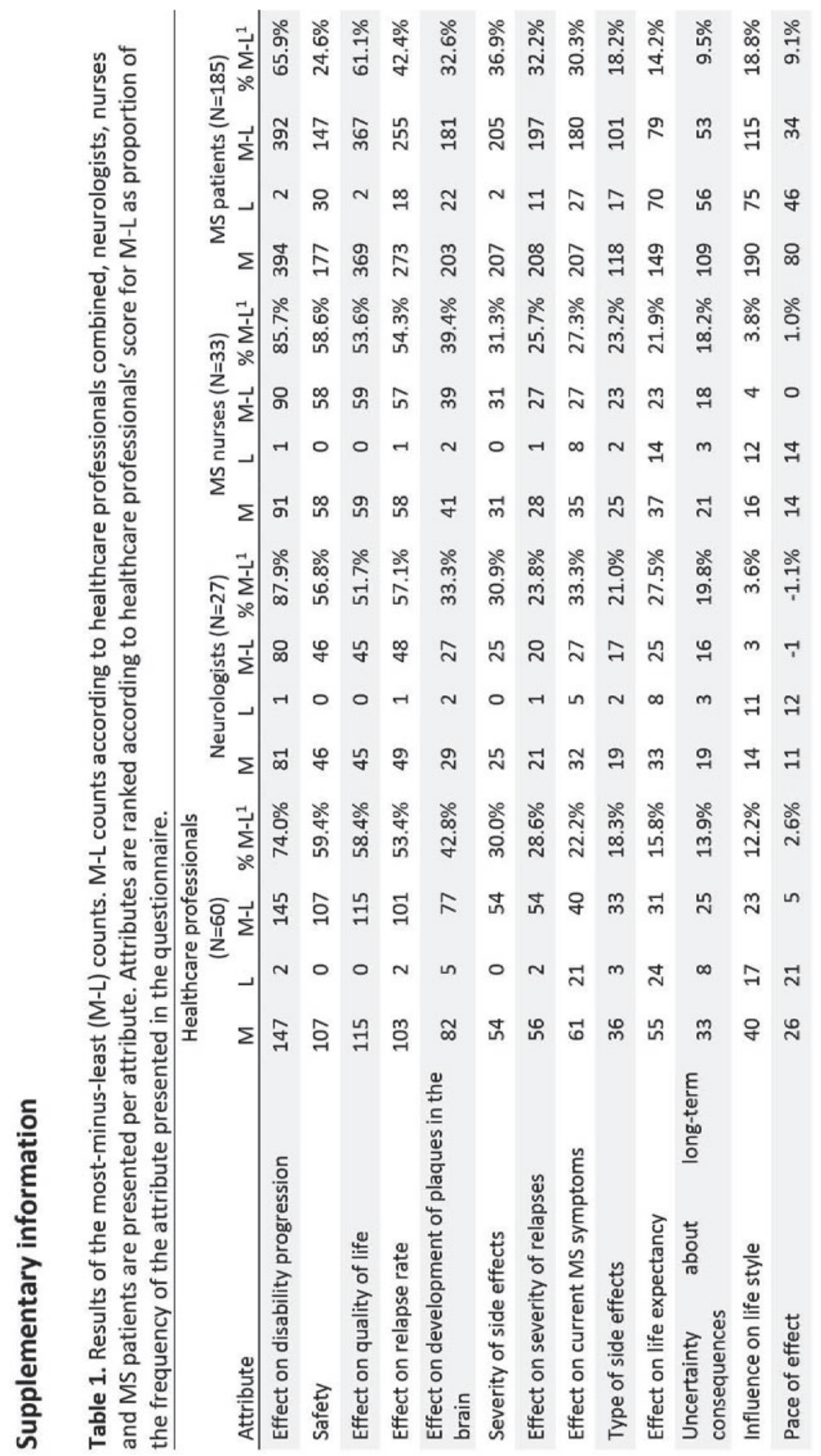




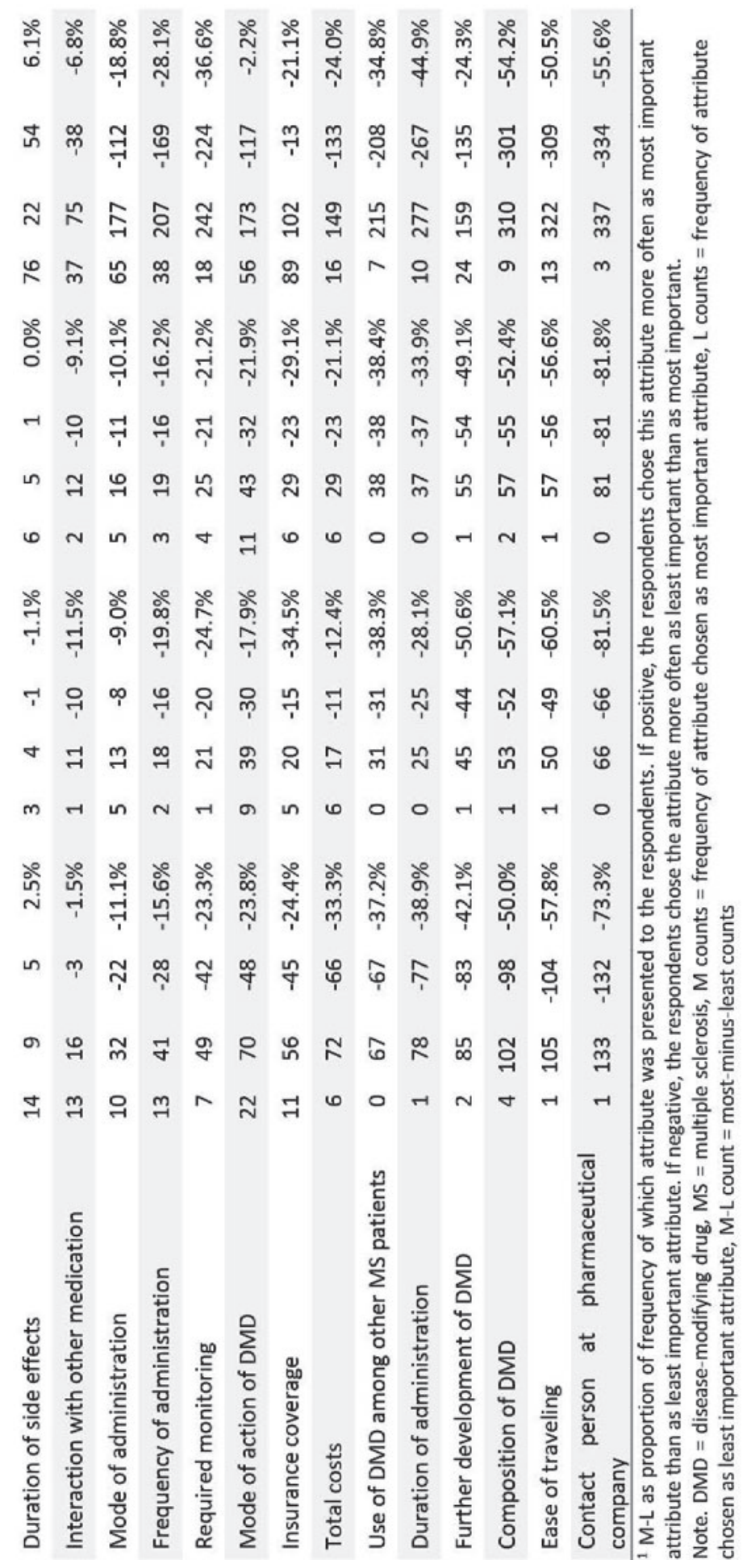





\section{Development of a patient decision aid based on multi-criteria decision analysis for disease-modifying drugs for multiple sclerosis}

Submitted as:

Kremer IEH, Jongen PJ, Evers, SMAA, Hoogervorst EL, Verhagen WIM, Hiligsmann M. Development of a patient decision aid based on multi-criteria decision analysis for diseasemodifying drugs for multiple sclerosis. 


\section{Abstract}

Background. The treatment decision with regard to start disease-modifying drugs (DMDs) for multiple sclerosis (MS) is preference sensitive. Shared decision making is important. Patient decision aids support patients and healthcare professionals in making a shared decision. To date, there is no patient decision aid available for MS patients in the Netherlands.

Aim. To describe the systematic development of a patient decision aid based on the principles of multi-criteria decision analysis (MCDA) of DMDs for MS.

Methods. Recommendations of the International Patient Decision Aid Standards were followed. The user-centred developmental process consisted of six stages: 1) determining the scope; 2) organizing focus groups and conducting best-worst scaling surveys of the intended users (patients, neurologists and nurses) to determine which characteristics of DMDs should be included in the MCDA-based patient decision aid; 3) determining the format and delivery; 4) conducting a literature review on the characteristics of the DMD; 5) developing a prototype; and 6) alpha testing of the patient decision aid on comprehensibility and usability with patients and healthcare professionals.

Results. The online MCDA-based patient decision aid is designed and intended to support patients with relapsing-remitting MS or a clinically isolated syndrome (CIS) with regard to DMDs labelled for MS. Alpha testing of the prototype identified several problems regarding content and framing, methods for weighting the importance of criteria, and the end screen providing an overview of the treatment options ranked according to the patient's preferences. Adaptations were made accordingly. However, further development is needed to verify rankings and validate the patient decision aid. Moreover, the feasibility of implementation and the value of the patient decision aid for supporting shared decisionmaking should be studied.

Discussion. The patient decision aid was well-received overall with patients and professionals, but further development is needed. Furthermore, beta pilot testing with patients and healthcare professionals at the point of clinical decision making will assess the feasibility of implementation in clinical practice. 


\section{Introduction}

Multiple sclerosis (MS) is a chronic demyelinating disease of the central nervous system that manifests most often during young adulthood. People diagnosed with the relapsingremitting disease course of multiple sclerosis (RRMS) experience exacerbations of MS signs and symptoms which can recover over time, though signs and symptoms may remain [1]. If patients have multiple relapses, disability can accumulate, resulting in substantial loss of quality of life [2-4].

RRMS patients and patients diagnosed with clinically isolated syndrome (CIS) - defined by a single event resembling an MS relapse, but in the absence of the MS diagnosis yet [1] face the decision of starting treatment with disease-modifying drugs (DMDs). DMDs can delay or prevent the accumulation of disabilities by reducing the number of relapses and reducing the number new (gadolinium enhancing on T1 or new T2) or enlarging lesions on MRI scans of the brain. Currently, twelve DMDs are formally authorized for the treatment of RRMS in the Netherlands; three of these have been authorized for CIS [5]. New DMDs are in the pipeline.

The decision for starting DMD treatment is preference-sensitive: it requires a trade-off between treatment benefits and treatment burden in which the patient's preferences and values should play a key role [6]. Healthcare professionals should invite the patient to participate in the decision making process, inform patients about their treatment options and elicit the patient's preferences for the treatment options in order to include these preferences while making a shared decision regarding treatment [7]. Shared decision making could potentially result in better drug use compliance [8]. However, MS patients may have difficulty in understanding treatment options: health literacy in itself is an issue for a substantial proportion of the Dutch population [9], and for MS patients the decision to start with a DMD can be even more difficult, due to the large number of treatment options and the cognitive and mental symptoms many patients experience $[10,11]$. Patient decision aids support and enable patients to participate in shared decision making by explaining the treatment options, their potential benefits and burdens, and help patients to form and communicate their preferences for the treatment options [12]. Patient decision aids have been shown to support patients in feeling more informed, feeling more certain about the decision, and for the decision to be more congruent with the patient's preferences [12]. Patient decision aids can thus affect the patient's decision substantially. Accordingly, the adequate development and quality of patient decision aids are important $[13,14]$.

Only a few patient decision aids are available or are being developed for decisions about DMDs for MS [15, 16], and no patient decision aids are currently available in the Netherlands. The objective of this paper was to describe our developmental process of a patient decision aid for decisions for all DMDs available for patients with RRMS and CIS in the Netherlands, provide transparency regarding the developmental process and the content of the patient decision aid, and discuss the challenges we encountered in developing such a tool. Transparency in the development and content of the patient 
decision aid enables the appraisal of whether the developmental process and quality of the patient decision aid are adequate.

\section{Methods}

Recommendations by the International Patient Decision Aid Standards (IPDAS) [13] guided the development of the patient decision aid, which consisted of six stages; these are described below. We applied the principles of a user-centred design, involving the endusers in different stages of the developmental process [17].

\section{Stage 1. Scope of the patient decision aid}

The scope of the patient decision aid was determined within a steering group consisting of three health services researchers and an MS neurologist, verified through consultation of an advisory group consisting of three representatives of patient organisations for MS, three MS neurologists, two MS nurses and an expert in patient decision aid development. The steering group determined a priori that the patient decision aid would be based on the principles of multi-criteria decision analysis (MCDA) [18].

\section{Stage 2. Assessment of decisional needs}

Focus groups and surveys of the prospective users (MS patients and healthcare professionals) were conducted to assess the patients' decisional needs, i.e. the information about treatment options that should be provided. Methods have been reported in detail elsewhere $[19,20]$. In short, three focus groups were conducted with RRMS patients with prior experience in making a decision about DMDs or using DMDs. Subjects were asked to list and define the DMD characteristics they considered important to consider while making the treatment decision, and to individually select the 10 most important characteristics. All characteristics selected at least once for the top 10 by any of the subjects were then included in a best-worst scaling survey to prioritize the characteristics according to importance in a larger sample of patients and among neurologists and MS nurses. The best-worst scaling survey presented 17 choice tasks. Each choice task consisted of a unique combination of five characteristics derived from the compiled list in the focus groups. In each choice task, respondents had to select the most and least important characteristic of DMDs for decision making. The best-worst scaling resulted in a ranking of DMD characteristics according to their importance in the treatment decision. This ranking guided the inclusion of information in the patient decision aid. The final selection of characteristics and their definitions were verified within the advisory group, and discussed with two experts in the development of MCDA-based patient decision aids. 


\section{Stage 3. Format}

The steering group chose to use MCDA to construct the patient decision aid because of the large number of DMD options and characteristics of DMDs important in the decision. Trading-off multiple characteristics of a number of alternatives could be difficult, especially if patients have cognitive and mental symptoms. The MCDA approach makes the trade-off, which is usually an implicit cognitive process, explicit. By combining the importance of characteristics with how well DMDs perform on these characteristics, MCDA provides a summary of how well the treatment options fit the preferences, i.e. the implicit cognitive process is performed by the MCDA tool. Therefore, we hypothesized that the MCDA tool may relieve overall cognitive burden for patients, which could be helpful for patients who might experience cognitive and mental problems. MCDA supports decision makers when having to trade-off many, often conflicting, characteristics of two or more alternative options. Without any formal support, such trade-offs could be a cognitively burdensome exercise, even for people without cognitive or mental issues, resulting in suboptimal and non-transparent decisions. By ranking the alternative treatment options according to the patient's preferences, the patient decision aid supports patients and healthcare professionals in directing the focus of the deliberation in terms of characteristics and alternative options to discuss [18].

\section{Stage 4. Review and synthesis of evidence}

To determine the performance of each DMD on efficacy characteristics, an inventory of all pivotal randomized controlled studies of DMDs for MS was made through a database search. Moreover, the database search identified relevant meta-analyses synthesizing the results of pivotal studies on the efficacy of DMDs in comparison with a placebo or other DMDs. The Cochrane Controlled Register of Trials (CENTRAL) was searched (latest update 12 June 2017) for reviews using the term "multiple sclerosis". Due to a lack of evidence of the effects of certain DMDs in comparison with a placebo in pivotal studies, network metaanalyses of DMDs were identified through a database search in Medline (Pubmed) (latest update 12 June 2017), a search for health technology assessment reports in databases of the National Institute for Health and Care Excellence and of the Centre for Review and Dissemination and through experts. Network meta-analyses include direct comparisons of DMDs to a placebo and indirect comparisons of DMDs to other DMDs to estimate the DMDs' performance in comparison with a placebo [21]. The network meta-analysis was selected based on search date, acceptability of quality and comprehensiveness in terms of relevant DMDs, according to the outcome measures of interest (i.e. the effect on relapse rate and disease progression). Effect estimates of DMDs in the selected network meta-analysis [22] were compared with results from other network meta-analysis for verification. Effect estimates for DMDs not included in the meta-analysis were derived from pivotal studies of the DMDs included in its Cochrane review. 
Since the network meta-analysis included only estimates for effects on relapse rate and disability progression, patient-reported effects on quality of life $(\mathrm{Q} o \mathrm{~L})$, cognitive capabilities and fatigue were derived from randomized controlled studies identified through a review of QoL [23], irrespective of the measurement instrument used. Outcomes for cognition and fatigue were based on relevant subdomains of the QoL instruments wherever included and reported. If the data of subdomains were not reported, corresponding authors - and in case of no response, first and/or last authors - were contacted to retrieve additional data.

The effect on MRI outcomes was defined - in agreement with the advisory group - as "no gadolinium-enhancing lesions and no new or enlarging T2-hyperintense lesions on the MRI" [1]. Heterogeneity in operationalization, measurement and reporting of MRI outcomes hinders the synthesis of data for many DMDs, and was therefore not included in the selected network meta-analysis. Other network-meta-analyses identified through the initial search were screened for relevancy of MRI outcomes. If DMDs were not included or only partial information was available in the network meta-analyses, missing data were obtained from the Cochrane reviews or the pivotal studies. If no pooling of data from multiple studies was conducted, the project team pooled the data using RevMan version 5 .

Ease of use, safety profiles and common side effects were based on the Summary of Product Characteristics of each DMD and on data from the Dutch Healthcare Institute. Information for contra-indications because of comorbidity or other use of medication use were identified using summary of product characteristics and information provided by the Dutch Healthcare Institute (www.farmacotherapeutischkompas.nl).

\section{Stage 5. Development of prototype}

A prototype of the patient decision aid was then developed. In MCDA decision aids, performances of each treatment on the characteristics as derived from literature need to be translated into a performance score between 0 and 1 [18]. A performance score of 1 represents optimal performance on this characteristic, while a score of 0 represents no effect or no evidence available. For efficacy on relapses, disease progression, MRI and time to MS diagnosis, linear functions based on relative risk and hazard ratio were assumed. For example, a change in relative risk on relapses of 0.65 to 0.80 would result in an equal change in performance score as would a change in relative risk of 0.25 to 0.40 . For efficacy characteristics based on patient-reported outcomes, linear functions were defined based on effect size (Cohen's d). If no data were available from network meta-analysis or the pivotal studies, or if no significant difference between the DMD and placebo was found, the performance scores of efficacy characteristics was set to zero. Performance scores for common side effects were estimated by calculating the DMDs' weighted risk for side effects. For DMDs' performance on safety profiles, a rule was defined according to the categorization of first line and second line medication, which was validated by two clinicians from the advisory group. The performance scores for ease of use were not pre-determined, since an objective assessment of the difficulty of using each DMD could not be made for all patients. Therefore, a patient-centred approach was applied for determining these scores. 
Each patient who uses the patient decision aid rates his/her own performance scores for ease of use per DMD by rating the expected burden of using the DMD on a scale of 0 (not difficult at all) to 10 (very difficult). Performance scores for all characteristics, with the exception of ease of use, were verified by two MS neurologist (EW, WV).

\section{Stage 6. Alpha pilot testing}

Iterative alpha pilot testing to evaluate the comprehensibility and usability of the patient decision aid was conducted with healthcare professionals $(n=3(M B, E W, W V)$ ), patient representatives ( $n=2$ (MK, JS)) and an expert in patient decision aid development (TW) from the advisory and project group. Additional patients were recruited using convenience sampling via advertisements on the social media platform of a patient organization, $M S$ Vereniging Limburg. Patients with prior experience with making a decision about DMDs or using DMDs (either with RRMS, CIS or secondary progressive MS (SPMS) and interested in participating in the study were asked to contact the researcher (I.K.). Patients who were thinking of changing their MS treatment were not eligible. Due to low response, snowball sampling was used in addition to the advertisements, via a patient representative in the advisory group and a member of the patient organization. A patient representative asked other eligible patients to participate. Patients were recruited until data saturation was reached.

A researcher (I.K.) visited the patients at home and healthcare professionals in their work environment. Patients and healthcare professionals were instructed to go through the patient decision aid in the presence of a researcher, and to verbalize any comments, thoughts or difficulties they had regarding the wording, functionality and usability of the information provided. The researcher took field notes of any comments, and noted answers to prompt questions seeking clarifying comments and observations about the functionality of the patient decision aid. A topic list was prepared before the interview to ensure that all relevant topics were addressed. If topics had not been fully addressed after the respondent had gone through the patient decision aid, the researcher asked additional questions. Based on the remarks and observations, revisions were made and the adapted prototype was tested with other patients until no new substantial comments came up concerning the usability or comprehensibility of the patient decision aid. The protocol of the alpha pilot testing was reviewed by the Medical Ethics Committee Academic Hospital Maastricht and Maastricht University in the Netherlands (nr. 2018-0434), and it was concluded that the Dutch Medical Research Involving Human Subjects Act (WMO) does not apply. The study was performed in agreement with the ethical standards laid down in the 1964 Declaration of Helsinki and its later amendments. All patients gave their written informed consent. 


\section{Results}

\section{Stage 1. Scope of the patient decision aid}

Patients diagnosed with RRMS or CIS were the target users of the patient decision aid. The patient decision aid includes all brand name and generic DMDs available for patients with RRMS and CIS in the Netherlands, i.e. interferon beta-1b, interferon beta- $1 \mathrm{a}$ IM, interferon beta-1a SC, peginterferon beta-1a, glatiramer acetate, teriflunomide, dimethyl fumarate, natalizumab, alemtuzumab, fingolimod, cladribine and ocrelizumab. The patient decision aid also includes the option of no drug treatment, which is the reference treatment in the patient decision aid. In the absence of an up-to-date national clinical guideline for MS in the Netherlands, the selection of options was informed by the Dutch Healthcare Institute [5] and expert opinions from members of the advisory group.

\section{Stage 2. Assessment of decisional needs}

Nineteen patients with RRMS (79\% female) with a mean (standard deviation, SD) age of 46.8 (8.8) years and a disease duration of 9.5 (8.4) years contributed through focus groups to the identification of important characteristics of DMDs with regard to decision making on treatment. In total, 34 attributes were identified and defined, and 27 attributes were ultimately included in the best-worst scaling survey. The survey was administered to 185 patients (87\% female, with a mean (SD) age of 42 (9.6) years and mean (SD) disease duration of 6.4 (5.9) years, and to 27 neurologists and 33 MS nurses. According to these patients and healthcare professionals, the effect on disease progression, QoL and relapse rate were the most important characteristics for consideration in the treatment decision, followed by safety - according to healthcare professionals - or the severity of side effects - according to patients. The importance scores of all characteristics are presented elsewhere $[19,20]$. Comparison of the average rankings of the ten most important characteristics according to patients and according to healthcare professionals did not reveal substantial differences. After assessment of the importance of the characteristics, the characteristics were categorized by the project group to match criteria for MCDA, i.e. avoidance of overlapping with other criteria and preference dependence (the importance of one criterion is not dependent on the performance of an alternative on another criterion) $[18,24]$. To avoid preferential dependence, characteristics related to common side effects and administration of the DMD were combined into one category each. Because of overlap with "influence on daily life", the administration-related characteristics were combined in a new characteristic "ease of use", which included administration method, frequency, duration, the possibility of drinking alcohol and the ability to drive a car. Relapse rate and severity of relapses were combined into "effect on relapses". To minimize the overlapping of "effect on MS symptoms" with "effect on disability progression", the former was split into the most common and burdensome symptoms, specifically "effect on fatigue" and "effect on cognition" as assessed from the patients' perspective. The effect on disability progression was defined as the change in EDSS score, assessed by a healthcare professional. "Effect on QoL" was included separately, as the 
domains included in QoL measures vary substantially, meaning that not all measures include fatigue and cognition specifically. The characteristics included and omitted from the patient decision aid are presented in Table 1. Ultimately, nine characteristics of DMDs for RRMS patients were included. For CIS patients, a tenth characteristic was included after consultation with the advisory group, i.e. "time to definite MS diagnosis". The advisory group agreed with the selection of the characteristics. 


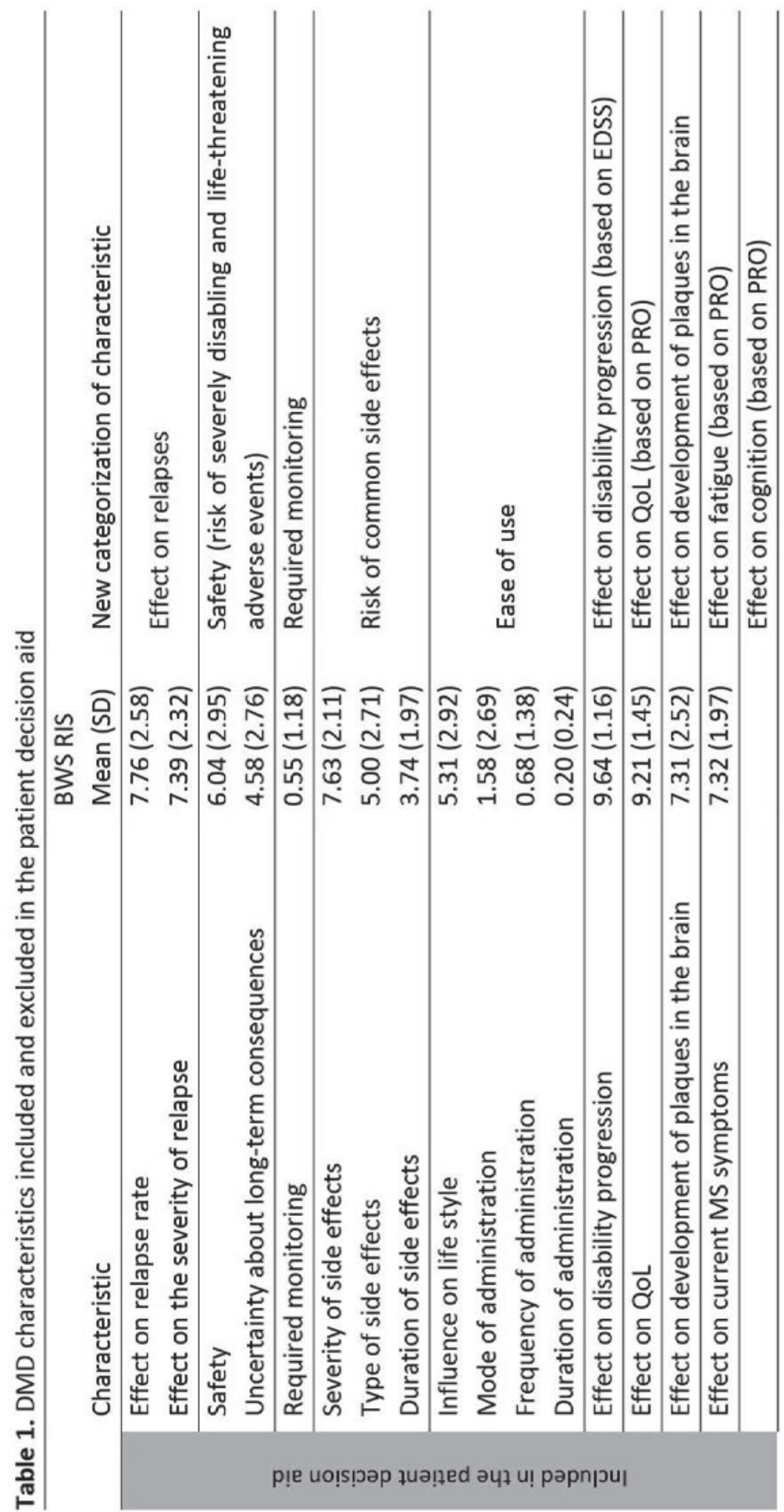




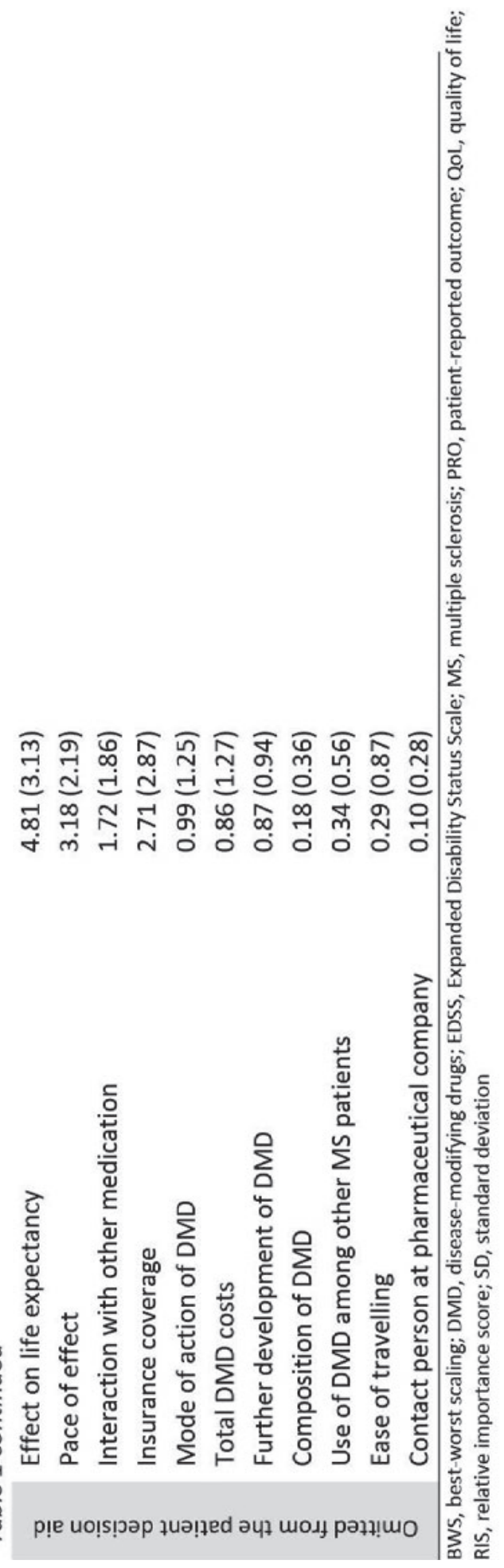




\section{Stage 3. Format}

The underlying algorithms needed in MCDA to estimate the weightings of characteristics and produce rankings of alternatives require a computer-based delivery to enable the embedding of MCDA in a patient decision aid. The patient decision aid was, therefore, built in a survey software combined with an MCDA-software, which allowed for the immediate alignment of the patient's preferences with the ranking of treatment options.

\section{Stage 4. Review and synthesis of evidence}

The search in Medline (Pubmed) identified 28 records, of which 7 network meta-analyses were assessed as potentially relevant for the outcome "effect on relapses" and "effect on disease progression". Three additional health technology assessment reports including network meta-analyses [25-27] were identified through experts. The supporting information includes a table (S1 Table) presenting the identified studies according to the search date, the DMDs included in the network meta-analysis and the outcomes included. The most comprehensive and recent network meta-analysis was selected [22]. Studies have shown that generic glatiramer acetate is as effective as brand glatiramer acetate and has similar side effects [28]. Therefore, outcomes for the generic DMD were equated to the effects and adverse effects of the brand.

The review for the effects of DMDs on QoL identified 14 RCTs reporting on any QoL measurement instrument for measuring the effects of the DMDs of interest. In these RCTs, nine different QoL-instruments were used. Reporting on the patient-reported outcomes QoL and its subdomains fatigue and cognition was often incomplete and inconsistent. QoLinstruments were used in 35 instances, of which in only 11 instances differences in change scores from baseline to the follow-up point between the DMD and the comparator were (partly) reported on subdomains of the QoL-measures. Contacting authors did not result in the inclusion of any additional data of interest in the patient decision aid, mainly due to low response rates. Since the meta-analysis and QoL-review did not include data for cladribine, parameter values for effect measures for cladribine were based on data aggregated by Giovannoni et al. [29] or from the pivotal study [29, 30].

For MRI outcomes, the network meta-analysis published by the Canadian Agency for Drugs Technology and Health was assessed as most relevant, based on the operationalization of the outcomes in terms of the proportion of patients with gadolinium-enhancing lesions and with new or enlarging T2-hyperintense lesions; this meta-analysis included data for natalizumab, dimethylfumarate, fingolimod, teriflunomide and interferon beta-1a SC. Through the additional database search specifically for MRI outcomes, a review reporting additional data on MRI outcomes was identified [31]. For five DMDs (aletmzumab, dimethylfumarate, fingolimod, ocrelizumab and teriflunomide), the data of multiple studies were pooled. For three DMDs (glatirameer acetate $40 \mathrm{mg}$, interferon beta-1a SC and interferon beta-1b), no data or data for only one of the dimensions of MRI outcomes were found. 


\section{Stage 5. Development of prototype}

The patient decision aid was embedded in the software Elicia/Annalisa (Maldaba). Fig 1 shows several screen shots, translated from Dutch for the purpose of this publication, illustrating the format and content of the first prototype of the patient decision aid. The patient decision aid consisted of four parts.

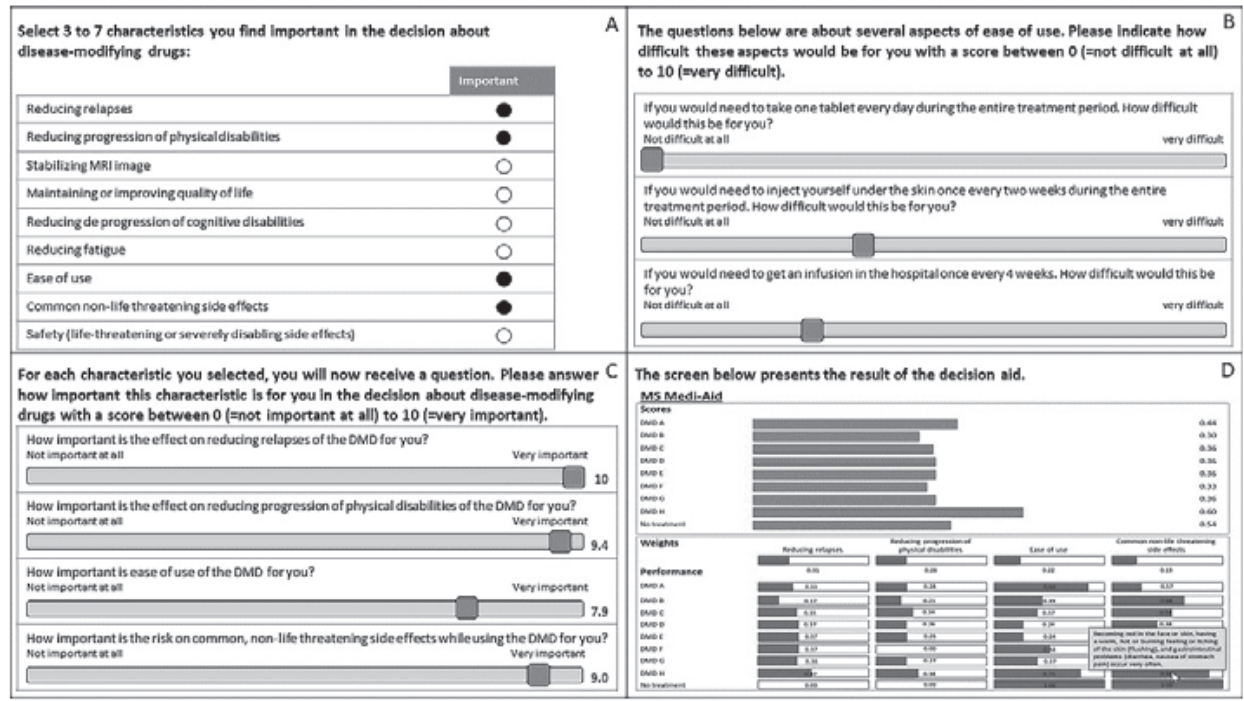

Fig 1. Screen shots of the patient decision aid for $\mathrm{MS}^{*}$

${ }^{*}$ The screenshots have been recreated from the Elicia/Annalisa ${ }^{\circledR}$ software for translation of the the Dutch content to English. Therefore, the layout may deviate slightly from the layout in the Elicia/Annalisa software.

First, general information is provided about MS, description of the different MS disease courses and the treatment options for RRMS. General information about the treatment options includes a listing of all available options, an explanation of the trade-off in treatment characteristics that patients and their healthcare professionals need to make, and a description of the treatment characteristics.

Second, the patient needs to answer a number of questions about their personal demographic characteristics and medical history relevant to the selection of suitable treatment options based on recommendations for clinical practice [5]. These characteristics are gender, type of MS, whether first-line and/or second-line treatment options are considered, comorbidity, current medication use, if the patient is pregnant or breastfeeding or wishes to have children within a year.

Third, the patient decision aid contains a value elicitation exercise to determine what treatment characteristics are important for the patient to consider in his/her treatment decision and to attach weights to each characteristic. The value elicitation exercise consists of two parts. Initially, the patient selects three to seven characteristics he/she wants to include in his/her decision (Fig $1 \mathrm{~A}$ ). Next, the patient rates the importance of each characteristic for the decision on a scale from 0 to 10, with 10 being very important, using 
sliders (Fig 1B/C). A direct rating method was selected by considering the cognitive burden for patients and the precision required [24].

Fourth, a ranking of treatment options is presented according to their suitability to the patient's preferences. The ranking is presented as separate bars for each DMD. Each bar is compiled by combining the performance scores based on evidence and literature and the weights of the characteristics according to the individual patient using an additive model [24]. The overall value per DMD is calculated in two steps. First, the performance score and weight of each characteristic are multiplied. Second, all characteristic scores are added. The bar representing the overall score for each DMD is broken down in fragments illustrating the contribution each characteristic makes to the overall score of the DMD. The ranking is purposed to stimulate a discussion between the patient and the healthcare professional about the treatment options by showing the patient's preferences for treatment characteristics, the performance of the treatment options on each treatment characteristic and how these two relate to each other visually in bars (Fig 1D). Using pop-ups, the performance of treatment options is explained in text.

For each DMD a performance score per characteristic was calculated. To calculate a weighted risk of the common side effects for each DMD, first, an inventory of all the common side effects associated with any of the DMDs and the associated risks was made. Over 300 different side effects were identified. Two members of the project group (IK and $\mathrm{PJ})$ clustered related or similar side effects into broader categories to reduce the extensive number of side effects to 36 categories. The risk of experiencing a common side effect during the use of a DMD was assigned a score between 0 (=high risk) and 1 (=low risk): $0=$ reported in $\geq 10 \%$ of patients using the DMD; $0.2=1-10 \% ; 0.4=0.1-1 \% ; 0.6=<0.1 \% ; 0.8=$ incidental report; $1=$ never reported. Users of the patient decision aid were able to indicate which side effects, with a maximum of five, they would prefer to avoid. Next, patients rated how burdensome these side effects would be for them. The performance scores of DMDs were calculated accordingly: the risk score per side effect was multiplied by the rating for burden and the scores across all side effects were added per DMD and divided by the maximum possible score (i.e. score of 36 in case of no side effects at all).

One of the neurologists indicated during the verification process that the relative performance on MRI outcomes of the first-line DMDs were too high or too low in his experience. This could result from the heterogeneity in operationalization, measurement and reporting the MRI outcomes in pivotal studies, resulting in missing or only partial available MRI outcome estimates. Of the first-line DMDs, only for teriflunomide was sufficient data available for both aspects considered in the MRI outcome. Therefore, in absence of more precise data, no distinction in performance on MRI outcomes was made for these DMDs, and the performance scores for first-line DMDs were equated to teriflunomide.

For DMDs' performance on safety profiles, first line, first generation DMDs scored 0.9 (relatively safe); first line, second generation DMDs scored 0.8 (due to less extensive experience with the DMD); and second line DMDs scored 0.6. Following suggestions of two neurologists, an exception was made for natalizumab, with regard to the JC-virus status of 
patients. If patients were negative, the performance of natalizumab was set at 0.8 , as the associated risk of serious adverse events is substantially lower.

\section{Stage 6. Alpha pilot testing}

Alpha testing was conducted in three rounds. First, a neurologist, an MS nurse and three patients were asked for feedback. Accordingly, revisions were made to the patient decision aid. Next, 10 additional patients were interviewed and observed. The characteristics of patients included in rounds 1 and 2 are presented in Table 2 . No new major comments came up in the last three interviews, indicating that data saturation was reached. Last, the neurologist from the first round, two additional neurologists and an expert in patient decision aid development provided feedback. The healthcare professionals had a lot of experience in the treatment of MS patients with DMDs, were from different hospitals in the Netherlands and were currently working in MS care, except for one neurologist, who was working as neurologist-researcher in MS. Respondents indicated that the patient decision aid has the potential to be a valuable addition to the decision making process. However, interviews and observations of respondents also identified issues and areas for improvement of the patient decision aid; these were clustered in three overall themes: content and framing, weighting methods for the importance of characteristics according to the patient, and the presentation of the result of the patient decision aid (Table 3). These three themes are discussed below.

Table 2. Characteristics of patients $(n=13)$ involved in the alpha testing

\begin{tabular}{lll}
\hline & & $\mathrm{N}(\%)^{*}$ \\
\hline Gender & Female & $10(77)$ \\
Age (years) & Male & $3(23$ \\
& Mean \pm SD & $53.9 \pm 9.0$ \\
Highest educational level & Range & $35-64$ \\
& Pre-vocational education & $3(23)$ \\
& Vocational education & $3(23)$ \\
MS type & Higher education & $7(54)$ \\
& RRMS & $11(85)$ \\
Time since MS diagnosis & SPMS & $2(15)$ \\
(years) & Mean $\pm S D$ & $17.0 \pm 11.6$ \\
Experience with DMDs & Range & $1-38$ \\
& Yes & $13(100)$ \\
\hline
\end{tabular}

\footnotetext{
* unless otherwise specified
}

MS: multiple sclerosis; RRMS: relapsing-remitting multiple sclerosis; SD: standard deviation; SPMS: secondary progressive multiple sclerosis

\section{Content and framing}

Three major issues were identified by healthcare professionals and/or patients regarding the content and framing. First, while the patient decision aid initially included only general information on RRMS and CIS, a healthcare professional in round 1 of the pilot test indicated 
that general information about the progressive disease courses would be useful in painting a complete picture for the patient. This information was added to the patient decision aid, including figures sketching the extent to which disabilities could increase over time in the different disease courses. In round 2, most patients agreed that the information about all disease courses was useful. Some patients commented that the figures would be more logical if they would illustrate how physical abilities could decrease instead of how physical disabilities could increase. No majority for one of the two possibilities was identified during the interviews with the patients, nor with the professionals in round 3 . Therefore, figures presenting increase in physical disability were used, as this was regularly used in the clinical practice of the healthcare professionals involved.

A second comment on the patient decision aid made by a nurse in round 1 and reinforced by a number of patients in round 2 concerned the query about selecting the side effects which the patient would like to avoid. The list of 36 side effects was too overwhelming for patients and off-putting. When confronted with the list, a number of patients stated: "I don't want to get any of them", wanting to select all side effects. Because many patients had this reaction to the question, the list of 36 side effects was reduced to ten side effects that occur very often or often when using any of the DMDs. The question about side effects was adapted to: "Which side effect would you definitely want to avoid?" The algorithm for calculating the performance score of DMDs on the side effects was adapted. Any DMD with a risk of occurring in $1 \%$ or more of patients using the DMD would score zero on the side effects. In round 3, no new comments on the cognitive burden for patients of answering this question were raised by the professionals.

As a third issue, in all rounds, the neurologists, MS nurses and the patients indicated that questions regarding the type of MS, comorbidity, other substance or medication use and whether patients are eligible for first-line and/or second-line medication could be difficult to answer, despite adaptations to the formulation of these questions in between rounds, with the goal of easing the understandability of the questions. Two solutions were considered appropriate and were discussed in rounds 2 and 3 with patients and healthcare professionals: 1 ) the patient receives a note summarizing their medical history, which the patient can copy into the patient decision aid; or 2) the healthcare professional (treating neurologist or MS nurse) fills out the specific questions on medical history before the patient uses the patient decision aid. Beta pilot testing would need to show which method is most feasible for implementation.

In addition, during all rounds a number of textual remarks were processed to clarify information or to match explanations currently given by healthcare professionals in clinical practice. Examples are to illustrate cognitive disabilities with examples and to elaborate on the role of monitoring in securing safety during second line drug use.

\section{Weighting methods for the importance of characteristics according to the patient}

During the first round of the alpha testing, a neurologist questioned whether the direct rating method would be the best approach as a weighting method as "all patients would rate the characteristics as very important." In round 2, observations and interviews with 
patients did not identify any problems for patients to weight characteristics using the direct rating methods, but showed indeed that the direct rating method resulted in relatively flat distributions in importance scores. The majority of the patients rated the selected characteristics with the same or almost the same score, most often a 9 or 10, representing "very important". In round 3, several other methods were considered and discussed with the professionals. Other methods, such as Simple Multi-Attribute Rating Technique and Point Allocation [24], were discussed with the professionals as alternatives to direct rating, since these methods specifically incite patients to compare the characteristics according to their relative importance. However, the neurologists, expert in patient decision aid development and the project group regarded these methods as too difficult and cognitively burdensome for patients. The risk of flatter distributions of importance scores for the characteristics in the direct rating method was therefore accepted, as characteristics could in theory be equally important for the patient in the decision.

In round 2, it became apparent that the initial format for patients to weight characteristics using sliders was problematic in several ways: the interval of 1 decimal was distracting; scoring 0 was difficult because respondents had to move the slider from zero and back; and in terms of coordination the sliders were difficult to use, especially using the mouse pad of a laptop. Patients indicated that they would prefer simply selecting the weight between zero and ten using check boxes. Adaptations were made accordingly.

\section{Presentation of the result of the patient decision aid}

Three major challenges were identified regarding the presentation of the result of the patient decision aid: ensuring that the patient understands the ranking of the DMDs according to the preferences, ensuring that healthcare professionals understand how DMDs have been filtered out based on the patient's eligibility, and ensuring that patients have both sufficient and structured information about the most suitable DMDs. From round 1, it became apparent that the result screen presenting the ranking of DMDs, the weightings of the characteristics and the performance levels of the DMDs according to the characteristics could be overwhelming for patients. Therefore, the result screen and its explanation underwent a number of adaptations throughout the pilot testing between the different rounds and, within round 2, between smaller groups of patients. After round 1 , the choice was made to present only the ranking of the DMDs to the patient and to collapse the information about the weighting of the characteristics and the performance scores of the DMDs. The patient would be able to fold out the additional information in the same screen. Instructions explaining the functionalities of the result screen were given one page earlier. This format was tested in subsequent rounds with patients. The most prominent challenge was to instruct patients adequately about the functionalities while considering the information processing capacities of MS patients: elaborating on the explanation was too tiresome, yet shorter explanations resulted in misunderstandings. In the different iterations, the instructions were constantly adapted in response to the patients' comments by adding figures, changing the layout to ease reading and adapting formulations of the instructions. Even so, most patients needed additional instructions from the interviewer to 
fully understand the results. Once the results were fully understood, the patients were enthusiastic about the richness of the patient decision aid: "It helps to deepen my knowledge and prepare me for the consultation." In round 3, the project team made the choice to present a simplified version of the result screen to the patient first, only presenting the rankings of the DMDs, without the ability to fold out extra information (Fig 2A). This limited the amount of instructions - presented just above the ranking - that the patient needs to understand all of the functions of the result screen. Next in the patient decision aid, the patient is asked whether he/she want to learn more about how the ranking was compiled. A subsequent screen includes the patient's weights for characteristics and the DMDs' performances on the characteristics in bars, with pop-ups explaining the bars (Fig $2 \mathrm{~B})$. This way, the patient decision aid was adapted to fit patient preferences and cognitive abilities in processing the amount of information about the DMDs better. After these adjustments, the patient decision aid expert and the neurologists still questioned whether the patient decision aid would be suitable for use by patients with low or middle levels of education. Beta pilot testing should show whether supervision by a trained MS nurse is needed when going through the patient decision aid and whether this delivery format is feasible in clinical practice.

In round 1, the neurologist commented that an understanding is needed of how questions concerning the patient's eligibility for the DMDs (e.g. type of MS, comorbidity) affect the selection of the DMDs in the patient decision aid for each individual patient. Therefore, a summary page was included at the end of the patient decision aid stating all criteria that affected the selection of DMDs suitable for the patient, the patient's answers and which DMDs were omitted as a result from the patient decision aid. If a patient answered "don't know", this was also presented. The summary page was further evaluated in the following rounds, and no additional comments were made by the respondents.

The result screen (the ranking and optionally the weighting of characteristics and the performance scores of the DMDs), the schematic overview of the DMDs' characteristics and the summary of the assessment of the patient's eligibility for the DMDs can be printed and/or sent to the healthcare professional.

In round 2, a couple of patients commented that they would prefer additional information on the result screen, summarizing the most suitable DMD options. One patient commented: "I would not be able to choose based on this [the ranking]." Therefore, in deliberation with the patients, a function was added through which the patient could select the three DMDs he/she wants to read more about, based on the initial ranking of the DMDs. This information, which is identical to the information in the pop-ups for the performance bars, is provided in a tabular form presenting the characteristics of the three DMDs side by side. 


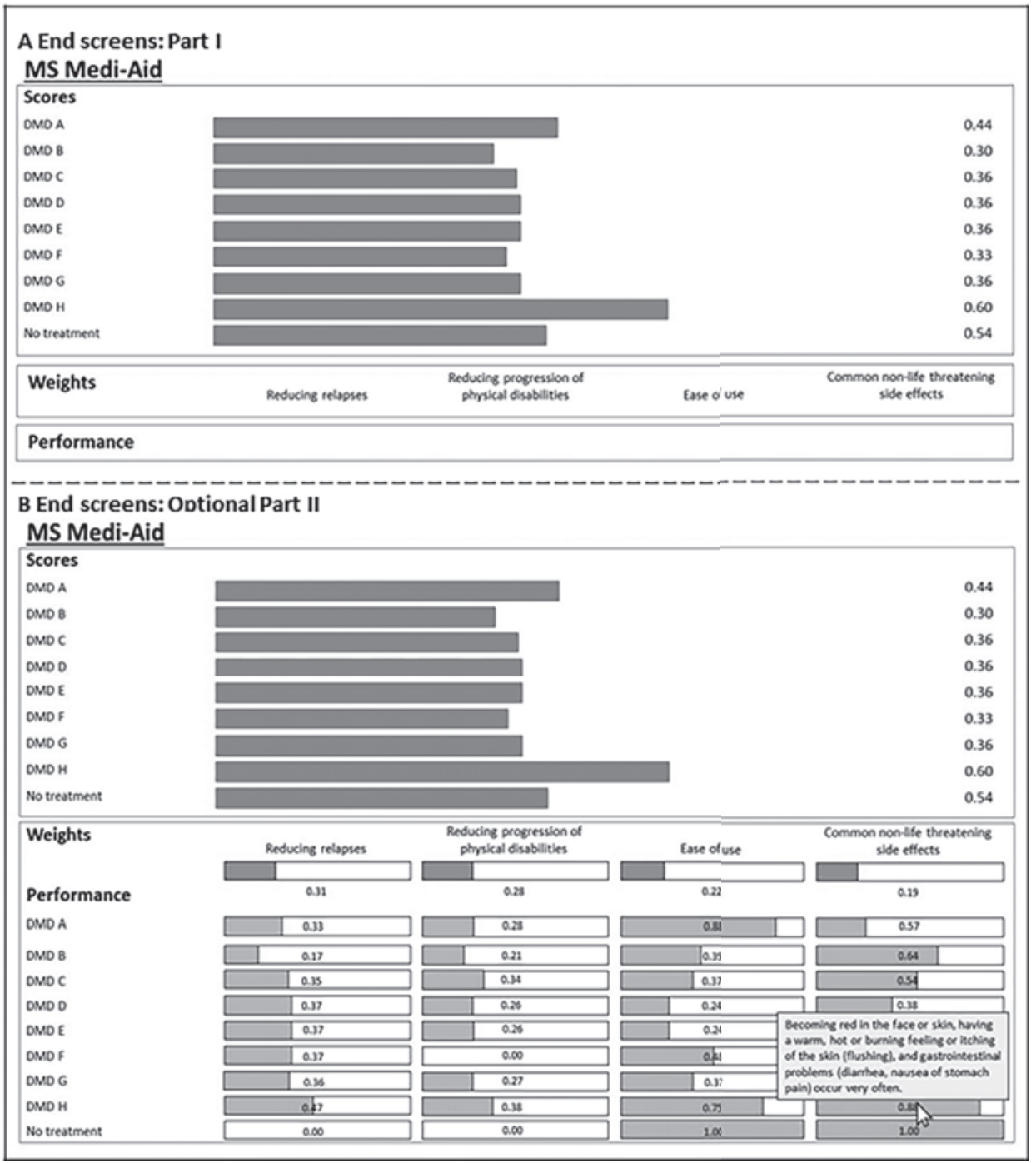

Fig 2. End screens: Parts I and II

\section{Other minor remarks}

A number of minor remarks regarding the format, scope and functionality of the patient decision aid were made in all rounds of the pilot testing, and adaptations were made accordingly where possible (S2 Table). However, technical functionalities of the software limited certain desired adjustments, such as spacing between text, enlarging check options, accentuating the cursor on the screen, using progress bars instead of page numbers, including menu tabs to switch between chapters, using pop-ups for more information and additional reading. Before beta-testing of the patient decision aid, a switch to different software will be made so that additional functionalities and layout requirements can be incorporated. 
Table 3. Major comments and adaptations in the alpha test

\begin{tabular}{ll}
\hline Round & Major comment \\
\hline 1 & $\begin{array}{l}\text { Direct rating does not force patient to } \\
\text { differentiate in importance of } \\
\text { characteristics }\end{array}$ \\
2 & $\begin{array}{l}\text { Several patients rated all characteristics as } \\
\text { very important. }\end{array}$ \\
3 & $\begin{array}{l}\text { Other weighting methods were found to } \\
\text { be too complex. }\end{array}$ \\
2 & $\begin{array}{l}\text { Intervals of } 1 \text { decimal are too small. } \\
2\end{array}$ \\
Sliders are difficult for scoring zero. \\
Sliders are difficult if patient's \\
coordination is reduced.
\end{tabular}

Rating side effects

Adaptations made

s by patient

Observations of rating by patients in round 2 .

Alternative weighting methods (i.e. Simple Multiattribute Rating Scale, (SMART) and Point Allocation) were incorporated in the patient decision aid as a try-out.

Direct rating was applied.

Check boxes replaced the sliders.

Framing of questions adapted: "Are you willing to accept higher risks of severe adverse events, for more efficacy?" Explanation of medications was added.

Question whether to include all DMDs was deleted.

Since a 'don't know' option was available, no adjustments were made.

Patients may receive a note summarizing their medical history or the healthcare professional fills out the question for the patient.

1 Do not include all 36 side effects. It could scare people.

2 The list of side effects puts off: "I don't want to get any of them."

3 No comments were made.

List was reduced to the 10 most common side effects.

Disease courses

1 Include the progressive types of MS and add illustrations to clarify the differences in disease courses.

$2 \quad$ Figures should illustrate the decline in abilities, instead of the increase in disabilities.

Information and figures were added.

Contradictory reactions. Figures were kept as they were to connect to the verbal explanation of the disease course. 
3

Consider whether to illustrate the decline in abilities, instead of the increase in disabilities.

\section{Summary page}

1

The healthcare professional needs to know how the patient's answers affected the selection of DMDs.

2 no additional comments

3

no additional comments

End screen

The amount of information on the end screen is overwhelming.

2

The instructions are too elaborate and difficult to understand.

3

The patient decision aid may not be suitable for patients to go through individually, except for highly-educated patients. Consider whether an MS nurse should guide the patient in the use of the patient decision aid.

\section{Additional reading}

$2 \quad$ Preference for the possibility of reading more information on DMDs of choice.

No additional comments were made.
Summary page was added, including information about DMD selection based on the patient's eligibility.

Information on weighting and performance scores of the DMDs was made optional. Instructions were added to explain the additional functions to patients.

The instructions were adjusted a number of times and tested with new patients. Visual instructions were added in figures which showed how to access additional information. Still, instructions were too difficult for all patients to understand the whole end screen. The end screen was divided in two parts. The first part presents only the rankings of the DMDs and explanations focus only on explaining these rankings. Access to the second part, which explains in depth how the rankings were compiled, is optional.

Beta test should show whether the guidance of an MS nurse is feasible and desirable for patients.

An option to select three DMDs to read more about was included. The patient decision aid provides a schematic overview of the selected DMDs, according to the characteristics. 


\section{Discussion}

\section{Summary}

A systematic approach was used to develop an online patient decision aid about DMDs for the treatment of MS. The approach consisted of defining the scope, assessing users' decisional needs, establishing a format, reviewing the evidence, developing a prototype and iteratively alpha testing the prototype. The alpha test showed the prototype had some issues regarding the content and framing, the methodologies used for weighting the options and the end screen. Adaptations were made accordingly, but room for improvement remains and some issues should be further studied, since only alpha testing has been conducted thus far.

\section{Strengths and weaknesses of the patient decision aid}

The developed patient decision aid differs from most other patient decision aids in the approach used. The MCDA-based approach was applied as we hypothesized that this approach averts putting a high cognitive burden on the MS patient to study and understand all available DMDs for the treatment of MS by performing an explicit trade-off of (conflicting) characteristics according to the patient's preferences. Using the approach in our patient decision aid, the patient is able to make a selection of treatment options he/she wants to read more about. The deliberation and consultation with the healthcare professional can then be focused on the selected DMDs, as these best fit the patient's preferences. The application of the MCDA approach did, however, also introduce new difficulties for patients in terms of understanding the ranking of the treatment options and how ranking was compiled. Changes in the delivery of the patient decision aid could support patients in this. Whether the MCDA-approach actually reduces overall cognitive burden should be further studied, preferably by comparing decision-making with the MCDA-based patient decision aid to decision-making without the decision aid or with the decision aids without decision analysis.

The application of the MCDA approach does mean that the patient decision aid may not fulfil all criteria for patient decision aids as established by the IPDAS [32]. For example, in the patient decision aid it is optional for patients to read information about all treatment options, including the probabilities on outcomes, risks and procedures involved; this information is provided per DMD is after the preference elicitation. Because the patient decision aid explicitly includes the patient's preferences in the ranking, it is only optional for the patient to read the information. This approach increases the personalization of the patient decision aid to the patient's informational needs, but could decrease the patient's knowledge gain about all treatment options in comparison with other patient decision aids. The MCDA approach resulted in other challenges as well, specifically concerning the translation of the outcome estimates into performance scores between zero and one. Comparability of the DMDs for a specific characteristic is difficult when some clinical data is 
lacking or has not been completely reported, such as the data for MRI outcomes. Performance scores were in that case set to zero, the same score if no significant difference between the treatment option and placebo was found. We, however, acknowledge that lack of evidence is not the same as no efficacy, and lower levels of evidence, such as results from observational studies and expert opinions. Validation of the performance scores with a larger group of clinical experts is needed to increase the objectivity of the scores. Moreover, inclusion of additional data from Phase IV studies, including observational ones, could enhance the overall picture of all treatment options.

The alpha testing was primarily aimed at establishing the content, usability and comprehensibility of the patient decision aid. Further development of the patient decision aid is still needed, such as improvements in layout and functionalities (which were limited by the software), and the appropriate delivery of the patient decision aid needs to be tested with regard to maximizing understanding of the results (i.e. whether the aid should be used by the individual patient or used under the supervision of a trained nurse).

This patient decision aid contains components specifically for MS patient in the Netherlands. The patient decision aid could, however, be transferred to other countries. Adaptations to the content of the patient decision aid should be made for it to fit countryspecific contexts, for instance regarding eligibility criteria for DMDs and, possibly, regarding aspects that should be included (e.g. out-of-pocket expenses might be important in countries where DMDs are not fully covered by health insurance).

\section{Recommendations and implications for implementation and further research}

The patient decision aid is designed and intended to support discussion about treatment options and patient's preferences between the patient and healthcare professional to ultimately make a shared decision about starting DMDs. Therefore, the patient decision aid must not replace the consultation with the healthcare professional, nor should the result of the patient decision aid dictate what the "best" DMD would be.

In absence of a clinical guideline from the Dutch Society for Neurology, the patient decision aid has been developed based on the best available evidence in the literature and following recommendations from the Dutch Healthcare Institute. The guideline is currently in development. To facilitate implementation, it is recommended that patient decision aids relate closely to clinical guidelines [33]. Therefore, the patient decision aid should be reviewed and updated, if needed, as soon as the clinical guideline has been completed, and formal relations with these clinical guidelines should be established. Moreover, the field for MS treatments is developing quickly, making the decision for treatment only more complex as new treatments come to market. Keeping the patient decision aid, and for that matter the clinical guidelines, up to date is challenging, but of great importance. The online format of the patient decision aid ensures that changes to its content, i.e. new treatment options, changes in eligibility criteria or new evidence about outcomes and burden, will reach users immediately. However, monitoring these developments will be challenging. Structures should be set up to ensure immediate updates when new evidence becomes available. 
Translating evidence into performance scores was more challenging for some characteristics than others, such as safety and MRI outcomes. Safety does not translate easily to a score between 0 and 1 because the data is textual and, although based on among others the summary of product characteristics, the translation introduces subjectivity. Moreover, the reporting of outcome measures on DMDs was inconsistent and there is a gap in high level evidence about the comparative effectiveness of DMDs on a number of characteristics, such as quality of life, MRI outcomes, and cognition. Lower level evidence, such as observational studies or expert opinions could fill these gaps until higher level evidence becomes available. Delphi studies could be useful to reach consensus among experts regarding the performance scores.

The patient decision aid has been user tested only with patients who had previously made a decision about DMDs, and were not considering switching treatment at the time of testing. Overall, the participants in the alpha test were positive about the potential use of the patient decision aid, but since implementation of the patient decision aid was not yet pilot tested, participants could only speculate and the actual added value for shared decision-making should be further studied. Further development of the patient decision aid is needed regarding the verification of the rankings made by the decision aid, including the influence of uncertainty about effect estimates, and improving understandability of the patient decision aid through evaluation of the required health literacy, and adaptation of the delivery of the patient decision aid and validation of the patient decision aid. Afterwards, a beta pilot test needs to be conducted to test the feasibility of implementing the patient decision aid in clinical practice with patients actually making the treatment decision, and to evaluate the potential benefits of the patient decision aid on the quality of the decision as other patient decision aids have been shown to demonstrate [12]. It has also been argued that patient decision aids positively affect treatment persistence and treatment adherence [34], and therefore increase health outcomes and decrease the use of healthcare resources [35], although evidence supporting this is still limited [12, 35]. A randomized controlled trial comparing the patient decision aid to usual care should be conducted to assess these effects and should evaluate what the influence is on the patient's cognitive burden in making the decision.

\section{Conclusion}

We systematically developed and alpha tested an MCDA-based online patient decision aid about DMDs for MS. MCDA-based decision support tools could be perceived as a black box if the developmental process and content of the tool have not been made transparent. This paper aimed to provide more insight into the developmental process and challenges faced during this process. Issues identified in the prototype were resolved as much as possible, though some issues remain. Whether adaptations in the delivery of the patient decision aid overcomes these issues, should be further studied. Further development is needed, 
including beta pilot testing to evaluate the feasibility of implementation in clinical practice, followed by a randomized controlled trial to assess clinical and economic effects.

\section{Acknowledgment}

We thank Trudy van der Weijden and Jack Dowie for their helpful advice during the research design process and during the development of the patient decision aid. We would also like to show our gratitude to Manita Karman, Jose Savelkoul and Laura van der Velde and the other members of the advisory group for sharing their valuable insights and expertise. We thank the patients with MS for their time and comments during the alpha testing of the patient decision aid.

\section{Source of funding}

Financial support for this study was provided by an unrestricted donation to the Limburg University Fund by Bayer B.V. The funding agreement ensured the authors' independence in designing the study, interpreting the data, writing, and publishing the report. 


\section{References}

1. Lublin FD, Reingold SC, Cohen JA, Cutter GR, Sorensen PS, Thompson AJ, et al. Defining the clinical course of multiple sclerosis: the 2013 revisions. Neurology. 2014;83(3):278-86. Epub 2014/05/30. doi: 10.1212/wnl.0000000000000560.

2. Burden of illness of multiple sclerosis: Part II: Quality of life. The Canadian Burden of Illness Study Group. Can J Neurol Sci. 1998;25(1):31-8. Epub 1998/04/09.

3. Nortvedt MW, Riise T, Myhr KM, Nyland HI. Quality of life in multiple sclerosis: measuring the disease effects more broadly. Neurology. 1999;53(5):1098-103. Epub 1999/09/25. doi: 10.1212/wnl.53.5.1098.

4. Riazi A, Hobart JC, Lamping DL, Fitzpatrick R, Freeman JA, Jenkinson C, et al. Using the SF-36 measure to compare the health impact of multiple sclerosis and Parkinson's disease with normal population health profiles. J Neurol Neurosurg Psychiatry. 2003;74(6):710-4. Epub 2003/05/20. doi: 10.1136/jnnp.74.6.710.

5. Entwistle V. Patient involvement in decision making: the importance of a broad conceptualization. In: Edwards A, Elwyn G, editors. Shared decision making in health care: achieving evidence-based patient choice. 2nd ed. Oxford: Oxford University Press; 2009.

6. Rae-Grant A, Day GS, Marrie RA, Rabinstein A, Cree BAC, Gronseth GS, et al. Practice guideline recommendations summary: Disease-modifying therapies for adults with multiple sclerosis: Report of the Guideline Development, Dissemination, and Implementation Subcommittee of the American Academy of Neurology. Neurology. 2018;90(17):777-88. Epub 2018/04/25. doi: 10.1212/wnl.0000000000005347.

7. Charles C, Gafni A, Whelan T. Shared decision making in the medical encounter: what does it mean? (or it takes at least two to tango). Soc Sci Med. 1997;44(5):681-92. Epub 1997/03/01.

8. Ben-Zacharia A, Adamson M, Boyd A, Hardeman P, Smrtka J, Walker B, et al. Impact of shared decision making on disease-modifying drug adherence in multiple sclerosis. Int J MS Care. 2018;20(6):287-97. Epub 2018/12/21. doi: 10.7224/1537-2073.2017-070.

9. Heijmans M, Brabers A, Rademakers J. Health literacy in Nederland. Utrecht: Nivel, 2018.

10. Kobelt G, Thompson A, Berg J, Gannedahl M, Eriksson J. New insights into the burden and costs of multiple sclerosis in Europe. Mult Scler. 2017;23(8):1123-36. Epub 2017/03/10. doi: $10.1177 / 1352458517694432$.

11. Marrie RA, Reingold S, Cohen J, Stuve O, Trojano M, Sorensen PS, et al. The incidence and prevalence of psychiatric disorders in multiple sclerosis: a systematic review. Mult Scler. 2015;21(3):305-17. Epub 2015/01/15. doi: 10.1177/1352458514564487.

12. Stacey $D$, Légaré $F$, Lewis $K$, Barry MJ, Bennett CL, Eden KB, et al. Decision aids for people facing health treatment or screening decisions. Cochrane Database Syst Rev. 2017;(4). doi: 10.1002/14651858.CD001431.pub5.

13. Coulter A, Stilwell D, Kryworuchko J, Mullen PD, Ng CJ, van der Weijden T. A systematic development process for patient decision aids. BMC Med Inform Decis Mak. 2013;13 Suppl 2:S2. Epub 2013/01/01. doi: 10.1186/1472-6947-13-s2-s2.

14. Joseph-Williams N, Newcombe R, Politi M, Durand MA, Sivell S, Stacey D, et al. Toward minimum standards for certifying patient decision aids: a modified delphi consensus process. Med Decis Making. 2014;34(6):699-710. Epub 2013/08/22. doi: 10.1177/0272989×13501721.

15. Kasper J, Kopke S, Muhlhauser I, Nubling M, Heesen C. Informed shared decision making about immunotherapy for patients with multiple sclerosis (ISDIMS): a randomized controlled trial. Eur J Neurol. 2008;15(12):1345-52. Epub 2008/12/04. doi: 10.1111/j.1468-1331.2008.02313.x.

16. Kopke S, Solari A, Rahn A, Khan F, Heesen C, Giordano A. Information provision for people with multiple sclerosis. Cochrane Database Syst Rev. 2018;10:Cd008757. Epub 2018/10/15. doi: 10.1002/14651858.CD008757.pub3. 
17. Witteman HO, Dansokho SC, Colquhoun H, Coulter A, Dugas M, Fagerlin A, et al. User-centered design and the development of patient decision aids: protocol for a systematic review. Syst Rev. 2015;4:11. Epub 2015/01/28. doi: 10.1186/2046-4053-4-11.

18. Thokala P, Devlin N, Marsh K, Baltussen R, Boysen M, Kalo Z, et al. Multiple criteria decision analysis for health care decision making--an introduction: report 1 of the ISPOR MCDA Emerging Good Practices Task Force. Value Health. 2016;19(1):1-13. Epub 2016/01/23. doi: 10.1016/j.jval.2015.12.003.

19. Kremer IE, Evers SM, Jongen PJ, van der Weijden T, van de Kolk I, Hiligsmann M. Identification and prioritization of important attributes of disease-modifying drugs in decision making among patients with multiple sclerosis: a nominal group technique and best-worst scaling. PLoS ONE. 2016;11(11):e0164862. Epub 2016/11/05. doi: 10.1371/journal.pone.0164862.

20. Kremer IEH, Evers S, Jongen PJ, Hiligsmann M. Comparison of preferences of healthcare professionals and MS patients for attributes of disease-modifying drugs: a best-worst scaling. Health Expect. 2018;21(1):171-80. Epub 2017/07/25. doi: 10.1111/hex.12599.

21. Li T, Puhan MA, Vedula SS, Singh S, Dickersin K. Network meta-analysis-highly attractive but more methodological research is needed. BMC Med. 2011;9:79. Epub 2011/06/29. doi: 10.1186/1741-7015-9-79.

22. Institute for Clinical and Economic Review. Disease-modifying therapies for relapsing-remitting and primary-progressive multiple sclerosis: effectiveness and value.2017 [14 December 2018]. Available from: https ://icer-revie w.org/wp-conte nt/uploa ds/2016/08/CTAF_MS_Final Repor t_03061 7.pdf.

23. Jongen PJ. Health-related quality of life in patients with multiple sclerosis: impact of diseasemodifying drugs. CNS Drugs. 2017;31(7):585-602. Epub 2017/06/14. doi: 10.1007/s40263-0170444-x.

24. Marsh K, M IJ, Thokala P, Baltussen R, Boysen M, Kalo Z, et al. Multiple criteria decision analysis for health care decision making-emerging good practices: report 2 of the ISPOR MCDA Emerging Good Practices Task Force. Value Health. 2016;19(2):125-37. Epub 2016/03/30. doi: 10.1016/j.jval.2015.12.016.

25. Canadian Agency for Drugs and Technologies in Health. CADTH therapeutic review. Comparative clinical and cost-effectiveness of drug therapies for relapsing-remitting multiple sclerosis. 2013 Oct; (CADTH Therapeutic Review vol.1, no. 2b). Available from: http://www.cadth.ca/media/pdf/TR0004_RRMS_ScienceReport_e.pdf.

26. Couto E, Hamidi V, Ringerike T, Odgaard-Jensen J, Harboe I, Klemp M. Medicines used for multiple sclerosis - a health technology assessment. Oslo: Norwegian Institute of Public Health, 2016.

27. Zimmermann M, Brouwer E, Tice JA, Seidner M, Loos AM, Liu S, et al. Disease-modifying therapies for relapsing-remitting and primary progressive multiple sclerosis: a cost-utility analysis. CNS Drugs. 2018;32(12):1145-57. Epub 2018/08/25. doi: 10.1007/s40263-018-0566-9.

28. Cohen J, Belova A, Selmaj K, Wolf C, Sormani MP, Oberye J, et al. Equivalence of generic glatiramer acetate in multiple sclerosis: a randomized clinical trial. JAMA Neurol. 2015;72(12):1433-41. Epub 2015/10/13. doi: 10.1001/jamaneurol.2015.2154.

29. Giovannoni G, Comi G, Cook S, Rammohan K, Rieckmann P, Soelberg Sorensen P, et al. A placebo-controlled trial of oral cladribine for relapsing multiple sclerosis. N Engl J Med. 2010;362(5):416-26. Epub 2010/01/22. doi: 10.1056/NEJMoa0902533.

30. Afolabi D, Albor C, Zalewski L, Altmann DR, Baker D, Schmierer K. Positive impact of cladribine on quality of life in people with relapsing multiple sclerosis. Mult Scler. 2018;24(11):1461-8. Epub 2017/08/19. doi: 10.1177/1352458517726380.

31. Pardo $G$, Jones $D E$. The sequence of disease-modifying therapies in relapsing multiple sclerosis: safety and immunologic considerations. J Neurol. 2017;264(12):2351-74. Epub 2017/09/08. doi: 10.1007/s00415-017-8594-9. 
32. Elwyn G, O'Connor A, Stacey D, Volk R, Edwards A, Coulter A, et al. Developing a quality criteria framework for patient decision aids: online international Delphi consensus process. BMJ. 2006;333(7565):417. Epub 2006/08/16. doi: 10.1136/bmj.38926.629329.AE.

33. van der Weijden T, Dreesens D, Faber MJ, Bos N, Drenthen T, Maas I, et al. Developing quality criteria for patient-directed knowledge tools related to clinical practice guidelines. A development and consensus study. Health Expect. 2019;22(2):201-8. Epub 2018/11/13. doi: 10.1111/hex.12843.

34. Stalmeier PF. Adherence and decision AIDS: a model and a narrative review. Med Decis Making. 2011;31(1):121-9. Epub 2010/06/04. doi: 10.1177/0272989x10370487.

35. Trenaman L, Bryan S, Bansback N. The cost-effectiveness of patient decision aids: a systematic review. Healthcare (Amsterdam, Netherlands). 2014;2(4):251-7. Epub 2015/08/08. doi: 10.1016/j.hjdsi.2014.09.002. 


\section{Supplementary information}

Table 1. Network meta-analyses identified for efficacy outcomes

\begin{tabular}{|c|c|c|c|}
\hline Reference & Search date & DMDs & Outcome \\
\hline CADTH 2014 [1] & Oct 2013 & $\begin{array}{l}\text { ATZ (ARR only), DMF, FIN, } \\
\text { GA20, IFN (excl. PEGINF), } \\
\text { TF }\end{array}$ & $\begin{array}{l}\text { ARR, patients with } \\
\text { sustained disability } \\
\text { progression (either } \\
\text { confirmed after } 3 \text { or } 6 \mathrm{~m} \text { ) }\end{array}$ \\
\hline $\begin{array}{l}\text { Couto et al. } 2016 \\
{[2]}\end{array}$ & 09 Nov 2015 & $\begin{array}{l}\text { ATZ,DMF, FIN, GA20, GA40 } \\
\text { (ARR only), IFNB, PEGIFN, } \\
\text { NTZ, TF }\end{array}$ & $\begin{array}{l}\text { ARR, patients with } \\
\text { disability progression }\end{array}$ \\
\hline $\begin{array}{l}\text { Del Santo et al. } \\
2012 \text { [3] }\end{array}$ & NR & $\begin{array}{l}\text { IFN, GA, NTZ, FIN vs. } \\
\text { placebo }\end{array}$ & relapse-free rate \\
\hline $\begin{array}{l}\text { Fillippini et al. } \\
2013 \text { [4] }\end{array}$ & Feb 2012 & $\begin{array}{l}\text { IFN, GA, NTZ, MTX, } \\
\text { Methotrexate, CYC, AZA, } \\
\text { IMM, Corticosteroids }\end{array}$ & $\begin{array}{l}\text { Recurrence of relapses, } \\
\text { patients with disability } \\
\text { progression }\end{array}$ \\
\hline $\begin{array}{l}\text { Fogarty et al. } \\
2016 \text { [5] }\end{array}$ & Mar 2016 & $\begin{array}{l}\text { ATZ, NTZ, FIN, DMF, } \\
\text { PEGIFN, GA, 20, GA0, IFNB, } \\
\text { TF }\end{array}$ & $\begin{array}{l}\text { ARR, patients with } \\
\text { confirmed disability } \\
\text { progression }\end{array}$ \\
\hline $\begin{array}{l}\text { Hadjigeorgiou et } \\
\text { al. } 2013 \text { [6] }\end{array}$ & 12 Nov 2012 & $\begin{array}{l}\text { IFNB, TF, GA, NTZ, FIN, } \\
\text { MTX, but not vs. placebo }\end{array}$ & $\begin{array}{l}\text { patients free of relapses, } \\
\text { patients without MR } \\
\text { progression, patients } \\
\text { without disability } \\
\text { progression }\end{array}$ \\
\hline $\begin{array}{l}\text { Huisman et al. } \\
2013 \text { [7] }\end{array}$ & 14 Nov 2014 & $\begin{array}{l}\text { FIN vs. DMF in highly } \\
\text { active RRMS; FIN vs. NTZ in } \\
\text { rapidly evolving severe MS }\end{array}$ & $\begin{array}{l}\text { ARR, difference in EDSS } \\
\text { change, patients with } \\
\text { confirmed disability } \\
\text { progression }\end{array}$ \\
\hline ICER 2017 [8] & 15 Sep 2016 & $\begin{array}{l}\text { ATZ, DMF, FIN, GA20, } \\
\text { GA40, IFNB, NTZ, PEGIFN, } \\
\text { TF, OCR, DAC, RTX }\end{array}$ & $\begin{array}{l}\text { ARR, patients with } \\
\text { disability progression } \\
\text { confirmed }\end{array}$ \\
\hline $\begin{array}{l}\text { Tramacere et al. } \\
2015 \text { [9] }\end{array}$ & 30 Sep 2014 & $\begin{array}{l}\text { IFN, GA, NTZ, MTX, FIN, TF, } \\
\text { DMF, ATZ, PEGIFN, DAC, } \\
\text { OCR, LAQ, AZA, IMM }\end{array}$ & $\begin{array}{l}\text { patients with new } \\
\text { relapses, patients with } \\
\text { disability worsening }\end{array}$ \\
\hline $\begin{array}{l}\text { Zintzaras et al. } \\
2012[10]\end{array}$ & Jan 2011 & $\begin{array}{l}\text { FIN, NTZ, RTX, CLAD, IFNB- } \\
\text { 1a, TF, FINVs. IFNB-1b } \\
\text { 250ug/ placebo }\end{array}$ & $\begin{array}{l}\text { Patients free of relapse, } \\
\text { Patients without MRI } \\
\text { progression, Patients } \\
\text { without disease } \\
\text { progression }\end{array}$ \\
\hline
\end{tabular}


Table 2. Minor comments and adaptations made in accordance with comments in response to the alpha test

\begin{tabular}{|c|c|c|}
\hline Round & Minor comments & Adjustments \\
\hline \multicolumn{3}{|c|}{ Content and framing } \\
\hline \multirow[t]{5}{*}{1} & Illustrate cognitive disabilities with examples & Adjusted accordingly. \\
\hline & Consistent use of terminology for "relapses" & Adjusted accordingly. \\
\hline & Provide nuances in discussing disease progression. & Adjusted accordingly. \\
\hline & $\begin{array}{l}\text { Differentiate in the occurrence of different side } \\
\text { effects. }\end{array}$ & Adjusted accordingly. \\
\hline & $\begin{array}{l}\text { Provide the generic drug names first, followed by the } \\
\text { brand name in brackets for reasons of independence. }\end{array}$ & $\begin{array}{l}\text { Brands are better known } \\
\text { to patients. Brand name } \\
\text { is followed by generic } \\
\text { name. }\end{array}$ \\
\hline
\end{tabular}

Elaborate on the role of monitoring programs to Adjusted accordingly. improve safety and reduce risks.

Information about whether the patient is planning to Adjusted accordingly. travel in the short term and needs vaccinations would support the consultation.

Explain second-line medication

Adjusted accordingly.

Patients need more information about the process of Adjusted accordingly. injecting medication.

Information about monitoring during use of second- Adjusted accordingly. line medication to feel at ease about safety

Link to useful/reliable patient information

Adjusted accordingly.

2 Wish to have children should include option "don't Adjusted accordingly. know"

Travel plans should include option "don't know".

Adjusted accordingly.

Choosing characteristics is difficult. "They are all important."

Pictures presenting the degree of disability progression for explaining natural course of different MS types is confronting.

Figures explaining MS types should be "wavy".

3 Difficulty distinguishing between characteristics, also after reading additional information.

\section{End screen}

1 Would be informative to see ranking of medication based on a single characteristic

The performance scores per DMD provide this information.

In result screen, add the possibility to change weights to see their effect immediately.

In result screen, rank medication from most to least fitting to patient's preferences.

Software limits the ability to make adjustments accordingly.

In result screen, distinguish between first-line and second-line medication.

Software limits the ability to make adjustments accordingly. 
Explain the direction of the side effects in the result screen as this could be counterintuitive

2 Repeat characteristics above the performance bars in result screen

Remove numbers in performance bars or put them in the bars, not underneath them

3 Selection of DMD to read more about should be presented under the result screen. The link between the ranking and the selection should also be clearer. Should be able to select DMD in Result screen for further information.

End screen seems like a black box.
Adjustments made accordingly.

Software limits the ability to make adjustments accordingly.

Software limits the ability to make adjustments accordingly

Software limits the ability to make adjustments accordingly.

Software limits the ability to make adjustments accordingly.

\section{Other}

1 Provide clinicians with an instructional card about the Beta-testing patient decision aid for use in clinical practice.

A separate patient decision aid for CIS might be obsolete because of the earlier diagnosis of RRMS according to the new McDonald diagnostic criteria.

Consider adding treatment options for PPMS and SPMS.

It's difficult for colour-blind people to distinguish red and green.

Software limits the ability to make adjustments accordingly.

Online is difficult because I would like to highlight text and go back to it if I need a break.

Consider whether text can be read out to people.

Option added to print text. Patient decision aid already included option for saving progress.

Beta-testing

2 Include the option to send results to the specialist.

Beta-testing

Include the option to print all results or send it to email.

Notice of missing answers is unclear.

Software limits the ability to make adjustments accordingly.

Difficult to select answer options: check boxes are too small

It's difficult to see the cursor on a white screen.

Difficulty with returning to patient decision aid after accessing an external link for further reading.

Reactions to questions should appear immediately under the question after answering instead of on the next page.
Software limits the ability to make adjustments accordingly.

Software limits the ability to make adjustments accordingly. pop-up in same screen. Software limits the ability to make adjustments accordingly.

Adjusted accordingly.
Include information as 
Space for summaries or notes would be useful.

Adjusted accordingly.

Effect on QoL should be excluded because QoL will never be the same again.

Page numbering at the top of the page is off-putting: Software limits the ability "29 pages!"

to make adjustments accordingly.

PPMS doesn't have to be explained. $-$

3 Formulate sentences addressing the reader directly.

Adjusted accordingly.

Simplify language. Too much jargon.

Adjusted accordingly. Before beta-testing the reading level of the patient decision aid will be reviewed.

Include menu tab that shows new chapters and ability to go back to a previous chapter.

Software limits the ability to make adjustments accordingly.

Use a progression bar instead of page numbers.

Software limits the ability to make adjustments accordingly

Switch order of safety and side effects in the Adjusted accordingly. presentation of DMD characteristics Too much emphasis on ease of use due to additional questions for rating the performance.

Questions concerning rating burden of use positioned after questions concerning weighting of criteria.

Delete question about alcohol. Puts too much Adjustedaccordingly. emphasis on it. Include a statement that all DMDs could be used with normal alcohol use. 


\section{References}

1. Canadian Agency for Drugs and Technologies in Health. CADTH therapeutic review. Comparative clinical and cost-effectiveness of drug therapies for relapsing-remitting multiple sclerosis. 2013 Oct; (CADTH Therapeutic Review vol.1, no. 2b). Available from: http://www.cadth.ca/media/pdf/TR0004_RRMS_ScienceReport_e.pdf.

2. Couto E, Hamidi V, Ringerike T, Odgaard-Jensen J, Harboe I, Klemp M. Medicines used for multiple sclerosis - a health technology assessment. Oslo: Norwegian Institute of Public Health, 2016.

3. Del Santo F, Maratea D, Fadda V, Trippoli S, Messori A. Treatments for relapsing-remitting multiple sclerosis: summarising current information by network meta-analysis. Eur J Clin Pharmacol. 2012;68(4):441-8. Epub 2011/11/08. doi: 10.1007/s00228-011-1141-1.

4. Filippini G, Del Giovane C, Vacchi L, D'Amico R, Di Pietrantonj C, Beecher D, et al. Immunomodulators and immunosuppressants for multiple sclerosis: a network meta-analysis. Cochrane Database Syst Rev. 2013;(6):Cd008933. Epub 2013/06/08. doi: 10.1002/14651858.CD008933.pub2.

5. Fogarty E, Schmitz S, Tubridy N, Walsh C, Barry M. Comparative efficacy of disease-modifying therapies for patients with relapsing remitting multiple sclerosis: systematic review and network meta-analysis. Mult Scler Relat Disord. 2016;9:23-30. Epub 2016/09/21. doi: 10.1016/j.msard.2016.06.001.

6. Hadjigeorgiou GM, Doxani C, Miligkos M, Ziakas P, Bakalos G, Papadimitriou D, et al. A network meta-analysis of randomized controlled trials for comparing the effectiveness and safety profile of treatments with marketing authorization for relapsing multiple sclerosis. J Clin Pharm Ther. 2013;38(6):433-9. Epub 2013/08/21. doi: 10.1111/jcpt.12090.

7. Huisman E, Papadimitropoulou K, Jarrett J, Bending M, Firth Z, Allen F, et al. Systematic literature review and network meta-analysis in highly active relapsing-remitting multiple sclerosis and rapidly evolving severe multiple sclerosis. BMJ open. 2017;7(3):e013430. Epub 2017/03/12. doi: 10.1136/bmjopen-2016-013430.

8. Institute for Clinical and Economic Review. Disease-modifying therapies for relapsing-remitting and primary-progressive multiple sclerosis: effectiveness and value.2017 [14 December 2018]. Available from: https ://icer-revie w.org/wp-conte nt/uploa ds/2016/08/CTAF_MS_Final Repor t_03061 7.pdf.

9. Tramacere I, Del Giovane C, Salanti G, D'Amico R, Filippini G. Immunomodulators and immunosuppressants for relapsing-remitting multiple sclerosis: a network meta-analysis. Cochrane Database Syst Rev. 2015;(9):Cd011381. Epub 2015/09/19. doi: 10.1002/14651858.CD011381.pub2.

10. Zintzaras E, Doxani C, Mprotsis T, Schmid CH, Hadjigeorgiou GM. Network analysis of randomized controlled trials in multiple sclerosis. Clin Ther. 2012;34(4):857-69.e9. Epub 2012/03/27. doi: 10.1016/j.clinthera.2012.02.018. 

CHAPTER 5

Exploring the cost-effectiveness of shared decision making for choosing between disease-modifying drugs for multiple sclerosis in the Netherlands: a state transition model

Submitted as:

Kremer IEH, Hiligsmann M, Carlson J, Zimmerman M, Jongen PJ, Evers, SMAA, Petersohn S, Pouwels XGLV, Bansback N. Exploring the cost-effectiveness of shared decision making for choosing between disease-modifying drugs for multiple sclerosis in the Netherlands: a state transition model. 


\begin{abstract}
Background. For patients with relapsing-remitting multiple sclerosis (RRMS), nonadherence and discontinuation of disease-modifying drug (DMD) treatment is problematic. Shared decision making can decrease non-adherence and discontinuation rates by ensuring that patients' treatment choices are congruent with their informed values. However, shared decision making may come at an additional cost, resulting, for example, from the implementation of patient decision aids or from increased consultation time with the physician or care team. This study aims to explore the potential cost-effectiveness of shared decision making for RRMS in comparison with usual care, from a limited societal perspective over a lifetime.
\end{abstract}

Methods. We adapted a previously developed state transition model that evaluates the cost-effectiveness of a range of DMDs for RRMS in comparison with the best supportive care. Three potential effects of shared decision making were explored: 1) a change in the initial DMD chosen; 2) a decrease in the patient's persistence in using the DMD; and 3) an increase in adherence to the DMD. One-way and probabilistic sensitivity analyses of a scenario that combined the three effects were conducted to evaluate the robustness of the results. A threshold analysis was further conducted to estimate at which costs SDM per patient may be cost-effective.

Results. Each effect separately and all three effects combined resulted in higher qualityadjusted life years (QALYs) and costs due to the increased utilization of DMD, the primary cost driver. A decrease in discontinuation of DMDs influenced the incremental costeffectiveness ratio (ICER) most. The combined scenario resulted in 1.12 QALYs gained and a $€ 20,009$ increase in costs, leading to an ICER of $€ 17,875$ per QALY gained. The probability of shared decision making being cost-effective for a threshold of $€ 50,000$ per QALY was $98.5 \%$. The ICER was sensitive to drug prices, the risk of disease progression, the discount rate and to the perspective taken. Shared decision making could maximally cost $€ 23,639$ to be costeffective at a threshold of $€ 50,000$ per QALY.

Conclusion. Shared decision making could potentially be cost-effective for supporting patients' choices between DMDs, especially if shared decision making would help to decrease treatment discontinuation. Shared decision making was found to be cost-effective even if upfront intervention costs are high. With new initiatives being explored to increase the uptake of shared decision making, this study informs clinicians and policy decision makers about the potential economic value of such investments, and which assumptions and parameters should be explored in future trial-based studies. 


\section{Introduction}

Currently, a large number of disease-modifying drugs (DMDs) are available to reduce the number and severity of relapses in patients with relapsing-remitting multiple sclerosis (RRMS) [1, 2]. Relapses are exacerbations of physical and cognitive symptoms that resolve partially or completely (remissions) after weeks or months [3]. By reducing the number of relapses, DMDs also delay the accumulation of disabilities. Patients with RRMS most often have several options in the treatment with DMDs, including the choice to refrain from DMD use. The use of DMDs can be burdensome for patients due to side effects and administration regimens; these characteristics differ between DMDs.

Decision making about treatment for RRMS is therefore difficult and the patient should be involved [4] for several reason. First, More efficacious DMDs are associated with a higher risk of severe or life-threatening adverse events, resulting in these DMDs typically being indicated for patients with high disease activity [5]. Moreover, patients experience the burden of administration and common side effects differently, which puts a different value on DMDs with certain attributes [6]. Second, healthcare providers making a treatment decision without consulting the patient often make inaccurate assessments of the patient's preferences for treatment options, instead basing assessment on personal preferences and experience [7]. Third, persistence with and adherence to treatment regimens are suboptimal among many patients [8-11]. Treatment persistence refers to patients continuing treatment over the long-term [12], and treatment adherence is defined as "the extent to which a patient acts in accordance with the prescribed interval, and dose of a dosing regimen" [12]. Real-world studies in MS show that discontinuation rates in the first year after DMD treatment initiation range between 10 and 31\% [9-11]. Of the people who do persist, only $60 \%$ of patients taking injectable and orally administered DMDs were reported to have optimal adherence [8].

Shared decision making is an approach that can help explicitly to integrate informed patient's preferences for treatment options into clinical decisions [13]. Healthcare professionals enable the patient to develop informed preferences for treatment options by sharing information. In turn, the patient shares his/her preferences with the healthcare provider. Consecutively, the patient and healthcare professional discuss the best matching treatment options, considering the patient's preferences and the best available evidence, to make a treatment decision together [13]. Shared decision making is often supported by patient decision aids which inform patients about their options and help them to understand and express their preferences [14]. Patient decision aids have been shown to facilitate shared decision making [14] and could improve treatment adherence [15].

The implementation of shared decision making with or without a patient decision aid can also have implications for resources. Trenaman et al. [16] distinguish three categories for how resources could be affected through the use of a patient decision aid, potentially increasing or decreasing costs: 1 ) delivery of the patient decision aid and its effect on consultation time; 2) short-term costs because patients may opt more often for more or less expensive options; or 3 ) long-term costs because of a postponed intervention or 
changes in persistence and adherence. For example, implementation of shared decision making with or without patient decision aids could increase consultation time and thus increase costs $[14,17]$. Furthermore, cost reductions in the short term have been reported for one-off interventions because patients chose less invasive and less costly interventions $[18,19]$. In addition, patient education and value elicitation could support patients in developing a more persistent and adherent attitude towards taking a particular medication. As a result, health outcomes would improve and utilization of health care, and consequently costs, would decrease [20]. The consequences for costs may depend, however, on the treatment decision and the context [16]. While there is less evidence on the consequences of shared decision making and patient decision aids regarding persistence, adherence, health outcomes and costs for chronic diseases requiring long-term treatment [16], various efforts are underway to create training and tools for MS.

An investment in shared decision making has an opportunity cost, diverting funds used for other aspects of the healthcare system, including the budgets used to pay for drugs. It is therefore important to understand the cost-effectiveness of interventions that support shared decision making, similar to how decision makers assess the cost-effectiveness of drugs for reimbursement decisions. [21]. Accordingly, this study aimed to evaluate the potential lifetime cost-effectiveness of shared decision making with regard to DMDs for RRMS in comparison with usual care from a societal perspective. The study has an exploratory nature to determine the headroom for implementation of shared decision making for DMDs for RRMS. Therefore, we also estimate the maximum costs at which shared decision making remains cost-effective. The results will inform decision makers and clinicians about the potential value of implementing shared decision making in clinical practice. By explicitly modeling the different consequences of shared decision making (i.e. the costs of delivery of shared decision making, treatment choice, persistence and adherence) on relapses, quality-adjusted life years (QALYs), and costs, this study also aimed to reveal which effects drive the cost-effectiveness. Results could underline the need to develop effective interventions for implementing shared decision making (e.g. patient decision aids), and to help in designing future trial-based and model-based economic evaluations of shared decision making and other interventions focused on improving persistence and adherence during long-term treatment.

\section{Methods}

We adapted a state transition model developed by the Institute for Clinical and Economic Review in the United States, which evaluated the cost-effectiveness of a range of DMDs for MS [22]. The model structure and inputs, based on various other models [23-29], has previously been validated through rounds of public comments, cross-validation with other models, and sensitivity analyses [22]. We modified the model to assess the costeffectiveness of implementing shared decision making regarding DMDs choice, and estimated the potential societal costs, QALYs and incremental cost-effectiveness using a 
Dutch perspective and following clinical practice and guidelines for economic evaluations in health care [30]. For reporting, we followed the Consolidated Health Economic Evaluation Reporting Standards (CHEERS) [31].

\section{Population}

The modeled population were adults with RRMS without prior experience with DMDs in the Netherlands. These patients had a mean age of MS onset of 37 years [32, 33]. Within this population, $29 \%$ were male $[32,33]$.

\section{Intervention and comparator}

Implementation of shared decision making in the intervention group was compared with usual care in the control group. In the intervention group, the healthcare professional applies the principles of shared decision making with the patient during the decision making process about DMDs. Patient decision aids are commonly used during or between two consultations to educate patients about their treatment options and to help clarify personal values regarding the treatment options [14]. During a (follow-up) consultation, the patient and healthcare professional discuss the treatment options and the patient's preferences to make an informed and shared decision on treatment [13]. In the control group, we assume that usual care decisions are mostly made in accordance with the healthcare professional's judgment of what fits best with the patient's needs, with little attempt to determine or acknowledge what the patient's preferences might be with regard to the decision. In both groups, patients would be prescribed a treatment with a DMD or no active treatment (best supportive care).

\section{Model structure}

To model the disease course of RRMS and the risk for progression to secondary progressive MS (SPMS), twenty health states defined by the Expanded Disability Status Scale (EDSS) were included according to the model described by Zimmermann et al. [34]. Patients with RRMS could enter the model in health states with an EDSS score between 0 and 9. During a cycle of 12 months, patients could improve or worsen in RRMS health states, remain stable, or progress to SPMS. The transition probabilities were estimated based on natural history [27]. The effectiveness of each DMD is modeled through applying a relative risk for each DMD to the transition probabilities [34]. In the SPMS health states, patients could progress to a higher EDSS state or remain in the same health state, i.e. patients could not improve. Patients could experience a relapse or die in each health state. If patients discontinued their first DMD, they could switch to another DMD, or to best supportive care. After discontinuation of the second DMD, patients were assumed to be switching to best supportive care. The model takes a lifetime horizon: the effects of shared decision making on costs and QALYs are simulated until a patient dies or reaches the age of 100. A limited 
societal perspective was taken, in which healthcare costs and costs outside the healthcare sector (i.e. productivity losses related to MS, informal care and community services) were included. A discount rate of $1.5 \%$ for effects and of $4.0 \%$ for costs was applied in accordance with the Dutch guideline for economic evaluations in health care [30]. Table 1 presents key assumptions made in the model.

Table 1. Key assumptions of the model by Institute for Clinical and Economic Review and the adapted model comparing for shared decision making with usual care

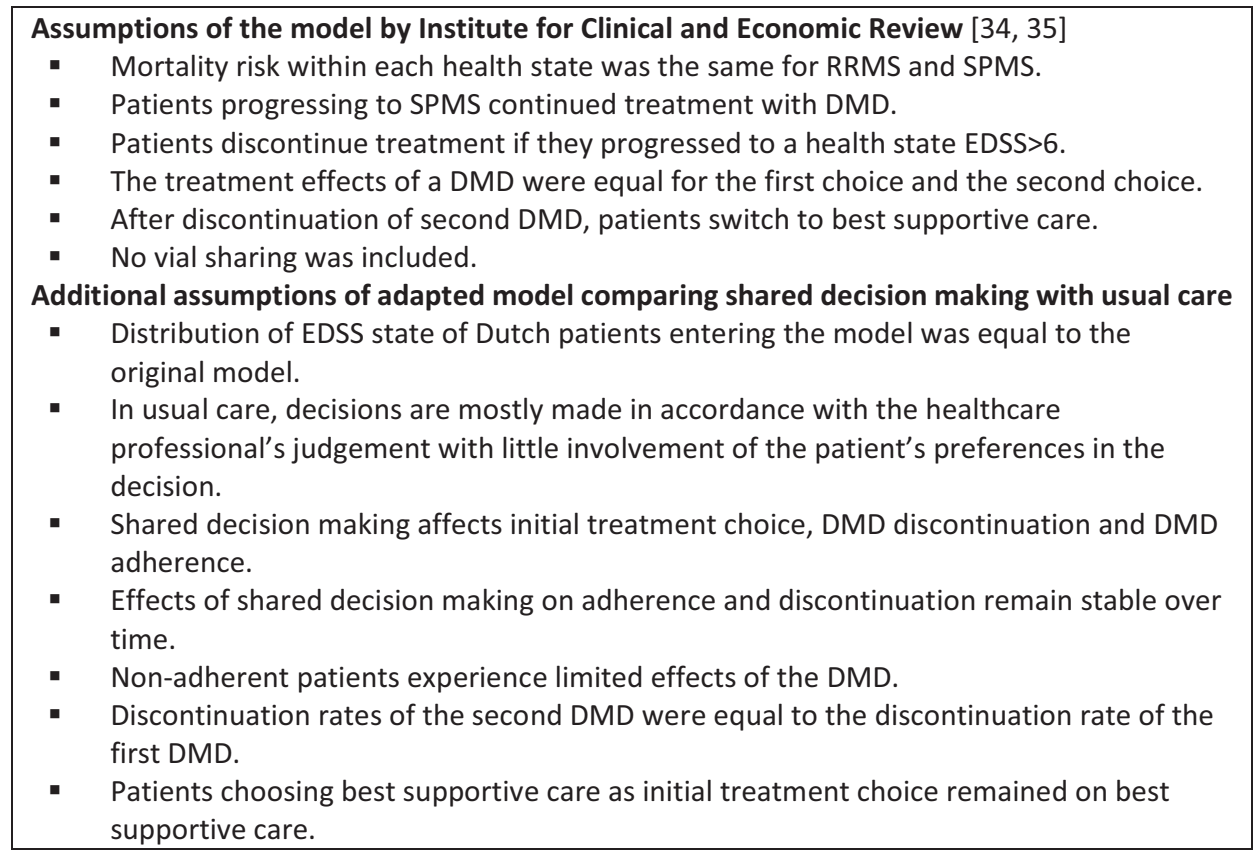

DMDs, disease-modifying drugs; EDSS, Expanded Disability Status Scale; QALYs, quality-adjusted life years; RRMS, relapsing-remitting MS; SPMS, secondary progressive MS

\section{Intervention effects}

Three effects of shared decision making were assumed and modeled (Figure 1 and further specified in the supplementary material): 1) shared decision making changes the DMD mix chosen; 2) shared decision making increases the proportion of optimally adherent patients, and 3) shared decision making increases persistence with the chosen treatment. Key assumptions for modeling shared decision making in comparison with usual care are presented in Table 1. Effect 1 was based on the fact that patients' preferences are elicited and included in the treatment choice during a shared decision making process and these preferences might differ from physicians' preferences [7]. The proportions of patients initiating a specific DMD treatment or opting for best supportive care were therefore assumed to differ between the groups, also following studies for other health decisions [18, $19,36,37]$. The treatment initiation and treatment sequencing, i.e. the categorization of DMDs in first-line treatments for mild to moderate RRMS and in second-line treatments for 
highly active RRMS or RRMS not responding to first-line treatment, was informed by current clinical practice in the Netherlands, based on expert opinions and recommendations provided by the Dutch Healthcare Institute [5], in the absence of formal up-to-date clinical guidelines. Effects 2 and 3 were based on the theory by Stalmeier [20] that patients develop a more pronounced attitude towards taking the medication continuously and accurately. Patients are expected to be better informed and consequently have more accurate expectations about the effects and treatment burden of the chosen treatment option [20]. Consequently, a better match is made between the patient's preferences and the treatment attributes. Patients on DMD treatment can be either optimally adherent or non-adherent over time. Non-adherent patients were assumed to not experience the full benefits of the DMDs, and have a $42 \%$ higher risk of relapses overall [8] and a $7.5 \%$ higher risk of severe relapses specifically [38]. A weighted average of the outcomes was calculated.

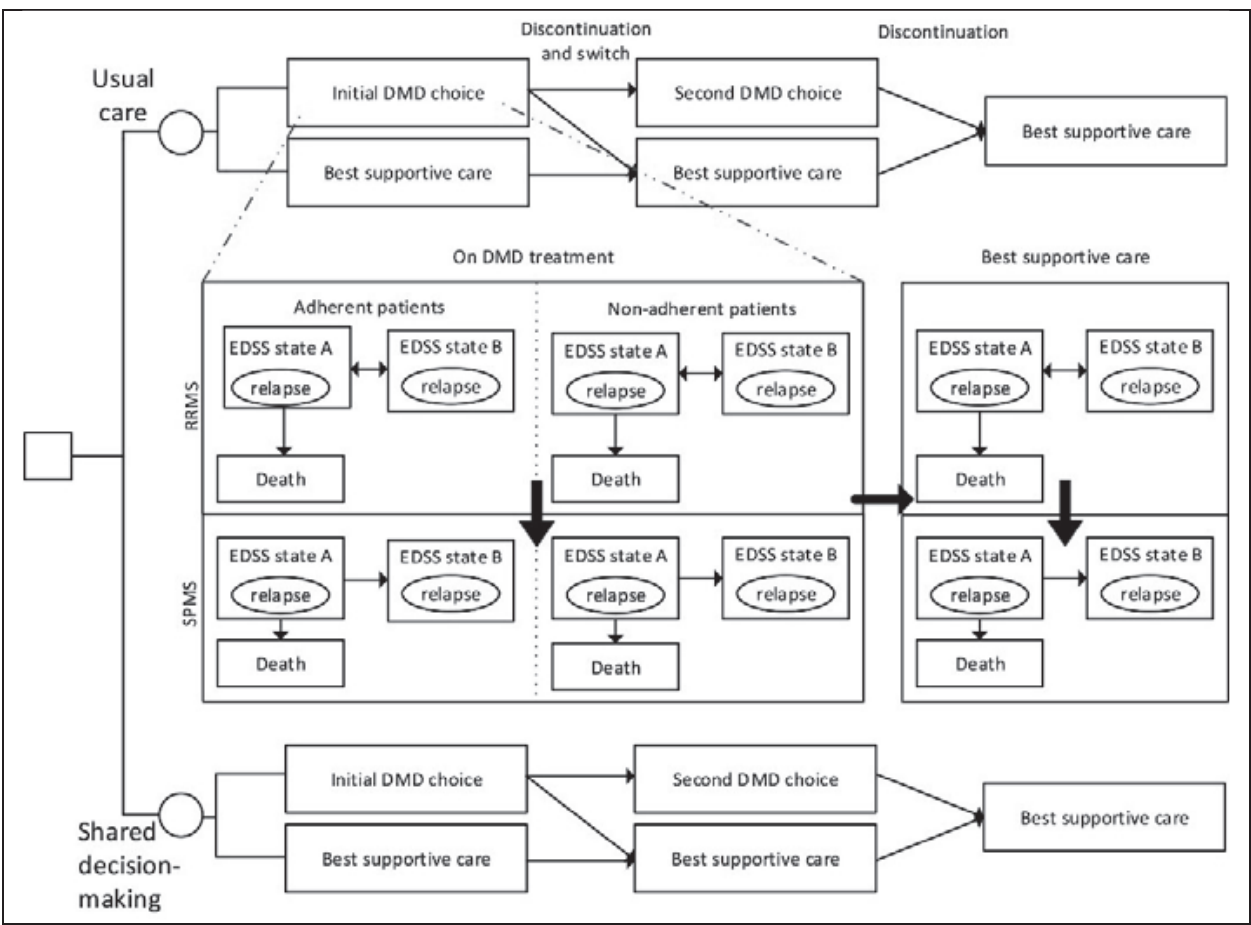

Figure 1. Model structure. Patients diagnosed with relapsing-remitting multiple sclerosis (RRMS) receive either shared decision making or usual care to make a decision regarding treatment with disease-modifying drug. Three effects of shared decision making are modeled: 1 ) a change in initial treatment choice; 2 ) a decrease in discontinuation rate (persistence); 3 ) an increase in the proportion of adherent patients. If patients choose a drug treatment, they are either adherent or non-adherent. Non-adherent patients were assumed to have higher risks of experiencing (severe) relapses. Patients enter the model in any of ten RRMS-related health states based on the Expanded Disability Status Scale (EDSS). During each 12-month cycle, the patients' disability status could worsen, improve or remain stable. Moreover, patients could progress to secondary progressive MS (SPMS). 
Patients could experience a relapse or die in any health state. If patients discontinue their initial treatment, they are assumed to switch to another active treatment or to best supportive care according to a pre-determined probability. If patients discontinue their second treatment, they are assumed to be switching to best supportive care. DMD, disease-modifying drug; EDSS, Expanded Disability Status Scale, RRMS, relapsing-remitting MS; SPMS, secondary progressive MS

\section{Usual care profile}

A profile for the usual care group was defined, and these parameters were kept constant for usual care in all further analyses. The usual care profile is presented in Table 2.

Treatment choice. Due to a lack of published data about the proportion of newly diagnosed patients choosing to start DMD treatment or best supportive care, rates were based on expert opinion, informed by data describing current use of each DMD by patients from the Drug Information System of the National Health Care Institute in the Netherlands [39].

Discontinuation. Discontinuation rates of drug therapies reported in controlled phase II or III trials are most likely the optimal persistence rates among patients using the DMD, but do not reflect real-world persistence as these are often lower [9-11, 40]. Therefore, discontinuation rates were based on real-world data [9-11]. No data were available for ocrelizumab and alemtuzumab. Discontinuation rates were therefore determined based on the rate of natalizumab, proportionately according to differences found in trial discontinuation rates between ocrelizumab, alemtuzumab and natalizumab. After discontinuation of the first DMD, patients could switch to another treatment or to best supportive care. Experts concluded that about $95 \%$ of patients who discontinued their first treatment would switch to another DMD treatment. From pivotal studies, it was estimated that $79 \%$ [41-51] of patients discontinue due to side effects and $21 \%[42-47,50]$ of patients discontinue due to a perceived lack of efficacy. Patients stopping first-line treatment due to side effects were assumed to switch to another first-line DMD. Patients stopping first-line treatment due to a perceived lack of efficacy were assumed to switch to a more effective (second-line) DMD, i.e. natalizumab, fingolimod, alemtuzumab or ocrelizumab. If secondline DMD-users discontinued treatment, they were assumed to switch to another secondline DMD (Supplementary material).

Adherence. The proportion of adherent patients was set to $58.9 \%$ for self-injectable and oral DMDs in the usual care group [8]. Since administration of alemtuzumab, ocrelizumab and natalizumab takes place in hospital, is less frequent and is prescribed to patients with more active disease, $100 \%$ of patients taking these DMDs were assumed to have optimal adherence. 
Table 2. Profiles of usual care and shared decision making based on assumed effects

\begin{tabular}{|c|c|c|c|c|c|c|}
\hline & \multicolumn{2}{|c|}{$\begin{array}{c}\text { Effect } 1 \\
\text { Treatment } \\
\text { initiation }\end{array}$} & \multicolumn{2}{|c|}{$\begin{array}{c}\text { Effect } 2 \\
\text { Discontinuation } \\
\text { rate }\end{array}$} & \multicolumn{2}{|c|}{ Proportion adherent } \\
\hline & CAU & $\mathrm{SDM}^{\#}$ & CAU & $\mathrm{SDM}^{\#}$ & CAU & $\mathrm{SDM}^{\#}$ \\
\hline Best supportive care & $25.0 \%$ & $20.0 \%$ & NA & NA & $100.0 \%$ & $100.0 \%$ \\
\hline Alemtuzumab & $0.2 \%$ & $0.3 \%$ & $10.4 \%$ & $5.2 \%$ & $100.0 \%$ & $100.0 \%$ \\
\hline Dimethyl fumarate & $33.6 \%$ & $41.3 \%$ & $21.4 \%$ & $10.7 \%$ & $58.9 \%$ & $63.9 \%$ \\
\hline Fingolimod & $0.0 \%$ & $0.0 \%$ & $10.6 \%$ & $5.3 \%$ & $58.9 \%$ & $63.9 \%$ \\
\hline $\begin{array}{l}\text { Glatiramer acetate } 20 \mathrm{mg} \\
\text { (generic) }\end{array}$ & $0.2 \%$ & $0.1 \%$ & $26.7 \%$ & $13.4 \%$ & $58.9 \%$ & $63.9 \%$ \\
\hline $\begin{array}{l}\text { Glatiramer acetate } 20 \mathrm{mg} \\
\text { (brand) }\end{array}$ & $10.6 \%$ & $3.5 \%$ & $26.7 \%$ & $13.4 \%$ & $58.9 \%$ & $63.9 \%$ \\
\hline $\begin{array}{l}\text { Glatiramer acetate } 40 \mathrm{mg} \\
\text { (brand) }\end{array}$ & $0.2 \%$ & $0.1 \%$ & $21.5 \%$ & $10.8 \%$ & $58.9 \%$ & $63.9 \%$ \\
\hline Interferon beta-1a & $1.0 \%$ & $0.3 \%$ & $26.8 \%$ & $13.4 \%$ & $58.9 \%$ & $63.9 \%$ \\
\hline Interferon beta-1a $22 \mathrm{mcg}$ & $0.5 \%$ & $0.2 \%$ & $27.1 \%$ & $13.6 \%$ & $58.9 \%$ & $63.9 \%$ \\
\hline Interferon beta-1a $44 \mathrm{mcg}$ & $0.5 \%$ & $0.2 \%$ & $30.1 \%$ & $15.1 \%$ & $58.9 \%$ & $63.9 \%$ \\
\hline Interferon beta-1b & $1.0 \%$ & $0.3 \%$ & $25.9 \%$ & $13.0 \%$ & $58.9 \%$ & $63.9 \%$ \\
\hline Natalizumab & $4.0 \%$ & $6.0 \%$ & $13.0 \%$ & $6.5 \%$ & $100.0 \%$ & $100.0 \%$ \\
\hline Ocrelizumab & $0.8 \%$ & $1.2 \%$ & $13.1 \%$ & $6.6 \%$ & $100.0 \%$ & $100.0 \%$ \\
\hline Peginterferon beta-1a & $1.0 \%$ & $0.3 \%$ & $26.4 \%$ & $13.2 \%$ & $58.9 \%$ & $63.9 \%$ \\
\hline Teriflunomide $14 \mathrm{mg}$ & $21.4 \%$ & $26.3 \%$ & $20.8 \%$ & $10.4 \%$ & $58.9 \%$ & $63.9 \%$ \\
\hline
\end{tabular}

\#Profile in the combined scenario. Parameter values were varied in one-way sensitivity analyses.

CAU, care as usual; NA, not applicable; SDM, shared decision making.

\section{Shared decision making profile}

The profile for shared decision making according to the three assumed effects was determined relative to the profile of usual care. The profile is specified in Table 2.

Effect 1: Treatment choice. Including the patient's preferences in treatment decisions may change the choice $[18,19,36,37]$. No evidence is yet available about how shared decision making could influence the treatment choice for MS. Based on stated preference studies, we constructed a possible profile regarding the initial treatment choice for the patients making a shared decision with their healthcare professional. Stated preference studies report that patients value the effects of the DMD most, more than safety, ease of use and side effects $[6,52]$. Moreover, oral medications have been reported to be preferred in comparison with injectable medications [53-56]. Because first-line medications have similar effects and safety profiles, the profile specified that fewer patients start self-injectable firstline DMDs. Stated preference research further suggests that MS patients are less risk averse than neurologists [57], and are willing to accept even higher risks than are currently associated with DMDs $[57,58]$. Therefore, this profile specified that a slightly larger proportion of patients with relatively high disease activity at first treatment initiation would initiate a second-line treatment if the decision were shared between the patient and the healthcare professional. The proportion of patients starting each treatment option is specified in Table 2. A variation on the scenario was conducted as well in sensitivity 
analyses, i.e. assuming the change in treatment would be $50 \%$ smaller, resulting in a more conservative profile.

Effect 2: Discontinuation. Patients in the intervention group were assumed to be more persistent in using the chosen DMD because they are better informed about its efficacy and side effects, have been involved in the treatment decision, and there is a better match between the patient's preferences and the chosen treatment [20]. A relative decrease in the discontinuation rate of $50 \%$ was applied for the group receiving shared decision making compared with the group receiving usual care. This resulted in an averaged absolute decrease in discontinuation rate of $11.1 \%$ over the different DMDs, which was in line with a previous economic evaluation regarding a decision aid for shared decision making in osteoporosis assuming a $10 \%$ decrease in the discontinuation after shared decision making [36]. The relative decrease in the discontinuation rate was varied to $25 \%$ and $75 \%$ in sensitivity analyses.

Effect 3: Adherence. In previous studies on patient decision aids for other shared healthcare decisions, improvement rates in the proportion of adherent patients varied between 0 and $50 \%$ [36, 37]. Because no data are available for MS, a conservative assumption was made regarding improvement for the proportion of adherent patients, i.e. a $5 \%$ improvement in comparison with usual care. This rate was increased in one-way sensitivity analyses to $10 \%$ and up to $100 \%$ of patients being adherent.

\section{Model inputs}

Effect estimates. Estimates of effectiveness of DMDs in reducing relapses, slowing down disease progression and transition probabilities between health states were in accordance with the model published by Zimmermann et al. [34] (supplementary material). Age and gender-specific background mortality rates were derived from Statistics Netherlands [59], which were adjusted for MS-specific mortality based on the EDSS-score [60].

Utilites. Utilities and disutilities associated with health states, relapses and adverse events were in accordance with the original model [34, 35].

Costs. Costs were expressed in Euros (1 Euro $=1.16$ US dollars: August 2018). All costs were, where necessary, inflated using the Consumer Price Index for August 2018 [61].

DMD costs. Costs of DMDs (supplementary material) were determined using the Pharmacy Purchase Price included in the database of the National Health Care Institute in the Netherlands (www.medicijnkosten.nl). A $€ 14$ dispensing fee for pharmacists was added for each first prescription and $€ 7$ for each subsequent prescription [62]. Administration costs for alemtuzumab, natalizumab and ocrelizumab were included since these DMDs are administered through intravenous infusion in the hospital. In the Netherlands, alemtuzumab requires hospitalization of patients during the treatment period, while natalizumab and ocrelizumab only require outpatient day treatment. Self-injectable or orally administrated DMDs do not incur additional administration costs. Costs related to monitoring recommended in the package inserts were included per DMD. Pre-treatment monitoring costs were included in the first year of treatment. Any monitoring required after discontinuation, including an extra specialist visit, were added as well [34]. Healthcare 
utilization unit costs were determined in accordance with the Dutch Manual for economic evaluations based on reference prices established by the National Healthcare Institute [63] or based on tariffs from the Dutch Healthcare Authority [64] (see the supplementary material).

Adverse events costs. The costs of adverse events are covered by the Dutch "Diagnosisrelated-group" (DRG) system. However, these DRG-rates are not publicly available. The costs of adverse events contribute only marginally to the total costs [34]. Therefore, we first calculated the adverse events costs as proportion of the healthcare costs in the original model [34], and applied the same percentage to calculate the adverse events costs as proportion of the healthcare costs for the Dutch context in our model.

Health state costs. Health state costs for each EDSS health state were calculated by interpolating the EDSS costs reported by Uitdehaag et al. [65] (supplementary material). From a societal perspective, healthcare costs (i.e. inpatient care, day admission, consultations, tests and medications other than DMDs), community services, investments, informal care and productivity losses were included. For productivity losses, only short-term absence costs were included according to the friction cost method required by the Dutch economic evaluation guideline [66]. A sensitivity analysis was conducted in which productivity losses included the costs of long-term absence, disability and early retirement, according to the human capital approach [67]. Relapse costs were also derived from Uitdehaag et al. 2017 [65].

Costs of shared decision making. Applying shared decision making incurs costs through, for example, using a patient decision aid (development and administration costs) and through extended consultation time. However, there is little data available about the costs of shared decision making and no data are available for shared decision making in MS. Therefore, we assumed a mean cost per patient of $€ 100$. Shared decision making is assumed to be applied each time a treatment choice is made, i.e. patients discontinuing their first treatment will choose their second treatment again via shared decision making.

\section{Analyses}

Analyses were conducted in Excel 2016 (Microsoft Corporation, Redmond, WA, USA). Drug costs, adverse event costs, other costs within and outside the healthcare sector, total societal costs, QALYs, number of relapses and life years were calculated separately for shared decision making and for usual care. This enabled the calculation of incremental cost effectiveness ratios (ICERs).

The three effects of shared decision making were first analysed separately in comparison with usual care and were then assessed in a combined scenario: a 10\% decrease in the discontinuation rate in comparison with usual care; a $5 \%$ increase in patients with optimal adherence in comparison with the usual care group, and initial treatment choices as specified in Table 2. A threshold analysis ( $€ 20,000 / Q A L Y$ and $€ 50,000 / Q A L Y$ ) was performed for each effect separately and for the three effects combined to determine the maximum costs of shared decision making at which the ICER would exceed the respective thresholds. 
For the combined profile of the three effects, we conducted further one-way sensitivity analyses to evaluate the influence of several parameters on the ICER: drug costs $(+20 \%$; $20 \%$ ), costs of implementing shared decision making (€0) discount rate (3\%; $0 \%$ for both QALYs and costs) and the perspective taken (healthcare perspective, societal perspective using the human capital approach for calculating productivity losses). In addition, a probabilistic sensitivity analysis with 10,000 iterations was conducted for the combined effects, which was presented in a cost-effectiveness plane. A cost-effectiveness acceptability curve was constructed to present the probability that shared decision making would be cost-effective in comparison with usual care at a range of willingness-to-pay thresholds. Specifications for distributions of the effects of shared decision making are included in the supplementary material. Distributions of other parameters were selected in line with the model developed earlier [34].

\section{Internal validity}

Model transparency and internal validity was reviewed by two independent researchers (SP, $X P)$. Evaluation of internal validity consisted of internal testing and debugging using null input values - as recommended by the ISPOR-SMDM Modeling Good Research Practices Task Force [68] - for utilities and disutilities, probabilities of relapses, adverse events costs, discount rates, drug costs, all costs, and changed the cohort size. In addition, cell-by-cell verification of input calculations and formulas was conducted to identify any errors.

\section{Results}

Modeling each effect of shared decision making separately showed that shared decision making resulted in higher QALYs and costs (Table 3 ). The associated ICERs ranged from $€ 4,384$ to $€ 315,555$ per QALY gained. 


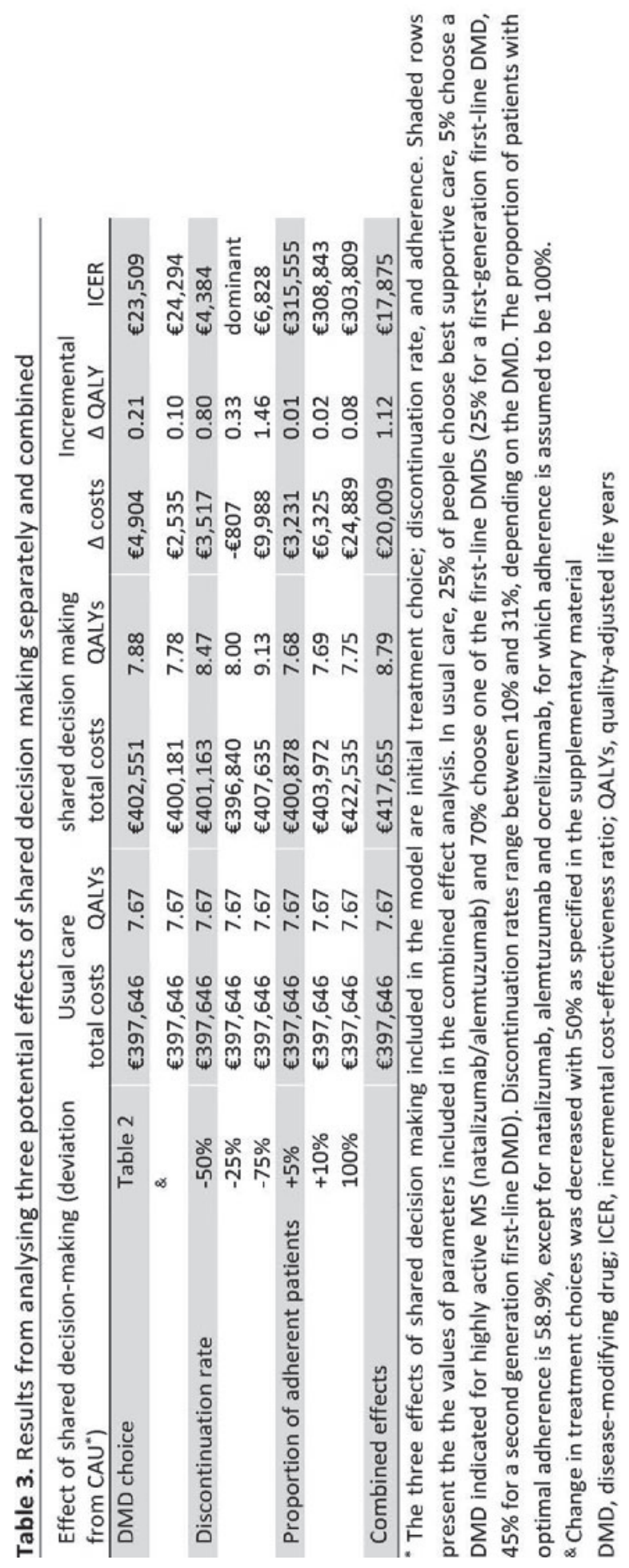


Treatment choice. A change in choice of the type of treatment as specified in Table 2 resulted in an increase in drug cost of $€ 8,288$. Health state costs decreased by $€ 3,384$, resulting in an overall cost increase. Overall QALYs increased (0.21 QALYs gained). A more conservative change in treatment choice resulted in similar, but slightly smaller consequences.

Discontinuation. Total costs increased if discontinuation rates dropped $50 \%$ due to a larger proportion of patients being persistent with their treatment choice, resulting in $€ 15,275$ in higher drug costs. On the other hand, patients also experienced more beneficial effects, resulting in 0.23 more life years, 0.29 less relapses, 0.80 more QALYs and, consequently, $€ 11,755$ less in health state costs. Varying the relative reduction in discontinuation rate of DMDs from a $50 \%$ decrease to $25 \%$ or $75 \%$ decrease affected the ICER slightly, resulting in an ICER of $€ 4,384$ and $€ 6,828$ per QALY gained, respectively, for a $50 \%$ and $75 \%$ reduction, and for shared decision making being the dominant choice if the relative reduction would only be $25 \%$.

Adherence. A change in the proportion of adherent patients of $5 \%$ showed minimal beneficial effects ( 0.01 QALY gained, 0.03 less relapses). This resulted in a major increase in the ICER to $€ 315,555$. Varying the adherence from $10 \%$ up to $100 \%$ did not affect the ICER substantially.

Combined effects. Combination of all three effects resulted in an ICER of $€ 17,875$ per QALY gained. The increase in total costs of $€ 20,009$ were driven by increased drug costs of $€ 36,678$. The beneficial effects translated into a QALY gain of 1.12 , reduction of relapses of 0.49 , life years gained of 0.31 and a reduction in health state costs of $€ 16,666$. More detailed results for all effects separately and the combined effects are included in the supplementary material.

\section{Sensitivity analyses}

Sensitivity analyses of the separate effects showed that, if shared decision making was assumed to decrease the relative reduction in discontinuation rate by $25 \%$, the total costs for the intervention group would be $€ 807$ less in comparison with the control group due to a decrease in health state costs of $€ 4,994$ and an increase of drug costs of $€ 4,189$, resulting in shared decision making being the dominant choice. In all scenarios, increased drug use was the main cost driver, while other costs within and outside the healthcare sector decreased (supplementary material).

Results of one-way sensitivity analyses of the combined effects as defined in Table 2 are presented in Table 4 (further detailed in the supplementary material). The ICER was highly sensitive to change in the relative risk of each DMD option for EDSS progression. Further, the substantial influence of drug costs on the ICER was confirmed: a $20 \%$ increase and decrease in DMD costs resulted in ICERs of $€ 24,147$ and $€ 11,604$ per QALY gained, respectively. Moreover, the ICER increased to $€ 25,568$ and $€ 29,191$ if, respectively, a discount rate of $3 \%$ or a healthcare perspective was applied. The threshold analyses 
suggests that, in the scenario of combined effects, shared decision making could maximally cost $€ 23,639$ to be cost-effective at a threshold of $€ 50,000$ per QALY (Table 5).

Figure 2 presents the ICERs for the 10,000 iterations of the probabilistic analysis in a costeffectiveness plane for the combined effects. The probability of shared decision making being cost-effective in comparison with usual care is $79.2 \%$ for a willingness-to-pay threshold of $€ 20,000$ per additional QALY, increasing to a probability above $98.5 \%$ and higher for thresholds of $€ 50,000$ and higher (Figure 3). 


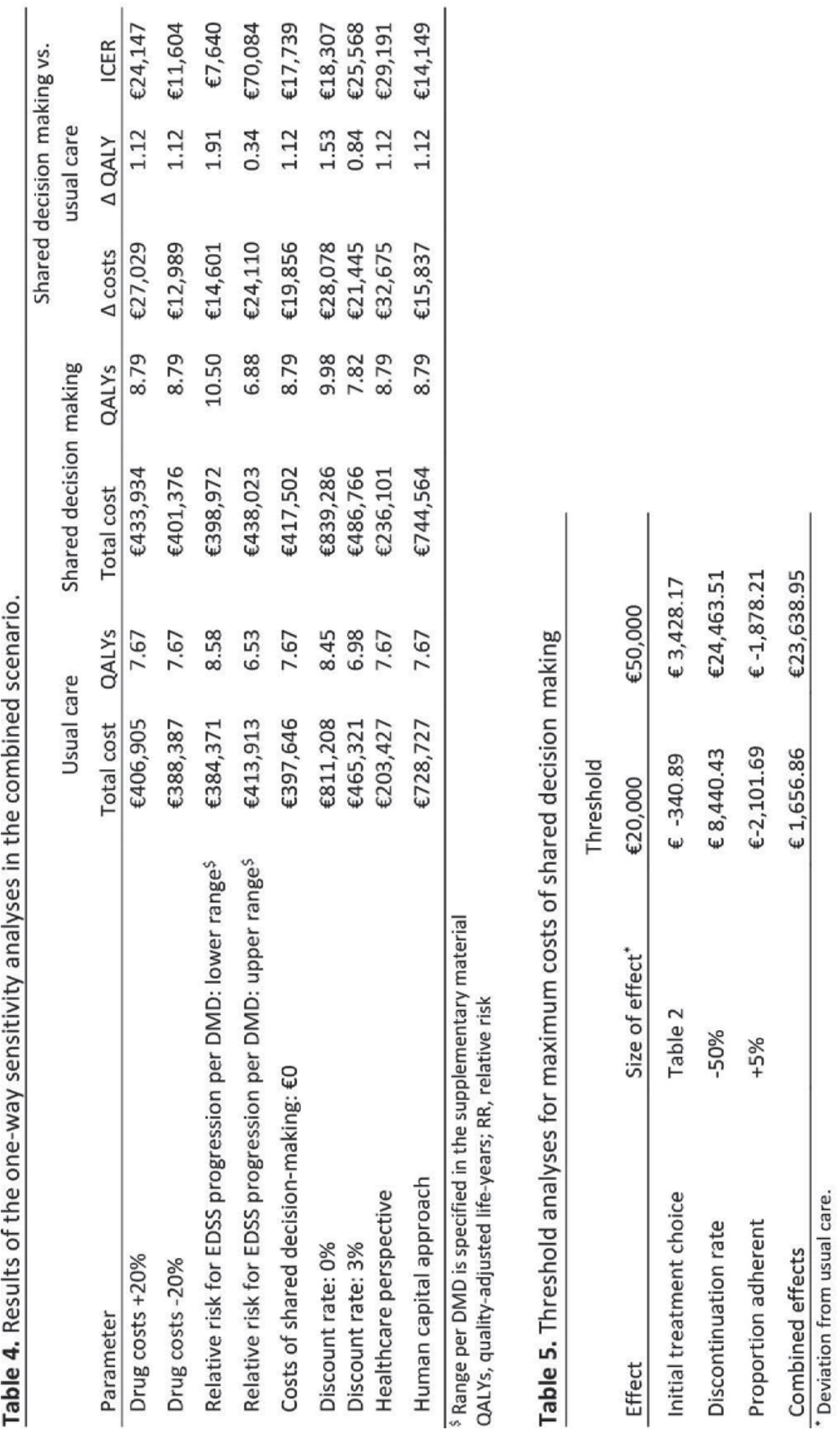




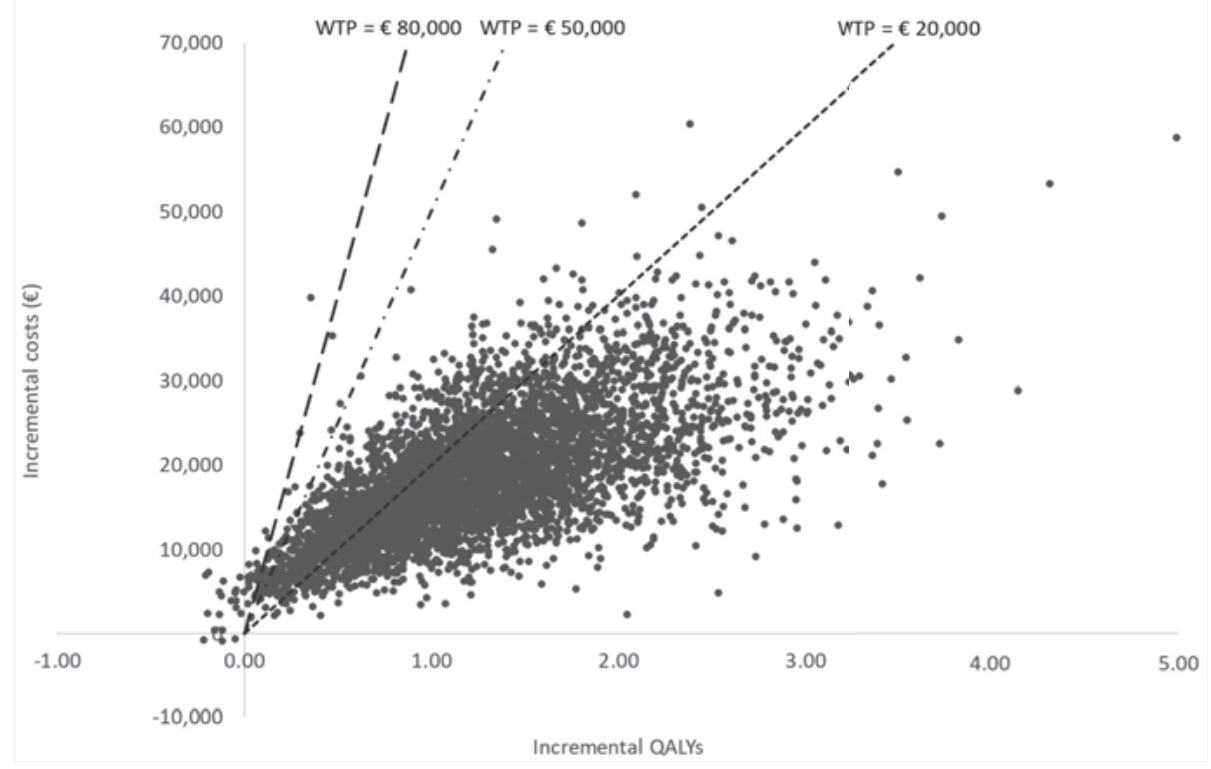

Figure 2. Incremental cost-effectiveness plane of shared decision making versus usual care WTP, Willingness-to-pay threshold; QALYs, quality-adjusted life years

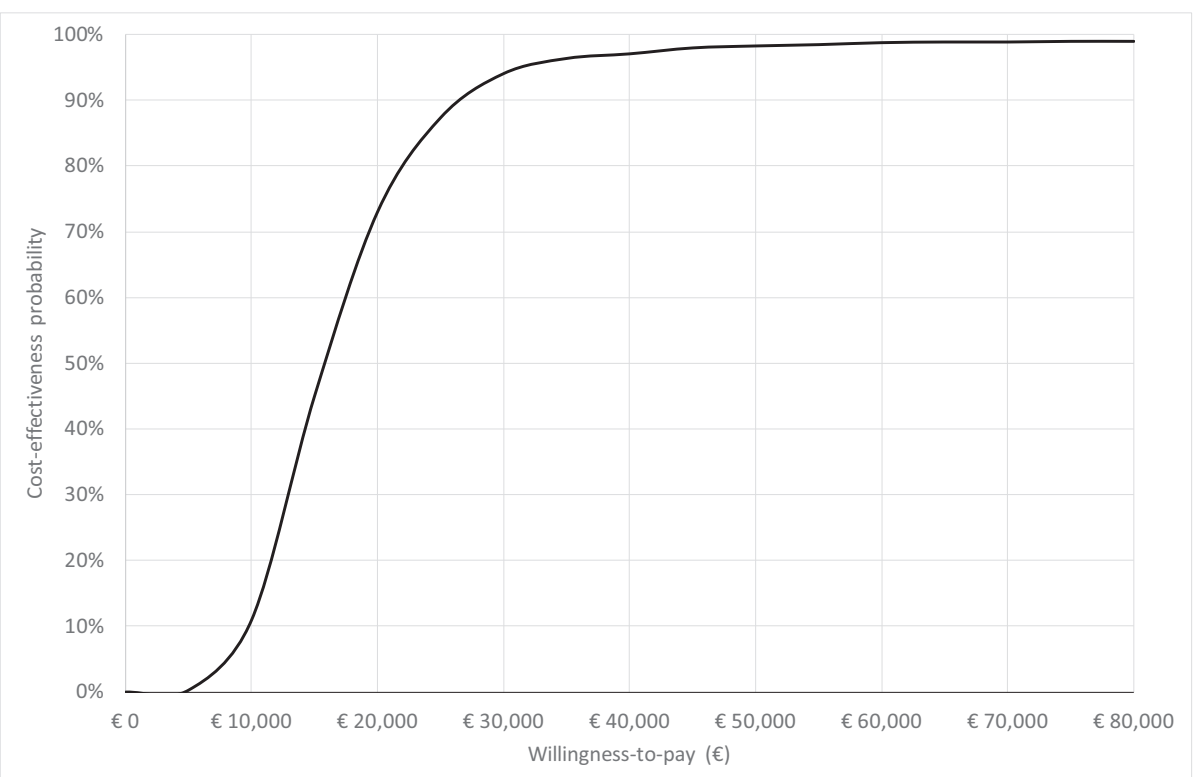

Figure 3. Cost-effectiveness acceptability curve of shared decision making versus usual care 


\section{Discussion}

Using a state transition model, this study suggests that shared decision making for DMDs for RRMS has the potential to be cost-effective, from a limited societal Dutch perspective, in comparison with usual care. Assuming that shared decision making would reduce discontinuation rates by $50 \%$, increase the proportion of adherent patients by $5 \%$, and would lead to a slight increase in DMD initiation and the uptake of second-line and orally administered first-line DMDs, the ICER fell below accepted cost-effectiveness thresholds of $€ 50,000$ for diseases categorized as moderately burdensome in the Netherlands [69]. The probability that the intervention would be cost-effective in comparison with usual care was $98.5 \%$ for a threshold of $€ 50,000$ per QALY. One-way sensitivity analyses showed that the ICER was robust for changes in costs of the intervention, but more sensitive to variation in relative risk of progression for each DMD, drug costs, discount rates or changes in perspectives. Nonetheless, all ICERs in the sensitivity analyses remained well below the commonly accepted threshold for cost-effectiveness of $€ 50,000$ per QALY gained [69], except when the relative risk of progression for each DMD would be considerably higher. Threshold analyses showed that shared decision making will be cost-effective up to a maximum cost of $€ 23,639$ for a threshold of $€ 50,000$ per QALY, assuming the intervention would result in changes in initial treatment choice and a decrease in the discontinuation rate and the proportion of non-adherent patients.

Two similar exploratory studies regarding the cost-effectiveness of shared decision making have been conducted, for obstructive sleep apnoea and osteoporosis, and concluded that a patient decision aid could potentially be cost-effective [36, 37]. In contrast to our study, these studies found that the intervention's cost of delivery had substantial influence on the cost-effectiveness of a patient decision aid, in addition to the influence of variations in the cost of the treatment [37]. We found that the cost of shared decision making had little impact on the ICER. This could be explained by the considerable difference in treatment costs for obstructive sleep apnoea and osteoporosis, which were only a fraction of the treatment costs for RRMS.

The actual effects of shared decision making for MS on treatment choice, persistence, adherence, and the cost of implementing the intervention are still largely unknown. Therefore, our study has an exploratory nature. Further trial- and registry-based evaluations would be needed to assess the real-life effects of shared decision making for MS. Modeling each potential effect of shared decision making separately allowed for assessment as to which of the three expected effects were most influential with regard to its costeffectiveness, and therefore informs further research and development of the intervention. Improvement in treatment adherence was found to have little effect on total QALYs. Various studies on enhancing adherence to medical intervention also failed to find a QALY and/or cost improvement with increased adherence rates - larger than the assumed adherence rate in our study - in trial-based economic evaluations [70, 71]. In contrast, the other two effects did affect the cost-effectiveness: a change in treatment initiation resulted in more incremental QALYs gained, and decreased discontinuation rates brought about the largest 
incremental QALY gain. If shared decision making would reduce the discontinuation by only $25 \%$, increased drug costs are leveled out by reduced health state costs causing shared decision making to be dominant over usual care, while with higher relative reductions in discontinuation rate, the drug cost increase exceeds the savings in health state costs. The importance of using shared decision making in decreasing discontinuation was also found for patient decision aids which support shared decision making in osteoporosis [36]. Our results suggest that the development of interventions to support shared decision making for RRMS should focus mainly on reducing the discontinuation of DMDs for the interventions to be cost-effective, since the type of treatment initiated is dependent on the patient's preferences and needs, and should not be directed by any intervention.

A strength of the current study is that a previously developed and validated model, used by regulatory bodies for policy decision making and pricing, was adapted to explore the costeffectiveness of shared decision making in comparison with usual care. Moreover, a number of sensitivity analyses were conducted to establish the robustness of the results and conclusions. Inherent to the study design, however, is the simplification of real-life situations in a model. In addition to the limitations described by Zimmerman et al. [34] concerning the quality and quantity of data available for the natural history of MS and DMD effectiveness, this model has some additional limitations. First, the model is based on the assumption that once patients choose best supportive care, as first, second or third treatment course, they remain on best supportive care. In clinical practice, however, patients might choose to postpone treatment initially, but decide after a while to start a DMD. This might underestimate the increase in drug costs as a consequence of shared decision making in comparison with usual care and thus, to some extent, the ICER. Further research is needed on whether shared decision making affects the probability of patients starting DMDs after initially opting for best supportive care. Second, non-adherence might increase over time, while in the model non-adherence is assumed to be constant over time. This could overestimate the effect of shared decision making. Third, cladribine has currently become available for patients with highly active RRMS or for patients who did not respond to a first-line DMD [5], but was not included in the model as treatment option. Since cladribine received market authorization for highly active RRMS only in 2017 and was not included in the basic health insurance package in the Netherlands until March 2018, we expect that the share of patients currently choosing cladribine would be small, and would therefore have only marginal impact on the results.

This exploratory study was specifically conducted for the Netherlands. Certain aspects of our model may limit the applicability of the results to contexts other than the Netherlands. For example, drug costs and recommendations for treatment sequencing (including the categorization in first-line and second-line therapy) differ between countries. In sensitivity analyses, we increased the drug cost with $20 \%$, which showed that this parameter has a substantial effect on the ICER. In this scenario, the Dutch drug costs would still be $50 \%$ to 84\% lower than the US drug costs [34]. Shared decision making may, therefore, have more 
substantial impact on drug costs and the ICER in the United States. Moreover, assumed treatment sequencing was validated with Dutch clinicians, but clinical practice could differ in other countries [72]: e.g. fingolimod is prescribed in the Netherlands only after another DMD has been ineffective, but is approved as first-line treatment option in the US.

In conclusion, this study suggests that shared decision making for MS could potentially be a cost-effective intervention. Although shared decision making requires short-term investments in training staff, setting up structures for shared decision making and developing and/or acquiring patient decision aids, long-term savings should be considered in policy decisions, since threshold analyses show that shared decision making could even be cost-effective even if upfront intervention cost are high. To our knowledge, this is the first study assessing the potential cost-effectiveness of shared decision making for RRMS. The current study could further inform the design of a trial-based study, which should be conducted to verify the assumptions made in the study and its results. This study provides insights for policy makers and clinicians regarding the potential value of implementing appropriate interventions to support shared decision making in treatment decisions for RRMS. Real-world current evidence on the cost-effectiveness of shared decision making is still limited [16], and not available for RRMS. Real-world data on long-term treatment discontinuation rates after shared decision making should be collected.

\section{Acknowledgments}

The study was conducted at the department of Collaboration for Outcomes Research and Evaluation (CORE), University of British Columbia, Vancouver, Canada, and the department of Health Services Research, Care \& Public Health Research Institute (CAPHRI), Maastricht University, Maastricht, the Netherlands. The visiting fellowship by Ingrid Kremer was in part made possible by a Student Research Award of the Association for Canada Studies in the Netherlands. 


\section{References}

1. Kasper J, Kopke S, Muhlhauser I, Nubling M, Heesen C. Informed shared decision making about immunotherapy for patients with multiple sclerosis (ISDIMS): a randomized controlled trial. Eur J Neurol. 2008;15(12):1345-52. doi: 10.1111/j.1468-1331.2008.02313.x.

2. Bansback N, Chiu JA, Carruthers R, Metcalfe R, Lapointe E, Schabas A, et al. Development and usability testing of a patient decision aid for newly diagnosed relapsing multiple sclerosis patients. BMC Neurol. 2019;19(1):173. doi: 10.1186/s12883-019-1382-7.

3. Lublin FD, Reingold SC, Cohen JA, Cutter GR, Sorensen PS, Thompson AJ, et al. Defining the clinical course of multiple sclerosis: the 2013 revisions. Neurology. 2014;83(3):278-86. doi: 10.1212/wnl.0000000000000560.

4. Rae-Grant A, Day GS, Marrie RA, Rabinstein A, Cree BAC, Gronseth GS, et al. Practice guideline recommendations summary: disease-modifying therapies for adults with multiple sclerosis: report of the Guideline Development, Dissemination, and Implementation Subcommittee of the American Academy of Neurology. Neurology. 2018;90(17):777-88. doi: 10.1212/wnl.0000000000005347.

5. Zorginstituut Nederland. Farmacotherapeutisch Kompas [cited 2018 October 16]. Available from: https://www.farmacotherapeutischkompas.nl/.

6. Kremer IE, Evers SM, Jongen PJ, van der Weijden T, van de Kolk I, Hiligsmann M. Identification and Prioritization of Important Attributes of Disease-Modifying Drugs in Decision Making among Patients with Multiple Sclerosis: A Nominal Group Technique and Best-Worst Scaling. PLoS ONE. 2016;11(11):e0164862. doi: 10.1371/journal.pone.0164862.

7. Mulley AG, Trimble C, Elwyn G. Stop the silent misdiagnosis: patients' preferences matter. BMJ. 2012;345:e6572. doi: 10.1136/bmj.e6572.

8. Burks J, Marshall TS, Ye X. Adherence to disease-modifying therapies and its impact on relapse, health resource utilization, and costs among patients with multiple sclerosis. Clinicoecon Outcomes Res. 2017;9:251-60. doi: 10.2147/ceor.S130334.

9. Evans C, Marrie RA, Zhu F, Leung S, Lu X, Melesse DY, et al. Adherence and persistence to drug therapies for multiple sclerosis: A population-based study. Multiple sclerosis and related disorders. 2016;8:78-85. doi: 10.1016/j.msard.2016.05.006.

10. Kramer J, Tenberge JG, Kleiter I, Gaissmaier W, Ruck T, Heesen C, et al. Is the risk of progressive multifocal leukoencephalopathy the real reason for natalizumab discontinuation in patients with multiple sclerosis? PLoS One. 2017;12(4):e0174858. doi: 10.1371/journal.pone.0174858.

11. Setayeshgar S, Kingwell E, Zhu F, Zhang T, Carruthers R, Marrie RA, et al. Persistence and adherence to the new oral disease-modifying therapies for multiple sclerosis: a populationbased study. Mult Scler Relat Disord. 2018;27:364-9. doi: 10.1016/j.msard.2018.11.004.

12. Cramer JA, Roy A, Burrell A, Fairchild CJ, Fuldeore MJ, Ollendorf DA, et al. Medication compliance and persistence: terminology and definitions. Value Health. 2008;11(1):44-7. doi: 10.1111/j.1524-4733.2007.00213.x.

13. Elwyn G, Frosch D, Thomson R, Joseph-Williams N, Lloyd A, Kinnersley P, et al. Shared decision making: a model for clinical practice. J Gen Intern Med. 2012;27(10):1361-7. doi: 10.1007/s11606-012-2077-6.

14. Stacey D, Legare F, Lewis K, Barry MJ, Bennett CL, Eden KB, et al. Decision aids for people facing health treatment or screening decisions. Cochrane Database Syst Rev. 2017;4:Cd001431. doi: 10.1002/14651858.CD001431.pub5.

15. Trenaman L, Selva A, Desroches S, Singh K, Bissonnette J, Bansback N, et al. A measurement framework for adherence in patient decision aid trials applied in a systematic review subanalysis. J Clin Epidemiol. 2016;77:15-23. doi: 10.1016/j.jclinepi.2016.03.032.

16. Trenaman L, Bryan S, Bansback N. The cost-effectiveness of patient decision aids: a systematic review. Healthc (Amst). 2014;2(4):251-7. doi: 10.1016/j.hjdsi.2014.09.002. 
17. Stacey D, Légaré F, Lewis K, Barry MJ, Bennett CL, Eden KB, et al. Decision aids for people facing health treatment or screening decisions. Cochrane Database of Systematic Reviews. 2017;(4). doi: 10.1002/14651858.CD001431.pub5.

18. Arterburn D, Wellman R, Westbrook E, Rutter C, Ross T, McCulloch D, et al. Introducing decision aids at Group Health was linked to sharply lower hip and knee surgery rates and costs. Health Aff (Millwood). 2012;31(9):2094-104. doi: 10.1377/hlthaff.2011.0686.

19. van Peperstraten A, Nelen W, Grol R, Zielhuis G, Adang E, Stalmeier P, et al. The effect of a multifaceted empowerment strategy on decision making about the number of embryos transferred in in vitro fertilisation: randomised controlled trial. BMJ. 2010;341:c2501. doi: 10.1136/bmj.c2501.

20. Stalmeier PF. Adherence and decision AIDS: a model and a narrative review. Med Decis Making. 2011;31(1):121-9. doi: 10.1177/0272989X10370487.

21. Drummond MF, Sculpher MJ, Claxton K, Stoddart GL, Torrance GW. Methods for the economic evaluation of health care programmes. 4th ed. New York: Oxford; 2015.

22. Institute for Clinical and Economic Review. Disease-modifying therapies for relapsing-remitting and primary-progressive multiple sclerosis: effectiveness and value. 2017.

23. Chevalier J, Chamoux C, Hammes F, Chicoye A. Cost-effectiveness of treatments for relapsing remitting multiple sclerosis: A french societal perspective. PLoS One. 2016;11(3):e0150703.

24. Chilcott J, McCabe C, Tappenden P, O'Hagan A, Cooper NJ, Abrams K, et al. Modeling the cost effectiveness of interferon beta and glatiramer acetate in the management of multiple sclerosis. Commentary: evaluating disease modifying treatments in multiple sclerosis. BMJ. 2003;326(7388):522; discussion doi: 10.1136/bmj.326.7388.522.

25. Gani R, Giovannoni G, Bates D, Kemball B, Hughes S, Kerrigan J. Cost-effectiveness analyses of natalizumab (Tysabri) compared with other disease-modifying therapies for people with highly active relapsing-remitting multiple sclerosis in the UK. Pharmacoeconomics. 2008;26(7):617-27. doi: 10.2165/00019053-200826070-00008.

26. Maruszczak MJ, Montgomery SM, Griffiths MJ, Bergvall N, Adlard N. Cost-utility of fingolimod compared with dimethyl fumarate in highly active relapsing-remitting multiple sclerosis (RRMS) in England. J Med Econ. 2015;18(11):874-85. doi: 10.3111/13696998.2015.1056794.

27. Mauskopf J, Fay M, Iyer R, Sarda S, Livingston T. Cost-effectiveness of delayed-release dimethyl fumarate for the treatment of relapsing forms of multiple sclerosis in the United States. J Med Econ. 2016;19(4):432-42. doi: 10.3111/13696998.2015.1135805.

28. Su W, Kansal A, Vicente C, Deniz B, Sarda S. The cost-effectiveness of delayed-release dimethyl fumarate for the treatment of relapsing-remitting multiple sclerosis in Canada. J Med Econ. 2016;19(7):718-27. doi: 10.3111/13696998.2016.1164174.

29. Tappenden P, McCabe C, Chilcott J, Simpson E, Nixon R, Madan J, et al. Cost-effectiveness of disease-modifying therapies in the management of multiple sclerosis for the Medicare population. Value Health. 2009;12(5):657-65. doi: 10.1111/j.1524-4733.2008.00485.x.

30. Zorginstituut Nederland. Richtlijn voor het uitvoeren van economische evaluaties in de gezondheidszorg. 2015.

31. Husereau D, Drummond M, Petrou S, Carswell C, Moher D, Greenberg D, et al. Consolidated Health Economic Evaluation Reporting Standards (CHEERS)--explanation and elaboration: a report of the ISPOR Health Economic Evaluation Publication Guidelines Good Reporting Practices Task Force. Value Health. 2013;16(2):231-50. doi: 10.1016/j.jval.2013.02.002.

32. Karampampa K, Gustavsson A, van Munster ET, Hupperts RM, Sanders EA, Mostert J, et al. Treatment experience, burden, and unmet needs (TRIBUNE) in Multiple Sclerosis study: the costs and utilities of MS patients in The Netherlands. J Med Econ. 2013;16(7):939-50. doi: 10.3111/13696998.2013.807267.

33. Kobelt G, Berg J, Lindgren P, Anten B, Ekman M, Jongen PJ, et al. Costs and quality of life in multiple sclerosis in The Netherlands. Eur J Health Econ. 2006;7 Suppl 2:S55-64. doi: 10.1007/s10198-006-0378-6. 
34. Zimmermann M, Brouwer E, Tice JA, Seidner M, Loos AM, Liu S, et al. Disease-modifying therapies for relapsing-remitting and primary progressive multiple sclerosis: a cost-utility analysis. CNS Drugs. 2018. doi: 10.1007/s40263-018-0566-9.

35. Institute for Clinical and Economic Review. Disease-modifying therapies for relapsing-remitting and primary-progressive multiple sclerosis: effectiveness and value. 2017 [cited 2018 December 14]. Available from: https://icer-review.org/wp-conte nt/uploa ds/2016/08/CTAF_MS_FinalReport_030617.pdf.

36. Penton $\mathrm{H}$, Hiligsmann $\mathrm{M}$, Harrison $\mathrm{M}$, Reginster JY, Boonen $A$, Bansback N. Potential costeffectiveness for using patient decision aids to guide osteoporosis treatment. Osteoporos Int. 2016;27(9):2697-707. doi: 10.1007/s00198-016-3596-5.

37. Trenaman L, Sadatsafavi M, Almeida F, Ayas N, Lynd L, Marra C, et al. Exploring the Potential Cost-Effectiveness of Patient Decision Aids for Use in Adults with Obstructive Sleep Apnea: A Case Study. Med Decis Making. 2015;35(5):671-82. doi: 10.1177/0272989x14556676.

38. Ivanova JI, Bergman RE, Birnbaum HG, Phillips AL, Stewart M, Meletiche DM. Impact of medication adherence to disease-modifying drugs on severe relapse, and direct and indirect costs among employees with multiple sclerosis in the US. J Med Econ. 2012;15(3):601-9. doi: 10.3111/13696998.2012.667027.

39. GIPdatabank: informatie over geneesmiddelen en hulpmiddelen van Zorginstituut Nederland [Internet]. 2018 [cited 2018 October 16]. Available from: https://www.gipdatabank.nl/.

40. Jongen PJ, Lemmens WA, Hupperts R, Hoogervorst E, Schrijver HM, Slettenaar A, et al. Persistence and adherence in multiple sclerosis patients starting glatiramer acetate treatment: assessment of relationship with care received from multiple disciplines. Patient Prefer Adherence. 2016;10:909-17. doi: 10.2147/ppa.S108121.

41. Calabresi PA, Kieseier BC, Arnold DL, Balcer LJ, Boyko A, Pelletier J, et al. Pegylated interferon beta-1a for relapsing-remitting multiple sclerosis (ADVANCE): a randomised, phase 3 , doubleblind study. Lancet Neurol. 2014;13(7):657-65. doi: 10.1016/s1474-4422(14)70068-7.

42. Calabresi PA, Radue EW, Goodin D, Jeffery D, Rammohan KW, Reder AT, et al. Safety and efficacy of fingolimod in patients with relapsing-remitting multiple sclerosis (FREEDOMS II): a doubleblind, randomised, placebo-controlled, phase 3 trial. Lancet Neurol. 2014;13(6):545-56. doi: 10.1016/s1474-4422(14)70049-3.

43. Coles AJ, Twyman CL, Arnold DL, Cohen JA, Confavreux C, Fox EJ, et al. Alemtuzumab for patients with relapsing multiple sclerosis after disease-modifying therapy: a randomised controlled phase 3 trial. Lancet. 2012;380(9856):1829-39. doi: 10.1016/s0140-6736(12)61768-1.

44. Gold R, Kappos L, Arnold DL, Bar-Or A, Giovannoni G, Selmaj K, et al. Placebo-controlled phase 3 study of oral BG-12 for relapsing multiple sclerosis. N Engl J Med. 2012;367(12):1098-107. doi: 10.1056/NEJMoa1114287.

45. Hauser SL, Bar-Or A, Comi G, Giovannoni G, Hartung HP, Hemmer B, et al. Ocrelizumab versus interferon beta-1a in relapsing multiple sclerosis. N Engl J Med. 2017;376(3):221-34. doi: 10.1056/NEJMoa1601277.

46. Khan O, Rieckmann P, Boyko A, Selmaj K, Zivadinov R. Three times weekly glatiramer acetate in relapsing-remitting multiple sclerosis. Ann Neurol. 2013;73(6):705-13. doi: 10.1002/ana.23938.

47. Mikol DD, Barkhof F, Chang P, Coyle PK, Jeffery DR, Schwid SR, et al. Comparison of subcutaneous interferon beta-1a with glatiramer acetate in patients with relapsing multiple sclerosis (the REbif vs Glatiramer Acetate in Relapsing MS Disease [REGARD] study): a multicentre, randomised, parallel, open-label trial. Lancet Neurol. 2008;7(10):903-14. doi: 10.1016/s1474-4422(08)70200-x.

48. O'Connor P, Filippi M, Arnason B, Comi G, Cook S, Goodin D, et al. 250 microg or 500 microg interferon beta- $1 \mathrm{~b}$ versus $20 \mathrm{mg}$ glatiramer acetate in relapsing-remitting multiple sclerosis: a prospective, randomised, multicentre study. Lancet Neurol. 2009;8(10):889-97. doi: 10.1016/s1474-4422(09)70226-1. 
49. Polman CH, O'Connor PW, Havrdova E, Hutchinson M, Kappos L, Miller DH, et al. A randomized, placebo-controlled trial of natalizumab for relapsing multiple sclerosis. N Engl J Med. 2006;354(9):899-910. doi: 10.1056/NEJMoa044397.

50. Vermersch P, Czlonkowska A, Grimaldi LM, Confavreux C, Comi G, Kappos L, et al. Teriflunomide versus subcutaneous interferon beta- 1 a in patients with relapsing multiple sclerosis: a randomised, controlled phase 3 trial. Mult Scler. 2014;20(6):705-16. doi: $10.1177 / 1352458513507821$.

51. Vollmer TL, Sorensen PS, Selmaj K, Zipp F, Havrdova E, Cohen JA, et al. A randomized placebocontrolled phase III trial of oral laquinimod for multiple sclerosis. J Neurol. 2014;261(4):773-83. doi: 10.1007/s00415-014-7264-4.

52. Lynd LD, Traboulsee A, Marra CA, Mittmann N, Evans C, Li KH, et al. Quantitative analysis of multiple sclerosis patients' preferences for drug treatment: a best-worst scaling study. Ther Adv Neurol Disord. 2016;9(4):287-96. doi: 10.1177/1756285616648060.

53. Bergmann A, Lang $M$, Bischoff $C L$, Schicklmaier $P$, Nolting HD, Schiffhorst $G$, et al. Patient preferences in the choice of disease modifying drugs for multiple sclerosis. Neurology. 2014;1.

54. Gustavsson A, Karampampa K, Miltenburger C, Eckert B. Treatment experience, burden, and unmet needs (TRIBUNE) in multiple sclerosis study: patient preferences for MS treatments. Multi Scler. 2011;1:S239. doi: http://dx.doi.org/10.1177/1352458511422300.

55. Sommers R, Phillips A. Unmet needs in the treatment of multiple sclerosis: patient perspectives. J Manag Care Pharm. 2009;15 (7):602-3.

56. Utz KS, Hoog J, Wentrup A, Berg S, Lammer A, Jainsch B, et al. Patient preferences for diseasemodifying drugs in multiple sclerosis therapy: a choice-based conjoint analysis. Ther Adv Neurol Disord. 2014;7(6):263-75. doi: 10.1177/1756285614555335.

57. Johnson FR, Van Houtven G, Özdemir S, Hass S, White J, Francis G, et al. Multiple Sclerosis patients' benefit-risk preferences: serious adverse event risks versus treatment efficacy. J Neurol. 2009;256:554-62.

58. Wilson L, Loucks A, Bui C, Gipson G, Zhong L, Schwartzburg A, et al. Patient centered decision making: use of conjoint analysis to determine risk-benefit trade-offs for preference sensitive treatment choices. J Neurol Sci. 2014;344(1-2):80-7. doi: 10.1016/j.jns.2014.06.030.

59. CBS. Statline. Overlevingskansen; geslacht, leeftijd. 2018 [cited 2018 October 16]. Available from: https://opendata.cbs.nl/\#/CBS/nl/dataset/70701ned/table?ts=1538592455891.

60. Pokorski RJ. Long-term survival experience of patients with multiple sclerosis. J Insur Med. 1997;29:101-6.

61. Statistics Netherlands. Consumer Price Index. 2018 [cited 2018 October 4]. Available from: https://opendata.cbs.nl/statline/\#/CBS/nl/dataset/83131ned/table?ts=1539116082871.

62. Zorginstituut Nederland. Medicijnkosten. Diemen, The Netherlands: Zorginstituut Nederlands; [cited 2018 October 16]. Available from: www.medicijnkosten.nl.

63. Hakkaart-van Roijen L, van der Linden N, Bouwmans C, Kanters T, Tan SS. Kostenhandleiding: Methodologie van kostenonderzoek en referentieprijzen voor economische evaluaties in de gezondheidszorg. Rotterdam, The Netherlands: Institute for Medical Technology Assessment, Erasmus Universiteit Rotterdam, 2015.

64. Nederlandse Zorgautoriteit (NZa). DBC zorgproducten tariefapplicatie. 2018 [cited 2018 October 16]. Available from: https://zorgproducten.nza.nl/.

65. Uitdehaag B, Kobelt G, Berg J, Capsa D, Dalen J. New insights into the burden and costs of multiple sclerosis in Europe: results for the Netherlands. Mult Scler. 2017;23(2_suppl):117-29. doi: $10.1177 / 1352458517708663$.

66. Brouwer WB, Koopmanschap MA. The friction-cost method. Pharmacoeconomics. 2005;23(2):105-11.

67. Koopmanschap MA, Rutten FF. A practical guide for calculating indirect costs of disease. Pharmacoeconomics. 1996;10(5):460-6. 
68. Eddy DM, Hollingworth W, Caro JJ, Tsevat J, McDonald KM, Wong JB. Model transparency and validation: a report of the ISPOR-SMDM Modeling Good Research Practices Task Force-7. Med Decis Making. 2012;32(5):733-43. doi: 10.1177/0272989x12454579.

69. Zwaap J, Knies S, van der Meijden C, Staal P, van der Heiden L. Kosteneffectiviteit in de praktijk. National Healthcare Institute, 2015.

70. Khdour MR, Agus AM, Kidney JC, Smyth BM, McElnay JC, Crealey GE. Cost-utility analysis of a pharmacy-led self-management programme for patients with COPD. Int J Clin Pharm. 2011;33(4):665-73. doi: 10.1007/s11096-011-9524-z.

71. Murray MD, Young J, Hoke S, Tu W, Weiner M, Morrow D, et al. Pharmacist intervention to improve medication adherence in heart failure: a randomized trial. Ann Intern Med. 2007;146(10):714-25.

72. Hernandez L, O'Donnell M, Postma M. Modeling approaches in cost-effectiveness analysis of disease-modifying therapies for relapsing-remitting multiple sclerosis: an updated systematic review and recommendations for future economic evaluations. Pharmacoeconomics. 2018;36(10):1223-52. doi: 10.1007/s40273-018-0683-9. 


\section{Supplementary information}

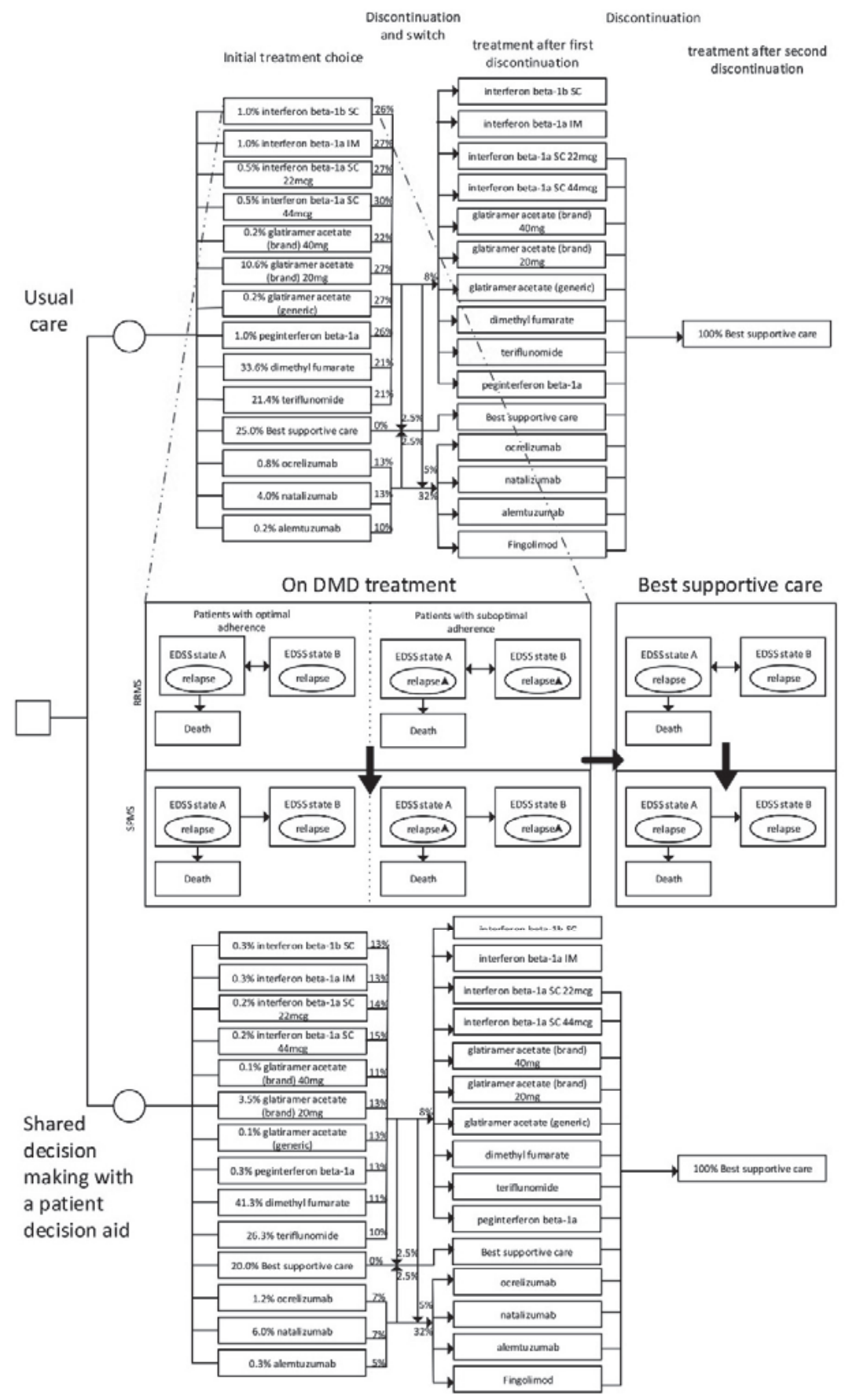

Figure 1. Detailed model structure 
Table 1. Parameters derived from the model by the Institute for Clinical and Economic Review $(1,2)$

\begin{tabular}{l}
\hline Parameter \\
\hline Distribution of patients entering the model in each EDSS state \\
Probability of moving between EDSS states, RRMS and SPMS \\
Probability of conversion from RRMS tot SPMS \\
Annual Relapse rate, RRMS, SPMS \\
Probability of severe relapse (adherent patients) \\
Mortality multipliers of all-cause general population mortality \\
Annual disutility from adverse events \\
Healthcare resource utilization due to adverse events \\
Annual utility scores per health state, RRMS and SPMS \\
Disutility mild/moderate and severe relapses \\
Relative risk for EDSS progression \\
Rate ratio for relapse rate (adherent patients)
\end{tabular}

Table 2. Distribution of patients entering the model (Source: Zimmerman et al. (2))

\begin{tabular}{lll}
\hline Health state $^{*}$ & $\mathrm{p}$ & Range \\
\hline 1 & 0.22 & $0.17-0.26$ \\
2 & 0.28 & $0.23-0.34$ \\
3 & 0.24 & $0.19-0.29$ \\
4 & 0.15 & $0.12-0.18$ \\
5 & 0.06 & $0.05-0.07$ \\
6 & 0.00 & $0.00-0.00$ \\
7 & 0.00 & $0.00-0.00$ \\
8 & 0.00 & $0.00-0.00$ \\
9 & 0.00 & $0.00-0.00$ \\
\hline
\end{tabular}


Table 3. Relative Risk of EDSS Progression per treatment option

\begin{tabular}{|c|c|c|c|c|c|c|}
\hline \multirow[b]{2}{*}{ Treatment option } & \multicolumn{2}{|c|}{ EDSS progression } & \multicolumn{2}{|c|}{$\begin{array}{l}\text { Relapses } \\
\text { adherent }\end{array}$} & \multicolumn{2}{|c|}{$\begin{array}{c}\text { Relapses } \\
\text { non-adherent }\end{array}$} \\
\hline & $\mathrm{RR}$ & Range & $\mathrm{RR}$ & Range & $\mathrm{RR}$ & Range \\
\hline Supportive Care & 1.00 & & 1.00 & & 1.00 & \\
\hline Alemtuzumab & 0.42 & $0.25-0.68$ & 0.28 & $0.22-0.35$ & 0.28 & $0.05-0.35$ \\
\hline Dimethyl fumarate & 0.62 & $0.46-0.84$ & 0.53 & $0.43-0.63$ & 0.73 & $0.63-0.83$ \\
\hline Fingolimod & 0.68 & $0.51-0.90$ & 0.46 & $0.39-0.55$ & 0.69 & $0.61-0.77$ \\
\hline Glatiramer acetate $20 \mathrm{mg}$ (generic) & 0.74 & $0.58-0.94$ & 0.63 & $0.55-0.71$ & 0.79 & $0.71-0.87$ \\
\hline Glatiramer acetate $20 \mathrm{mg}$ (brand) & 0.74 & $0.58-0.94$ & 0.63 & $0.55-0.71$ & 0.79 & $0.71-0.87$ \\
\hline Glatiramer acetate $40 \mathrm{mg}$ (brand) & 1.17 & 0.69-1.92 & 0.67 & $0.52-0.86$ & 0.81 & $0.64-0.98$ \\
\hline Interferon beta-1a IM & 0.79 & $0.63-1.00$ & 0.83 & $0.74-0.94$ & 0.90 & $0.80-1.00$ \\
\hline Interferon beta-1a $22 \mathrm{mcg}$ SC & 0.81 & $0.52-1.23$ & 0.70 & $0.55-0.85$ & 0.83 & $0.68-0.98$ \\
\hline Interferon beta-1a $44 \mathrm{mcg}$ SC & 0.73 & $0.52-0.99$ & 0.64 & $0.54-0.73$ & 0.79 & $0.70-0.89$ \\
\hline Interferon beta-1b & 0.66 & $0.46-0.89$ & 0.65 & $0.55-0.77$ & 0.80 & $0.69-0.91$ \\
\hline Natalizumab & 0.56 & $0.37-0.84$ & 0.31 & $0.25-0.40$ & 0.31 & $0.25-0.40$ \\
\hline Ocrelizumab & 0.47 & $0.28-0.76$ & 0.35 & $0.27-0.44$ & 0.35 & $0.27-0.44$ \\
\hline Peginterferon beta-1a & 0.63 & $0.37-1.02$ & 0.63 & $0.47-0.86$ & 0.79 & $0.59-0.98$ \\
\hline Teriflunomide & 0.72 & $0.52-0.97$ & 0.67 & 0.56-0.79 & 0.81 & 0.69-0.92 \\
\hline
\end{tabular}

EDSS, Expanded Disability Status Score; RR, relative risk 
Table 4. Healthcare utilization unit costs, range and standard error

\begin{tabular}{|c|c|c|}
\hline Parameter & Unit cost & $\begin{array}{l}\text { Standard } \\
\text { error }\end{array}$ \\
\hline \multicolumn{3}{|l|}{ Drug costs (3) } \\
\hline Teriflunomide $14 \mathrm{mg}$ & $€ 992.88 / 28 \mathrm{EA}$ & \\
\hline Interferon beta-1a IM & $€ 916.68 / 4 \mathrm{EA}$ & \\
\hline Interferon beta-1b & $€ 766.92 / 14 \mathrm{EA}$ & \\
\hline Glatiramere acetate $20 \mathrm{mg}$ (brand) & $€ 856.80 / 30 \mathrm{EA}$ & \\
\hline Glatiramere acetate $40 \mathrm{mg}$ (brand) & $€ 794.76 / 30 \mathrm{EA}$ & \\
\hline Fingolimod & $€ 1,916.70 / 30 \mathrm{EA}$ & \\
\hline Glatiramere acetate $20 \mathrm{mg}$ (generic) & $€ 771.00 / 30 \mathrm{EA}$ & \\
\hline Alemtuzumab & $€ 7,420.00 / 1.2 \mathrm{ml}$ & \\
\hline Peginterferon beta-1a & $€ 1,126.34 / 1 \mathrm{ml}$ & \\
\hline Interferon beta-1a $22 \mathrm{mcg}$ SC & $€ 868.56 / 0.5 \mathrm{ml}$ & \\
\hline Interferon beta-1a 44 mcg SC & $€ 1,076.88 / 0.5 \mathrm{ml}$ & \\
\hline Dimethyl fumarate & $€ 1,295.40 / 60 \mathrm{EA}$ & \\
\hline Natalizumab & $€ 1,670.58 / 15 \mathrm{ml}$ & \\
\hline Ocrelizumab & $€ 5,871.20 / 300 \mathrm{mg}$ vial & \\
\hline \multicolumn{3}{|l|}{ Utilization costs } \\
\hline \multicolumn{3}{|l|}{ Administration Costs (4) } \\
\hline Inpatient stay & $€ 413.08$ & 42.15 \\
\hline Outpatient day treatment & $€ 288.63$ & 29.45 \\
\hline \multicolumn{3}{|l|}{ Laboratory Costs (5) } \\
\hline Complete blood count & $€ 14.57$ & 1.49 \\
\hline Serum Creatinine & $€ 3.52$ & 0.36 \\
\hline Urine analysis & $€ 4.33$ & 0.44 \\
\hline Thyroid & $€ 14.30$ & 1.46 \\
\hline Liver & $€ 21.40$ & 2.18 \\
\hline MRI & $€ 240.54$ & 24.54 \\
\hline ECG & $€ 47.54$ & 4.85 \\
\hline ALT & $€ 3.76$ & 0.38 \\
\hline Metabolic panel & $€ 61.47$ & 6.27 \\
\hline \multicolumn{3}{|l|}{ Visit Costs (4) } \\
\hline GP visit & $€ 34.51$ & 3.52 \\
\hline Specialist visit & $€ 103.53$ & 10.56 \\
\hline \multicolumn{3}{|l|}{ Adverse event costs ${ }^{\#}(2)$} \\
\hline PML & $€ 26,008.09$ & $2,653.89$ \\
\hline $\begin{array}{l}\text { Hospital stay for disorders of the biliary } \\
\text { without complications }\end{array}$ & $€ 4,966.30$ & 506.77 \\
\hline Inpatient stay for depression & $€ 4,308.94$ & 439.69 \\
\hline Hospital stay for influenza/pneumonia & $€ 6,309.02$ & 643.78 \\
\hline Serious infection & $€ 12,398.49$ & $1,265.15$ \\
\hline Cranial nerve disorder & $€ 8,685.00$ & 886.22 \\
\hline Patient decision aid costs (6) & $€ 100.00$ & 10.20 \\
\hline
\end{tabular}

* Normal distribution was applied for costs.

\# Estimation of adverse event costs is explained in the supplementary material.

GP, general practitioner; PML, Progressive multifocal leukoencephalopathy 
Table 5. Health state and relapse cost

\begin{tabular}{|c|c|c|c|}
\hline Parameter & Unit cost & Range & Standard error \\
\hline \multicolumn{4}{|c|}{$\begin{array}{l}\text { EDSS state costs: healthcare costs only } \\
\text { (7) }\end{array}$} \\
\hline 0 & $€ 2,496$ & $1997-2996$ & 255 \\
\hline 1 & $€ 3,539$ & $2831-4247$ & 361 \\
\hline 2 & $€ 4,582$ & $3665-5498$ & 468 \\
\hline 3 & $€ 5,624$ & $4499-6749$ & 574 \\
\hline 4 & $€ 6,667$ & $5333-8000$ & 680 \\
\hline 5 & $€ 7,709$ & $6167-9251$ & 787 \\
\hline 6 & $€ 8,541$ & $6833-10250$ & 872 \\
\hline 7 & $€ 9,303$ & $7443-11164$ & 949 \\
\hline 8 & $€ 10,065$ & $8052-12079$ & 1,027 \\
\hline 9 & $€ 10,828$ & $8662-12993$ & 1,105 \\
\hline
\end{tabular}

EDSS state costs: productivity costs

(FCM), informal care, investments and services (7)

0
1
2
3
4
5
6
7
8
9

EDSS state costs: productivity costs

$\begin{array}{rrr}€ 105 & 84-125 & 11 \\ € 1,118 & 894-1342 & 114 \\ € 2,131 & 1705-2558 & 217 \\ € 3,145 & 2516-3774 & 321 \\ € 4,158 & 3327-4990 & 424 \\ € 5,172 & 4137-6206 & 528 \\ € 9,398 & 7518-11278 & 959 \\ € 14,695 & 11756-17634 & 1,500 \\ € 19,993 & 15994-23991 & 2,040 \\ € 25,290 & 20232-30348 & 2,581\end{array}$

(HCA), informal care, investments and services (7)

0
1
2
3
4
5
6
7
8
9

Relapse costs: healthcare costs (8)

$\begin{array}{rrr}€ 11,322 & 9058-13586 & 1,155 \\ € 13,373 & 10698-16047 & 1,365 \\ € 15,423 & 12339-18508 & 1,574 \\ € 17,474 & 13979-20969 & 1,783 \\ € 19,525 & 15620-23430 & 1,992 \\ € 21,576 & 17261-25891 & 2,202 \\ € 27,122 & 21698-32546 & 2,768 \\ € 33,833 & 27067-40600 & 3,452 \\ € 40,545 & 32436-48654 & 4,137 \\ € 47,256 & 37805-56707 & 4,822 \\ € 2,042 & 1634-2451 & 208 \\ € 2,042 & 1634-2451 & 208\end{array}$

$\begin{array}{llll}\text { Mild/moderate } & € 2,042 & 1634-2451 & 208 \\ \text { Severe } & € 2,042 & 1634-2451 & 208\end{array}$

Relapse costs: productivity costs*, informal care, investments and services (8)

\begin{tabular}{llll} 
Mild/moderate & $€ 1,052$ & $842-1263$ & 107 \\
Severe & $€ 1,052$ & $842-1263$ & 107 \\
\hline
\end{tabular}

Health state costs were calculated using interpolation of data from Uitdehaag et al. (7). A separate formula was used to calculate health states costs of Expanded Disability Status Scores (EDSS) 0 to 5 (direct costs $=1,002.7$ EDSS $x$ 
$+2,403$; indirect costs $=1,972.8$ EDSS $_{x}+10,891.8$ ) and for EDSS 6 to 9 (direct costs $=733.1$ EDSS $_{x}+3,818.3$; indirect costs $=6,456.4 E_{D S S}+12,646.9$ ) because of the categorization of costs in Uitdehaag et al. (7).

For probabilistic sensitivity analyses, a normal distribution was applied in according with the previous published model $(1,2)$.

FCM, Friction Cost Method; HCA, Human Capital Approach

* Early retirement, invalidity and DMD costs excluded 


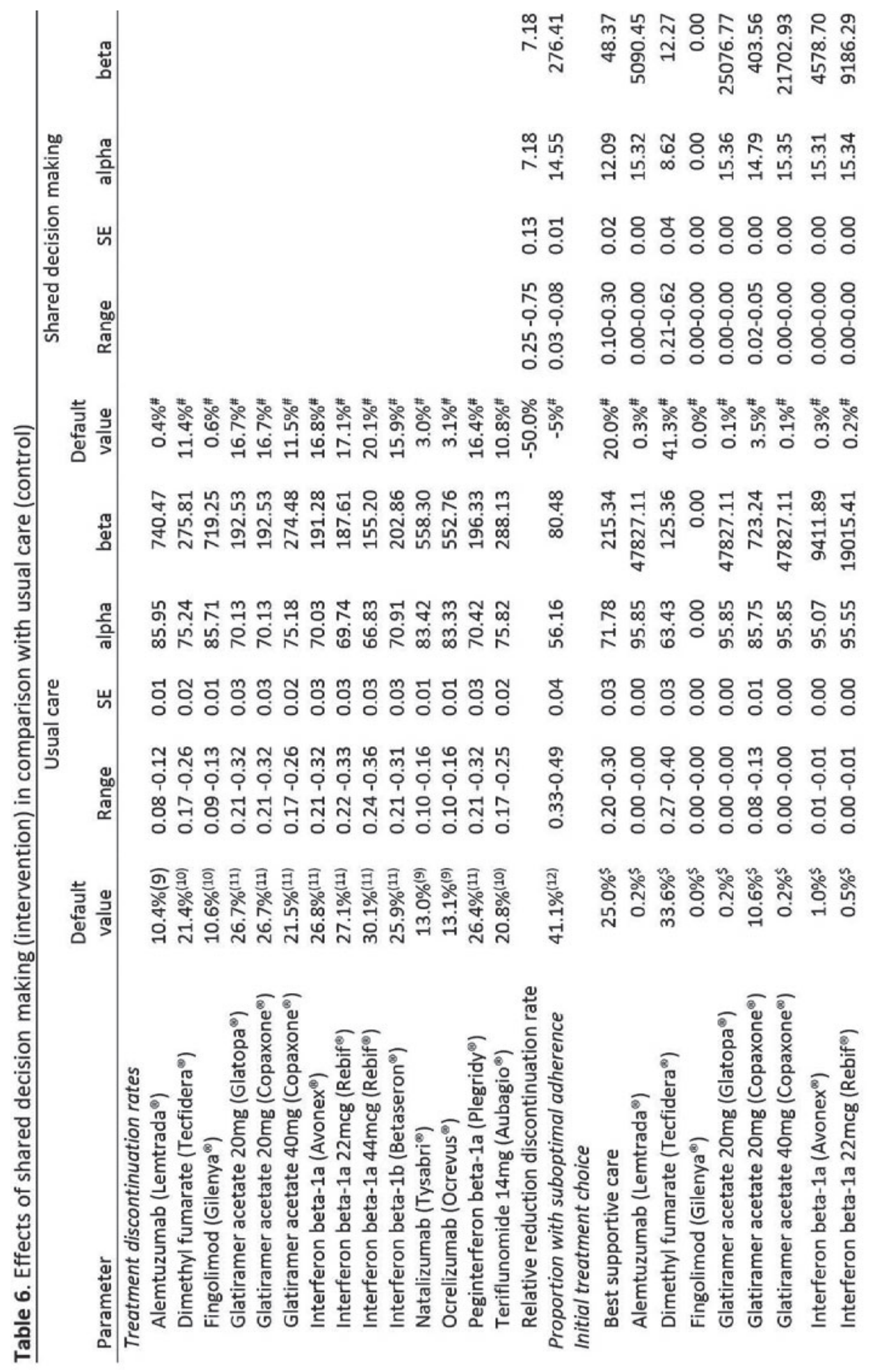




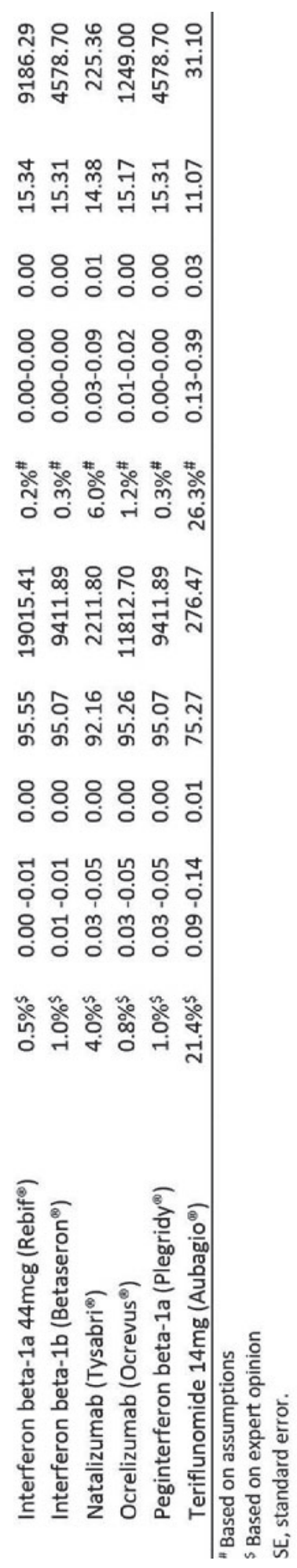




\section{Treatment initiation}

The proportions of patients initiating a specific DMD treatment or opting for best supportive care were assumed to differ among the groups, following studies for other health decisions (6, 13-15).

The mix of treatment initiations was informed by current clinical practice in the Netherlands based on expert opinions and recommendations provided by the Dutch Healthcare Institute (16), in the absence of formal up-to-date clinical guidelines. A patient's eligibility for certain types of DMDs is determined by the degree of disease activity and whether previous DMD treatment has been unsuccessful in reducing relapses (16). Interferon beta-1a IM, interferon beta-1a $22 \mathrm{mcg}$ and $44 \mathrm{mcg}$ SC, interferon beta-1b SC, peginterferon beta-1a, glatiramer acetate (generic $20 \mathrm{mg}$ and brand $40 \mathrm{mg}$ and $20 \mathrm{mg}$ ), teriflunomide and dimethyl fumarate are generally considered first-line treatments in the Netherlands. Natalizumab, alemtuzumab, fingolimod, ocrelizumab and cladribine are considered second-line treatments for patients with highly active MS because of their higher efficacy, but also less favourable safety profiles (16). Patients choosing for DMD treatment were assumed to either start first-line DMDs or, in the case of highly active MS at onset, directly start a DMD usually defined as a second-line treatment, with the exception of fingolimod. In the Netherlands, fingolimod can be prescribed only if treatment with another (first-line) DMD has been ineffective. Table 1 presents the proportion of patients initiating each treatment for usual care and different profiles of shared decision making.

Table 7. Specification of treatment initiation in the intervention and control group

\begin{tabular}{lrrr}
\hline & Treatment initiation \\
& CAU & \multicolumn{1}{c}{ SDM $^{\#}$} & \multicolumn{1}{c}{ SDM $^{\$}$} \\
\hline Best supportive care & $25.0 \%$ & $20.0 \%$ & $22.5 \%$ \\
Alemtuzumab & $0.2 \%$ & $0.3 \%$ & $0.3 \%$ \\
Dimethyl fumarate & $33.6 \%$ & $41.3 \%$ & $37.4 \%$ \\
Fingolimod & $0.0 \%$ & $0.0 \%$ & $0.0 \%$ \\
Glatiramer acetate 20mg (generic) & $0.2 \%$ & $0.1 \%$ & $0.1 \%$ \\
Glatiramer acetate 20mg (brand) & $10.6 \%$ & $3.5 \%$ & $7.1 \%$ \\
Glatiramer acetate 40mg (brand) & $0.2 \%$ & $0.1 \%$ & $0.1 \%$ \\
Interferon beta-1a & $1.0 \%$ & $0.3 \%$ & $0.7 \%$ \\
Interferon beta-1a 22mcg & $0.5 \%$ & $0.2 \%$ & $0.3 \%$ \\
Interferon beta-1a 44mcg & $0.5 \%$ & $0.2 \%$ & $0.3 \%$ \\
Interferon beta-1b & $1.0 \%$ & $0.3 \%$ & $0.7 \%$ \\
Natalizumab & $4.0 \%$ & $6.0 \%$ & $5.0 \%$ \\
Ocrelizumab & $0.8 \%$ & $1.2 \%$ & $1.0 \%$ \\
Peginterferon beta-1a & $1.0 \%$ & $0.3 \%$ & $0.7 \%$ \\
Teriflunomide 14mg & $21.4 \%$ & $26.3 \%$ & $23.8 \%$ \\
\hline
\end{tabular}

\#Profile in the combined scenario.

$\$$ Values in the one-way sensitivity analyses 


\section{Switching between treatments after first discontinuation}

After discontinuation of the first DMD, patients could switch to another treatment or to best supportive care. Experts concluded that about $95 \%$ of patients who discontinued their first treatment would switch to another DMD treatment. From pivotal studies, it was estimated that $79 \%$ (17-27) of patients discontinue due to side effects and $21 \%(18-23,26)$ of patients discontinue due to a perceived lack of efficacy. The $5 \%$ of patients switching to best supportive care were assumed to be equally distributed between the patients discontinuing due to side effects and those discontinuing due to lack of efficacy. Patients stopping treatment due to side effects were assumed to switch to another first-line DMD, resulting in an $8 \%$ chance of switching from a first-line DMD to each of the other first-line DMDs (i.e. $79 \%$ of those discontinuing due to side effects switch to one of the other nine first-line DMDs - and 5\%/2 switch to best supportive care). Patients stopping treatment due to a perceived lack of efficacy were assumed to switch to a second-line DMD, i.e. natalizumab, fingolimod, alemtuzumab or ocrelizumab, resulting in a $5 \%$ chance of switching from a first-line DMD to each second-line DMD (i.e. $21 \%$ of those discontinuing due to side effects switch to one of the four second-line DMDs, and 5\%/2 switch to best supportive care). If second-line DMD-users discontinued treatment, they were assumed to switch to another second-line DMD. 
Table 8a. Detailed results of scenario analyses and sensitivity analyses

\begin{tabular}{|c|c|c|c|c|c|c|c|c|}
\hline & & $\begin{array}{l}\text { total } \\
\text { costs }\end{array}$ & $\begin{array}{l}\text { Drug } \\
\text { Costs }\end{array}$ & $\begin{array}{l}\text { usua } \\
\text { Direct } \\
\text { and } \\
\text { indirect } \\
\text { cost }\end{array}$ & $\begin{array}{l}\mathrm{AE} \\
\text { Costs }\end{array}$ & $\begin{array}{l}\text { total } \\
\text { QALYs }\end{array}$ & Relapses & $\begin{array}{l}\text { Life- } \\
\text { Years }\end{array}$ \\
\hline \multicolumn{9}{|l|}{ Effect of SDM vs. CAU * } \\
\hline \multirow[t]{2}{*}{ DMD choice } & $\#$ & $€ 397,646$ & $€ 47,986$ & $€ 349.650$ & $€ 10$ & 7.67 & 15.28 & 26,59 \\
\hline & $\&$ & $€ 397,646$ & $€ 47,986$ & $€ 349.650$ & $€ 10$ & 7.67 & 15.28 & 26,59 \\
\hline \multirow[t]{3}{*}{ Discontinuation rate } & $-10 \%$ & $€ 397,646$ & $€ 47,986$ & $€ 349.650$ & $€ 10$ & 7.67 & 15.28 & 26,59 \\
\hline & $-5 \%$ & $€ 397,646$ & $€ 47,986$ & $€ 349.650$ & $€ 10$ & 7.67 & 15.28 & 26,59 \\
\hline & $-20 \%$ & $€ 397,646$ & $€ 47,986$ & $€ 349.650$ & $€ 10$ & 7.67 & 15.28 & 26,59 \\
\hline \multirow[t]{3}{*}{ Proportion adherent } & $+5 \%$ & $€ 397,646$ & $€ 47,986$ & $€ 349.650$ & $€ 10$ & 7.67 & 15.28 & 26,59 \\
\hline & $+10 \%$ & $€ 397,646$ & $€ 47,986$ & $€ 349.650$ & $€ 10$ & 7.67 & 15.28 & 26,59 \\
\hline & $100 \%$ & $€ 397,646$ & $€ 47,986$ & $€ 349.650$ & $€ 10$ & 7.67 & 15.28 & 26,59 \\
\hline Combined effects $\$$ & & $€ 397,646$ & $€ 47,986$ & $€ 349.650$ & $€ 10$ & 7.67 & 15.28 & 26,59 \\
\hline \multicolumn{9}{|l|}{$\begin{array}{l}\text { Sensitivity analyses: } \\
\text { combined effects }\end{array}$} \\
\hline \multicolumn{2}{|l|}{ Drug costs $+20 \%$} & $€ 406,905$ & $€ 57,245$ & $€ 349,650$ & $€ 10$ & 7.67 & 15.28 & 26.59 \\
\hline \multicolumn{2}{|l|}{ Drug costs $-20 \%$} & $€ 388,387$ & $€ 38,727$ & $€ 349,650$ & $€ 10$ & 7.67 & 15.28 & 26.59 \\
\hline \multicolumn{2}{|c|}{$\begin{array}{l}\text { Relative risk progression rate } \\
\text { EDSS states: improvement }\end{array}$} & $€ 384,371$ & $€ 49,886$ & $€ 334,475$ & $€ 10$ & 8.58 & 15.84 & 26.85 \\
\hline \multicolumn{2}{|c|}{$\begin{array}{l}\text { Relative risk progression rate } \\
\text { EDSS states: worsening }\end{array}$} & $€ 413,913$ & $€ 44,895$ & $€ 369,007$ & $€ 11$ & 6.53 & 14.62 & 26.27 \\
\hline \multicolumn{2}{|l|}{ Costs pDA: $€ 0$} & $€ 397,646$ & $€ 47,986$ & $€ 349,650$ & $€ 10$ & 7.67 & 15.28 & 26.59 \\
\hline \multicolumn{2}{|l|}{ Discount rate: $3 \%$} & $€ 465,321$ & $€ 50,231$ & $€ 415,077$ & $€ 12$ & 6.98 & 15.28 & 21.29 \\
\hline \multicolumn{2}{|l|}{ Discount rate: $0 \%$} & $€ 811,208$ & $€ 58,601$ & $€ 752,584$ & $€ 23$ & 8.45 & 15.28 & 34.28 \\
\hline \multicolumn{2}{|c|}{ Healthcare perspective } & $€ 203,427$ & $€ 47,986$ & $€ 155,436$ & $€ 5$ & 7.67 & 15.28 & 26.59 \\
\hline \multicolumn{2}{|c|}{ Human capital approach } & $€ 728,727$ & $€ 47,986$ & $€ 680,721$ & $€ 20$ & 7.67 & 15.28 & 26.59 \\
\hline
\end{tabular}


Table 8b. Detailed results of scenario analyses and sensitivity analyses

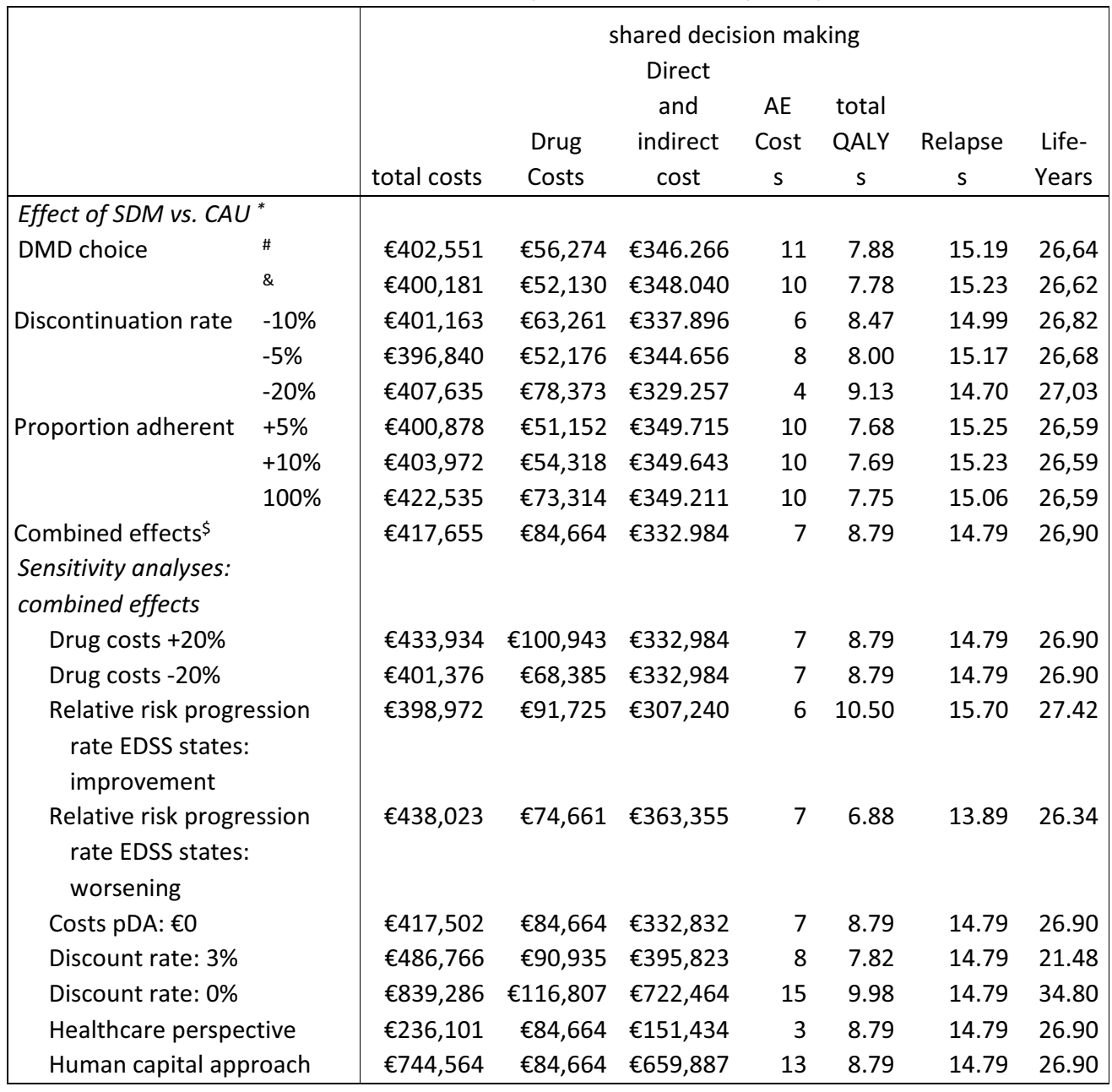


Table 8c. Detailed results of scenario analyses and sensitivity analyses

\begin{tabular}{|c|c|c|c|c|}
\hline \multirow{2}{*}{\multicolumn{2}{|c|}{ Effect of SDM vs. CAU * }} & $\begin{array}{c}\Delta \text { total } \\
\text { costs }\end{array}$ & \multicolumn{2}{|l|}{$\Delta$} \\
\hline & & & & \\
\hline \multirow[t]{2}{*}{ DMD choice } & $\#$ & $€ 4,904$ & 0.21 & $€ 23,509$ \\
\hline & $\&$ & $€ 2,535$ & 0.10 & $€ 24,294$ \\
\hline \multirow[t]{3}{*}{ Discontinuation rate } & $-10 \%$ & $€ 3,517$ & 0.80 & $€ 4,384$ \\
\hline & $-5 \%$ & $-€ 807$ & 0.33 & DOMINANT \\
\hline & $-20 \%$ & $€ 9,988$ & 1.46 & $€ 6,828$ \\
\hline \multirow[t]{3}{*}{ Proportion adherent } & $+5 \%$ & $€ 3,231$ & 0.01 & $€ 315,555$ \\
\hline & $+10 \%$ & $€ 6,325$ & 0.02 & $€ 308,843$ \\
\hline & $100 \%$ & $€ 24,889$ & 0.08 & $€ 303,809$ \\
\hline \multicolumn{5}{|l|}{$\begin{array}{l}\text { Sensitivity analyses: } \\
\text { combined effects }\end{array}$} \\
\hline \multicolumn{2}{|l|}{ Drug costs $+20 \%$} & $€ 27,029$ & 1.12 & $€ 24,147$ \\
\hline \multicolumn{2}{|l|}{ Drug costs $-20 \%$} & $€ 12,989$ & 1.12 & $€ 11,604$ \\
\hline \multicolumn{2}{|c|}{$\begin{array}{l}\text { Relative risk progression rate } \\
\text { EDSS states: improvement }\end{array}$} & $€ 14,601$ & 1.91 & $€ 7,640$ \\
\hline \multicolumn{2}{|c|}{$\begin{array}{l}\text { Relative risk progression rate } \\
\text { EDSS states: worsening }\end{array}$} & $€ 24,110$ & 0.34 & $€ 70,084$ \\
\hline \multicolumn{2}{|l|}{ Costs pDA: $€ 0$} & $€ 19,856$ & 1.12 & $€ 17,739$ \\
\hline \multicolumn{2}{|l|}{ Discount rate: $3 \%$} & $€ 21,445$ & 0.84 & $€ 25,568$ \\
\hline \multicolumn{2}{|l|}{ Discount rate: $0 \%$} & $€ 28,078$ & 1.53 & $€ 18,307$ \\
\hline \multicolumn{2}{|c|}{ Healthcare perspective } & $€ 32,675$ & 1.12 & $€ 29,191$ \\
\hline \multicolumn{2}{|c|}{ Human capital approach } & $€ 15,837$ & 1.12 & $€ 14,149$ \\
\hline
\end{tabular}

*In usual care, $25 \%$ of people choose best supportive care, $5 \%$ choose a DMD indicated for highly active MS (natalizumab/alemtuzumab) and 70\% choose one of the first-line DMDs (25\% for a first-generation first-line DMD, $45 \%$ for a second generation first-line DMD). Discontinuation rates range between $10 \%$ and $31 \%$, depending on the DMD. The proportion of patients with optimal adherence is $60 \%$, except for natalizumab, alemtuzumab and ocrelizumab for which adherence is assumed to be $100 \%$.

\$ The three effects of shared decision making included in the model are initial treatment choice; discontinuation rate, and adherence. Shaded rows present the the values of parameters included in the combined effect analysis. \# Specified in Table 4

\& Specification of change in treatment initiation as specified in Table 4 decreased by $50 \%$.

$A E$, adverse events. 


\section{References}

1. Institute for Clinical and Economic Review. Disease-modifying therapies for relapsing-remitting and primary-progressive multiple sclerosis: effectiveness and value. 2017 [cited 2018 December 14]. Available from: https://icer-review.org/wp-conte nt/uploa ds/2016/08/CTAF_MS_FinalReport_030617.pdf.

2. Zimmermann M, Brouwer E, Tice JA, Seidner M, Loos AM, Liu S, et al. Disease-modifying therapies for relapsing-remitting and primary progressive multiple sclerosis: a cost-utility analysis. CNS Drugs. 2018.

3. Zorginstituut Nederland. Medicijnkosten. Diemen, The Netherlands: Zorginstituut Nederlands; [cited 2018 October]. Available from: www.medicijnkosten.nl.

4. Hakkaart-van Roijen L, van der Linden N, Bouwmans C, Kanters T, Tan SS. Kostenhandleiding: Methodologie van kostenonderzoek en referentieprijzen voor economische evaluaties in de gezondheidszorg. Rotterdam, The Netherlands: Institute for Medical Technology Assessment, Erasmus Universiteit Rotterdam; 2015.

5. Nederlandse Zorgautoriteit (NZa). DBC zorgproducten tariefapplicatie. 2018 [Available from: https://zorgproducten.nza.nl/.

6. Penton H, Hiligsmann M, Harrison M, Reginster JY, Boonen A, Bansback N. Potential costeffectiveness for using patient decision aids to guide osteoporosis treatment. Osteoporos Int. 2016;27(9):2697-707.

7. Uitdehaag B, Kobelt G, Berg J, Capsa D, Dalen J. New insights into the burden and costs of multiple sclerosis in Europe: results for the Netherlands. Mult Scler. 2017;23(2_suppl):117-29.

8. Kobelt G, Berg J, Lindgren P, Anten B, Ekman M, Jongen PJ, et al. Costs and quality of life in multiple sclerosis in The Netherlands. Eur J Health Econ. 2006;7 Suppl 2:S55-64.

9. Kramer J, Tenberge JG, Kleiter I, Gaissmaier W, Ruck T, Heesen C, et al. Is the risk of progressive multifocal leukoencephalopathy the real reason for natalizumab discontinuation in patients with multiple sclerosis? PLoS One. 2017;12(4):e0174858.

10. Setayeshgar S, Kingwell E, Zhu F, Zhang T, Carruthers R, Marrie RA, et al. Persistence and adherence to the new oral disease-modifying therapies for multiple sclerosis: a populationbased study. Mult Scler Relat Disord. 2018;27:364-9.

11. Evans C, Marrie RA, Zhu F, Leung S, Lu X, Melesse DY, et al. Adherence and persistence to drug therapies for multiple sclerosis: A population-based study. Multiple sclerosis and related disorders. 2016;8:78-85.

12. Burks J, Marshall TS, Ye X. Adherence to disease-modifying therapies and its impact on relapse, health resource utilization, and costs among patients with multiple sclerosis. Clinicoecon Outcomes Res. 2017;9:251-60.

13. Arterburn D, Wellman R, Westbrook E, Rutter C, Ross T, McCulloch D, et al. Introducing decision aids at Group Health was linked to sharply lower hip and knee surgery rates and costs. Health Aff (Millwood). 2012;31(9):2094-104.

14. Trenaman L, Sadatsafavi M, Almeida F, Ayas N, Lynd L, Marra C, et al. Exploring the Potential Cost-Effectiveness of Patient Decision Aids for Use in Adults with Obstructive Sleep Apnea: A Case Study. Med Decis Making. 2015;35(5):671-82.

15. van Peperstraten A, Nelen W, Grol R, Zielhuis G, Adang E, Stalmeier P, et al. The effect of a multifaceted empowerment strategy on decision making about the number of embryos transferred in in vitro fertilisation: randomised controlled trial. BMJ. 2010;341:c2501.

16. Zorginstituut Nederland. Farmacotherapeutisch Kompas [Available from: https://www.farmacotherapeutischkompas.nl/.

17. Calabresi PA, Kieseier BC, Arnold DL, Balcer L, Boyko A, Pelletier J, et al. Pegylated interferon beta-1a for relapsing-remitting multiple sclerosis (ADVANCE): a randomised, phase 3 , doubleblind study. Lancet Neurol. 2014;13(7):657-65. 
18. Calabresi PA, Radue EW, Goodin D, Jeffery D, Rammohan KW, Reder AT, et al. Safety and efficacy of fingolimod in patients with relapsing-remitting multiple sclerosis (FREEDOMS II): a doubleblind, randomised, placebo-controlled, phase 3 trial. Lancet Neurol. 2014;13(6):545-56.

19. Coles AJ, Twyman CL, Arnold DL, Cohen JA, Confavreux C, Fox EJ, et al. Alemtuzumab for patients with relapsing multiple sclerosis after disease-modifying therapy: a randomised controlled phase 3 trial. Lancet. 2012;380(9856):1829-39.

20. Gold R, Kappos L, Arnold DL, Bar-Or A, Giovannoni G, Selmaj K, et al. Placebo-controlled phase 3 study of oral BG-12 for relapsing multiple sclerosis. N Engl J Med. 2012;367(12):1098-107.

21. Hauser SL, Bar-Or A, Comi G, Giovannoni G, Hartung HP, Hemmer B, et al. Ocrelizumab versus interferon beta-1a in relapsing multiple sclerosis. N Engl J Med. 2017;376(3):221-34.

22. Khan O, Rieckmann P, Boyko A, Selmaj K, Zivadinov R. Three times weekly glatiramer acetate in relapsing-remitting multiple sclerosis. Ann Neurol. 2013;73(6):705-13.

23. Mikol DD, Barkhof F, Chang P, Coyle PK, Jeffery DR, Schwid SR, et al. Comparison of subcutaneous interferon beta-1a with glatiramer acetate in patients with relapsing multiple sclerosis (the REbif vs Glatiramer Acetate in Relapsing MS Disease [REGARD] study): a multicentre, randomised, parallel, open-label trial. Lancet Neurol. 2008;7(10):903-14.

24. O'Connor P, Filippi M, Arnason B, Comi G, Cook S, Goodin D, et al. 250 microg or 500 microg interferon beta- $1 \mathrm{~b}$ versus $20 \mathrm{mg}$ glatiramer acetate in relapsing-remitting multiple sclerosis: a prospective, randomised, multicentre study. Lancet Neurol. 2009;8(10):889-97.

25. Polman CH, O'Connor PW, Havrdova E, Hutchinson M, Kappos L, Miller DH, et al. A randomized, placebo-controlled trial of natalizumab for relapsing multiple sclerosis. $\mathrm{N}$ Engl J Med. 2006;354(9):899-910.

26. Vermersch P, Czlonkowska A, Grimaldi LM, Confavreux C, Comi G, Kappos L, et al. Teriflunomide versus subcutaneous interferon beta-1a in patients with relapsing multiple sclerosis: a randomised, controlled phase 3 trial. Mult Scler. 2014;20(6):705-16.

27. Vollmer TL, Sorensen PS, Selmaj K, Zipp F, Havrdova E, Cohen JA, et al. A randomized placebocontrolled phase III trial of oral laquinimod for multiple sclerosis. J Neurol. 2014;261(4):773-83. 


CHAPTER 6

\section{Adherence to web-based self-assessments in long-term direct-to-patient research: two-year study of multiple sclerosis patients}

Published as:

Jongen PJ, Kremer IE, Hristodorova E, Evers SM, Kool A, van Noort EM, Hiligsmann M. Adherence to web-based self-assessments in long-term direct-to-patiënt research: two year study of multiple sclerosis patients. J Med Internet Res. 2017;19(7):e249. 


\section{Abstract}

Background. Direct-to-patient research via Web-based questionnaires is increasingly being used. Missed data or delayed reporting of data may negatively affect the quality of study results. It is insufficiently known to what degree patients adhere to agreed self-assessment schedule over the long term and whether questionnaires are filled out in a timely manner. The objective of this study was to investigate patients' adherence to a self-assessment schedule with low-frequency long questionnaires versus that with a high-frequency short questionnaire.

Methods. In this study, the 36-item MS Impact Profile (MSIP) questionnaire measured (perceived) disabilities and the 54-item MS Quality of Life-54 (MSQoL-54) questionnaire measured health-related quality of life at 6-month intervals. Additionally, the 2-item Medication and Adherence (MA) questionnaire documented medication and adherence to disease-modifying medication every month. An experienced MS nurse assessed the Expanded Disability Status Scale (EDSS) score via phone. For both the self-assessment schedules, we calculated the percentage of patients who had completed all the questionnaires in the first 2 years (completion adherence), the percentage of patients who completed all the questionnaires within set time frames (interval adherence), the relationship between adherence and the EDSS score, and the timing of EDSS assessment.

Results. Of the 331 patients who enrolled themselves, 301 patients completed at least one questionnaire. At month six (M6), M12, M18, and M24, the MSIP was completed by $83.4 \%$ (251/301), 71.8\% (216/301), 68.1\% (205/301), and 58.5\% (176/301) of the patients, respectively; the MSQoL-54 by $82.1 \%$ (247/301), $71.8 \%$ (216/301), $66.8 \%$ (201/301), and $57.1 \%$ (172/301), respectively; and the MA questionnaire by $80.1 \%$ (241/301), $70.4 \%$ (212/301), 62.1\% (187/301), and 53.5\% (161/301), respectively. For the MSIP, 56.8\% (171/301) of the patients were 2-year completion adherent; $55.5 \%$ (167/301) and 53.5\% (161/301) of the patients were completion adherent for the MSQoL-54 and MA questionnaires, respectively. Whereas $85.5 \%(142 / 166)$ of the patients were interval adherent for the MSIP and MSQoL-54, 25.5\% (41/161) were interval adherent for the MA questionnaire. Completion adherence for the monthly short MA questionnaire was higher in patients with moderately high disability (EDSS 5.0-5.5) than for those with no or minimal disability (EDSS 0-2.5) (OR 5.47, 95\% Cl 1.08-27.69; P=.040). Completion adherence was also higher in patients with EDSS assessment within 6 months after baseline than in those with later assessment (OR 1.810, 95\% $\mathrm{Cl}$ 0.999-3.280; $\mathrm{P}=.050$ ).

Conclusions. The 2-year completion adherence to Web-based self-assessments did not differ between the low-frequency long questionnaires and a high-frequency short questionnaire, but the interval adherence was substantially higher for the low-frequency long questionnaires. Personal contact with a member of the research team regarding a clinically relevant professional-reported outcome early in the study might positively affect the long-term completion adherence in direct-to-patient studies. 


\section{Introduction}

Multiple sclerosis (MS) is a chronic inflammatory demyelinating and degenerative disease of the central nervous system, mainly affecting persons in young adulthood. In about $80 \%$ of patients the first phase is characterized by a pattern of recurrent episodes of symptoms (relapses), typically followed by complete or partial remissions: relapsing remitting MS (RRMS) [1]. Although disease-modifying drugs (DMDs) reduce the frequency and severity of relapses, after about 20 years most persons with RRMS progress to the secondary progressive (SP) phase, experiencing a steady and unstoppable increase in disability $[2,3]$. In about $10-15 \%$ of the patients symptoms start insidiously and develop slowly without relapses: primary progressive MS (PPMS) [1]. In both SPMS and PPMS the continuous increase in disability results mainly from degenerative processes that cannot be modified by the available DMDs. The multifocal localization of the lesions accounts for the wide variety of symptoms that may arise in the course of the disease; these symptoms often interfere with physical, cognitive, social or occupational activities. Over the long term the MS-related disabilities often represent a substantial burden to patients and their environment.

To enable neurologists to better prognosticate the disease course in individual patients, they need to be informed in more detail about the degree of and variation in long-term disabilities. To obtain this information patient-reported outcomes (PROs) are increasingly being used, in addition to physician-based measures like the Expanded Disability Status Scale (EDSS). A PRO is any report of the status of a patient's health condition that comes directly from the patient, without interpretation of the patient's response by a clinician or anyone else [4]. A PRO that is increasingly being used in clinical research is health-related quality of life (HRQoL), an overall measure of wellbeing from a patient's perspective that provides a comprehensive measure of health status [5].

The internet empowers patients to directly participate in research projects without the involvement of their physician or physician's setting $[6,7]$. The rapid adoption of the internet by MS patients, the limited costs of web-based contacts, and the easy access to large numbers of potential participants are all in favour of a direct-to-patient study design $[6,8]$. The data that can thus be obtained include PROs on various symptoms, (perceived) disabilities, HRQoL and treatment, and may complement neurologist- or nurse-reported data about diagnosis, disease course, and MRI [6].

In view of the scarcity of long-term data on (perceived) disabilities and HRQoL in MS patients in the Netherlands, we conceived the prospective, direct-to-patient, interactive, Dutch MS Study [9]. The study participants enrolled themselves and agreed to complete two long questionnaires on (perceived) disabilities (36 items) and HRQoL (54 items) at six-month intervals, and a short questionnaire on medication and adherence to DMD treatment (two items) at monthly intervals [9].

One of the crucial aspects of long-term direct-to-patient research is the participants' adherence to the predetermined assessment schedule. A reduction in the amount of data that patients provide may seriously affect the validity and meaningfulness of the study results $[10,11]$. Conceivably, the same amount of data can be acquired by the infrequent 
use of long questionnaires, or by the frequent use of short questionnaires. In fact, different factors might determine the adherence to a self-assessment schedule: a high frequency short questionnaire could be bothersome to patients due to the frequent interference with their daily life or frequent confrontation with their disabilities and limitations, whereas a low frequency long questionnaire might be cumbersome due to requiring more time to complete and thus potentially increasing MS-related fatigue.

In a previous patient-centred web-based study in RRMS patients, who were included by their neurologists, we investigated the adherence to monthly online self-assessments after the start of DMD treatment [12]. It was found that $75.5 \%$ of the patients completed two short questionnaires at all monthly time points over the course of one year, although only one in five patients adhered to the monthly intervals between consecutive self-assessments [12]. In order to become informed about the long-term adherence of MS patients to low frequency completions of long questionnaires versus high frequency completions of short questionnaires in a direct-to-patient research setting, this study analysed the two-year adherence data in the Dutch MS Study [9]. Given the study design, participation in this study was not a priori integrated into patient care. As the embedding of research activities in care processes may positively affect patient adherence, and as adherence may decrease over time, it was hypothesized that, at least regarding the high frequency short questionnaire, the two-year completion adherence would be less than $75 \%$.

\section{Methods}

\section{Dutch Multiple Sclerosis Study}

The Dutch MS Study is a prospective, web-based, direct-to-patient, interactive study of long-term disabilities, perception of disabilities and HRQoL in patients with MS in the Netherlands. The innovative study design is characterized by online patient-driven enrolment, online data acquisition, the use of PROs, and the use of personal study data by patients and authorized healthcare professionals for (self-)monitoring, (self-)management or multidisciplinary care. The objectives of the study, design, target population, recruitment, ethical aspects, data acquisition, technical aspects, outcome measures, assessment schedule, organisation and funding have been described in detail elsewhere [9]. Patients were informed about the study via the websites of three patient organisations and of the MS4 Research Institute (www.ms4ri.nl). By regular mail neurologists and MS nurses were sent an informative letter with patient brochures, which they were asked to hand out to their patients. The brochure was also sent to the patrons of the National MS Foundation Netherlands, as an attachment to the foundations' quarterly journal and related mailings. In the journal, study information was presented by the principal investigator (PJ). Information about the study was published twice in health specials of large national and regional Dutch newspapers. The protocol was submitted to the ethics committee Medisch Ethische Toetsing Onderzoek Patiënten en Proefpersonen in Tilburg, the Netherlands (nr 
M379). The committee concluded that a review was not indicated, as the study did not qualify for being tested according to the Dutch Medical Research Involving Human Subjects Act (http://wetten.overheid.nl/BWBR0009408) [13]. The study is being performed in agreement with the Declaration of Helsinki (Ethical Principles for Medical Research Involving Human Subjects version 2013; 64th World Medical Association General Assembly, Fortaleza, Brazil, October 2013) (www.wma.net) and the Dutch Medical Research Involving Human Subjects Act (www.wetten.overheid.nl/BWBR0009 408).

Technically, the study is a modular application on the Curavista e-Health Platform, build on an Oracle database with JAVA-scripting, XML-applets and AJAX protocols. Data processing is 256-bits encrypted with VPN-tunnelling. The databases are physically and software secured in a dedicated data centre in the Netherlands [9]. On the day of the scheduled assessment patients receive a notification by email that a questionnaire is available for completion. If the questionnaire is not completed on the scheduled date reminders are sent after four and seven days.

Disabilities, perceptions of disabilities and HRQoL are measured every six months via the Multiple Sclerosis Impact Profile (MSIP) and the Multiple Sclerosis Quality of Life-54 Item (MSQoL-54) questionnaires. The MSIP is made available first and the MSQOL-54 one week later. The medication that is being taken and the adherence to DMD treatment are secondary outcomes; these are measured every month via the Medication and Adherence (MA) questionnaire. Every six months the completion of the MA questionnaire coincides with the completion of the MSIP and MSQoL-54. The completion of the combined MSIP and MSQoL-54 takes about 30-45 minutes; completion of the MA questionnaire takes less than five minutes.

\section{Questionnaires}

\section{Multiple Sclerosis Impact Profile}

The MSIP is a measure of MS-related disabilities and perception of disabilities with established psychometric properties $[14,15]$. It is based on the International Classification of Functioning, Disability and Health and reflects an objectified view of the prevalence and severity of the impact of MS. The MSIP comprises 36 questions assessing disability (Q1aQ36a) and perception of disability (Q1b-Q36b) in the domains muscle and movement functions, excretion and reproductive functions, activities involving basic movements, activities of daily living, participation in life situations, environmental factors, mental functions, and the symptoms fatigue, pain, speech and vision [14, 15].

\section{Multiple Sclerosis Quality of Life-54}

HRQoL is assessed with the MSQoL-54 questionnaire, a psychometrically validated MSspecific multi-dimensional inventory of patient-centred health status [16]. The MSQoL-54 consists of the 36-item Short Form health survey as a generic core measure to enable comparisons to other patient populations and to the general population, supplemented with 18 additional questions exploring items relevant to MS patients in the areas of health 
distress (four items), sexual function (four items), satisfaction with sexual function (one item), overall quality of life (two items), cognitive function (four items), energy (one item), pain (one item) and social function (one item) [16].

\section{Medication and Adherence questionnaire}

The MA questionnaire gives an update of medications that are taken, the number of DMD doses missed in the past month, and the date and reason of DMD discontinuation (if applicable).

\section{Disability assessment by phone}

The EDSS is a widely used disability measure in MS. The EDSS quantifies disability in eight functional systems and allows neurologists and qualified nurses to assign a functional system score in each of these [17]. The functional systems are: pyramidal, cerebellar, brainstem, sensory, bowel and bladder, visual, cerebral and other. EDSS steps 0.0 to 4.5 refer to patients with MS who are fully ambulatory, and EDSS steps 5.0 to 9.5 are defined by the impairment to ambulation. A version of the EDSS that can be used as a structured interview by phone and that has been validated for serial assessments in a research setting, is being used in the Dutch MS Study $[18,19]$. All patients were sent an email in which they were asked if they agreed to a disability assessment via an interview by phone. The emails were sent in order of enrollment. If patients agreed, they were asked to provide information about the days of the week and the time of the day they were available for the assessment by phone. Patients were free when to contact the study team and when to schedule the EDSS interview. In addition to answering the questions of the structured interview during the phone contact, the patients had the opportunity to ask study-related information or discuss study aspects with the assessing researcher, an experienced nurse specialized in MS.

\section{Study outcomes}

The outcomes of the present analysis are the adherence to the assessment schedules of the MSIP, MSQoL-54 and MA questionnaires during the first two years of the study. Regarding the MSIP and the MSQoL-54, patients were classified as completion adherent for the respective questionnaire if they had performed all five scheduled six-month assessments during the first two years; patients were classified as completion adherent for the MA questionnaire if they had performed all scheduled monthly assessments during the first two years. Patients were classified as overall completion adherent if they had performed all scheduled MSIP, MSQoL-54 and MA assessments in this period.

Patients who were completion adherent for the MSIP or MSQoL-54 were classified as interval adherent if they met the following three criteria: a) median inter-assessment interval was $180+10$ days or less, b) maximum inter-assessment interval was $180+20$ days or less, and c) month 24 (M24) completion was within 30 days after the scheduled date. Patients who were completion adherent for the MA questionnaire were classified as 
interval adherent if a) the median inter-assessment interval was 30+3 days or less, b) the maximum inter-assessment interval was $30+6$ days or less, and c) the $\mathrm{M} 24$ completion was within 30 days after the scheduled date.

\section{Statistical analysis}

The numbers of patients who completed the respective questionnaires at the various time points were calculated, as well as the intervals between two consecutive assessments and between the baseline and M24 assessment. The intervals between two consecutive assessments (days) are presented as mean, standard deviation (SD), median, minimum, maximum and inter-quartile range (IQR). Friedman's ANOVA and the Wilcoxon signed ranks test were used to test whether the intervals for consecutive time points differed between the MSQoL-54, MSIP and MA questionnaires. The numbers of patients who were completion or interval adherent are expressed as the percentage of patients who actually started participating in the study by completing at least one of the questionnaires. To compare the completion adherence rates and interval adherence rates of the three questionnaires, Cochran's $Q$ test was performed. In order to test for significant associations between sex, age, EDSS score, and the timing of EDSS assessment on the one hand, and completion adherence and interval adherence regarding the low frequency long questionnaires (MSIP, MSQoL-54) and the high frequency short questionnaire (MA) on the other hand, we used logistic regression analysis. All test were performed in SPSS for Windows version 24.

The EDSS score was categorized into no to minimal disability (scores 0-2.5), fully ambulatory with moderate disabilities (scores 3.0-3.5), fully ambulatory with little to moderate effect on daily activities (scores 4.0-4.5), ability to walk about 100-200 meters without aid and fully or severely impaired in performing daily activities (scores 5.0-5.5), ability to walk about 20100 meters with aid (scores 6.0-6.5), and severely disabled in walking or fully restricted to bed or chair (scores above 7.0). The timing of EDSS assessment by phone was dichotomized into assessment within six months after baseline self-assessment and later than 6 months after baseline self-assessment. A $P$ value of 0.05 was applied for significance.

\section{Results}

\section{Patients}

Three-hundred-thirty-one patients had enrolled themselves in the study at least two years before the date of analysis (July 2015), from 23 March 2011 to 15 March 2012. Of these, 301 (90.94\%) had actually started participating in the study by completing at least one questionnaire at baseline, whereas 30 (9.06\%) patients had effectively not started participation. Of the 331 patients 246 (74.32\%) were female, 67 (20.24\%) male, and for 18 $(5.40 \%)$ the sex was unknown. The mean (SD) age was 45.59 (11.05) years; the median was 
45.13 , the minimum was 17.18 , and the maximum age was 70.57 , IQR $37.82-53.92(\mathrm{~N}=310)$. Of the 301 patients who had completed at least one questionnaire at baseline, 234 (77.74\%) were female, and 67 (22.25\%) were male. The mean (SD) age was 45.52 (11.08), the median was 44.96 , the minimum was 17.18 , and maximum was 70.57 , IQR $37.82-53.92(\mathrm{~N}=298)$.

\section{Completions}

The numbers and percentages of patients who completed the MSIP at baseline, M6, M12, M18 and M24 were 296 (98.3\%), 251 (83.4\%), 216 (71.8\%), 205 (68.1\%) and 176 (58.5\%), respectively, and the numbers and percentages of patients who completed the MSQoL-54 at baseline, M6, M12, M18 and M24, were 281 (93.4\%), 247 (82.1\%), 216 (71.8\%), 201 (66.8\%) and 172 (57.1\%) (Figure 1). The numbers and percentages of patients who completed both these questionnaires at baseline, M6, M12, M18 and M24 were 281 (93.4\%), 247 (82.1\%), 215 (71.4\%) 199 (66.1\%) and 171 (56.8\%) (Figure 1).

Figure 2 shows the numbers of patients who had completed the MA questionnaire at the various time points, expressed as the percentage of patients $(\mathrm{N}=301)$ who had started study participation. The numbers of patients who had completed the MA questionnaire at baseline, M6, M12, M18 and M24, were 301 (100\%), 241 (80.1\%), 212 (70.4\%), 187 (62.1\%) and 161 (53.5\%).

Table 1 shows the numbers and percentages of patients who completed the MA questionnaire at all 25 time points, at 24 to one time point(s), or at no time point, irrespective of it being consecutive assessments.

The numbers and percentages of patients who completed the respective questionnaires at baseline and at M6, M12, M18 and M24 (five time points), at four, three, two or one time point(s), or at no time point, irrespective of it being consecutive assessments, are shown in Table 2. 


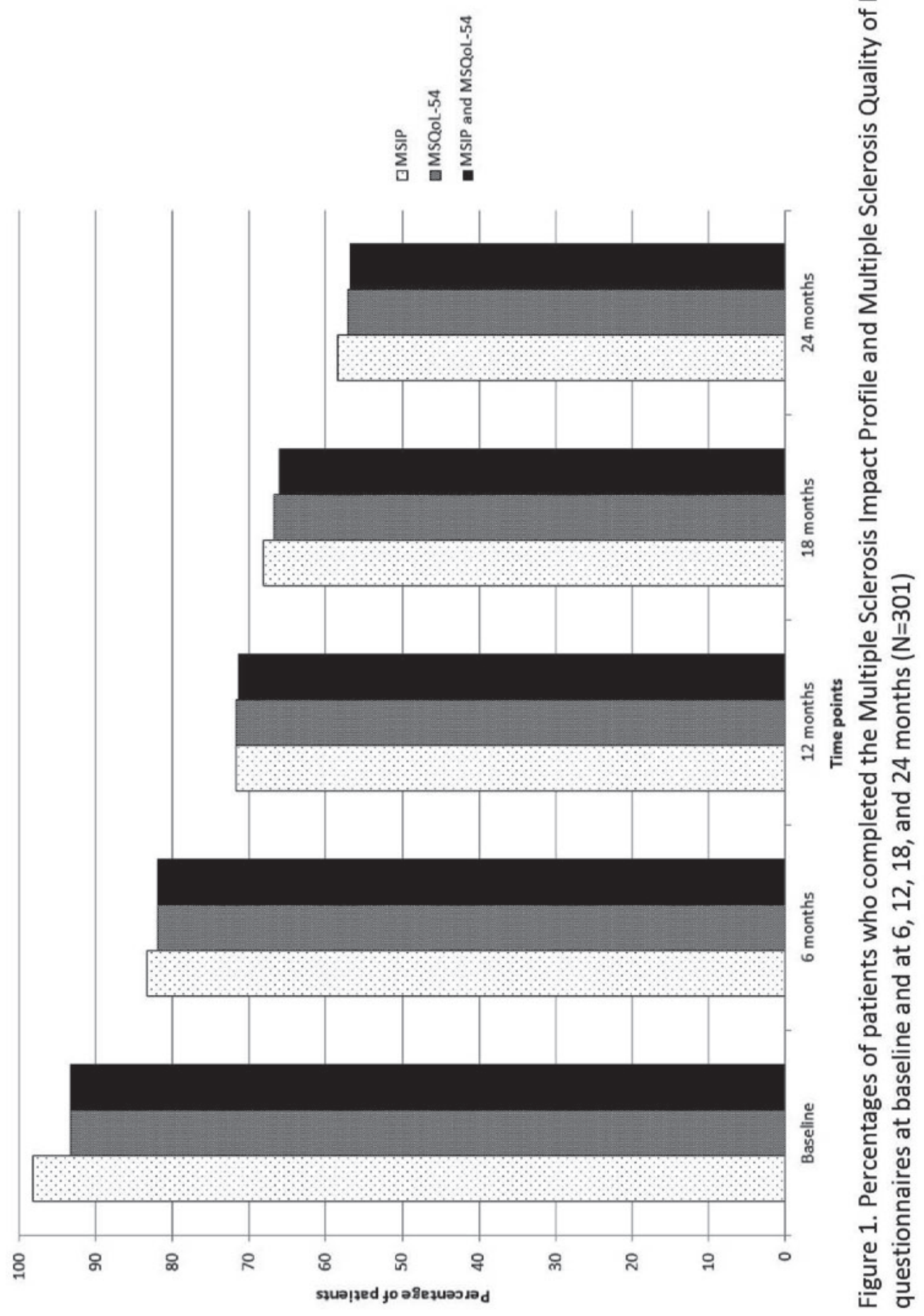




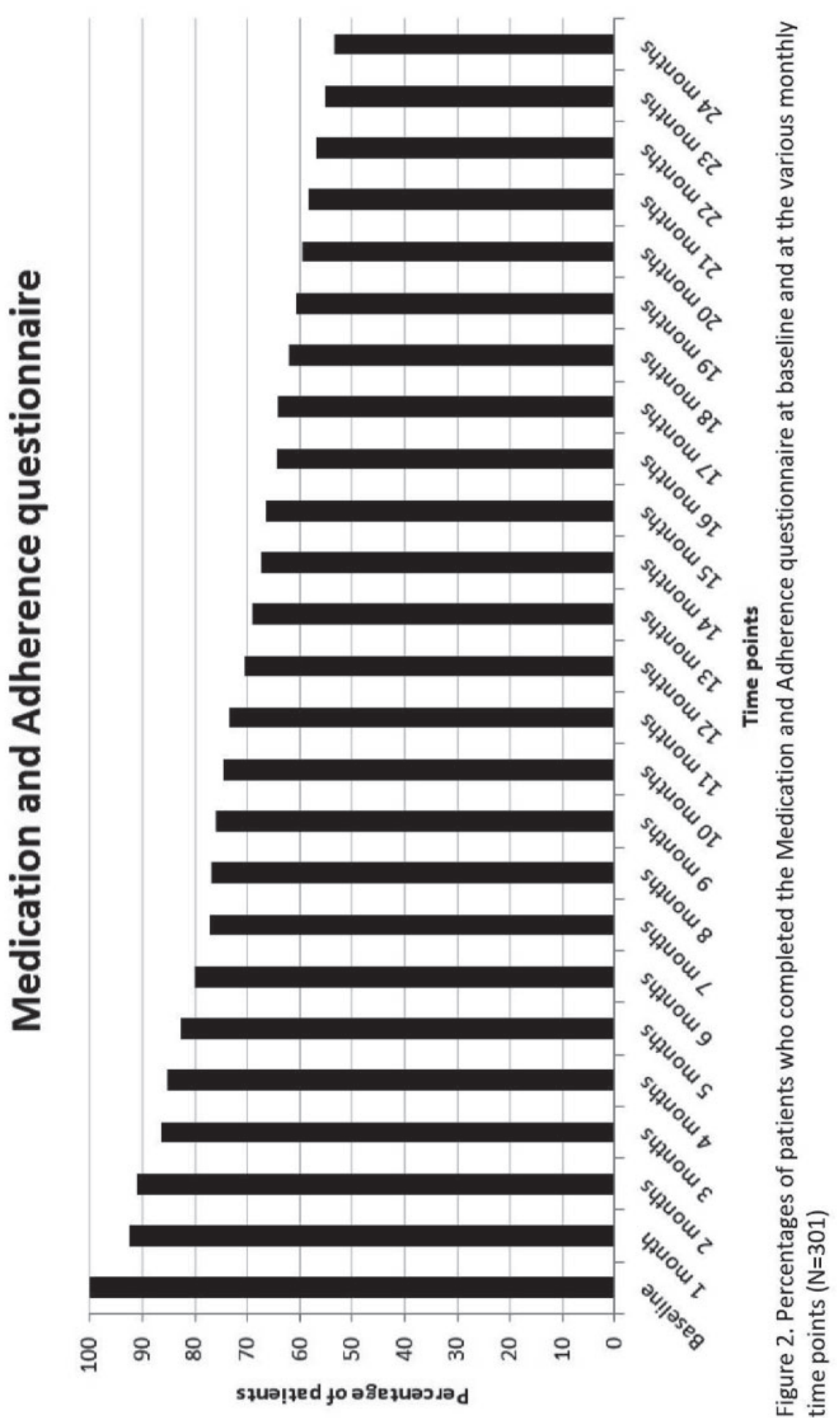


Table 1. Numbers and percentages of patients who completed the short Medication and Adherence questionnaire at all 25 time points, at 24 to one time point(s), or at no time point, irrespective of these being consecutive assessments $(N=301)$.

\begin{tabular}{ll}
\hline Number of completions & $\mathrm{n}(\%)$ \\
\hline 25 (all) & $161(53.5)$ \\
24 & $166(55.1)$ \\
23 & $171(56.8)$ \\
22 & $176(58.5)$ \\
21 & $179(59.5)$ \\
20 & $183(60.8)$ \\
19 & $187(62.1)$ \\
18 & $193(64.1)$ \\
17 & $194(64.5)$ \\
16 & $200(66.4)$ \\
15 & $203(67.4)$ \\
14 & $208(69.1)$ \\
13 & $212(70.4)$ \\
12 & $221(73.4)$ \\
11 & $223(74.1)$ \\
10 & $227(75.4)$ \\
9 & $230(76.4)$ \\
8 & $233(77.4)$ \\
7 & $242(80.4)$ \\
6 & $249(82.7)$ \\
5 & $256(85.0)$ \\
4 & $262(87.0)$ \\
3 & $274(91.0)$ \\
2 & $279(92.7)$ \\
1 & $301(100)$ \\
0 & \\
\hline & 30 \\
\hline
\end{tabular}


Table 2. Numbers and percentages of patients who completed the Multiple Sclerosis Impact Profile, Multiple Sclerosis Quality of Life-54, and Medication and Adherence questionnaires at baseline and at $6,12,18$, and 24 months (five time points) at four, three, two, or one time point(s), or at no time point, irrespective of it being consecutive assessments ( $N=301)$.

\begin{tabular}{lcrr}
\hline $\begin{array}{l}\text { Number of 6-month } \\
\text { completions }\end{array}$ & $\begin{array}{c}\text { Multiple Sclerosis } \\
\text { Impact Profile } \\
\mathrm{n}(\%)\end{array}$ & $\begin{array}{c}\text { Multiple Sclerosis } \\
\text { Quality of Life-54 } \\
\mathrm{n}(\%)\end{array}$ & $\begin{array}{c}\text { Medication and } \\
\text { Adherence } \\
\mathrm{n}(\%)\end{array}$ \\
\hline 5 (all) & $171(56.8)$ & $167(55.5)$ & $161(53.5)$ \\
4 & $203(67.4)$ & $202(67.1)$ & $187(62.1)$ \\
3 & $222(73.8)$ & $219(72.8)$ & $212(70.4)$ \\
2 & $252(83.7)$ & $246(81.7)$ & $241(80.1)$ \\
1 & $296(98.3)$ & $283(94.0)$ & $301(100)$ \\
0 & 35 & 48 & 30 \\
\hline
\end{tabular}

\section{Intervals}

The intervals (days) between two consecutive assessments and between the baseline and M24 assessment (mean, SD, median, minimum, maximum and IQR values) are given in Table 3.

Median values for the intervals between two consecutive six-month assessments ranged from 182 to183 days for the MSQoL-54 and the MSIP. The median time between baseline and M24 was 730 days for the MSQoL-54 and 731 days for the MSIP. For the MA questionnaire the median values for inter-assessment intervals ranged from 30 to 32 days, and the M24 assessment was at 749 days (median). The interval between baseline and M6 significantly differed between the three questionnaires (MSIP vs MSQoL-54 $z=-5.37, P$ $<.001$; MSQoL-54 vs MA $z=-8.73, P<.001$; MSIP vs MA $z=-8.05, P<.001$ ), as did the M6-M12 interval between the MSIP and MSQoL-54 ( $z=-2.42, P=.014)$, and the M12-M18 intervals between MSQoL-54 and MA $(z=-11.70, P<.001)$ and between MSIP and MA $(z=-11.44, P$ $<.001$ ). For the M18-M24 interval no significant differences were found between the three questionnaires. Significant differences in time from baseline to M24 were found between all three questionnaires (MSIP vs MSQoL-54 $z=-4.04, P<.001$; MSQoL-54 vs MA $z=-6.17 P$ $<.001 ;$ MSIP vs MA $z=-5.59, P<.001)$. 


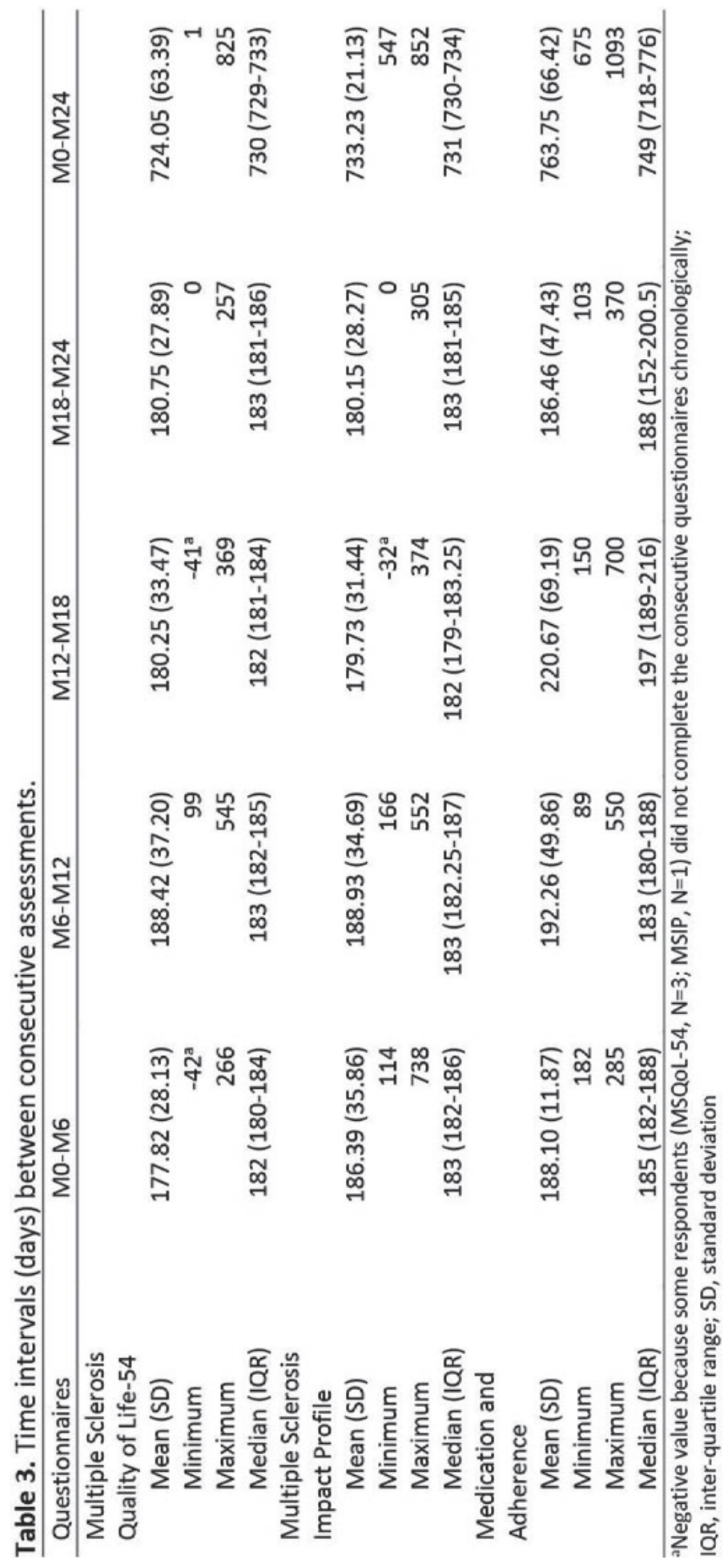


Adherence to low frequency long questionnaires

Of the 301 patients who started with the study, 166 (55.1\%) completed the MSIP and MSQoL-54 questionnaires at all five time points, and were therefore completion adherent for the low frequency long questionnaires. Of these, 159 (95.8\%) completed the M24 questionnaires within 30 days of the scheduled date; 163 (98.2\%) had a median interassessment interval of $180+10$ days or less; and $143(86.1 \%)$ had a maximum interassessment interval of $180+20$ days or less. In all, $85.5 \%(\mathrm{~N}=142)$ of the patients who were completion adherent for the low frequency long questionnaires, were interval adherent for these questionnaires.

\section{Adherence to high frequency short questionnaire}

Of the 301 patients who started participation, 161 (53.5\%) completed the MA questionnaire at all monthly time points, and were thus completion adherent for the high frequency short questionnaire. Of these, 99 (62\%) performed the M24 assessment within 30 days of the scheduled date; 153 (95.0\%) had a median inter-assessment interval of $30+3$ days or less; and 42 (26\%) had a maximum inter-assessment interval of $30+6$ days or less. In all, $26 \%$ $(\mathrm{N}=41)$ of the patients who were completion adherent for the high frequency short questionnaire, were interval-adherent for this questionnaire.

\section{Overall adherence}

One-hundred-fifty-two (50.5\%) patients were completion adherent for both the low frequency long questionnaires and the high frequency short questionnaire, and were therefore considered overall completion adherent. In addition, $36(24 \%)$ of the patients who were overall completion adherent were interval adherent for both the low frequency long questionnaires and the high frequency short questionnaire, and were therefore considered overall interval adherent. In all, $12 \%$ of the patients who started with the study were overall completion and interval adherent.

\section{Comparative analyses}

The completion rates did not differ between the three questionnaires (Cochran's $Q$ test: $\mathrm{x} 2=5.630 ; P=.063)$. From the above it follows that $91.6 \%\left(152 / 166^{*} 100\right)$ of the patients who were completion adherent for the low frequency long questionnaires were also completion adherent for the high frequency short questionnaire. Vice versa, $94.4 \%$ (152/161*100) of the patients who were completion adherent for the high frequency short questionnaire were also completion adherent for the low frequency long questionnaires. Moreover, $25 \%(36 / 142 * 100)$ of the patients who were interval adherent for the low frequency long self-assessments were also completion adherent for the high frequency short self-assessments. Vice versa, $88 \%\left(36 / 41^{*} 100\right)$ of those who were interval adherent 
for the high frequency short self-assessments were also completion adherent for the low frequency long self-assessments.

There were no statistically significant differences between men and women regarding the completion and interval adherence to the low frequency long questionnaires, the high frequency short questionnaire, nor regarding the overall adherence rates. Likewise, no association was found between age and adherence.

As to the EDSS, patients with an EDSS score of 5.0 or 5.5 were found to have higher odds of being completion adherent for the high frequency short questionnaire than patients with an EDSS score of 0 to 2.5 ( $\mathrm{OR}=5.4795 \% \mathrm{Cl}=1.08-27.69, P=.040)$. Moreover, patients who had an EDSS assessment within 6 months after baseline were more likely to be completion adherent for the high frequency short questionnaire than those whose EDSS score was assessed later (OR=1.810; 95\% $\mathrm{Cl}$ : 0.999-3.280, $P=.050$ ).

\section{Discussion}

In recent years the direct-to-subject approach is being applied increasingly in clinical studies, both in trials organized by clinical research organisations and in investigator-driven academic research $[20,21]$. This development is paralleled by a growing number of studies that make use of the internet for the acquisition of patient-reported data. However, it is insufficiently known to which degree patients who enrol themselves in web-based studies do indeed perform the scheduled assessments and whether they do so on time, especially over the longer term. Such knowledge is relevant, as patients who prematurely discontinue their participation or who provide data only infrequently or delayed may hamper the validity of the study results.

To obtain insight into patients' long-term adherence to a self-assessment schedule in a setting of web-based direct-to-patient research, we analyzed the numbers of completed questionnaires and the inter-assessment intervals in the first two years of the Dutch MS Study regarding two low frequency long questionnaires (MSIP, MSQoL-54) and one high frequency short questionnaire (MA).

\section{Principal results}

We found, first, that about $56 \%$ of the patients completed the two long questionnaires at all five six-month time points (MSIP 56.8\%, MSQoL-54 55.5\%), and second, that about $54 \%$ of the patients completed the short questionnaire at all 25 monthly time points. Third, we found that over $90 \%$ of the patients who completed all questionnaires for one type of assessment, also completed all questionnaires for the other type; fourth, that the number of patients who completed the questionnaires decreased gradually over time, and, fifth, that the patients who completed all of the long questionnaires at six-month intervals in a timely fashion by far outnumbered the patients who performed all of the monthly short self-assessments in time ( $85.5 \%$ vs. $26 \%)$. 
So, interestingly, over a two-year period no difference was found in completion adherence (completion of all scheduled assessments) between less frequent long questionnaires and a more frequent short questionnaire. This was so in spite of the evident differences in patient burden: the short MA questionnaire had to be completed 5 times more frequently than the long MSIP and MSQoL-54, and the completion time of the latter was 6-9 times longer than that of the MA questionnaire. This suggests that completion adherence is influenced not so much by quantitative aspects like frequency of assessments and completion time, but other factors. These factors could be the perceived relevance of the questionnaires' content and the degree to which healthcare providers use the questionnaires' outcomes in their disease management.

It may well be that patients' adherence to the completion of online questionnaires is influenced by the outcomes' relevance for the disease management, like decisions on treatment initiation, continuation or discontinuation. It is of note that one of the characteristics of the Dutch MS Study is that patients may give healthcare professionals access to the completed questionnaires and the automatically generated scores. Although we suggested the study participants inform their neurologists, MS nurses and other healthcare professionals about this option, only 21 patients have authorized one or more healthcare professionals. Accordingly, we think that the low utilization of the interactive aspect of the study may also explain why at two years about $45 \%$ of the patients failed to complete all questionnaires.

Figure 2 suggests that the number of patients who completed the short monthly MA questionnaire at a given time point decreased on average by $2.4 \%$ per month, an exception being the decrease of $7.6 \%$ at the first interval. Remarkably, the decrease over time in the number of patients who completed the six-month long questionnaires fits in with the pattern of decreasing completions of the MA questionnaire. There was another interesting observation: the less frequent long and more frequent short questionnaires showed almost identical completion percentages at M6, M12, M18 and M24. In combination with the fact that more than $90 \%$ of the patients who were completion adherent for one type of assessment were also completion adherent for the other type, and the quasi-linear decrease in the number of completion adherent patients for both types of assessment, this observation suggests that non-adherent patients completed virtually all scheduled questionnaires up to a certain time point, at which they decided not to complete any more questionnaires. From patients' phone calls to the help desk it became clear, rather unexpectedly, that participants were sometimes reluctant to complete the monthly MA questionnaire, e.g. because no changes in medication occurred over longer periods or because they felt 'spied on' by the frequent assessments. It may therefore be hypothesized that a reluctance to complete one specific questionnaire may have affected not only the completion of that particular questionnaire, but that of the other questionnaires as well.

Differences between the two types of assessment were found for interval adherence. Whereas the majority (85.5\%) of patients were interval adherent for the low frequency long questionnaires, only a minority (26\%) was so for the high frequency short questionnaire. The non-adherence in the latter group was mainly due to the fact that approximately three 
out of four patients (73.9\%) exceeded the maximum inter-assessment interval of 30+6 days at least once, and less so to four out of ten (38.5\%) patients performing the M24 assessment later than 30 days after the scheduled date. This difference in interval adherence may relate to the difference in assessment frequencies, as less frequent assessments lower the risk of one assessment exceeding the maximum inter-assessment interval. The difference may also be due to the pre-defined criteria for interval adherence: the allowed time window of six days for the monthly completions may have been too narrow for patients who, e.g. due to an MS relapse or a concomitant disease, were temporarily unable to complete questionnaires. When comparing the intervals for the consecutive time points no consistent differences were found between the MSQoL-54, MSIP and MA questionnaires.

It was found that patients with the ability to walk about 100-200 meters without aid and fully/severely impaired in performing daily activities (EDSS 5.0 or 5.5) were five times more completion adherent for the more frequent short questionnaire than patients with no or minimal disability (EDSS 0 to 2.5). We speculate that this may relate to the former patients being more housebound and thus possibly having more time at their disposal, and the latter being more involved in familial, professional and societal activities with less time for or interest in the regular completion of questionnaires. However, at higher EDSS scores (6.0 and higher) this association was not found, which could relate to the circumstance that cognitive and physical disabilities prevented these patients from performing moderately demanding tasks.

Interestingly, patients who - within six months after completion of the first questionnaire had their disability assessed by an experienced MS nurse via phone, were almost twice as likely to be completion adherent for the high frequency short questionnaire than were those whose EDSS score was assessed later. This observation suggests that an early personal contact between the patient and a member of the research team - with the opportunity to ask questions about the study or about individual health status - may positively influence adherence to an assessment schedule.

\section{Comparison to prior work}

Whereas a first experience has been reported with direct-to-patient recruitment for enrolment into clinical trials [22], to our knowledge no studies have investigated the adherence to online assessments in long-term direct-to-patient research. In general, early discontinuation of study participation has been associated with various socio-demographic and health-related factors, like male gender [23], being black [24], cognitive impairment $[25,26]$ and difficulties in activities of daily living [25]. We did not find differences in completion or interval adherence between males and females. Our finding that patients with moderately high disability were more completion adherent for the frequent short questionnaire than were patients with no or minimal disability does not contradict a previous report on higher drop-out rates in very ill persons. In MS patients disability mostly results from impaired mobility and not from deficiencies in general health. 
In the present study $66.4 \%$ of the patients had completed all monthly MA questionnaires one year after baseline. In a previous one-year study in MS patients who started daily glatiramer acetate treatment, we found that $75.5 \%$ of the patients completed all monthly short questionnaires on fatigue (five items) and HRQoL (eight items) [12]. This higher percentage could relate to the content of the questionnaires: fatigue is a frequent and often debilitating symptom in MS that was expected to improve during glatiramer acetate treatment, whereas the documentation of medication and missed DMD doses may be less appealing to patients. Moreover, in the glatiramer acetate study, patients were included by their treating neurologists at the time of treatment initiation, whereas in the present study patients enrolled themselves at an arbitrary point in time. Nonetheless, the median monthly inter-assessment intervals (30 to 32 days) and the median baseline-M24 interval $([2 \times 365]+19$ days) in the present study compare favourably with the median interassessment intervals ( 32 to 34 days) and the median baseline-M12 interval ( $365+52$ days) in our previous study [12].

\section{Limitations}

Our study has several limitations. First, we analyzed data from a study that was not primarily designed too (also) investigate the adherence to assessment schedules. Second, by comparing the adherence to low frequency long questionnaires with that to a high frequency short questionnaire we investigated two variables simultaneously, and we therefore cannot identify the relative contribution of a questionnaire's frequency and length to the adherence. Third, we confined ourselves to the analysis of formal aspects of the questionnaires and did not consider their content, so it may well be that, irrespective of the assessment frequency, patients experienced questions about (perceived) disabilities (MSIP) as more disturbing and less motivating than questions about DMD adherence. Fourth, although the fairly even distribution of the Dutch MS Study participants throughout the Netherlands suggests that the study group is representative of the Dutch MS population, this has not been demonstrated; moreover, relatively healthy IT users and enthusiasts may be overrepresented in the study group. Fifth, in view of the direct-topatient study design we did not verify the MS diagnosis with the patients' neurologists, nor whether the diagnosis was made according to the latest criteria.

As to the instruments we used, it is important to note that the e-versions of the questionnaires have not been validated. There is, however, a vast amount of literature showing that e-versions of questionnaires and scales are equivalent to paper-and-pencil versions, and that both can be used interchangeably. This has been demonstrated, among others, for questionnaires about disability [27], symptoms [28, 29], HRQoL [30, 31], psychopathology [28, 32, 33] and psychology [34]. Against this background we thought it reasonable to apply e-versions of the MSIP, MSQoL-54 and the Medication and Adherence questionnaire. Moreover, should any discrepancies exist between paper and e-version of these questionnaires, these will be of minor relevance as we consequently used the eversions throughout the study. As to the EDSS assessment, the scoring via interview by 
phone has been validated for serial assessments in research settings, but it is not interchangeable with the physician-derived EDSS, especially for the lower range of disability [19].

Finally, our definitions of completion and interval adherence were based on what we considered both realistic from a patient perspective and desirable from the researcher's point of view. To be qualified as completion adherent we required patients to have completed all questionnaires. Yet, the completion of five long questionnaires may be easier for patients to realize that the completion of 25 short questionnaires over the same time period. And, from a research perspective, it may be questioned whether the missing of one out five or even one out of 25 assessments substantially hampers the data quality. Moreover, the time windows for interval adherence used by us are debatable and, in general, criteria for interval adherence will depend on the phenomenon under study and the time span covered by a questionnaire.

\section{Conclusions}

In analysing the two-year adherence to self-assessments in the direct-to-patient Dutch MS Study, we found no differences in completion adherence (completion of all scheduled questionnaires) between the two low frequency long questionnaires versus the high frequency short questionnaire; whereas the interval adherence (completion of questionnaires within pre-defined time frames) was considerably higher for the low frequency long questionnaires. Moreover, patients with moderately high disability were more likely to be completion adherent for the high frequency short questionnaire than were patients with no or minimal disability, as were patients who within six months after completion of the first questionnaire had their disability assessed by an experienced MS nurse via phone in comparison with those who had their assessment later. The latter observation may suggest that in web-based direct-to-patient research personal contact with a member of the research team or feedback on a clinically relevant professionallyreported outcome early in the study may positively affect the long-term adherence to selfassessments.

\section{Acknowledgement}

We are thankful to Marco Heerings, nurse specialized in MS, for performing the EDSS assessments.

\section{Funding information}

The Dutch MS Study is funded by the National MS Foundation Netherlands, Rotterdam; Curavista bv, Geertruidenberg, and the MS4 Research Institute, Nijmegen, in the Netherlands. 


\section{References}

1. Lublin FD. New multiple sclerosis phenotypic classification. Eur Neurol. 2014;72 Suppl 1:1-5. Epub 2014/10/04. doi: 10.1159/000367614.

2. Koch $M$, Kingwell $E$, Rieckmann $P$, Tremlett $H$. The natural history of secondary progressive multiple sclerosis. J Neurol Neurosurg Psychiatry. 2010;81(9):1039-43. Epub 2010/07/20. doi: 10.1136/jnnp.2010.208173.

3. Trojano M, Pellegrini F, Fuiani A, Paolicelli D, Zipoli V, Zimatore GB, et al. New natural history of interferon-beta-treated relapsing multiple sclerosis. Ann Neurol. 2007;61(4):300-6. Epub 2007/04/21. doi: 10.1002/ana.21102.

4. U.S. Department of Health and Human Services. Patient-Reported Outcome Measures: Use in Medical Product Development to Support Labeling Claims. 2009.

5. Richards RG, Sampson FC, Beard SM, Tappenden P. A review of the natural history and epidemiology of multiple sclerosis: implications for resource allocation and health economic models. Health Technol Assess. 2002;6(10):1-73. Epub 2002/05/23.

6. Cascade E. Direct-to-Patient Studies 2011 [updated November]. Available from: https://www.google.nl/search?q=direct-to-patient+studies+CASCADE\&ie=utf-8\&oe=utf8\&gws_rd=cr\&ei=sByyVuLIOomPU_emgvAH.

7. Eichmann F. Evidence from direct-to-subject study designs for health (outcomes) research and (pharmaco) epidemiology. 2015. Value \& Outcomes Spotlight. [cited September/October].

8. Lejbkowicz I, Paperna T, Stein N, Dishon S, Miller A. Internet usage by patients with multiple sclerosis: implications to participatory medicine and personalized healthcare. Mult Scler Int. 2010;2010:640749. Epub 2010/01/01. doi: 10.1155/2010/640749.

9. Jongen PJ, Heerings $M$, Lemmens WA, Donders R, van der Zande A, van Noort E, et al. A prospective web-based patient-centred interactive study of long-term disabilities, disabilities perception and health-related quality of life in patients with multiple sclerosis in The Netherlands: the Dutch Multiple Sclerosis Study protocol. BMC Neurol. 2015;15:128. Epub 2015/08/05. doi: 10.1186/s12883-015-0379-0.

10. Eerola $\mathrm{M}$, Huurre $\mathrm{T}$, Aro $\mathrm{H}$. The problem of attrition in a Finnish longitudinal survey on depression. Eur J Epidemiol. 2005;20(1):113-20. Epub 2005/03/11.

11. Launes J, Hokkanen L, Laasonen M, Tuulio-Henriksson A, Virta M, Lipsanen J, et al. Attrition in a 30-year follow-up of a perinatal birth risk cohort: factors change with age. PeerJ. 2014;2:e480. Epub 2014/07/30. doi: 10.7717/peerj.480.

12. Jongen PJ, Sanders E, Zwanikken C, Koeman J, Visser LH, Koopmans P, et al. Adherence to monthly online self-assessments for short-term monitoring: a 1-year study in relapsing-remitting multiple sclerosis patients after start of disease modifying treatment. Patient Prefer Adherence. 2013;7:293-300. Epub 2013/04/17. doi: 10.2147/PPA.S40173.

13. Ministry of Health, Welfare and Sports. Dutch Medical Research Involving Human Subjects Act (WMO). International Publication Series Health, Welfare and Sport. (2):1-34.

14. Wynia K, Middel B, van Dijk JP, de Ruiter H, de Keyser J, Reijneveld SA. The Multiple Sclerosis impact Profile (MSIP). Development and testing psychometric properties of an ICF-based health measure. Disabil Rehabil. 2008;30(4):261-74. Epub 2007/09/14. doi: 10.1080/09638280701256868.

15. Wynia K, Middel B, de Ruiter H, van Dijk JP, de Keyser JH, Reijneveld SA. Stability and relative validity of the Multiple Sclerosis Impact Profile (MSIP). Disabil Rehabil. 2008;30(14):1027-38. Epub 2008/10/28.

16. Vickrey BG, Hays RD, Harooni R, Myers LW, Ellison GW. A health-related quality of life measure for multiple sclerosis. Qual Life Res. 1995;4(3):187-206. Epub 1995/06/01.

17. Kurtzke JF. Rating neurologic impairment in multiple sclerosis: an expanded disability status scale (EDSS). Neurology. 1983;33(11):1444-52. Epub 1983/11/01. 
18. Lechner-Scott J, Kappos L, Hofman M, Polman CH, Ronner H, Montalban X, et al. Can the Expanded Disability Status Scale be assessed by telephone? Mult Scler. 2003;9(2):154-9. Epub 2003/04/24.

19. Collins CD, Ivry B, Bowen JD, Cheng EM, Dobson R, Goodin DS, et al. A comparative analysis of Patient-Reported Expanded Disability Status Scale tools. Mult Scler. 2016;22(10):1349-58. Epub 2015/11/14. doi: 10.1177/1352458515616205.

20. Sharma NS. Patient centric approach for clinical trials: Current trend and new opportunities. Perspect Clin Res. 2015;6(3):134-8. Epub 2015/08/01. doi: 10.4103/2229-3485.159936.

21. Dreyer NA, Blackburn SC, Mt-Isa S, Richardson JL, Thomas S, Laursen M, et al. Direct-to-Patient Research: Piloting a New Approach to Understanding Drug Safety During Pregnancy. JMIR Public Health Surveill. 2015;1(2):e22. Epub 2016/05/27. doi: 10.2196/publichealth.4939.

22. Krischer J, Cronholm PF, Burroughs C, McAlear CA, Borchin R, Easley E, et al. Experience With Direct-to-Patient Recruitment for Enrollment Into a Clinical Trial in a Rare Disease: A Web-Based Study. J Med Internet Res. 2017;19(2):e50. Epub 2017/03/02. doi: 10.2196/jmir.6798.

23. Radler BT, Ryff CD. Who participates? Accounting for longitudinal retention in the MIDUS national study of health and well-being. J Aging Health. 2010;22(3):307-31. Epub 2010/01/28. doi: $10.1177 / 0898264309358617$.

24. Newcomb ME, Swann G, Estabrook R, Corden M, Begale M, Ashbeck A, et al. Patterns and Predictors of Compliance in a Prospective Diary Study of Substance Use and Sexual Behavior in a Sample of Young Men Who Have Sex With Men. Assessment. 2016. Epub 2016/09/03. doi: 10.1177/1073191116667584.

25. Chatfield MD, Brayne CE, Matthews FE. A systematic literature review of attrition between waves in longitudinal studies in the elderly shows a consistent pattern of dropout between differing studies. J Clin Epidemiol. 2005;58(1):13-9. Epub 2005/01/15. doi: 10.1016/j.jclinepi.2004.05.006.

26. Cattie J, Marquine MJ, Bolden KA, Obermeit LC, Morgan EE, Franklin DR, et al. Predictors of Attrition in a Cohort Study of HIV Infection and Methamphetamine Dependence. J Subst Use. 2015;20(6):407-16. Epub 2016/01/12. doi: 10.3109/14659891.2014.942397.

27. Bishop FL, Lewis G, Harris S, McKay N, Prentice $P$, Thiel H, et al. A within-subjects trial to test the equivalence of online and paper outcome measures: the Roland Morris disability questionnaire. BMC Musculoskelet Disord. 2010;11:113. Epub 2010/06/10. doi: 10.1186/1471-2474-11-113.

28. Vallejo MA, Jordan CM, Diaz MI, Comeche MI, Ortega J. Psychological assessment via the internet: a reliability and validity study of online (vs paper-and-pencil) versions of the General Health Questionnaire-28 (GHQ-28) and the Symptoms Check-List-90-Revised (SCL-90-R). J Med Internet Res. 2007;9(1):e2. Epub 2007/05/05. doi: 10.2196/jmir.9.1.e2.

29. Bushnell DM, Martin ML, Scanlon M, Chen T, Chau D, Viswanathan HN. Equivalence and measurement properties of an electronic version of the Psoriasis Symptom Inventory. Qual Life Res. 2014;23(3):897-906. Epub 2013/09/21. doi: 10.1007/s11136-013-0527-1.

30. Bernstein AN, Levinson AW, Hobbs AR, Lavery HJ, Samadi DB. Validation of online administration of the sexual health inventory for men. J Urol. 2013;189(4):1456-61. Epub 2012/10/23. doi: 10.1016/j.juro.2012.10.053.

31. Kruse S, Schneeberg A, Brussoni M. Construct validity and impact of mode of administration of the PedsQL among a pediatric injury population. Health Qual Life Outcomes. 2014;12:168. Epub 2014/12/01. doi: 10.1186/s12955-014-0168-2.

32. Verkuil B, Brosschot JF. The online version of the Dutch Penn State Worry Questionnaire: factor structure, predictive validity and reliability. J Anxiety Disord. 2012;26(8):844-8. Epub 2012/10/02. doi: 10.1016/j.janxdis.2012.08.002.

33. Dias JC, Maroco J, Campos JA. Weight concerns scale applied to college students: comparison between pencil-and-paper and online formats. Cyberpsychol Behav Soc Netw. 2015;18(3):18892. Epub 2015/03/10. doi: 10.1089/cyber.2014.0392. 
34. Brock RL, Barry RA, Lawrence E, Dey J, Rolffs J. Internet administration of paper-and-pencil questionnaires used in couple research: assessing psychometric equivalence. Assessment. 2012;19(2):226-42. Epub 2010/10/01. doi: 10.1177/1073191110382850. 


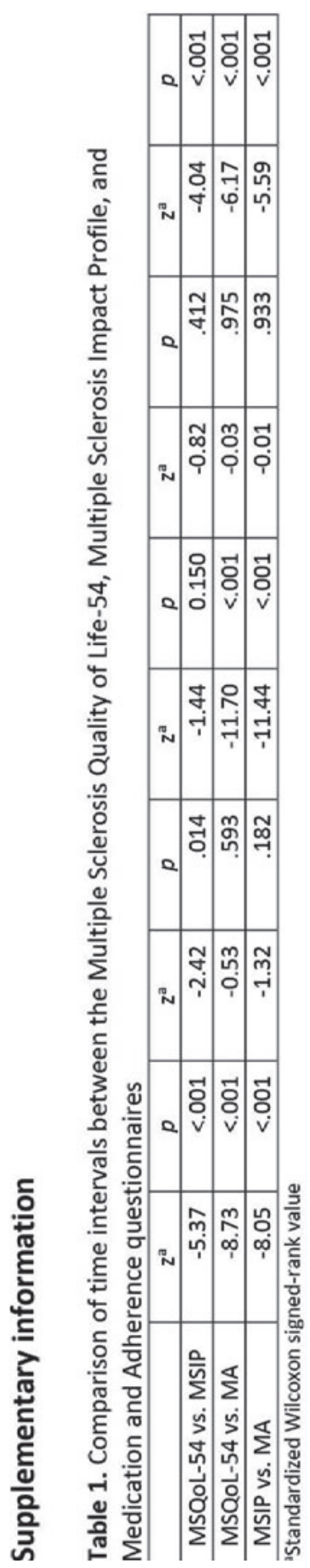



CHAPTER 7

General discussion 
The landscape of disease-modifying drugs (DMDs) for multiple sclerosis (MS) is expanding quickly, particularly for relapsing-remitting MS (RRMS). In the last decade, a number of new DMDs have entered the market for RRMS; these are either more efficacious or perceived as less burdensome in terms of administration regimens (administration method and frequency) and side effects. Earlier approved DMDs indicated for RRMS and clinically isolated syndrome (CIS) have an advantage over newly introduced drugs, in that many of those approved earlier have been in use for over twenty years or more, so there is considerable experience with their utilization in clinical practice, and thus extensive knowledge is available about their safety. The advances in DMDs for MS provide patients with new opportunities to delay disease progression, but also make identifying the right DMD for the individual patient more difficult. Knowing the patient's preferences with regard to DMD characteristics and incorporating this knowledge in the decision for a DMD could improve the patients' satisfaction with their treatment and with the quality of care provided. Moreover, it could positively affect the patients' commitment to continuing treatment with the chosen DMD over the long term, and to missing no or only a minimal number of doses. Patients should thus be actively involved in making decisions for DMDs using the shared decision making approach.

The aim of this thesis was two-fold. Part I of this dissertation aimed to develop and pilot test a patient decision aid to support patients with MS and their healthcare professionals in making a shared decision about treatment with DMDs. To address this aim, three subobjectives were formulated: 1 ) to assess which information about the DMD options is important to consider when making a treatment decision, from the patients' and professionals' perspectives (Chapters 2 and 3); 2) to develop a prototype of the patient decision aid that incorporates the informational needs of the patient (Chapter 4); and 3) to assess the comprehensibility, usability and acceptability of the patient decision aid for both patients and healthcare professionals (Chapter 4).

Part II of this thesis aimed to inform the design of web-based research in MS and economic evaluation of shared decision making for MS. More specifically, Part II aimed 1) to evaluate whether shared decision making for DMDs for MS, whether supported with a patient decision aid or not, could potentially be cost-effective, and which parameters would most affect the cost-effectiveness (Chapter 5); and 2) to evaluate whether a difference in frequency and length of questionnaires affects patients' adherence to online selfassessment in direct-to-patient research (Chapter 6).

This final chapter provides a summary of the main findings of this dissertation, discusses the methodological challenges and suggests implications for clinical practice, policy and further research and development of the patient decision aid. 


\section{Summary of main findings}

Part I of this dissertation presented several studies conducted to develop a patient decision aid according to the recommendations for development of the International Patient Decision Aids Standards (IPDAS)[1]. The patient decision aid was intended for patients with RRMS and CIS, in the Netherlands, who are considering first time treatment with DMDs or switching between DMDs. All DMDs available for MS and CIS were included, as well as the option of no treatment. An advisory group consisting of patient representatives, neurologists, MS nurses and experts in patient decision aid development was consulted at various stages in the developmental process (Chapter 4).

For the first objective of Part I, focus groups with patients and a best-worst scaling survey (Chapter 2) were conducted to identify characteristics of DMDs that patients find important to consider when deciding about treatment with DMDs, and to prioritize these characteristics in the decision according to their importance. As a group, patients found primarily benefits - specifically the effects of DMDs on disease progression, quality of life and relapse rate-most important, and secondarily, possible treatment burden, such as side effects, safety and ease of use. Exploratory analysis identified heterogeneity in preferences between patients with different characteristics, such as prior DMD use, disease duration and gender. Heterogeneity in preferences shows that there is no "one size fits all" approach in decision making for DMDs for RRMS, and that an approach of shared decision making to include the individual's preferences in the decision is warranted. A second best-worst scaling survey with neurologists and MS nurses (Chapter 3) enabled assessing what healthcare professionals find most important to consider. Overall, neurologists and MS nurses agreed that benefits are highly important, just as the patients do, but healthcare professionals put more priority on safety aspects, i.e. the risk of severely disabling or lifethreatening adverse events, than did patients. The results of both best-worst scaling surveys identified which information should be included in the patient decision aid for DMDs for MS, a recommended step by the IPDAS in the development of decision aids for patients [1]: to optimally meet decisional patients' needs, their perspectives and the perspectives of healthcare professionals on what should be considered should be elicited. Nine characteristics were selected for inclusion in the patient decision aid, and a tenth characteristic was included specifically for patients with CIS.

An approach of multi-criteria decision analysis (MCDA) was selected as the underlying algorithm for the patient decision aid, as it can relieve the cognitive burden of weighting many different (conflicting) characteristics of many different treatment options. This choice was also directive in addressing the second objective of developing the prototype of the patient decision aid. The patient decision aid is accessible online, which allowed for the mathematical computations needed for MCDA. Moreover, the online format enables interaction: the patient enters his/her personal and medical information that may influence his/her eligibility for DMDs, selects the characteristics he/she finds important in the decision 
for DMDs and indicates the weight of each characteristic in the decision. Information about the different DMDs was obtained through an extensive literature review and was validated within the steering group. Based on the information provided by the patient and the information retrieved from the literature, the patient decision aid provides the patient with a ranking of the DMDs from most to least suitable with regard to his/her preferences. Moreover, with the decision aid the patient is able to compare the performance of a DMD on a specific characteristic with the performance of other DMDs.

Three rounds of alpha pilot testing with MS patients and healthcare professionals were conducted to address the third objective. Both patients and healthcare professionals acknowledged the potential added value of the patient decision aid for the decision making process, but also points for improvement were reported. Three overarching themes for improvement were identified: content and framing, weighting methods for the importance of characteristics according to patients, and the presentation of the results of the patient decision aid. Adaptations to the patient decision aid were made accordingly, meaning that the description of the different MS courses were detailed more fully, unnecessary text and questions that were deemed too difficult were adapted or omitted. Moreover, the presentation of the results was expanded. Based on a selection of three DMDs made by the patient, the adapted version of the patient decision aid provides the patient with a printable one-page summary of the DMDs according to their important characteristics. In addition, a summary of the patient's personal and medical history was included and its consequences with regard to the patient's eligibility for each DMD for the interest of the treating healthcare professional(s). The ranking of the DMDs, the summary of the three selected DMDs, and the summary of the patient's eligibility for DMD treatment could be shared with the healthcare professional(s) and serves as support for the discussion in making a shared decision (Chapter 4).

Part II of this dissertation informs the design of web-based health services and research for MS, and specifically to assess the potential cost-effectiveness of shared decision making for MS. A model-based economic evaluation (Chapter 5) was conducted to address the first objective of Part II. The state transition model explored whether shared decision making for DMDs for RRMS could potentially be a cost-effective intervention and determined which parameters most affect its cost-effectiveness. A change in which DMD treatments are initiated, along with increased persistence and increased adherence to DMDs as a result of shared decision making were shown to result in increased quality-adjusted life years (QALYs) and societal costs, when these effects were modeled separately and combined. In the combined scenario the following effects were assumed: 1) more patients initiate DMD treatment after diagnosis with RRMS and slightly more patients initiate second generation first-line DMDs and second-line DMDs; 2) their discontinuation decreases by $50 \%$, and 3 ) the proportion of patients with optimal adherence increases by $5 \%$. The scenario resulted in 1.12 more QALYs and $€ 20,009$ more total costs for shared decision making for DMDs for RRMS in comparison with usual care. The incremental cost-effectiveness ratio (ICER, i.e. the 
difference in costs between shared decision making and usual care, divided by the difference in QALYS) comes to $€ 17,875$ per QALY gained, which is lower than the acceptable threshold of $€ 50,000$ per QALY gained. Shared decision making for RRMS could thus potentially be a cost-effective intervention. Of the three assumed effects of shared decision making, a change in relative reduction of discontinuation influenced the ICER most. Moreover, a change in drug prices, the risk of disease progression, the discount rate and the perspective taken substantially affected the ICER. This study informs clinicians and policy makers about the potential economic value of investing in research and implementation of interventions to support shared decision making for RRMS. In addition, the study provides a rationale for future trial-based studies.

In a direct-to-patient web-based study with MS patients (Chapter 6), the effect of different schedules for self-assessment of perceived disability, health-related quality of life (HRQoL) and adherence to medication was assessed to address the second objective of Part II of this dissertation. Perceived disability and HRQoL were addressed in 36-item and 54-item questionnaires, respectively, every six months, while adherence was questioned using a 2item questionnaire every month. Over a 2-year period, no difference was found in the proportion of patients completing all scheduled assessments between the two less frequent long questionnaires (perceived disabilities and $\mathrm{HRQOL}$ ) and the more frequent short questionnaire (adherence), but patients completed the low-frequency long questionnaires more often within a predefined time frame than the high-frequency short questionnaire. Moreover, study results suggest that personal contact with a researcher within six months after completion of the first questionnaire could beneficially affect long-term adherence to completing self-assessments in direct-to-patient research.

\section{Methodological considerations}

In this section, first the generalizability and transferability of the study results included in this dissertation are discussed. Next, the methodological challenges encountered in the development of the web-based patient decision aid will be addressed.

\section{Generalisability}

Generalisability refers to the extent to which inferences based on the results of a study concerning a specific sample can be made for the population at large [2]. Patient recruitment for the studies included in this dissertation (Chapters 2, 3, 4 and 6) was primarily done via the internet, i.e. via social media, advertisements on the websites of patient organizations and online mailings from patient organizations. Online recruitment made it possible to reach many patients, irrespective of their geographical location, treatment centre or latest out-patient consultation. Although the MS patient population has been argued to be relatively active on the internet in comparison with other chronicallyill patient populations [3], the recruitment methods used in the studies have the 
disadvantage that patients with high levels of health literacy and internet use are possibly overrepresented in the study samples in comparison with the study population. Relatively large proportions of higher educated participants were included in the focus groups and best-worst scaling survey in comparison with the average MS patient population in the Netherlands. The alpha pilot testing, which included higher and lower educated patients, revealed that individual use of the patient decision aid in clinical practice might be too difficult for some patients. Beta pilot testing with patients with a range of different demographic and disease characteristics should be conducted to evaluate how patients with different levels of education and health literacy can be supported in optimally using the patient decision aid.

\section{Transferability}

Transferability refers to the extent the results of the study could be applied in other contexts than the specific context of the study [2]. The focus groups and surveys (Chapters 2, 3 and 6) in this dissertation have been performed with MS patients and healthcare professionals in the Netherlands. Moreover, the patient decision aid (Chapter 4) was developed and the economic evaluation of shared decision making (Chapter 5) was conducted specifically for the Dutch context. Topics such as the importance of characteristics of DMDs in the decision making process could be country-specific, determined by characteristics of the healthcare system. For example, Dutch patients do not have additional out-of-pocket costs for prescription medication, except for the mandatory deductible, which patients may have elsewhere. A characteristic such as out-of-pocket costs might, therefore, be important in the decision for DMDs if patients need to pay additional fees. Differences in the healthcare systems may thus result in other characteristics being included in the patient decision aid. Differences in factors other than reimbursement of DMDs, such as country-specific eligibility criteria defined by clinical guidelines or national regulatory agencies, ensure that the patient decision aid in the current form and the results of the economic evaluation are specifically applicable to the Dutch context. These aspects should be considered when transferring the results of the study to other context. The structure of the patient decision aid, though, enables relatively easy adaptation for application in other contexts if characteristics and eligibility criteria have been identified and verified specifically for those contexts.

\section{Approaches for development and evaluation of the patient decision aid}

The patient decision aid is based on the principles of MCDA $[4,5]$. This means that the DMDs are described according to certain characteristics and the patient weighs the importance of these characteristics. The patient decision aid ranks the available DMDs based on what characteristics the patient finds important and how well each DMD performs with regard to these characteristics. The ranking of DMDs thus presents which DMDs fit most with the 
patient's preferences. A number of methodological challenges were encountered in the development of the patient decision aid.

Although an MCDA-based decision support tool is a thorough and systematic approach for making decisions by minimizing heuristic decision making, such a tool might seem a black box for patients and professionals. First, because solely presenting a ranking of DMDs without justification might seem arbitrary if no insight is given into how these rankings have been computed. Second, because evidence from clinical trials and other sources needs to be translated into a performance score between 0 and 1 for each DMD on each characteristics, which comes with its challenges. A first challenge is the variety in the amount and quality of evidence between characteristics and per characteristic between DMDs. A lack of uniformity in outcome measures between pivotal studies of DMDs and incomplete reporting of these outcomes hinder the presentation of equivalent performance data for characteristics. A second challenge is that the translation of data into a score between 0 and 1 might be vulnerable to manipulation. Whereas such a translation of hazard ratios and relative risks is rather straightforward, determining a score for side effects and safety based on descriptive data is more challenging and prone to discussion. Consensus among experts should be reached. A third challenge is that the quality of the evidence and uncertainty surrounding the point estimates of hazard ratios, relative risks, etc. also need to be made transparent in (reporting about) the MCDA [4]. Insights into these aspects increase the face validity and trustworthiness of the patient decision aid, but communicating these uncertainties to patients and healthcare professionals and enabling them to include these uncertainties in the decision making is complex. Different measures were undertaken to make more transparent for patients, healthcare professionals and/or external reviewers, how the patient decision aid arrives at the results, i.e. the ranking of the DMDs. The tool provides insight into the performance of each DMD on the characteristics in bar charts and in descriptive text, and a paper accompanying the patient decision aid describes how the patient decision aid was developed and the type of data that were included.

An important step in developing decision instruments based on MCDA is determining the criteria that describe the decision - or for this project the characteristics of DMDs - that need to be included in the instrument $[4,5]$. Omission of relevant criteria or selection of irrelevant criteria would substantially affect the validity of the decision instrument [4], resulting in ineffective decision support. For the development of the patient decision aid, initial qualitative research was followed with a best-worst scaling survey to prioritize the criteria (Chapter 2). In best-worst scaling surveys, respondents state their preferences using hypothetical choice scenarios [6]. As respondents do not suffer actual consequences of their choices in these surveys, it is uncertain whether their answers reflect the choices they would make if there were consequences [7], i.e. if they actually had to start using the medication. Choice scenarios may be less carefully considered, resulting in inconsistent answers or considering only one or a few characteristics, or respondents might provide socially 
desirable answers [7]. The application of a best-worst scaling in the development of a patient decision aid was a relatively novel approach. Conducting a best-worst scaling survey enables questioning a larger sample of the total patient population. This approach facilitates the development of a patient decision aid that meets the needs of many patients. Moreover, priorities can be set with regard to the information needed by patients. A limitation of conducting an online survey is, however, that no impression can be obtained of how respondents complete these surveys, other than tracking the time for completing each question and the whole survey. Accordingly, little can be said about the carefulness with which patients completed the choice tasks.

Development of an instrument for a specific target group requires making choices about what should be included, but also what should be left out, to ultimately develop an instrument that suits patients' needs as best as possible without the instrument becoming too complex or overly burdensome to use. The average stated preferences obtained through the best-worst scaling surveys (Chapters $\mathbf{2}$ and $\mathbf{3}$ ) were therefore used to determine the selection of criteria included in the MCDA-decision support tool and thus determined its content. The heterogeneity of preferences also need to be considered. Exploratory analysis showed that respondents with specific characteristics put more emphasis on certain characteristics of DMDs in comparison with patients with other characteristics. In the best-worst scaling surveys, these preferences were averaged, but individual preferences can deviate from the average preference. This shows that clinicians must not automatically project results of stated preference research on the patient in front of them. However, these averages can be useful for developing interventions for patients. A consideration in this is that using average preferences to develop instruments might result in instruments being developed for the "average patient", even though the "average patient" most often does not exist. The functionalities of the MCDA-based decision aid to let patients select what characteristics they would like to consider in the decision and to put individualized weights on these characteristics results in a tool more tailored to the individual patient.

A model-based economic evaluation was conducted to explore whether introducing shared decision making, possibly supported by a patient decision aid, in addition to the usual care, could potentially be cost-effective. A challenge with such an early-stage health economic model is that it focuses on interventions that are still in development or in the early stages of empirical studies [8], but information concerning the performance of the intervention is needed for the evaluation. Although theories suggest that shared decision making and/or a patient decision aids could improve treatment initiation, treatment persistence and treatment adherence $[9,10]$, evidence supporting these theories is not conclusive [10]. Point estimates included in the model for the increase in the proportion of patients initiating each DMD, for treatment persistence and treatment adherence were, therefore, based on assumptions, informed by expert opinions and studies on patients' preferences for DMD characteristics or on the evaluation of patient decision aids for other healthcare decisions. There is, therefore, considerable uncertainty about the point estimates and the future 
outcomes of the intervention. One-way sensitivity analyses and probabilistic analysis were conducted to evaluate the robustness of the conclusions regarding the cost-effectiveness of shared decision making for DMDs for MS. Still, the study results should be interpreted in the context of the assumptions made regarding the three parameters, and can therefore give only an indication of the potential cost-effectiveness of shared decision making for DMDs for MS.

\section{Implications for further development and research}

This dissertation covers the development and alpha user-testing on the comprehensibility, usability and acceptability of a web-based patient decision aid for DMDs for MS. The alpha test included patients who had experience with using DMDs, but were not considering switching or starting a DMD at the time of testing. A number of questions and points for improvement remain that should be addressed in the further development of the patient decision aid. Further development of the patient decision aid is needed regarding the verification of the rankings made by the decision aid, including the influence of uncertainty about effect estimates, and improving understandability of the patient decision aid through evaluation of the required health literacy and adaptation of the delivery of the patient decision aid. Next, a beta pilot test should be conducted including patients and healthcare professionals who are actually having to make a decision about DMDs [1]. Pilot implementation of the patient decision aid in clinical practice would answer questions such as 1 ) what is the most appropriate time point for introducing the patient decision aid to the patient?; 2 ) are all patients able to go through the patient decision aid individually or should a trained MS nurse guide the patients in the usage?; 3) what are other barriers and facilitators for the implementation in clinical practice? Moreover, the beta pilot would provide insights into whether implementation of the patient decision aid results in a trend towards resolving decisional conflict compared to baseline and in successful shared decision making taking place, as other patient decision aids have been shown to demonstrate positive effects on decision quality and on the quality of the decision making process [11]. After optimization of the patient decision aid based on the results of the beta pilot test, further research should focus on the effectiveness of the patient decision aid in comparison with usual care. It has been argued that patient decision aids positively affect patients' persistence and adherence to treatment [9], resulting in improved health outcomes and decreased use of healthcare resources [12]. However, evidence supporting these theories is limited [11, 12]. A randomized controlled trial would provide the strongest evidence to confirm or reject this theory. However, the risk of contamination bias of the control group and variations in daily practice, clinical expertise, work culture and patient population should be taken into consideration in designing such a trial. Cluster randomization at the hospital level would minimize the risk of contamination bias [13]. Variation between hospitals is difficult to minimize in the design, as matching of hospitals on such characteristics is not feasible, and would thus be limited to controlling for in the analyses. 
An alternative could be an interrupted time series, in which data for the control condition is first collected, followed by implementation of shared decision making supported by the patient decision aid and collection of data for this intervention [13]. It is necessary to have data on the effectiveness of the patient decision aid in comparison with usual care, in order to encourage healthcare professionals and policy makers of healthcare organizations to invest resources in the implementation of the patient decision aid. Accordingly, this study would contribute to providing patients access to the patient decision aid.

The findings in Chapters 5 and $\mathbf{6}$ provide further guidance for the design of the trial. Since MS patients are in general relatively active online [3], online self-assessment during the trial would be feasible for the majority of patients, resulting in the efficient collection and processing of data. Chapter 6 suggests that personal contact with a member of the research team during the trial follow-up could enhance the patients' adherence to the measurement schedule. Chapter 5 identified the extent to which certain outcome measures affect the cost-effectiveness of shared decision making. Most importantly, real-world data regarding the initiation of DMD treatment (including the type of DMD), patients' persistence and adherence to treatment in the first year, and preferably over the longer term, should be collected, in addition to data on MS outcomes, quality-adjusted life years, resource use and costs. Using these data, the lifetime effectiveness and cost-effectiveness of shared decision making can be estimated more precisely by updating the state transition model described in Chapter 5. Moreover, the hypothesis that shared decision making could increase persistence and adherence to treatment could be confirmed. If shared decision making would indeed result in these beneficial consequences for patients' commitment to treatment, a combination of the patient decision aid with self-managed interventions for optimizing treatment persistence and adherence could further be considered.

Currently, dozens of potential new DMDs for RRMS and progressive MS are being studied in Phase II and Phase III studies [14] and more are on their way in Phase I studies. The number of available treatments is increasing rapidly. This seems promising for the options which patients with MS will have in the future. A consequence of the rapid advancements in the treatment of MS is that instruments concerning these treatments, such as clinical guidelines, patient education material and thus patient decision aids, are perhaps already outdated at the moment they become available for the target users. Continuous review of new developments and updating of these instruments is called for, which may be time consuming and expensive. With limited resources and funding for research, development and updating of patient decision aids, this is challenging. Therefore, structures should be set up for the immediate collection and processing of data as new DMDs and evidence about their efficacy and their cost-effectiveness become available. Periodically updated guidelines, such as the yearly-updated Dutch guidelines for epilepsy, may be warranted.

Another direction for research could be exploring possibilities for internationalization of the patient decision aid. Currently, patient decision aids and shared decision making are 
receiving increasing attention. Their importance for increasing quality of care, as well as for ethical reasons ("no decision about me without me"), have been recognized internationally by the medical profession [15] and by governmental bodies [16]. The patient decision aid described in this dissertation contains components specifically for MS patients in the Netherlands, such as the availability of DMDs, but the structure and content of the patient decision aid could be adapted to fit other settings, making it viable for patients in other countries and settings. For DMDs for MS, the development of interventions for patient decision support has been initiated in several countries [17-19]. International collaboration with patient decision aid developers for DMDs for MS could provide a unique opportunity for combining forces, integrating the strengths of the patient decision aids into a patient decision aid adaptable to country-specific settings.

\section{Implications for clinical practice and policy}

This MCDA-based patient decision aid was developed to support patients and healthcare professionals in making a shared decision about starting DMDs, but simultaneously to minimize the cognitive burden for patients in being involved in such complex healthcare decisions. The patient decision aid provides patients with information about the various treatment options, asks patients to indicate what is important to them, and based on what is important, provides a ranking of the treatment options for the specific patient. In the consultation with the healthcare professional, this ranking and the patient information is used to start the discussion about the decision for DMDs. The patient decision aid must never replace the consultation with the healthcare professional, nor should the ranking dictate which DMD the patient should choose. Based on the findings presented in this dissertation, it can be concluded that the patients and healthcare professionals were positive about the potential use of the patient decision aid for clinical decision making, but further development is needed before implementation in clinical practice (Chapter 4). An early health economic model (Chapter 5) showed that the implementation of shared decision making in clinical practice could potentially be cost-effective, which could be an incentive for policy makers in healthcare institutions to consider implementing the patient decision aid.

The implementation of a patient decision aid per se is unlikely to automatically result in actual shared decision making taking place between patients and healthcare professionals [20]. In previous studies, various barriers to the implementation of shared decision making according to healthcare professionals have been identified, most importantly lack of time to practice shared decision making [21]. Strategies for successful implementation of shared decision making include training of healthcare professionals and making patient decision aids available, but both require investments. A commitment to prioritize shared decision making in all layers of the healthcare organisation - from the healthcare professional making decisions with patients to the upper management and board - thus needs to be 
made in terms of time, funding and efforts [22]. In addition to the healthcare organizations, healthcare insurers also need to play a role in facilitating the (financial) accessibility to shared decision making [23]. From 2018, the Dutch Health Authority has included a registration code for consultations in which shared decision making has been applied [24]. The purpose is to make more transparent the degree to which shared decision making takes place [24]. Indirectly this could contribute to the financing of shared decision making using established finance methods, because the data can be used in negotiations between healthcare institutions and health insurers, in the purchase of healthcare services [24]. However, healthcare organizations are reluctant to use the code, as it is suitable only for specific situations, there is an increase in administrative work and the code provides no financial compensation. An even more pronounced hurdle for healthcare institutions are the investments required during the start-up phase of implementing shared decision making [23]. Both parties, i.e. healthcare insurers and healthcare institutes, agree that they share responsibilities in financing this phase [23], which is encouraging for realising the wide implementation of shared decision making. However, pioneers are needed to ensure the financial and organizational sustainability of implementation of shared decision making in clinical practice.

Another important issue for consideration is the public availability of patient decision aids. Public availability empowers patients to inform themselves with regard to their healthcare and their treatment options even if they have not been made aware by their clinician that their preferences matter in the decision. A downside could be, however, that patients are presented with treatment options for which they are not eligible because patients cannot appropriately answer the eligibility questions themselves. In that case, the patient decision aid may be more confusing and obstruct the decision making process rather than supporting making a shared decision. Additional studies on the level of support needed by a MS nurse or clinician during the use of the patient decision aid in the pilot test should provide more insight as to whether public availability of the patient decision aid would be feasible.

\section{Highlights of this dissertation}

- A patient decision aid to support shared decision making between patient and healthcare professionals for DMDs for MS was developed, using certain methodologies typically applied in health technology assessment, i.e. best-worst scaling surveys and multi-criteria decision analysis.

- A patient decision aid based on the principles of multi-criteria decision analysis may have its advantages in the utilisation if many characteristics of many treatment options need to be made, leading to individualised treatment recommendation, but its development also has its challenges, such as determining performance scores for treatment options for all characteristics. 
- An early economic evaluation suggests that shared decision making for MS could potentially be a cost-effective intervention. Policy makers should consider implementation of shared decision making to improve quality of care.

- Further development of the patient decision aid is recommended to optimise the content of the tool and the implementation strategy. Real-world data should be collected about the (cost-) effectiveness of the patient decision aid in clinical practice. 


\section{References}

1. Coulter A, Stilwel D, Kryworuchko J, Dolan Mullen P, Jenn Ng C, van der Weijden T. A systematic development process for patient decision aids. BMC Med Inform Decis Mak. 2013;13(Suppl 2).

2. Mulligan J-A, Fox-Rushby J. Transferring cost-effectiveness data across space and time. In: FoxRushby J, Carirns J, editors. Economic evaluation: Open University Press; 2005.

3. Heesen C, Rahn AC. Guest Editorial: Shared Decision Making in Managing Multiple Sclerosis: Revisiting the Research Agenda. Int J MS Care. 2018;20(6):v-vi. doi: 10.7224/1537-2073.2018098.

4. Marsh K, M IJ, Thokala P, Baltussen R, Boysen M, Kalo Z, et al. Multiple criteria decision analysis for health care decision making-emerging good practices: report 2 of the ISPOR MCDA Emerging Good Practices Task Force. Value Health. 2016;19(2):125-37. doi: 10.1016/j.jval.2015.12.016.

5. Thokala P, Devlin N, Marsh K, Baltussen R, Boysen M, Kalo Z, et al. Multiple criteria decision analysis for health care decision making--an introduction: report 1 of the ISPOR MCDA Emerging Good Practices Task Force. Value Health. 2016;19(1):1-13. doi: 10.1016/j.jval.2015.12.003.

6. Flynn TN, Louviere JJ, Peters TJ, Coast J. Best--worst scaling: What it can do for health care research and how to do it. J Health Econ. 2007;26(1):171-89. doi: 10.1016/j.jhealeco.2006.04.002.

7. Bridges JFP, Onukwugha E, Johnson FR, Hauber AB. Patient preference methods - a patient centered evaluation paradigm. ISPOR Connections. 2007:4-7.

8. MJ IJ, Koffijberg H, Fenwick E, Krahn M. Emerging Use of Early Health Technology Assessment in Medical Product Development: A Scoping Review of the Literature. PharmacoEconomics. 2017;35(7):727-40. doi: 10.1007/s40273-017-0509-1.

9. Stalmeier PF. Adherence and decision AIDS: a model and a narrative review. Med Decis Making. 2011;31(1):121-9. doi: 10.1177/0272989X10370487.

10. Ben-Zacharia A, Adamson M, Boyd A, Hardeman P, Smrtka J, Walker B, et al. Impact of shared decision making on disease-modifying drug adherence in multiple sclerosis. Int J MS Care. 2018;20(6):287-97. doi: 10.7224/1537-2073.2017-070.

11. Stacey D, Légaré F, Lewis K, Barry MJ, Bennett CL, Eden KB, et al. Decision aids for people facing health treatment or screening decisions. Cochrane Database Syst Rev. 2017;(4). doi: 10.1002/14651858.CD001431.pub5.

12. Trenaman L, Bryan S, Bansback N. The cost-effectiveness of patient decision aids: a systematic review. Healthc (Amst). 2014;2(4):251-7. doi: 10.1016/j.hjdsi.2014.09.002.

13. Complex interventions in health: an overview of research methods. Richards DA, Rahm Hallberg I, editors. London: Routledge; 2015.

14. De Angelis F, Chataqay J. Novel multiple sclerosis drugs in the pipeline. Clin Pharmacol Ther. 2019;105(5):1082-90. doi: 10.1002/cpt.1412.

15. Parsa-Parsi RW. The Revised Declaration of Geneva: A Modern-Day Physician's Pledge. Jama. 2017;318(20):1971-2. doi: 10.1001/jama.2017.16230.

16. Harter M, Moumjid N, Cornuz J, Elwyn G, van der Weijden T. Shared decision making in 2017: International accomplishments in policy, research and implementation. Z Evid Fortbild Qual Gesundhwes. 2017;123-124:1-5. doi: 10.1016/j.zefq.2017.05.024.

17. Bansback N, Chiu JA, Carruthers R, Metcalfe R, Lapointe E, Schabas A, et al. Development and usability testing of a patient decision aid for newly diagnosed relapsing multiple sclerosis patients. BMC Neurol. 2019;19(1):173. doi: 10.1186/s12883-019-1382-7.

18. Col NF, Solomon AJ, Springmann V, lonete C, Alvarez E, Tierman B, et al. Evaluation of a Novel Preference Assessment Tool for Patients with Multiple Sclerosis. Int J MS Care. 2018;20(6):260-7. doi: 10.7224/1537-2073.2017-021.

19. Rahn AC, Kopke S, Backhus I, Kasper J, Anger K, Untiedt B, et al. Nurse-led immunotreatment DEcision Coaching In people with Multiple Sclerosis (DECIMS) - Feasibility testing, pilot 
randomised controlled trial and mixed methods process evaluation. Int J Nurs Stud. 2018;78:2636. doi: 10.1016/j.ijnurstu.2017.08.011.

20. Elwyn G, Laitner S, Coulter A, Walker E, Watson P, Thomson R. Implementing shared decision making in the NHS. Brit Med J. 2010;14(341):c5146. doi: 10.1136/bmj.c5146.

21. Legare F, Ratte S, Gravel K, Graham ID. Barriers and facilitators to implementing shared decision making in clinical practice: update of a systematic review of health professionals' perceptions. Patient Educ Couns. 2008;73(3):526-35. doi: 10.1016/j.pec.2008.07.018.

22. Nelson WA, Donnellan JJ, Elwyn G. Implementing shared decision making: an organizational imperative. In: Elwyn G, Edwards A, Thompson R, editors. Shared decision making in health care: achieving evidence-based patient choice. 3rd ed. New Yrok: Oxford University Press; 2016.

23. Savelberg W, de Bruijn D. Samen Beslissen: ziekenhuis en zorgverzekeraar in gesprek (report). Maastricht UMC+, 2019.

24. Dutch healthcare Authority. Verantwoording dbc-pakket 2018 (RZ18a). 2018.

25. Rogers EM. Diffusion of innovations. 5th ed. New York: Simon \& Schuster; 2003. 



\section{ADDENDA}

Summary

\section{Samenvatting}

Valorisation

Dankwoord

About the author 

Summary 
Patients with multiple sclerosis (MS) can experience various physical, cognitive and mental symptoms, which substantially affect quality of life. Advances in disease-modifying drug (DMD) treatment for MS provide patients with new opportunities to delay disease progression. Twelve different DMDs are currently available for the relapsing-remitting course of MS (RRMS) in the Netherlands; four are also available for clinically isolated syndrome (CIS), and more DMDs are expected to enter the market in the coming years. The increasing number of available drugs makes choosing the right DMD more complex, especially since the DMDs have different characteristics in terms of effects and treatment burden. Moreover, the choice for a DMD is preference-sensitive: there is no obvious "best" choice. Particularly for those with MS, where both the symptoms and the possible DMDs are so various, the patient's preferences for the treatment options should be taken into account. This requires the patient's active participation in the decision making process: a shared decision should be made. Shared decision making is a collaborative process between the healthcare professional and the patient; the patient is informed by the healthcare professional about the disease characteristics, prognosis and the treatment options, so that he/she can form preferences for the treatment options, and these preferences can be incorporated in the decision. Patient decision aids are designed to support this process. To ensure the quality of the developmental process and the patient decision aids, the International Patient Decision Aid Standards recommends the following steps for development: 1 ) scoping the patient decision aid; 2) forming a steering group of experts; 3 ) assessing patients' informational needs according to patients and healthcare professionals; 4) reviewing and synthesizing clinical evidence for treatment options; 5) developing a prototype; 6 ) testing the comprehensibility and usability of the prototype (alpha pilot test), and 7) testing the feasibility of implementing the patient decision aid (beta pilot test).

Part I of this dissertation aimed to develop and pilot test a patient decision aid to support patients with RRMS or CIS and their healthcare professionals in making a shared decision about treatment with DMDs, following the recommended steps by the the International Patient Decision Aid Standards.

Chapter 2 addresses the assessment of patients' informational needs according to patients. Understanding what information about DMDs patients take into consideration when choosing a DMD contributes to the selection of information for the patient decision aid. Consecutive actions were undertaken to identify characteristics of DMDs that influence patients' decisions for treatment and to prioritize these characteristics according to their importance. Three focus groups with RRMS patients $(\mathrm{N}=19)$ were performed. A nominal group technique was used in these focus groups to obtain a complete list of DMD characteristics that could be considered during the decision making process. Afterwards, a best-worst scaling survey was developed to prioritize the characteristics. In this survey, patients were presented with 17 choice tasks. In each choice task, patients were asked to answer which characteristic from a list of five characteristics they found most and least 
important to consider when having to make the treatment decision. The characteristics' mean relative importance scores (RISs) were calculated.

Twenty-seven characteristics, which were identified in the focus groups, were included in the best-worst scaling survey. RISs were highest for the effect on disease progression (mean RIS: 9.64, 95\% confidence interval: [9.48-9.81]), quality of life (RIS: 9.21 [9.00-9.42]), relapse rate (RIS: 7.76 [7.39-8.13]), severity of side effects (RIS: 7.63 [7.33-7.94]) and relapse severity (RIS: 7.39 [7.06-7.73]. Differences in RIS per characteristic were found in patient subgroups such as prior experience with DMD use. Explorative subgroup analyses showed statistically significant higher RIS for side effect-related characteristics for patients who had no experience in using DMDs, in comparison with experienced patients $(p<.001)$. This study shows that, on average, patients valued effectiveness and unwanted effects as most important to consider when making the decision for a DMD, but there is heterogeneity in patient preferences.

In Chapter 3, the perspective of healthcare professionals (neurologists and MS nurses) on the information about DMDs needed in the patient decision aid was also assessed as healthcare professionals may not adequately predict the patient's preferences. Therefore, this study also compared the healthcare professionals' perspective with the patients' perspective obtained in Chapter 2. Multivariable linear regression analyses were used to compare the RIS per characteristic according to the different perspectives. According to the 27 neurologists and 33 nurses, safety of the DMD (mean RIS (standard deviation): 9.29 $( \pm 0.92))$ was the most important DMD characteristic in the treatment decision, closely followed by effect on disability progression (RIS: $9.27( \pm 1.58)$ ), quality of life (RIS: 9.19 $( \pm 0.83))$ and relapse rate (RIS: $8.89( \pm 0.88)$ ). Little difference was found between the perspectives of neurologists and MS nurses, but comparing their perspective with the patients' perspective showed that the RIS for safety was significantly lower in the patient group $(b=-2.59, p<.001)$. Accordingly, this study suggests that, overall, neurologists and nurses agree about the importance of DMD characteristics, and that in general the MS patients' perspective is similar, with the exception of the relative importance of safety.

The systematic development of the patient decision aid is further described in Chapter 4. The online patient decision aid was designed and intended to support patients with RRMS or CIS with regard to DMDs labelled for MS in the Netherlands. A steering group consisting of neurologists, MS nurses, patient representatives and experts in the development of patient decision aids was formed and consulted during the development. A web-based format was selected to enable incorporation of the approach of multi-criteria decision analysis (MCDA) in the patient decision aid. MCDA can relieve the cognitive burden of weighting many different potentially conflicting characteristics of many different treatment options. Based on personal and medical information entered in the patient decision aid, a selection of DMDs suitable for the individual patient is made. Additionally, the patient selects which DMD characteristic he/she wants to consider in the decision and weighs the characteristics by rating the importance. The characteristics available for patients to select 
in the patient decision aid are based on the results of the best-worst scaling surveys described in Chapters 2 and 3. Results of an extensive literature review on the effects and burdens of the DMDs, validated within the steering group, were incorporated into the patient decision aid to describe the different DMD options according to the characteristics. The patient decision aid compares the weights of the characteristics to the performance of the available DMDs, resulting in a ranking of DMDs from most to least matching the patient's preferences. Moreover, the patient is able to compare the performance of a DMD on a specific characteristic to the other DMDs.

The patient decision aid was then alpha pilot tested with MS patients and healthcare professionals in three rounds of interviews (Chapter 4). Both patients and healthcare professionals were positive about potential use of the patient decision aid for supporting the decision making process, but also reported points for improvement concerning the content and framing, the weighting methods for the importance of characteristics, and the presentation of the results of the patient decision aid. Adaptations were made accordingly. Further development of the patient decision aid is still needed regarding the verification of the rankings made by the decision aid, including the influence of uncertainty about effect estimates, and improving understandability of the patient decision aid through evaluation of health literacy and adaptation of the delivery of the patient decision aid. Moreover, beta pilot testing to assess the feasibility of implementation in clinical practice should be performed next before implementation of the tool in clinical practice.

Part II of this dissertation aimed to inform the design of web-based health services for MS, such as self-monitoring applications and patient decision aids, and research into these services.

In Chapter 5, the potential cost-effectiveness of shared decision making for RRMS in comparison with usual care from a societal perspective over a lifetime was explored in an early-stage economic evaluation. A previously developed state transition model that evaluates the cost-effectiveness of a range of DMDs for RRMS in comparison with best supportive care was adapted to model three potential effects of shared decision making: 1) a change in initial DMD chosen; 2) an increase in the patient's persistence to the chosen DMD; and 3) an increase in adherence to the chosen DMD. One-way and probabilistic sensitivity analyses of a scenario that combined the three effects were conducted to evaluate the robustness of the results. A threshold analysis was further conducted to estimate at which costs SDM per patient may be, for it to be cost-effective. Each effect separately and all three effects combined resulted in increased quality-adjusted life years (QALYS) and costs for shared decision making in comparison with usual. The increase in utilization of DMDs was the primary cost driver. The combined scenario resulted in 1.12 QALYs gained and $€ 20,009$ increased health state costs. The incremental cost-effectiveness ratio (ICER) was $€ 17,875$ per QALY gained. For a threshold of $€ 50,000$ per QALY, shared decision making was $98.5 \%$ likely to be cost-effective, but the ICER was sensitive to changes in drug prices, risk of disease progression, the discount rate and the perspective taken. For 
shared decision making to be cost-effective, the intervention could maximally cost $€ 23,639$ for a threshold of $€ 50,000$ per QALY. We concluded that shared decision making has the potential to be cost-effective for supporting patients' choices between DMDs. Of the three assumed effect, the cost-effectiveness is most influenced by a reduction in the discontinuation rates. With new initiatives being explored to increase the uptake of shared decision making, this study informs clinicians and policy decision makers about the potential economic value of such investments. Moreover, this study shows that obtaining real-world data on long-term treatment discontinuation after shared decision making is needed.

Chapter 6 focused on optimizing direct-to-patient research via web-based questionnaires. Since MS patients are in general relatively active online, online self-assessment during trials would be feasible, resulting in the efficient collection and processing of data. Missing data or delayed reporting of data by patients may negatively affect the quality of study results. Data from the Dutch MS study were analysed to investigate patients' adherence to a selfassessment schedule with low-frequency long questionnaires versus a high-frequency short questionnaire. The 36-item MS Impact Profile (MSIP) questionnaire and the 54-item MS Quality of Life-54 (MSQoL-54) questionnaire measured, respectively, (perceived) disabilities and health-related quality of life at 6-month intervals. The 2-item Medication and Adherence (MA) questionnaire measured medication and adherence to DMDs at 1-month intervals. The Expanded Disability Status Scale (EDSS) score was administered once via telephone by an experienced nurse. For both the self-assessment schedules, completion adherence (i.e. percentage of patients who completed all the questionnaires in the first 2 years) and interval adherence (i.e. the percentage of patients who completed all the questionnaires within a set time frame) were calculated. We also assessed whether there was a relationship between adherence and the timing of EDSS assessment. Over a 2-year period, no difference was found in the proportion of patients completing all scheduled assessments between the two less frequent long questionnaires (perceived disabilities and HRQoL) and the more frequent short questionnaire, but patients completed the lowfrequency long questionnaires more often (85.5\%) within a predefined time frame than the high-frequency short questionnaire (25.5\%). If a nurse administered the EDSS within 6 months after baseline, completion adherence was higher than if the EDSS was administered later (OR 1.810, 95\% Cl 0.999-3.280), suggesting that long-term completion adherence in direct-to-patient studies may be positively affected if patients are personally contacted by a member of the research team regarding early in the study.

The last chapter of this dissertation (Chapter 7) summarizes the main findings, and discusses the methodological considerations. Moreover, implications for further development and research into the patient decision aid and implications for clinical practice and policy are discussed. Overall, this dissertation described the systematic and rigorous development of a patient decision aid for DMDs for MS. However, further development and research into its effects is warranted, starting with optimization of the content and delivery of the decision aid and a beta pilot test to optimize implementation strategy of the patient 
decision aid. These studies should be followed by a (cost-) effectiveness study to establish the value for clinical practice and provide grounds for wide implementation. 


Samenvatting 
Patiënten met multiple sclerose (MS) kunnen verschillende lichamelijke, cognitieve en mentale symptomen van hun ziekte ervaren. Deze symptomen hebben een aanzienlijke invloed op de kwaliteit van leven van deze patiënten. Door ontwikkeling van ziektemodulerende medicijnen voor MS kan verergering van de ziekte vertraagd worden. Momenteel zijn er in Nederland 12 verschillende ziektemodulerende medicijnen beschikbaar voor de relapsing-remitting vorm van MS (RRMS); vier van deze medicijnen zijn ook beschikbaar voor klinisch geïsoleerd syndroom (clinically isolated syndroom, CIS). Naar verwachting zullen er in de komende jaren meer nieuwe medicijnen beschikbaar komen. Dit groeiend aantal ziektemodulerende medicijnen maakt de keuze voor een medicijn ter behandeling van MS gecompliceerd. Dit komt met name door de verscheidenheid in eigenschappen van deze medicijnen, dat wil zeggen de positieve en negatieve consequenties van de behandeling. Bovendien is de keuze voor een ziektemodulerend medicijn ook afhankelijk van de voorkeuren van de individuele patiënt. Dit betekent dat er niet één duidelijk "beste" keuze bestaat. Met name voor MS, waarbij er zoveel verscheidenheid is in zowel de symptomen die patiënten ervaren als in de medicijnen die beschikbaar zijn, is het van belang om de voorkeuren van de patiënt mee te nemen in het maken van een keuze. Dit vraagt om actieve participatie door de patiënt in het keuzeproces: Samen Beslissen met de zorgverlener.

Samen Beslissen is een gezamenlijk proces tussen de zorgverlener en de patiënt: de patiënt wordt door de zorgverlener geïnformeerd over de ziekte, de prognose en de behandelmogelijkheden, zodat de patiënt voorkeuren kan ontwikkelen voor de verschillende behandelmogelijkheden, en deze voorkeuren meegenomen kunnen worden in de keuze. Keuzehulpen hebben als doel om dit proces te ondersteunen. Om de kwaliteit van het ontwikkelingsproces van keuzehulpen te waarborgen beveelt de International Patient Decision Aid Standards aan, om de volgende stappen te doorlopen in de ontwikkeling: 1) vaststellen van het doel en de doelgroep voor de keuzehulp; 2 ) vormen van een stuurgroep bestaande uit klinische experts en patiënten; 3) in kaart brengen van de informatie die patiënten nodig hebben om een keuze te kunnen maken, ook volgens zorgverleners; 4) in kaart brengen van de behandelmogelijkheden op basis van wetenschappelijk en klinisch bewijs; 5) ontwikkelen van een prototype; 6) testen van de begrijpelijkheid en bruikbaarheid van het prototype (alfa-pilot test), en 7) testen van de haalbaarheid van het implementeren van de keuzehulp in de klinische praktijk (bèta-pilot test).

Deel I van dit proefschrift beschrijft de ontwikkeling en pilot test van een keuzehulp die dient om patiënten met RRMS of CIS en hun zorgverleners te ondersteunen in het Samen Beslissen over de behandeling met ziektemodulerende medicijnen. Hierbij zijn de aanbevolen stappen van de International Patient Decision Aid Standards gevolgd.

Hoofdstuk 2 brengt in kaart welke informatie over ziektemodulerende medicijnen patiënten nodig hebben om een keuze voor een behandeling te kunnen maken. Dit om te bepalen 
welke informatie opgenomen moet worden in de keuzehulp. Verschillende stappen zijn doorlopen. Door middel van drie focusgroepen met RRMS-patiënten $(N=19)$ is geïdentificeerd welke eigenschappen van ziektemodulerende medicijnen de keuze van patiënten beïnvloeden. Een nominale groepstechniek is toegepast in deze focusgroepen om een volledige lijst van eigenschappen samen te stellen. Vervolgens is een best-worst scaling vragenlijst ontwikkeld om de geïdentificeerde eigenschappen te prioriteren aan de hand van hun belangrijkheid bij de keuze. Deze vragenlijst bestond uit 17 keuzevragen. In elke vraag is aan de patiënt gevraagd om uit een rijtje van vijf eigenschappen te kiezen welke $\mathrm{hij} / \mathrm{zij}$ het belangrijkst en minst belangrijkst vindt om mee te nemen in de keuze voor een ziektemodulerend medicijn. Op basis van de antwoorden is een relatieve belangrijkheidsscores per eigenschap berekend.

Op basis van de resultaten uit de focusgroepen werden 27 eigenschappen geïdentificeerd en opgenomen in de best-worst scaling vragenlijst. Relatieve belangrijkheidsscores waren het hoogst voor effect van het medicijn op ziekteachteruitgang (gemiddelde score: 9.64, 95\% betrouwbaarheidsinterval [9.48-9.81]), de kwaliteit van leven (score: 9.21 [9.00-9.42]), het aantal relapses (score: 7.76 [7.39-8.13]), ernst van de bijwerkingen (score: 7.63 [7.337.94]) en ernst van de relapses (score: 7.39 [7.06-7.73]. Er zijn verschillen gevonden in de belangrijkheidsscores voor eigenschappen op basis van verschillende subgroepen van patiënten met bepaalde karakteristieken, zoals hun ervaring met ziektemodulerende medicijnen. Exploratieve subgroepanalyses lieten zien dat de belangrijkheidsscores voor eigenschappen gerelateerd aan bijwerkingen statistisch hoger waren voor patiënten die geen ervaring hadden met het gebruik van ziektemodulerende medicijnen dan voor patiënten die wel eerder al een medicijn gebruikt hadden $(p<.001)$. Deze studie laat zien, dat patiënten effectiviteit en bijwerkingen, gemiddeld, het belangrijkst vinden om in hun overweging mee te nemen bij het maken van een keuze voor een ziektemodulerend medicijn, maar ook dat er sprake is van heterogeniteit in de patiëntvoorkeuren.

In Hoofdstuk $\mathbf{3}$ van dit proefschrift is beschreven welke informatie over ziektemodulerende medicijnen in de keuzehulp opgenomen moet worden volgens zorgverleners, dus volgens neurologen en MS-verpleegkundigen. Zorgverleners kunnen namelijk mogelijk niet juist inschatten wat de voorkeuren van de individuele patiënt zijn. Daarom vergelijkt de studie beschreven in Hoofdstuk 3 het perspectief van zorgverleners met het perspectief van patiënten, zoals verkregen in Hoofdstuk 2. Multivariabele lineaire regressieanalyses zijn uitgevoerd om de relatieve belangrijkheidsscores per eigenschap te vergelijken volgens de verschillende perspectieven. Volgens 27 neurologen en 33 MS-verpleegkundigen was veiligheid van het ziektemodulerend medicijn (gemiddelde belangrijksheidsscore (standaarddeviatie): $9.29( \pm 0.92)$ ) de belangrijkste eigenschap in de keuze voor de behandeling, op de voet gevolgd door het effect op ziekteachteruitgang (score: 9.27 $( \pm 1.58)$ ), kwaliteit van leven (score: $9.19( \pm 0.83)$ ) en het aantal relapses (score: $8.89( \pm 0.88)$ ). Weinig verschillen zijn gevonden tussen de perspectieven van neurologen en MSverpleegkundigen, maar een vergelijking van hun gezamenlijke perspectief met het perspectief van patiënten liet zien dat de belangrijkheidsscore voor veiligheid significant 
lagers was volgens de groep patiënten $(b=-2.59, p<.001)$. Deze studie suggereert daarom dat de perspectieven van neurologen en MS-verpleegkundigen onderling over het belang van de eigenschappen van ziektemodulerende medicijnen in het algemeen overeenstemmen, net als met het perspectief van patiënten, met uitzondering van het belang van veiligheid.

De systematische ontwikkeling van de keuzehulp is verder beschreven in Hoofdstuk 4. De online keuzehulp is ontwikkeld om patiënten met RRMS en CIS te ondersteunen in het maken van de behandelkeuze voor één van de ziektemodulerende medicijnen, beschikbaar in Nederland. Een stuurgroep bestaande uit neurologen, MS-verpleegkundigen, patiëntvertegenwoordigers en experts in de ontwikkeling van keuzehulpen is gevormd. Deze stuurgroep gaf op verschillende momenten gedurende de ontwikkeling van de keuzehulp advies. Een online format voor de keuzehulp was noodzakelijk om de benadering van multi-criteria decision analysis (MCDA) in de keuzehulp in te bouwen. MCDA kan de cognitieve belasting verminderen: het afwegen van een groot aantal verschillende behandelmogelijkheden met ieder zijn eigen eigenschappen, die ook nog kunnen conflicteren kan een moeilijke taak zijn. In de MCDA-keuzehulp voert de patiënt persoonlijke en medische informatie, zoals geslacht en type MS. Deze informatie kan namelijk van invloed zijn op de medicijnen waarvoor de patiënt in aanmerking komt. Op basis van deze informatie worden de medicijnen, waarvoor de patiënt niet in aanmerking komt, uitgefilterd. Ook selecteert de patiënt welke eigenschappen van ziektemodulerende medicijnen hij/zij van belang vindt in de keuze voor een medicijn en geeft iedere eigenschap een weging door een belangrijksheidsscore toe te kennen. De patiënt kan hierbij kiezen uit eigenschappen die op basis van de onderzoeken uit Hoofdstukken $\mathbf{2}$ en $\mathbf{3}$ geselecteerd zijn. Een uitgebreide literatuurstudie naar de effecten en nadelige gevolgen van het gebruik van ziektemodulerende medicijnen is uitgevoerd. De resultaten van deze studie zijn gevalideerd door de stuurgroep. Daarna zijn deze resultaten in de keuzehulp opgenomen om de verschillende ziektemodulerende medicijnen te beschrijven aan de hand van hun eigenschappen. De keuzehulp vergelijkt het belang van de eigenschap (zoals gescoord door de patiënt) met de mate waarin elk medicijn presteert op iedere eigenschap. Op basis van deze vergelijking geeft de keuzehulp een ranking weer van de medicijnen die het best tot het minst overeenkomen met wat de patiënt belangrijk vindt. Bovendien kan de patiënt de prestatie van elk medicijn op een specifieke eigenschap vergelijken met de andere medicijnen beschikbaar voor deze patiënt.

Nadat de ontwikkeling van een initieel prototype van de keuzehulp was afgerond, is een alfa pilot test uitgevoerd onder MS-patiënten en zorgverleners in drie rondes van interviews (Hoofdstuk 4). Zowel patiënten als zorgverleners hadden een positieve houding over het potentieel van de keuzehulp om het proces van Samen Beslissen te ondersteunen, maar zij rapporteerden ook verschillende verbeterpunten. Deze verbeterpunten betroffen de inhoud en verwoording, de methoden die gehanteerd werden om de belangrijkheid van eigenschappen te scoren en de presentatie van de eindresultaten van de keuzehulp. Op basis van de opmerkingen is de keuzehulp aangepast. Verdere ontwikkeling van de 
keuzehulp is vereist om de rankings van de keuzehulp te verifiëren, inclusief de onzekerheid over de puntschattingen, en de begrijpelijkheid van de keuzehulp te verbeteren door evaluatie van de benodigde gezondheidsvaardigheden en adaptatie van de manier waarop de keuzehulp aangeboden wordt aan de patiënt. Vervolgens dient de haalbaarheid van de implementatie in de klinische praktijk onderzocht te worden in een bèta-pilot test.

Deel II van dit proefschrift had als doel om de ontwikkeling van en onderzoek naar gezondheidsdiensten voor MS, - die online worden aangeboden - zoals zelfmanagementapplicaties en keuzehulpen, te informeren.

Hoofdstuk 5 beschrijft een vroege economische evaluatie om de potentiële kosteneffectiviteit van Samen Beslissen voor behandeling van RRMS in vergelijking met reguliere zorg te bepalen. Deze modelmatige economische evaluatie is uitgevoerd over een levenslange tijdshorizon vanuit een maatschappelijk perspectief. Een eerder ontwikkeld model dat de kosteneffectiviteit van verschillende ziektemodulerende medicijnen voor RRMS vergeleek met geen behandeling (ofwel ondersteunende zorg zonder medicatie) is aangepast om drie potentiële effecten van Samen Beslissen te modelleren: 1) een verandering in de keuze voor het initiële ziektemodulerende medicijn; 2) verbeterde volharding door patiënten met het gekozen medicijn; en 3) een verbetering in therapietrouw aan het gekozen medicijn. Resultaten van een scenario dat de drie effecten combineert zijn verder geëvalueerd in sensitiviteitsanalyses. Een referentiewaarde-analyse (threshold analysis) is uitgevoerd om te schatten wat de maximale kosten van Samen Beslissen per patiënt mogen zijn, wil de interventie Samen Beslissen nog kosteneffectief zijn. Elk effect apart en gecombineerd resulteerde in een toename in het aantal voor kwaliteit van leven gecorrigeerde levensjaren (quality-adjusted life years, QALYs) en een toename in de kosten wanneer Samen Beslissen zou worden toegepast in plaats van reguliere zorg. De toename in kosten werd primair veroorzaakt door een toename in het gebruik van ziektemodulerende medicijnen. Het gecombineerde scenario resulteerde in een toename van 1,12 QALYs en $€ 20.009$ meer kosten gerelateerd aan de gezondheidstoestand van de patiënt. De incrementele kosteneffectiviteitsratio (IKER) was 17.875 per extra QALY. Bij een referentiewaarde waarbij de maatschappij maximaal $€ 50.000$ extra zou willen betalen voor een extra QALY is er een kans van $98.5 \%$ dat Samen Beslissen kosteneffectief is, ofwel dat de IKER lager of gelijk aan de referentiewaarde is. De IKER bleek echter gevoelig voor veranderingen in medicijnkosten, risico op ziekteprogressie, de disconteringsvoet en het perspectief. Samen Beslissen mag maximaal €23.639 kosten bij een referentiewaarde van $€ 50.000$ per extra QALY. Geconcludeerd is dat Samen beslissen de potentie heeft om kosteneffectief te zijn als interventie om keuzes te maken in ziektemodulerende medicijnen. Als apart gekeken wordt naar de drie mogelijke effecten van Samen Beslissen, dan wordt de kosteneffectiviteit meest beïnvloed door een toename in de volharding van patiënten met het gekozen medicijn. Nu nieuwe initiatieven worden onderzocht om een toename in het toepassen van Samen Beslissen te bewerkstelligen, informeert deze studie clinici en beleidsmaker over de potentiële economische waarde van 
investeringen in Samen Beslissen. Daarnaast laat deze studie zien dat data over het effect van Samen Beslissen op voortijdig stoppen met medicatie, verzameld buiten gecontroleerde studies om, nodig is.

Hoofdstuk 6 focust op het optimaliseren van direct-to-patient onderzoek dat plaatsvindt via online vragenlijsten. Patiënten kunnen zichzelf opgeven voor dit type onderzoek, zonder tussenkomst van een zorgverlener. Omdat MS-patiënten over het algemeen relatief actief zijn op internet, kan online afname van vragenlijsten een optie zijn in onderzoek. Dit resulteert in efficiënte verzameling en verwerking van data. Missende data of het te laat invullen van vragenlijsten door patiënten kan de kwaliteit van de studieresultaten beïnvloeden. Data van de Nederlandse MS studie zijn geanalyseerd om na te gaan in hoeverre patiënten zelfevaluatievragenlijsten van verschillende frequenties en tijdsduur invullen volgens het vooraf bepaalde invulschema. In het onderzoek werden twee typen invulschema's gehanteerd die verschilden ten aanzien van lengte van de vragenlijst en de frequentie waarmee de vragenlijst ingevuld dient te worden. De vragenlijst MS Impact Profile (MSIP) met 36 items brengt functioneringsproblemen in kaart. De MS Quality of Life54 (MSQoL-54) met 54 items meet gezondheidsgerelateerde kwaliteit van leven. Beide vragenlijsten typeerden het eerste invulschema en werden in het onderzoek elke zes maanden ingevuld. De Medication and Adherence vragenlijst brengt in kaart welke medicijnen een patiënt gebruikt en in welke mate de patiënt therapietrouw is in het gebruik van het medicijn. Deze vragenlijst typeerde het tweede invulschema en werd elke maand ingevuld door patiënten. Daarnaast is de Expanded Disability Status Scale (EDSS) eenmalig telefonisch afgenomen door een ervaren verpleegkundige. Voor beide invulschema's is nagegaan in hoeverre patiënten het invulschema naleefden. Dat wil zeggen dat het percentage patiënten dat alle vragenlijsten in de eerste twee jaar van het onderzoek ingevuld heeft in kaart is gebracht en het percentage patiënten dat alle vragenlijsten ingevuld heeft binnen een vooraf vastgestelde tijdslimiet. Ook is nagegaan of er een relatie is tussen het naleven van het invulschema en het moment van afnemen van de EDSS. Er is geen verschil gevonden tussen de twee typen invulschema's in het percentage patiënten dat alle vragenlijsten had ingevuld over een periode van twee jaar. Patiënten vulden de laagfrequente lange vragenlijst (functioneringsproblemen en gezondheidsgerelateerde kwaliteit van leven) wel vaker $(85,5 \%)$ binnen de vooraf vastgestelde tijdslimiet in dan de hoogfrequente korte vragenlijst $(25,5 \%)$. Daarnaast lieten de studieresultaten zien dat patiënten vaker alle vragenlijsten invulden indien zij binnen 6 maanden na starten met het onderzoek contact hadden gehad met een verpleegkundige ten behoeve van de afname van de EDSS (OR 1,810, 95\% Cl 0,999-3,280). Dit suggereert dat persoonlijk contact met een onderzoeker aan het begin van direct-to-patient studies mogelijk de naleving van de invulschema's positief beïnvloedt.

Het laatste hoofdstuk van dit proefschrift (Hoofdstuk 7) vat de belangrijkste bevindingen samen en bediscussieert methodologische overwegingen en beperkingen. Daarnaast zijn de implicaties voor verdere ontwikkeling en onderzoek over keuzehulpen en implicaties voor 
de klinische praktijk en beleid weergegeven. Samenvattend beschrijft dit proefschrift de systematische ontwikkeling van een keuzehulp voor ziektemodulerende medicijnen voor MS. Verdere ontwikkeling en onderzoek in de effecten van de keuzehulpen is echter nodig. Hierbij dient begonnen te worden bij het optimaliseren van de inhoud van de keuzehulp, gevolgd door bèta-pilot testen, om de inhoud en implementatiestrategie verder te kunnen optimaliseren. Vervolgens dient een (kosten-)effectiviteitsstudie uitgevoerd te worden om de waarde van de keuzehulp voor de klinische praktijk vast te stellen, dat uiteindelijk kan motiveren tot brede implementatie van de keuzehulp. 

Valorisation 
This chapter discusses the societal value of the results found in this thesis for three groups of stakeholders: patients and healthcare professionals, policy makers, and the scientific community. Moreover, the efforts made to disseminate the knowledge gained from this thesis and the additional actions to be taken are described.

\section{Societal value of this dissertation}

\section{Patients and healthcare professionals}

The number of treatment options for reducing the number of relapses and/or delay disease progression for patients with multiple sclerosis (MS) has been increasing rapidly. Patients with the relapsing-remitting type of MS (RRMS) or clinically isolated syndrome (CIS) often have often two or more options of treatment with disease-modifying drugs (DMDs). Therefore, an adequate treatment decision needs to be made; no single treatment option is the dominant choice, as the most suitable option can differ according to the patient's situation and preferences. Consequently, international recommendations for MS treatment have highlighted the importance of involving patient preferences in the treatment decision $[1,2]$. Accordingly, the different characteristics of treatment options need to be considered and weighed. This can be a difficult process for patients and healthcare professionals. The patient needs to capture all of the information, develop preferences and communicate these preferences with the healthcare professional. The healthcare professional needs to educate the patient about the treatment options, balance the information provided and elicit the patient's preferences.

This dissertation aims to develop a patient decision aid to facilitate shared decision making for DMDs for MS. Patient decision aids help patients to feel informed, to have more confidence in the decision, and, importantly, to achieve more congruence between the treatment chosen and the patient's preferences [3]. The online patient decision aid proposed in this dissertation is based on the principles of multi-criteria decision analysis (MCDA). This patient decision aid enables the filtering of treatment options based on the patient's personal and medical characteristics, elicitation of the patient's preferences for specific characteristics of treatments, and ranking of the treatments for which the patient is eligible from most to least fitting with the patient's individual preferences. The ranking can be used to focus the deliberation process of studying and discussing the treatment options, i.e., based on the ranking, the patient can identify a small number of treatment options to read more about. Accordingly, in contrast with other approaches for patient decision aids, such as schematic summaries of treatment options according to frequently asked questions, in which the patient needs to grasp the characteristics of all available treatment options, an MCDA-based approach for patient decision aids may relieve the cognitive burden of considering the treatments in situations with many options and many varying characteristics. The proposed patient decision aid is one of the first MCDA-based patient decision aids for MS, and the first patient decision aid for MS in the Netherlands. 
During the development of our tool, alpha pilot testing of the developed patient decision aid enabled the identification and resolution of problems regarding patients' comprehension and the usability of the decision aid for patients and healthcare professionals. Further development and evaluation of our patient decision aid for optimizing the content and implementation strategy and assessing whether the patient decision aid results in the effects on the quality of the decision and of the decision making process as reported for patient decision aids for other decisions [3]. Both patients and healthcare professionals expressed a positive attitude towards the potential use of of our patient decision aid for supporting shared decision making about DMDs.

The implementation of shared decision making supported with the patient decision aid in clinical practice could improve the quality of care for patients, and could also result in improved persistence and adherence levels in taking prescribed medication, and consequently in improved health outcomes and quality of life, as our early economic evaluation of the cost effectiveness of shared decision making for MS suggested.

\section{Policy makers}

Healthcare policy makers and healthcare insurance companies decide on the allocation of funds for the implementation and reimbursement of new interventions based on a number of factors, including cost effectiveness [4]. Like all assessments of consequences in terms of the costs of an intervention and benefits gained, policy makers need to make decisions in the face of uncertainties [4]. This dissertation informs policy makers about the potential cost-effectiveness of implementing a shared decision aid in clinical practice in order to determine whether shared decision making should be implemented and reimbursed. The early economic evaluation demonstrated a favourable incremental cost-effectiveness ratio in different scenarios, which supports arguments for implementation and reimbursement. This study suggests that if shared decision making improves persistence and adherence to treatment with DMD, shared decision making could potentially be cost-effective in achieving improved health outcomes.

\section{Scientific community}

Both parts of this dissertation, i.e. the chapters focusing on the development of the patient decision aid and the chapters exploring how web-based health services and research for MS can be optimized, are of added value for researchers in the field of patient decision aid development, and in the assessment of shared decision making and MS. First, methodologies which have been increasingly applied in health technology assessment, i.e. best-worst scaling surveys and MCDA, have been applied successfully in the development of patient decision aids. Researchers could therefore consider using stated preference research to prioritize which information should be included in a patient decision aid. Moreover, MCDA can be considered as an approach for the development of a decision aid 
in situations with many different options and/or many characteristics which must be considered or for patients with impaired cognitive abilities.

In part two of this dissertation, the adherence of patients to assessment schedules in webbased research was examined. Long assessments at low frequency are more often completed within a set time frame in comparison with highly frequent short assessments. In addition, personal contact with a researcher shortly after commencing participation in the study could positively affect patient adherence to assessment schedules. Researchers considering web-based measurement schedules could consider these findings in the design of protocols for direct-to-patient research.

\section{Dissemination of knowledge}

Several efforts have been undertaken to disseminate the findings from this dissertation to the various stakeholders [Table 1]. Dissemination among researchers and policy makers has been stimulated through publication of the study results in scientific journals and by publication of this dissertation. Three articles have already been published in open access peer-reviewed journals, and the two remaining articles have been submitted to open access journals. In addition, the results of the studies described in this dissertation have been presented at several international conferences, such as the conferences of the Society for Medical Decision Making, the International Shared Decision Making Society, the European Committee for Treatment and Research in Multiple Sclerosis, and ISPOR- the Professional Society for Health Economics and Outcomes Research.

Moreover, patients and healthcare professionals have been involved in a number of phases of the developmental process. An advisory committee was formed consisting of patient representatives from two patient organizations (Nationaal MS Fonds, MS Vereniging Nederland) as well as neurologists and nurses from several hospitals in the Netherlands. This collaboration brought about continuous contact with patient organizations regarding the progress of the development of the patient decision aid, and led to interest in the patient decision aid from patient and professional magazines. Two articles about the patient decision aid for MS were published in these magazines (i.e. Nieuwslijn, 2017 and Medidact Neurologie, 2019), creating awareness among patients and healthcare professionals about the future availability of the patient decision aid, and stimulating both patients and healthcare professionals to participate in the decision aid's development.

The attention paid to the patient decision aid by these magazines also highlights for policy makers the need for its implementation in clinical practice. The implementation of patient decision aids in hospitals is not straightforward, due to the initial investments needed by hospitals to acquire licenses, train staff and adjust structures to facilitate the use of patient decision aids [5]. Moreover, shared decision making could result in longer consultation time and in more expensive or cheaper treatments being chosen [6]. The successfulness of securing sustainable implementation of patient decision aids in clinical practice is reported to be, in part, dependent on available financing [5], i.e. who is paying for it. We are currently 
examining the feasibility of different financial structures and incentives to achieve organizational and financial sustainability for the implementation in clinical practice and to optimize the uptake of implementation across hospitals in the Netherlands, in collaboration with a partner experienced in the implementation of patient decision aids. We have been working on acquiring research and implementation grants from consortiums formed by the pharmaceutical industry and government grants to overcome the initial financial barriers for hospitals, such as training staff and acquiring licenses. Other structures, such as healthcare insurers' reimbursement of shared decision making, could also be considered, aiming at achieving sustainable implementation of shared decision making supported with patient decision aids on a large scale for all treatment and screening decisions. For example, the National Healthcare Authority's policy "Experiments" allows conditional reimbursement by a healthcare insurer if both healthcare insurer and healthcare provider want an innovation to be embedded for limited time [7]. After the experiment is terminated, a decision could be made about structural reimbursement for the innovation [7].

Before the initiation of such structures, further information about the consequences for patients and healthcare budgets is needed. This information enables determining the costeffectiveness of shared decision making supported with a patient decision aid for MS and its budgetary impact for budget holders, i.e. policy makers from healthcare providers and/or healthcare insurers. Moreover, a business case should be developed, which summarizes the costs and benefits in monetary and non-monetary terms for each stakeholder, including the effects on the quality of healthcare and the benefits for patients. A business case and budget impact analysis could provide grounds that support implementation of the new intervention, and convince budget holders that these investments are worthwhile in improving quality of care.

Additional research concerning the patient decision aid is planned. Before implementation in hospitals, we will optimize and update the patient decision aid in terms of content, userfriendliness and health literacy, and test the feasibility of implementing the patient decision aid in a before-and-after pilot study. Moreover, a controlled trial is planned to research the effects of the patient decision aid on the quality of the decision, the decision making process, on adherence, persistence and treatment choice, health outcomes, quality of life and costs.

Other research areas of value are optimization of risk communication for patients with MS, setting up an international network of patient decision aid developers for MS to possibly develop an international tool, and to embed the patient decision aid in a multicomponent intervention to support patients in the management of their MS. Pending the update of the Dutch clinical guidelines for MS, we will also strive to connect the patient decision aid to these guidelines to keep the content of the patient decision aid up-to-date. 
Table 1. Completed and intended activities for dissemination of knowledge

Patients and healthcare professionals

$\checkmark \quad$ Involvement during the developmental process, involvement in advisory group

$\checkmark$ Continuous contact with patient organizations

$\checkmark \quad$ Article in patient and professional magazines (Nieuwslijn, 2017; Medidact Neurologie, 2019)

- Optimize and update content, user-friendliness (e.g. risk communication) and health literacy of patient decision aid

- Increase commitment of intended users to implementation

- Connect patient decision aid with guidelines for clinical practice

- Embed patient decision aid in a multicomponent intervention for MS management

Policy makers

$\checkmark$ Publications of papers in scientific journals and of dissertation

$\checkmark$ Presentation of studies during (inter)national conferences

- Mapping structures to ensure financial sustainability of implementation

- Conduct a controlled trial to determine the (cost-)effectiveness, perform budget impact analysis and develop a business case

Scientific community

$\checkmark$ Publications of papers in scientific journals and of dissertation

$\checkmark$ Presentation of studies during (inter)national conferences

- Investigate opportunities for international collaboration for MS patient decision aids 


\section{References}

1. Montalban X, Gold R, Thompson AJ, Otero-Romero S, Amato MP, Chandraratna D, et al. ECTRIMS/EAN Guideline on the pharmacological treatment of people with multiple sclerosis. Mult Scler. 2018;24(2):96-120. doi: 10.1177/1352458517751049.

2. Rae-Grant A, Day GS, Marrie RA, Rabinstein A, Cree BAC, Gronseth GS, et al. Practice guideline recommendations summary: Disease-modifying therapies for adults with multiple sclerosis: Report of the Guideline Development, Dissemination, and Implementation Subcommittee of the American Academy of Neurology. Neurology. 2018;90(17):777-88. doi: 10.1212/wnl.0000000000005347.

3. Stacey D, Legare F, Lewis K, Barry MJ, Bennett CL, Eden KB, et al. Decision aids for people facing health treatment or screening decisions. Cochrane Database Syst Rev. 2017;4:Cd001431. doi: 10.1002/14651858.CD001431.pub5.

4. Drummond MF, Sculpher MJ, Claxton K, Stoddart GL, Torrance GW. Methods for the economic evaluation of health care programmes. Fourth ed. New York: Oxford University Press 2015.

5. Savelberg W, de Bruijn D. Samen Beslissen: ziekenhuis en zorgverzekeraar in gesprek (report). Maastricht UMC+, 2019.

6. Trenaman L, Bryan S, Bansback N. The cost-effectiveness of patient decision aids: A systematic review. Healthcare (Amsterdam, Netherlands). 2014;2(4):251-7. doi: 10.1016/j.hjdsi.2014.09.002.

7. Dutch Healthcare Authority (NZa). Beleidsregel Innovatie voor kleinschalige experimenten - BR/REG-19158. Versie 12019. [cited 201916 December]. Available from: http://puc.overheid.nl/doc/PUC_289778_22 

Dankwoord 
Dan zijn bijna alle hoofdstukken geschreven en rest nu nog dit laatste hoofdstuk. Een hoofdstuk dat ik niet makkelijk vind om te schrijven, want ik ben niet iemand die haar hart op de tong heeft. Maar wat een mooie kans om - na deze jaren - de mensen te bedanken die me op welke manier dan ook geholpen, geïnspireerd, geadviseerd en meegedacht hebben bij het schrijven van dit proefschrift. Dankjewel. Ik waardeer dit zeer. Ik wil een aantal mensen in het bijzonder bedanken.

Ten eerste wil ik iedereen bedanken die instemden om mee te doen aan de focusgroepen, interviews en vragenlijstonderzoeken en via deze weg hun kennis en inzichten hebben gedeeld. Jullie hulp was onmisbaar voor dit proefschrift.

Ik wil mijn promotieteam Silvia, Mickaël en Sjef bedanken voor jullie begeleiding. Al in het eerste jaar van de research master schreef ik onder jullie begeleiding een subsidievoorstel, dat ik in het tweede jaar verder uitwerkte naast het onderzoek voor mijn afstudeerthesis. Uiteindelijk heeft dit subsidievoorstel eraan bijgedragen dat ik bij jullie kon beginnen aan mijn promotieonderzoek. Zo heb ik dus een aantal jaren onder jullie begeleiding en met jullie steun mogen werken en zullen we onze samenwerking in de toekomst ook voortzetten. Bedankt voor jullie betrokkenheid, de constructieve feedback, het delen van jullie kennis en het vertrouwen dat jullie in mij hadden.

Silvia, ik waardeer hoe jij bij problemen meteen in oplossingen denkt. Het kwam meer dan eens voor dat ik twijfelde hoe ik verder moest en dat je me weer op weg hielp, onder andere door me te verbinden met anderen. Daarnaast heb je mij meer dan eens gestimuleerd om ook aan de grote lijnen van het onderzoek te denken wanneer ik mezelf verloor in details, om bewust te worden van mijn eigen kwaliteiten en die ook uit te stralen.

Mickaël, onze gezamenlijke wekelijkse overleggen en jouw kritische blik op mijn werk hebben mij veel geholpen bij het uitvoeren van dit promotieonderzoek. Ik waardeer je nuchtere kijk en de rust die je altijd uitstraalt, ook als ik zelf beren op de weg zie. Ook was jij het die vroeg of ik een paar maanden in Canada wilde gaan werken, waar ik uiteindelijk unieke (werk-) ervaringen heb opgedaan. Dankjewel!

Sjef, je passie voor onderzoek en specifiek voor MS, is aanstekelijk. Ik kon altijd rekenen op jouw kritische feedback. Jij hielp me om mijn project in een bredere context te plaatsen en stimuleerde me om ook vooruit te denken. Dank voor je betrokkenheid en de vele telefoontjes tussen de overleggen door. Ik kijk ernaar uit om onze samenwerking ook na mijn promotie voor te zetten.

Graag zou ik de leden van de beoordelingscommissie, bestaande uit prof. dr. Manuela Joore, dr. Elske van den Akker-van Marle, prof. dr. Rik Crutzen, prof. dr. Joep Killestein en dr. Ghislaine van Mastrigt, hartelijk willen bedanken voor het lezen en beoordelen van mijn proefschrift.

During my PhD, I had the opportunity to work with people in the Netherlands and abroad. I would like to thank all coauthors of the articles in this dissertation for their collaboration and their contribution to the articles: Nick Bansback, Josh Carlson, Erwin Hoogervorst, Elena Hristodorova, Ilona van de Kolk, Anton Kool, Esther van Noort, Svenja Petersohn, Xavier Pouwels, Wim Verhagen, Trudy van der Weijden and Marita Zimmerman. 
Hartelijk dank aan de leden van de adviesgroep, Martijn Beenakker, Karin Hameetman, Erwin Hoogervorst, Tiny Janssen, Manita Karman, José Savelkoul, Laura van der Velde en Wim Verhagen, die gedurende de ontwikkeling van de keuzehulp verschillende keren bereid waren om tijd vrij te maken en hun deskundigheid met mij te delen. Daarnaast ook hartelijk dank aan Trudy van der Weijden voor je advies ten aanzien van de ontwikkeling van de keuzehulp. Thank you to Jack Dowie and Mette Kaltoft for you critical remarks and guidance during the development of the research protocol and the conduct of the protocol for the development of the MCDA-based patient decision aid.

I also had the opportunity to travel to Canada and work with experts in the field of patient decision aids and MS and economic evaluations, which was made possible by the Student Research Award 2018 from the Association for Canada Studies in the Netherlands. Thank you to Nick Bansback, Larry Lynd and Mark Harrison for hosting me at the University of British Columbia in Vancouver, and to everyone at the departments of the Collaboration for Outcomes Research and Evaluation and Centre for Health Evaluation \& Outcomes Sciences for your kindness and hospitality. Nick, thank you for collaboration and academic guidance on the economic evaluation during and after my stay in Vancouver, and for the lovely dinner with your family and colleagues during the last days of my visit to UBC. Larry and Mark, thank you for welcoming me at your department and giving me the opportunity to learn from you are your teams.

Dank aan alle partijen, waaronder PATIËNT+ en Adriana Berlanga van het Knowledge Transfer Office, voor jullie samenwerking en het meedenken met hoe de keuzehulp in de klinische praktijk uitgerold zou kunnen worden.

Op mijn eerste dag als junior onderzoeker kwam ik terecht op kamer 0.015 en over de jaren, ook gedurende mijn promotieonderzoek, heb ik met een heel aantal mensen deze kamer mogen delen. Wat zijn jullie allemaal belangrijk geweest om de leuke en minder leuke kanten van promoveren mee te delen.

Daan, Sofie, Linda en Willemine, als eerste kwam ik bij jullie op de kamer en kon ik bij jullie afkijken hoe zo'n promotieonderzoek nu eigenlijk in zijn werk gaat. Een dikke dankjewel dat jullie mij een beetje wegwijs hebben gemaakt, maar ook voor alle kameruitjes naar de Lidl en gezellige lunches. Daan, van jou heb ik ook geleerd dat ik chocoladeletters nooit te lang moet laten liggen. Linda, de donderdag was de gezelligste dag van de week! Dit kwam de productiviteit niet altijd ten goede, maar de leuke gesprekken over van alles en nog wat waren de inhaaluren zeker waard :-). Sofie, wat vond ik het fijn dat we een aantal jaren een kamer hebben gedeeld: het sparren over onze onderzoeken, klagen over de problemen die we tegen kwamen in de projecten, en bijkletsen na het weekend. Ik ben zo blij voor je dat je - al weer twee jaar geleden - een baan hebt gevonden waar je helemaal je draai in hebt gevonden en ik vind het onwijs knap hoe je hebt doorgezet om je promotie af te ronden naast je baan én je mooie gezin. Maar eigenlijk had ik niet anders verwacht :).

Jullie konden niet eeuwig PhD studenten blijven, dus één voor één promoveerden jullie, verlieten jullie kamer 0.015 en kwamen er nieuwe PhD'ers in de plaats.

Inge, met jouw komst naar 0.015 kwam er ook een heleboel gezelligheid mee, ook in de styling van de kamer. Je bent altijd bereid om te helpen, adviezen te geven, te sparren over stellingen, en je hebt een talent voor organiseren en coördineren: knap hoe jij alle ballen in 
de lucht houdt. Zo fijn dat we voorlopig nog een kamer zullen blijven delen en op mekaars steun kunnen blijven rekenen.

Viviënne, we hebben niet zo heel lang een kamer gedeeld, maar lang genoeg om er een vriendschap aan over te houden. Jouw promotieonderzoek is zeker niet zonder zijn uitdagingen. Knap hoe jij je door die uitdagingen heen vecht. Je positiviteit en sportiviteit zijn aanstekelijk, zo erg dat je me hebt laten beloven om in april een tour van $65 \mathrm{~km}$ te gaan fietsen! Super fijn dat je mijn paranimf zult zijn bij de verdediging van mijn proefschrift.

Ruth, jouw enthousiasme straalt overal in door. Jij ziet altijd de zon al schijnen, voordat het onweer is opgetrokken en ik denk dat dit jouw kracht is in het afronden van je PhD. Jammer dat je onze kamer gaat verlaten. Ook al ga je he-le-maal naar de andere kant van het gebouw, ik kijk uit naar onze geplande lunches om bij te kletsen.

Robin, nog niet zo heel lang op 0.015 en helaas ga je al weer naar een ander kamer. Gelukkig om een hele leuke reden: je gaat ook promotieonderzoek doen! Ik denk dat jij dat met je nieuwsgierigheid en je motivatie helemaal gaat rocken. Nog maar vier jaar en dan staan we bij jouw promotie ;).

De buurvrouwen aan de overkant! Het ontstond toen Anne, Linda, Inge en ik een gezamenlijke liefde voor spelletjes ontdekten tijdens één van de HSR-uitjes. Sindsdien hebben we een heel aantal spelletjesavonden gehad, waarbij we allemaal heel competitief bleken, en het groepje steeds verder uitbreidde. Dankjewel voor deze leuke avonden! Al zal het nu stukken moeilijker worden om nog eens een avondje te plannen, hopelijk lukt het toch nog eens een keer nu iedereen zich langzaam verspreidt over het land.

Collega's van de vakgroep HSR, dankjewel voor jullie behulpzaamheid en jullie gezelligheid. Ik denk dat de laagdrempeligheid - het even kunnen binnen lopen met een vraag, voor advies of een praatje - de kracht is van onze vakgroep. De gezamenlijke lunches, HSR-uitjes en verjaardag vlaaien dragen hier alleen maar aan bij en zorgen voor een welkome onderbreking van de uren achter de pc. In het bijzonder ook dank aan Janet, Brigitte en Suus voor alle keren dat ik met kleine en grote vragen bij jullie binnen mocht lopen en ik op jullie hulp kon rekenen. Naast de ondersteuning die jullie geven, maken jullie de vakgroep ook nog eens zo veel gezelliger.

Daarnaast heb ik me ook met heel veel plezier ingezet voor de ISPOR Student Chapter. Dank aan de (oud-)leden van het bestuur van de ISPOR Student Chapter, Adrienne, Xavier, Ben, Kei Long, Marije, Inge, HoiYau, Svenja, Luca en Irina voor de workshops en seminars die we samen hebben mogen organiseren. Ook dank aan de collega's van KEMTA voor de inhoudelijke discussies tijdens de (HTA-) seminars.

ledereen, vrienden, collega's en kennissen, die soms bewust, maar meestal onbewust geholpen hebben bij het zoeken van afleiding door het juist helemaal niet over mijn werk en mijn proefschrift te hebben: dankjewel! 
Ik heb al een hele lieve familie, en nu heb ik er ook nog een hele leuke familie bijgekregen. Miguel, Monique, Susan en Wilbert, dank jullie wel voor jullie hartelijke ontvangst in jullie familie, jullie betrokkenheid en jullie lieve woorden toen ik mijn proefschrift ingediend had bij de beoordelingscommissie. Muchas Gracias! :)

Denise, Marcel, Ize, Jarne en de kleine mup die er op het moment van mijn verdediging misschien al net wel of net niet is. De hectiek van jullie gezin, de schaterlachen en pretoogjes van Ize en Jarne zorgden ervoor dat ik niet anders kon dan mijn gedachten verzetten van mijn proefschrift als we samen waren.

Daphne en Sander, ook al kon ik niet iedere keer zeggen dat ik grote stappen had gemaakt - want onderzoek gaat nu vaak eenmaal langzaam - jullie altijd oprechte interesse in de vorderingen van mijn proefschrift was heel fijn. Nog fijner zijn de gezellige avonden samen, vaker met spelletjes dan zonder. Ik hoop dat daar nog veel van mogen volgen.

Lieve pap, wat ik me nog goed kan herinneren is dat je uren en uren helemaal kon opgaan in het uitpluizen van onze stamboom. Mijn nieuwsgierigheid en drive om iets tot op het bot uit te zoeken, moet ik dus wel van jou hebben. Ook al ben je er al zo lang niet meer, zo heb je me toch geholpen om dit proefschrift te schrijven. Ik hoop dat je dit op de één of andere manier toch mee krijgt...

Lieve mam, mijn voorbeeld op meerdere vlakken. Het was allesbehalve makkelijk toen jij er alleen voor kwam te staan met vier meiden. Jouw doorzettingsvermogen, jouw vastberadenheid om je mannetje te staan en jouw lieve en goede zorgen voor de mensen om je heen, bewonder ik. Dankjewel dat je er altijd voor me bent en dat je me altijd de vrijheid hebt gegeven om zelf uit te zoeken wat ik wilde. En hoe bijzonder was het om mijn tijd in Canada af te sluiten met een roadtrip door de Canadese Rockies samen met jou!

Lieve Kirsten, wat ben ik blij dat ik een zus en vriendin als jij heb. We zijn er voor elkaar in de leuke, minder leuke en spannende perioden. Daarom ben ik ook zo ontzettend blij dat je mijn paranimf wilt zijn en naast mij zult staan bij de verdediging van mijn proefschrift! Dankjewel dat je altijd wilde luisteren naar mijn verhalen over mijn onderzoek en probeerde om mijn geratel te ontcijferen.

Lieve Frank, al kennen wij elkaar nu pas bijna een jaar, het voelt als zo veel langer en zo vertrouwd. In deze korte periode ben je ook van onschatbare waarde geweest in de laatste maanden van het afronden van mijn proefschrift. Jouw steun in mijn werk, maar ook op alle andere vlakken, was en is zo ontzettend fijn, en maakt het allemaal net wat makkelijker. Dankjewel! Ik kan niet wachten op wat we nog allemaal samen gaan beleven, de mooie reizen die we gaan maken, alle momenten die we samen gaan doorbrengen en om ons eigen huisje te vinden. Ik houd van jou! 



\section{List of publications \& awards}




\section{Scientific articles in international journals}

Cheung KL, Mayer S, Simon J, de Vries H, Evers S, Kremer IEH, et al. Comparison of statistical analysis methods for object case best-worst scaling. J Med Econ. 2018:1-14. doi: 10.1080/13696998.2018.1553781

Kremer IEH, Evers S, Jongen PJ, Hiligsmann M. Comparison of preferences of healthcare professionals and MS patients for attributes of disease-modifying drugs: A best-worst scaling. Health expectations : an international journal of public participation in health care and health policy. 2018;21(1):171-80. doi: 10.1111/hex.12599.

Jongen PJ, Kremer IE, Hristodorova E, Evers S, Kool A, van Noort E, Hiligsmann M. Adherence to Online Self-Assessments in Long-Term Direct-to-Patient Research:A Two-Year Study of Multiple Sclerosis Patients. J Med Internet Res. 2017 Jul 21; 19 (7): e249. doi: 10.2196/jmir.6729

Kremer IE, Evers SM, Jongen PJ, van der Weijden T, van de Kolk I, Hiligsmann M. Identification and Prioritization of Important Attributes of Disease-Modifying Drugs in Decision Making among Patients with Multiple Sclerosis: A Nominal Group Technique and Best-Worst Scaling. PLoS One. 2016;11(11):e0164862. doi: 10.1371/journal.pone.0164862

\section{Submitted articles}

Kremer IEH, Jongen PJ, Evers, SMAA, Hoogervorst EL, Verhagen WIM, Hiligsmann M. Development of a web-based patient decision aid for disease-modifying drugs for multiple sclerosis.

Kremer IEH, Hiligsmann M, Carlson J, Zimmerman M, Jongen PJ, Evers, SMAA, Petersohn S, Pouwels XGLV, Bansback N. Exploring the cost-effectiveness of shared decision making for choosing between disease-modifying drugs for multiple sclerosis in the Netherlands: a state transition model.

\section{Scientific articles in national journals}

Kremer IEH, Kann-Weedage D, van den Berg G, Dirksen CD, Hiligsmann M, Evers SMAA. Kosteneffectiviteit van jeugdinterventies in Nederland: een systematische literatuurreview. [Cost-effectiveness of interventions for youth in the Netherlands: a systematic literature review]. Kind en Adolescent. 2017; 38(1);1-30. Doi: 10.1007/s12453-017-0135-x 
Kremer I, Göertz E, Thilmann M, Stans SEA, Werrij M. Elementen in de fysieke omgeving ter bevordering van de communicatie: een systematisch literatuuronderzoek. Wetenschappelijk tijdschrift voor ergotherapie. 2012:5,3.

\section{Reports}

Kremer IEH, Kann D, van den Berg G, Dirksen CD, Hiligsmann M, Evers SMAA. Welke jeugdinterventies in Nederland zijn kosteneffectief: systematische literatuurreview naar de huidige stand van zaken. 2016. Utrecht: Nederlands Jeugdinstituut/ Universiteit Maastricht. http://www.nji.nl/nl/Publicaties/NJi-Publicaties/Welke-jeugdinterventies-in-Nederlandzijn-kosteneffectief

Kann D, van den Berg G, Kremer I. State of the art: Kosteneffectiviteit in het jeugddomein. 2016. Nederlands Jeugdinstituut. http://www.nji.nl/nl/Download-NJi/Publicatie-NJi/Stateof-the-Art-Kosteneffectiviteit-in-het-jeugddomein.pdf

\section{Conference contributions - oral presentations}

Kremer IEH, Hiligsmann M, Carlson J, Zimmermann M, Jongen PJ, Evers SMAA, Bansback N. Potential cost-effectiveness of a patient decision aid to support shared decision making about disease-modifying drugs for multiple sclerosis in the Netherlands: a Markov model. $11^{\text {th }}$ Lowlands Health Economics' Study Group (LolaHESG) conference, 23-24 May 2019, Enschede, the Netherlands.

Kremer IEH, Evers S, Jongen PJ, Hiligsmann M. Attribute selection for discrete choice experiments: a nominal group technique and best-worst scaling to identify the most important MS treatment attributes. $12^{\text {th }}$ European conference on health economics (EuHEA), 11-14 July 2018, Maastricht, the Netherlands.

Kremer IEH, Evers SM, Jongen PJ, Hiligsmann M. Innovative methods for the identification of treatment criteria in the development of a patient decision aid. $9^{\text {th }}$ International Shared Decision Making Conference, 2-5 July 2017, Lyon, France.

Kremer IEH, Kann D, van den Berg G, Dirksen CD, Hiligsmann M, Evers SMAA. Literature review of the state of the art of cost-effectiveness research in youth care: the Dutch case. Cost-effectiveness and evidence-based policy. 14th Biannual European Scientific Association on Residential \& Family Care for Children and Adolescents (EUSARF) Conference, 13-16 September 2016, Oviedo, Spain. 
Kremer IEH, Evers SM, Jongen PJ, Hiligsmann M. A comparison of MS patients' and healthcare professionals' preferences for the characteristics of disease modifying drugs for decision making. $16^{\text {th }}$ Biennial European Conference Society of Medical Decision Making, 12-14 June 2016, London, United Kingdom.

Kremer IEH, Evers S, Jongen PJ, Hiligsmann M. A comparison of MS patients' and healthcare professionals' preferences for the characteristics of disease modifying drugs for decision making. $8^{\text {th }}$ Lowlands Health Economics' Study Group (LolaHESG) conference, 26-27 May 2016, Gent, Belgium.

\section{Conference contributions - poster presentations}

Kremer IEH, Evers SM, Jongen PJ, Hiligsmann M. Development of a web-based patient decision aid for disease-modifying drugs in multiple sclerosis. $17^{\text {th }}$ Biennial European Conference Society of Medical Decision Making, 10-12 June 2018, Leiden, the Netherlands.

Kremer IEH, Evers SM, Jongen PJ, Hiligsmann M. A comparison of MS patients' and healthcare professionals' preferences for the characteristics of disease modifying drugs for decision making. $32^{\text {nd }}$ Congress of the European Committee for Treatment and Research in Multiple Sclerosis, 14-17 September 2016, London, United Kingdom.

Kremer IE, Evers SM, Jongen PJ, Dowie J, van der Weijden T, van de Kolk I, Hiligsmann M. Preferences of Patients With Multiple Sclerosis for Attributes of Disease Modifying Drugs In Decision making: A Nominal Group Technique And Best-Worst Scaling. ISPOR $18^{\text {th }}$ Annual European Congress 7-11 November 2015, Milan, Italy. Value Health. 2015 Nov; 18(7):A761.

\section{Grants and scientific honors}

The ACSN Student Research Award 2018 to conduct research at a Canadian university, Association for Canada Studies in the Netherlands, personal award.

Unrestricted donation 2015 awarded by Bayer to the Universiteitsfonds Limburg/SWOL labelled for the development of a patient decision aid for MS (PhD-project), co-applicant.

Catharina Pijls Encouragement Award 2015 for an outstanding Master's thesis and study results, Maastricht University, The Netherlands, personal award. 
2015 Student Travel Grant to attend and present at the European conference in Milan, ISPOR $18^{\text {th }}$ Annual European Congress, personal grant. 

About the author

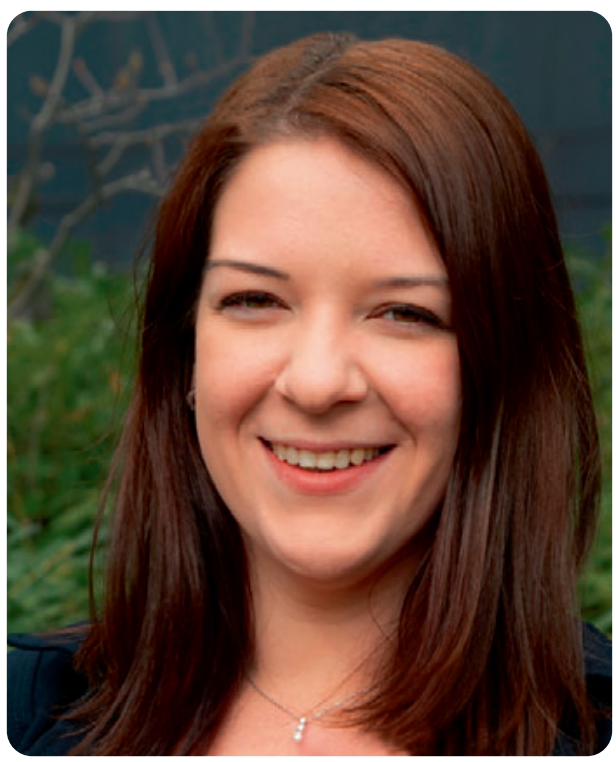


Ingrid Kremer was born on December $6^{\text {th }}, 1989$ in Leiderdorp, the Netherlands. After completing the Atheneum at the Bernardinuscollege in Heerlen, she studied Occupational Therapy at Zuyd University of Applied Sciences in Heerlen, and she obtained her Bachelor of Health degree in 2012. After completing a pre-Master's degree in Epidemiology, Methodology and Statistics at Maastricht University in 2013, Ingrid continued her education at Maastricht University and graduated cum laude from the Health Sciences Research Master. She was awarded the Catharina Pijls Encouragement Award 2015 for an outstanding Master's thesis and study results. Ingrid's thesis focused on patients' preferences for disease-modifying drugs for multiple sclerosis, which she wrote during an internship at the Department of Health Services Research of Maastricht University. During her internship, she also co-wrote a grant proposal that partly financed her PhD research. After obtaining her master's degree, Ingrid was employed as a junior researcher at Maastricht University.

In 2016, Ingrid started her PhD trajectory at the Department of Health Services Research. Her PhD research focused on the development of a patient decision aid for diseasemodifying drugs for patients with multiple sclerosis. In 2018, Ingrid received a Student Research Award by the Association for Canada Studies in the Netherlands, which enabled her to visit the University of British Columbia, Vancouver, Canada for two months, to work with experts from the Centre for Health Evaluation \& Outcome Sciences and the Collaboration for Outcome Research and Evaluation on a model-based economic evaluation of shared decision making for multiple sclerosis. Ingrid has presented her PhD research at several national and international conferences. She also received a Student Travel Grant to attend and present at the $18^{\text {th }}$ annual European congress of the ISPOR- the Professional Society for Health Economics and Outcomes Research in Milan, Italy in 2015. In 2019, she was selected for the Care and Public Health Research Institute (CAPHRI) Research Talent Program for "high potential" junior researchers, to further develop her own research idea.

During her PhD program, Ingrid had several positions of responsibility, such as chair of the early career researchers of the department, member of the CAPHRI PhD panel, president of the ISPOR Maastricht University student chapter, and member of the Host Organizing Committee of the European Health Economics Association conference 2018. Moreover, Ingrid has been tutor, trainer, lecturer and theses supervisor in Master programs (Healthcare Policy, Innovation and Management and Health Sciences Research) and Bachelor programs (Health Sciences and European Public Health).

Ingrid is currently working as a postdoctoral researcher and teacher at the Department of Health Services Research. She continues to work on research projects related to health technology assessment in several functions, including co-promotor, and fulfills various teaching roles. 
